\title{
Detecção de fraudes em cartões: um classificador baseado em regras de associação e regressão logística
}

Paulo Henrique Maestrello Assad Oliveira

DisSERTAÇÃO APRESENTADA

AO

Instituto DE MATEMÁtica e EstatísticA

DA

Universidade De SÃo Paulo

PARA

OBTENÇÃO DO TÍTULO

$\mathrm{DE}$

Mestre em CiÊnCIAS

Programa: Programa de Pós-Graduação em Ciência da Computação

Orientador: Prof. Dr. Alair Pereira do Lago

São Paulo, janeiro de 2016 


\section{Deteç̧ão de fraudes em cartões: um classificador baseado em regras de associação e regressão logística}

Esta versão da dissertação contém as correções e alterações sugeridas pela Comissão Julgadora durante a defesa da versão original do trabalho, realizada em 11/12/2015. Uma cópia da versão original está disponível no Instituto de Matemática e Estatística da Universidade de São Paulo.

Comissão Julgadora:

- Prof. Dr. Alair Pereira do Lado (orientador) - IME-USP

- Prof. Dr. Edson Satoshi Gomi - Escola Politécnica-USP

- Prof. Dr. Roberto Hirata Júnior - IME-USP 


\section{Agradecimentos}

Primeiramente, agradeço a Deus, aos meus pais, Paulo e Sônia, e às minhas irmãs, Tatiana e Thaís. Também agradeço aos meus avós, em especial, ao meu avô Ribamar. Eles deram suporte, não só à minha formação intelectual, mas, sobretudo, à minha formação moral.

Sem nenhuma dúvida, os principais responsáveis pela minha formação intelectual foram os diversos professores que passaram pela minha vida acadêmica, em especial, o meu orientador, Prof. Dr. Alair Pereira do Lago. Além de abrir as portas da Universidade de São Paulo para mim, ele abriu minha mente para diversas questões importantes que um ser humano enfrenta ou enfrentará. Além disso, suas contribuições para minha visão técnica e, em particular, para o projeto de pesquisa, foram essenciais para que eu me tornasse um mestre. Obrigado!

Como namorada e esposa, a Juliana, que me acompanha há cerca de 10 anos, participou e compartilhou comigo do meu sonho de progresso, que se tornou o sonho dela também, assim como os sonhos dela se tornaram os meus. Já temos uma construção e uma história juntos que evoluirão ainda mais! Muito Obrigado!

Aos meus sogros, Julio Cesar e Sara; às cunhadas, Ana Paula e Daniela, e aos cunhados, Alexandre, Eduardo, Eduardo e Rafael, muito obrigado!

Agradeço fortemente aos amigos de infância e faculdade, representados aqui por: André, Aldo, Lucas, Marco, Paulo, Vinícius e Tiago.

Agradeço também aos amigos do mundo corporativo, em especial, ao Fidel e ao Neto, que, além de me ensinarem a trabalhar, foram fundamentais nesse projeto. Além deles, o mundo corporativo me apresentou grandes figuras que compartilharam o sonho desse projeto comigo. Algumas delas foram: Leonardo, Moises, Estevan, Dener, Fabio Alexandre, Erick, Fernando, Fabio e toda a equipe que desde julho/14 apoia meu trabalho!

Guardadas as devidas proporções, nesses momentos, gosto de lembrar de uma frase de Sir Isaac Newton: "Se pude enxergar mais longe, é porque estava apoiado em ombros de gigantes." 


\section{Resumo}

Oliveira, P. H. M. A. Detecção de fraudes em cartões: um classificador baseado em regras de associação e regressão logística. 2015. 100 f. Dissertação (Mestrado) Instituto de Matemática e Estatística, Universidade de São Paulo, São Paulo, 2015.

Os cartões, sejam de crédito ou débito, são meios de pagamento altamente utilizados. Esse fato desperta o interesse de fraudadores. O mercado de cartões enxerga as fraudes como custos operacionais, que são repassados para os consumidores e para a sociedade em geral. Ainda, o alto volume de transações e a necessidade de combater as fraudes abrem espaço para a aplicação de técnicas de Aprendizagem de Máquina; entre elas, os classificadores. Um tipo de classificador largamente utilizado nesse domínio é o classificador baseado em regras. Entretanto, um ponto de atenção dessa categoria de classificadores é que, na prática, eles são altamente dependentes dos especialistas no domínio, ou seja, profissionais que detectam os padrões das transações fraudulentas, os transformam em regras e implementam essas regras nos sistemas de classificação. Ao reconhecer esse cenário, o objetivo desse trabalho é propor a uma arquitetura baseada em regras de associação e regressão logística - técnicas estudadas em Aprendizagem de Máquina - para minerar regras nos dados e produzir, como resultado, conjuntos de regras de detecção de transações fraudulentas e disponibilizá-los para os especialistas no domínio. Com isso, esses profissionais terão o auxílio dos computadores para descobrir e gerar as regras que embasam o classificador, diminuindo, então, a chance de haver padrões fraudulentos ainda não reconhecidos e tornando as atividades de gerar e manter as regras mais eficientes. Com a finalidade de testar a proposta, a parte experimental do trabalho contou com cerca de 7,7 milhões de transações reais de cartões fornecidas por uma empresa participante do mercado de cartões. A partir daí, dado que o classificador pode cometer erros (falso-positivo e falso-negativo), a técnica de análise sensível ao custo foi aplicada para que a maior parte desses erros tenha um menor custo. Além disso, após um longo trabalho de análise do banco de dados, 141 características foram combinadas para, com o uso do algoritmo FP-Growth, gerar 38.003 regras que, após um processo de filtragem e seleção, foram agrupadas em cinco conjuntos de regras, sendo que o maior deles tem 1.285 regras. Cada um desses cinco conjuntos foi submetido a uma modelagem de regressão logística para que suas regras fossem validadas e ponderadas por critérios estatísticos. Ao final do processo, as métricas de ajuste estatístico dos modelos revelaram conjuntos bem ajustados e os indicadores de desempenho dos classificadores também indicaram, num geral, poderes 
de classificação muito bons (AROC entre 0,788 e 0,820). Como conclusão, a aplicação combinada das técnicas estatísticas - análise sensível ao custo, regras de associação e regressão logística - se mostrou conceitual e teoricamente coesa e coerente. Por fim, o experimento e seus resultados demonstraram a viabilidade técnica e prática da proposta.

Palavras-chave: deteç̧ão e prevenção de fraudes, aprendizagem de máquina, análise sensível ao custo, mineração de regras de associação, regressão logística. 


\section{Abstract}

Oliveira, P. H. M. A. Card fraud detection: a classifier based on association rules and logistic regression. 2015. 100 f. Dissertação (Mestrado) - Instituto de Matemática e Estatística, Universidade de São Paulo, São Paulo, 2015.

Credit and debit cards are two methods of payments highly utilized. This awakens the interest of fraudsters. Businesses see fraudulent transactions as operating costs, which are passed on to consumers. Thus, the high number of transactions and the necessity to combat fraud stimulate the use of machine learning algorithms; among them, rule-based classifiers. However, a weakness of these classifiers is that, in practice, they are highly dependent on professionals who detect patterns of fraudulent transactions, transform them into rules and implement these rules in the classifier. Knowing this scenario, the aim of this thesis is to propose an architecture based on association rules and logistic regression - techniques studied in Machine Learning - for mining rules on data and produce rule sets to detect fraudulent transactions and make them available to experts. As a result, these professionals will have the aid of computers to discover the rules that support the classifier, decreasing the chance of having non-discovered fraudulent patterns and increasing the efficiency of generate and maintain these rules. In order to test the proposal, the experimental part of the thesis has used almost 7.7 million transactions provided by a real company. Moreover, after a long process of analysis of the database, 141 characteristics were combined using the algorithm FP-Growth, generating 38,003 rules. After a process of filtering and selection, they were grouped into five sets of rules which the biggest one has 1,285 rules. Each of the five sets was subjected to logistic regression, so their rules have been validated and weighted by statistical criteria. At the end of the process, the goodness of fit tests were satisfied and the performance indicators have shown very good classification powers (AUC between 0.788 and 0.820 ). In conclusion, the combined application of statistical techniques - cost sensitive learning, association rules and logistic regression - proved being conceptually and theoretically cohesive and coherent. Finally, the experiment and its results have demonstrated the technical and practical feasibilities of the proposal.

Keywords: fraud detection and prevention, machine learning, cost sensitive learning, association rule learning, logistic regression. 


\section{Sumário}

Lista de Figuras $\quad$ viii

Lista de Tabelas $\quad$ x

1 Introdução $\quad 1$

1.1 Considerações Preliminares . . . . . . . . . . . . . . . . . . . . . . . . 1

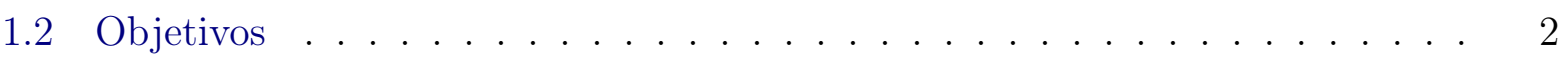

1.3 Contribuições . . . . . . . . . . . . . . . . . . . . 3

1.4 Organização do Trabalho . . . . . . . . . . . . . . . . . . . 3

2 Mercado de Cartões e Fraudes $\quad 5$

2.1 Organização e Funcionamento . . . . . . . . . . . . . . . . . . . 5

2.2 Os Cartões no e-commerce . . . . . . . . . . . . . . . . . . 7

2.3 Números do Mercado de Cartões . . . . . . . . . . . . . . . . . 8

2.3 .1 Números Gerais . . . . . . . . . . . . . . . . . . . . . . . . . 8

2.3.2 Números do e-commerce . . . . . . . . . . . . . . . . . . . . 10

2.4 Fraudes no Mercado de Cartões . . . . . . . . . . . . . . . . . . . . . . . 10

2.4 .1 Definição . . . . . . . . . . . . . . . . . . . . . 11

2.4 .2 Tipos de Fraudes . . . . . . . . . . . . . . . . . . . 11

2.4.3 Custos Envolvidos e Combate às Fraudes . . . . . . . . . . . . . . . . 12

3 Fundamentação Teórica 18

3.1 Classificadores . . . . . . . . . . . . . . . . . . . . . . 19

3.1 .1 Árvores de Decisão . . . . . . . . . . . . . . . . . . . . . . . . . 19

3.1.2 Redes Neurais Artificiais . . . . . . . . . . . . . . . . . . 20

3.1.3 Naive Bayes . . . . . . . . . . . . . . . . . . . . . . . . . 20

3.1.4 Algoritmos Genéticos . . . . . . . . . . . . . . . . . . . 21

3.1.5 Classificação Baseada em Regras . . . . . . . . . . . . . . . . . . . . 23

3.1 .6 Modelos de Pontuação . . . . . . . . . . . . . . . . . . . . . 25

3.2 Extração e Seleção de Características . . . . . . . . . . . . . . . . . . 26

3.3 Regras de Associação . . . . . . . . . . . . . . . . . . . . . . . . 27

3.3.1 Algoritmo Apriori . . . . . . . . . . . . . . . . . . . . 28 
3.3.2 Algoritmo FP-Growth . . . . . . . . . . . . . . . . . . . . 29

3.4 Classificação Baseada em Associações . . . . . . . . . . . . . . . . . . . . . . 32

3.5 Regressão Logística . . . . . . . . . . . . . . . . . . . . . . . . . . . . . . 34

3.5 .1 A Função Resposta . . . . . . . . . . . . . . . . . . . . . . . . 34

3.5.2 Estimação dos Parâmetros . . . . . . . . . . . . . . . . . 35

3.5.3 Seleção das Variáveis Explicativas . . . . . . . . . . . . . . . . 36

3.5.4 O Método Stepwise . . . . . . . . . . . . . . . . 37

3.5.5 Multicolinearidade e Fator de Inflação de Variância . . . . . . . . . . 38

3.6 Análise Sensível ao Custo . . . . . . . . . . . . . . . . . . . . . . . . . . . . 38

3.7 Desafios Presentes em Aprendizagem de Máquina . . . . . . . . . . . . . . . 40

3.7.1 Ruídos e Dados Ausentes . . . . . . . . . . . . . . . . . . . . . 40

3.7 .2 Maldição da Dimensionalidade . . . . . . . . . . . . . . . . 40

3.7.3 Overfitting e Underfitting . . . . . . . . . . . . . . . . 40

3.7 .4 Variância e Viés . . . . . . . . . . . . . . . . . . . . . . . . . . . 41

3.7.5 Classes Desbalanceadas . . . . . . . . . . . . . . . 41

3.8 Avaliação de Desempenho . . . . . . . . . . . . . . . . . . . 42

3.8.1 Razão de Chances . . . . . . . . . . . . . . . . . . . . . . . . . 42

3.8.2 Precisão e Cobertura . . . . . . . . . . . . . . . . . . . 42

3.8 .3 Taxa de Negação . . . . . . . . . . . . . . . . . . . . . 43

3.8.4 Índice de Chargeback . . . . . . . . . . . . . . . . 43

3.8 .5 Área sob a curva ROC . . . . . . . . . . . . . . . . . . . . . . 43

3.9 A metodologia CRISP-DM (CRoss Industry Standard Process for Data Mining) 44

4 Experimento e Metodologia $\quad 47$

4.1 Introdução . . . . . . . . . . . . . . . . . . . . . . . 47

4.2 Compreensão do Negócio . . . . . . . . . . . . . . . . . . . . . . . . 48

4.3 Compreensão e Preparação dos Dados . . . . . . . . . . . . . . . . . . . 48

4.3 .1 Equipamentos . . . . . . . . . . . . . . . . . . . 48

4.3 .2 Dados . . . . . . . . . . . . . . . . . . . . . . . . 48

4.3.3 Análise Descritiva e Amostragem . . . . . . . . . . . . . . . . 53

4.4 Modelagem e Validação dos Modelos . . . . . . . . . . . . . . . . . 56

4.4.1 Aplicação do FP-Growth - Obtenção de Regras . . . . . . . . . . . . 56

4.4 .2 Modelos de Regressão Logística . . . . . . . . . . . . . . . . . . . 63

4.4 .3 Validação dos Modelos . . . . . . . . . . . . . . . . 80

4.4.4 Avaliação e Comparação dos Indicadores de Desempenho . . . . . . . 81

4.4.5 Validação dos Critérios Utilizados na Análise Descritiva . . . . . . . . 82

4.4.6 Ponderação com Regressão Logística versus Abordagens Usuais . . . 84

4.5 Sumário da Parte Experimental . . . . . . . . . . . . . . . . 86 
5 Conclusões $\quad 88$

5.1 Considerações Finais . . . . . . . . . . . . . . . . . . . . . . . . . . . . . . . . . . . 88

5.2 Sugestões para Pesquisas Futuras . . . . . . . . . . . . . . . 89

Apêndice A Características Base para a Mineração de Regras de Associação 90

Apêndice B Implementação em Python do algoritmo FP-Growth

Apêndice C As Características Selecionadas pelo FP-Growth e pela Regressão Logística

Referências Bibliográficas 


\section{Lista de Figuras}

1.1 Diagrama conceitual para ilustrar o objetivo do trabalho. . . . . . . . . . . 3

1.2 Exemplo de um conjunto de regras simples resultante da aplicação da técnica. 3

2.1 Os passos para uma transação de cartão. Fonte: MasterCard . . . . . . . . . 6

2.2 Terminal "POS" . . . . . . . . . . . . . . . . . . . 8

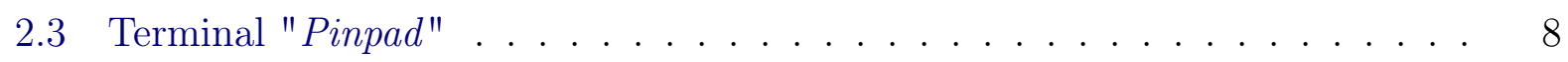

2.4 A evolução anual do mercado de cartões. Fonte: ABECS . . . . . . . . . . . 9

2.5 Proporção de pagamentos realizados com cartões em alguns países. Fonte:

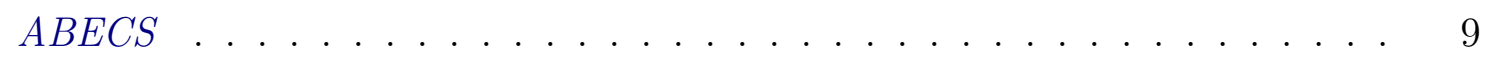

2.6 Evolução anual do ticket médio das transações de crédito e débito. Fonte: ABECS . . . . . . . . . . . . . . . . . . . . 10

3.1 Os passos para a construção da FP-Tree (MM14) . . . . . . . . . . . . . . 30

3.2 As FP-Trees condicionais para o item D. (MM14). . . . . . . . . . . . . . . 31

3.3 As diferentes FP-Trees condicionais. (MM14) . . . . . . . . . . . . . . . 32

3.4 A interação e interdependência entre as fases do CRISP-DM. Fonte: (Wir00) 44

3.5 Fases, tarefas genéricas (negrito) e saídas sugeridas (itálico) do CRISP-DM.

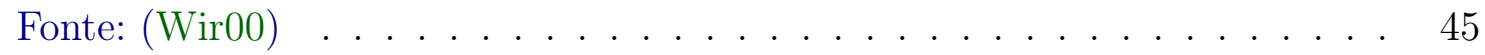

4.1 Processo de amostragem de dados . . . . . . . . . . . . . . . . . 56

4.2 Diagrama conceitual para ilustrar a aplicação do algoritmo FP-Growth. . . . 57

4.3 Diagrama conceitual para ilustrar a aplicação do modelo de regressão logística. 64

4.4 Um esquema visual para facilitar a compreensão do uso do score de fraude. . 74

4.5 Gráfico sensibilidade x especificidade do conjunto Suporte_050 . . . . . . . 75

4.6 Gráfico sensibilidade $x$ especificidade do conjunto MedidaF_050. . . . . . . . 76

4.7 Gráfico sensibilidade $x$ especificidade do conjunto Confianca_050. . . . . . . 77

4.8 Gráfico sensibilidade $x$ especificidade do conjunto Confiança_040. . . . . . . 78

4.9 Gráfico sensibilidade x especificidade do conjunto Confiança_030. . . . . . . 79

4.10 As matrizes de confusão para os dados de validação dos cinco conjuntos de regras. . . . . . . . . . . . . . . . . 80

4.11 Box-plot utilizado para se definir os limiares de fraude da segunda abordagem usual. ........................... 85 
4.12 As matrizes de confusão para comparar as abordagens usuais com a regressão logística. . . . . . . . . . . . . . . . . 85 


\section{Lista de Tabelas}

3.1 Quadro comparativo entre diversos classificadores (AK12). . . . . . . . . 23

3.2 Um exemplo de matriz de benefícios. . . . . . . . . . . . . . . . . . . . . . . 39

3.3 Tabela descritiva dos erros e acertos da classificação. . . . . . . . . . . . . . 42

3.4 Poder de classificação de um modelo dado pela AROC. . . . . . . . . . . . . 43

4.1 Atividades desenvolvidas ao longo do trabalho. . . . . . . . . . . . . . . 47

4.2 Um exemplo de tabela criada durante a análise descritiva dos dados para as categorias da variável "valor da transação". . . . . . . . . . . . . . . 53

4.3 A matriz de benefícios utilizada no trabalho. . . . . . . . . . . . . . 55

4.4 Exemplos de regras mineradas pelo FP-Growth e suas respectivas métricas de suporte e confiança. . . . . . . . . . . . . . . . 57

4.5 Tabela com exemplos dos grupos de confiança. . . . . . . . . . . . . . . 59

4.6 Estatísticas de resumo para métricas de interesse do conjunto de 24.144 regras. 59

4.7 Estatísticas de resumo para métricas de interesse do conjunto Suporte_050 na entrada da regressão logística. Esse conjunto tem 412 regras. . . . . . . . . 61

4.8 Estatísticas de resumo para métricas de interesse do conjunto MedidaF_050 na entrada da regressão logística. Esse conjunto tem 930 regras. . . . . . . . 61

4.9 Estatísticas de resumo para métricas de interesse do conjunto Confiança_050 na entrada da regressão logística. Esse conjunto tem 1.285 regras. . . . . . . . 61

4.10 Estatísticas de resumo para métricas de interesse do conjunto Confiança_040 na entrada da regressão logística. Esse conjunto tem 966 regras. . . . . . . . 62

4.11 Estatísticas de resumo para métricas de interesse do conjunto Confiança_030 na entrada da regressão logística. Esse conjunto tem 174 regras. . . . . . . . . 62

4.12 Tabela com a quantidade de regras pertencentes a cada combinação de conjuntos para entrada da regressão logística.

4.13 Um exemplo da base de dados resultado da preparação de dados para a regressão logística. . . . . . . . . . . . . . . . . . .

4.14 Estatísticas de resumo para métricas de interesse do conjunto Suporte_050 na saída da regressão logística. Esse conjunto tem 89 regras. . . . . . . . . .

4.15 Estatísticas de resumo para métricas de interesse do conjunto MedidaF_050 na saída da regressão logística. Esse conjunto tem 108 regras. . . . . . . . . . 66 
4.16 Estatísticas de resumo para métricas de interesse do conjunto Confiança_050 na saída da regressão logística. Esse conjunto tem 226 regras. . . . . . . . . . .

4.17 Estatísticas de resumo para métricas de interesse do conjunto Confiança_040 na saída da regressão logística. Esse conjunto tem 147 regras. . . . . . . . . . 66

4.18 Estatísticas de resumo para métricas de interesse do conjunto Confiança_030 na saída da regressão logística. Esse conjunto tem 121 regras. . . . . . . . . .

4.19 Regras selecionadas e estimativas do modelo utilizando a técnica stepwise para o conjunto Suporte_050. Esse conjunto tem 89 regras. . . . . . . . . .

4.20 Regras selecionadas e estimativas do modelo utilizando a técnica stepwise para o conjunto MedidaF_050. Esse conjunto tem 108 regras. . . . . . . . .

4.21 Regras selecionadas e estimativas do modelo utilizando a técnica stepwise para o conjunto Confiança_050. Esse conjunto tem 226 regras. . . . . . . . .

4.22 Regras selecionadas e estimativas do modelo utilizando a técnica stepwise para o conjunto Confiança_040. Esse conjunto tem 147 regras. . . . . . . . .

4.23 Regras selecionadas e estimativas do modelo utilizando a técnica stepwise para o conjunto Confiança_030. Esse conjunto tem 121 regras. . . . . . . . .

4.24 Quadro comparativo contendo as métricas de ajuste dos modelos para os diferentes conjuntos de regras. . . . . . . . . . . . . . . . . . . 72

4.25 Poder de classificação de um modelo dado pela AROC. . . . . . . . . . . . . 72

4.26 Tabela com a quantidade de regras pertencentes a cada combinação de conjuntos na saída da regressão logística. . . . . . . . . . . . . . . . . 73

4.27 Tabela de classificação da regressão logística do conjunto Suporte_050. . . . 75

4.28 Tabela de classificação da regressão logística do conjunto MedidaF_050 . . . 76

4.29 Tabela de classificação da regressão logística do conjunto Confianca_050 . . 77

4.30 Tabela de classificação da regressão logística do conjunto Confiança_040. . . 78

4.31 Tabela de classificação da regressão logística do conjunto Confiança_030. . . 79

4.32 As métricas cobertura/sensibilidade e a especificidade para as amostras de treinamento e validação para cada um dos cinco conjuntos de regras. . . . . . 80

4.33 Quadro comparativo contendo os indicadores de desempenho dos modelos frente à amostra de validação. . . . . . . . . . . . . . . . . . . . 81

4.34 Estatísticas das características nos diferentes estágios do experimento. . . . . 83

4.35 Quadro comparativo contendo os indicadores de desempenho das abordagens usuais frente à amostra de validação. . . . . . . . . . . . . . . 86

A.1 Características selecionadas para o algoritmo FP-Growth. Parte 01 de 03. . . 90

A.2 Características selecionadas para o algoritmo FP-Growth. Parte 02 de 03. . . 91

A.3 Características selecionadas para o algoritmo FP-Growth. Parte 03 de 03. . . 92

C.1 Características presentes nas regras selecionadas pelo o algoritmo FP-Growth. Parte 01 de $02 . \ldots \ldots \ldots \ldots \ldots$. . . . . . . . . . . . . . . 96 
C.2 Características presentes nas regras selecionadas pelo o algoritmo FP-Growth. Parte 02 de $02 . \ldots \ldots \ldots$. . . . . . . . . . . . . . . . . . . . 97

C.3 Características presentes nas regras selecionadas pela regressão logística. Parte

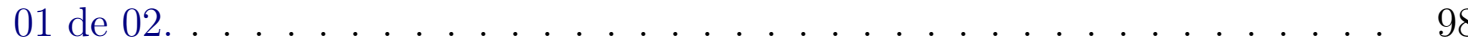

C.4 Características presentes nas regras selecionadas pela regressão logística. Parte 02 de $02 \ldots \ldots \ldots \ldots \ldots \ldots \ldots \ldots$. . . . . . . . . . . . . . . . . . . . . . . 


\section{Capítulo 1}

\section{Introdução}

\subsection{Considerações Preliminares}

Os cartões, sejam de crédito ou débito, são meios de pagamento altamente utilizados no comércio em geral. Mesmo assim, há espaço para que eles sejam ainda mais usados. Esses fatores despertam o interesse de fraudadores. Numa primeira análise, quando uma fraude é bem sucedida, poderia se dizer que as empresas envolvidas arcam com os custos, mas, na verdade, essa perda operacional encarece os preços para o consumidor final. Daí, combater fraudes nesse meio de pagamento traz benefícios para toda a sociedade. Essa tarefa, devido à sua complexidade e tamanho, tem que ser feita de uma forma concomitantemente eficaz e eficiente. Logo, há oportunidade para a aplicação de técnicas de Aprendizagem de Máquina, ou Machine Learning.

Os cartões, também conhecidos como meios eletrônicos de pagamento, são uma importante forma de pagamento, seja no mundo, no Brasil, em transações presenciais ou nas que o portador não está fisicamente diante do terminal no qual a transação é realizada. Como será visto ao longo do trabalho, o uso desse meio de pagamento cresce a taxas substanciais ano após ano. Há várias razões para esse crescimento: para quem utiliza o cartão como forma de pagamento, ele é prático e, sob determinadas condições, o crédito é instantâneo, os gastos são concentrados na fatura e os cartões são um instrumento aceito em muitos estabelecimentos; já para quem recebe pagamentos com cartões, o risco de inadimplência é consideravelmente baixo, o controle das vendas é facilitado e há muitas pessoas dispostas a pagarem suas compras com eles.

Porém, um requisito fundamental para esse sistema de pagamentos é a segurança. Por se tratar de um meio de pagamento, ou seja, estar intimamente ligado aos dados financeiros dos usuários, caso as fraudes sejam muito frequentes e envolvam muitos custos, o cartão perderá seu apelo de uso por parte das pessoas. Além disso, quanto maiores os volumes financeiros envolvidos nas fraudes, maiores serão as perdas financeiras das empresas participantes desse mercado, o que pode inviabilizar a manutenção desse sistema de pagamentos.

Esse cenário - volume de transações alto e crescente e necessidade de prevenir e detectar fraudes - cria a oportunidade para aplicação de técnicas de Aprendizagem de Máquina no combate às fraudes em cartões, pois o alto número de transações impede que cada uma delas seja analisada por um recurso humano. Assim, essas técnicas podem ser aplicadas para que as transações, na iminência de acontecerem, sejam classificadas entre fraudulentas e legítimas, impedindo-se a realização daquelas apontadas como fraudulentas. 


\subsection{Objetivos}

Com a evolução das pesquisas em Aprendizagem de Máquina, vários classificadores foram propostos, assim como a utilização deles na detecção de fraudes em cartões (DAP09). Os classificadores baseados em regras estão entre os mais utilizados nesse domínio. No mercado de cartões, o uso desses classificadores é difundido devido a fatores como:

- Desempenho: com o uso desses classificadores, é possível atingir altos níveis de desempenho na classificação;

- Flexibilidade: novos padrões de detecção de fraudes podem ser adicionados ao conjunto de regras tão logo quando forem descobertos;

- Controle: como a implementação de regras é feita por profissionais especialistas, eles têm alto grau de conhecimento sobre o sistema e domínio das razões que levaram as transações a serem consideradas fraudulentas.

Além disso, devido à depreciação dos modelos de detecção de fraudes, as companhias especializadas no desenvolvimento deles geralmente permitem, através de acordos comerciais, que esses modelos sejam posteriormente complementados com o acréscimo de regras de detecção de fraudes. Essas novas regras são desenvolvidas manualmente por especialistas no domínio.

A atividade de reconhecer os padrões de transações fraudulentas e traduzi-los em regras cabe a esse especialista, mas para detectar esses padrões, ele, usualmente, se apoia em análises estatísticas clássicas (modelos descritivos), conduzidas por ele próprio (sem o uso de técnicas de aprendizagem) e que, ou só conseguem revelar o padrão depois que muitas fraudes ocorreram, ou classificam muita transação legítima como fraudulenta, pois como as variáveis nesses modelos têm que ser incluídas pelo especialista, devido a necessidade de se estancar a fraude rapidamente, frequentemente, o especialista não inclui uma variável necessária ou delimita erroneamente o valor específico de cada variável que discrimina a transação fraudulenta da legítima. Assim, até que todo o padrão seja precisamente reconhecido e traduzido como uma regra, leva-se um tempo e, enquanto isso, as fraudes continuam acontecendo.

Dessa forma, uma fragilidade dos classificadores baseados em regras é que para criar e manter um conjunto de regras robustas, depende-se da capacidade dos especialistas no domínio em reconhecer os padrões das transações fraudulentas $\left(\mathrm{RMN}^{+} 99\right)$. Logo, se os especialistas demorarem para detectar, compreender e implementar padrões de fraudes, os classificadores não apontarão essas transações fraudulentas, que serão realizadas como se fossem legítimas.

Portanto, o objetivo desse trabalho é utilizar Aprendizagem de Máquina para propor uma arquitetura baseada em regras de associação e regressão logística, sem esquecer da análise sensível ao custo, para produzir conjuntos de regras de detecção de transações fraudulentas fundados nos dados como resultado e disponibilizá-los para os especialistas no domínio. Com isso, eles terão o auxílio dos computadores para gerar e extrair as regras que embasam o classificador, diminuindo, então, a chance de haver padrões fraudulentos ainda não reconhecidos.

Cada regra do conjunto de regras resultante do método proposto nesse trabalho deve ser composta não apenas pela regra em si, expressa pela descrição de seus elementos constituintes e por seus respectivos limiares ou valores, mas também pelo peso que essa regra terá no conjunto total. A Figura 1.1 ilustra o arranjo conceitual do trabalho com o papel de cada técnica utilizada. Enquanto isso, a Figura 1.2 traz um exemplo simples de um conjunto de regras que pode ser obtido como resultado final do trabalho. 


\section{Entrada}

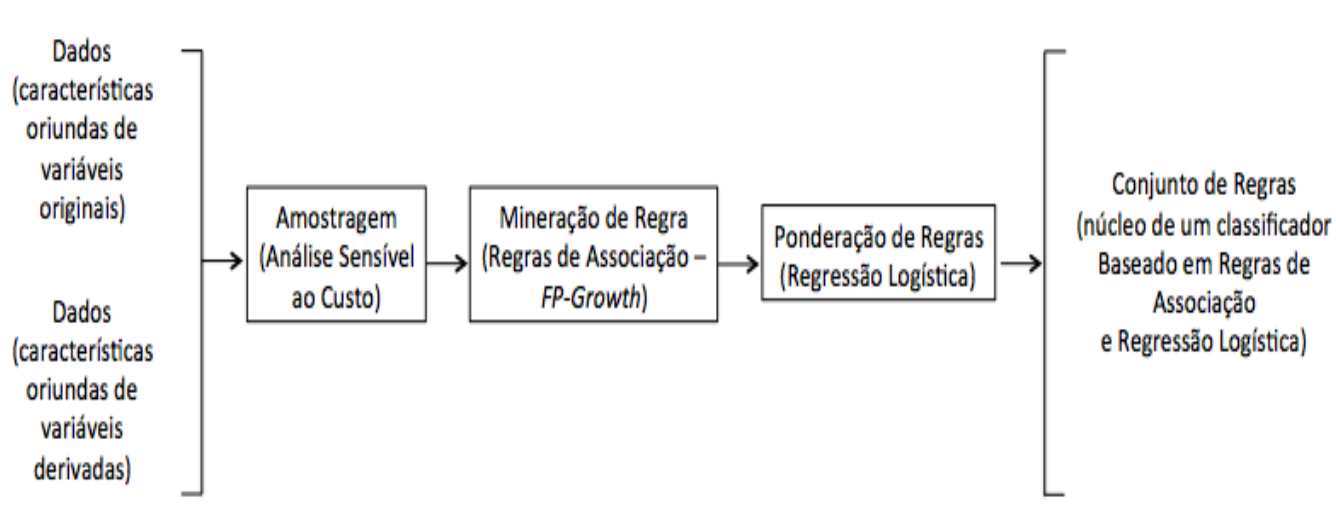

Figura 1.1: Diagrama conceitual para ilustrar o objetivo do trabalho.

\begin{tabular}{lll} 
Descrição da Regra & Limiar & Peso \\
\hline Quantidade de transações efetuadas em 24 horas & $>=2$ & 10 \\
Quantidade de transações efetuadas em 7 dias & $>=4$ & 15 \\
Transação efetuada no estabelecimento & Identificador de um estabelecimento específico & 50
\end{tabular}

Figura 1.2: Exemplo de um conjunto de regras simples resultante da aplicação da técnica.

Apesar do objetivo do trabalho ser a aplicação combinada das técnicas mencionadas para a concepção de um conjunto de regras que, por sua vez, será a base de um classificador de transações fraudulentas, a parte experimental do trabalho consistirá na construção e comparação de cinco conjuntos de regras. Dessa forma, será possível fazer uma análise comparativa que ajudará na extração das conclusões.

\subsection{Contribuições}

Este trabalho contribuirá para o desenvolvimento de uma técnica que auxilia os especialistas no domínio na tarefa de reconhecer novos padrões, transcritos no formato de regras, para a detecção de fraude em transações de cartões. Ainda, a técnica pode ser replicada em diversas situações, pois os classificadores baseados em regras são largamente utilizados no mercado.

Do ponto de vista conceitual e acadêmico, o trabalho subsidiará a discussão de um problema, detecção de fraudes em cartões, que, devido à questão de confidencialidade dos dados, não possui uma literatura ampla e apresenta diversos desafios conceituais, principalmente em se tratando de extração de regras de associação, como o desbalanceamento de classes.

\subsection{Organização do Trabalho}

Nesse capítulo introdutório buscou-se mostrar, em linhas gerais, o contexto e a importância na qual o trabalho foi aplicado e um resumo das contribuições feitas com a elaboração dele.

No capítulo 2, o mercado de cartões será discutido em maiores detalhes, com uma explanação sobre sua organização e funcionamento, as peculiaridades do uso dos cartões como meios de pagamento no comércio eletrônico e alguns números e estatísticas para evidenciar a importância desses meios de pagamento. Além disso, também será feita uma explicação 
sobre como as fraudes afetam esse instrumento, com detalhes de sua definição, dos custos envolvidos e de formas de combate.

O capítulo 3 aborda uma revisão da fundamentação teórica que sustenta as técnicas de Aprendizagem de Máquina e do seu uso em tarefas de classificação, como é o caso da detecção de fraudes em transações de cartões. Nesse capítulo serão discutidos alguns dos classificadores empregados nessa tarefa, com foco na classificação baseada em regras. Em seguida, é discutido o problema da mineração de regras de associação e como ela pode ser utilizada para subsidiar a geração de regras do classificador baseado em regras. Então, o capítulo traz as dificuldades encontradas durante a aplicação de técnicas de Aprendizagem de Máquina e os métodos de avaliação de desempenho utilizados para aferir a performance da detecção de fraudes em transações de cartões.

Por fim, o capítulo 4 discute o experimento em um nível maior de profundidade descrevendo o que foi feito para se alcançar os objetivos desejados, bem como a análise de seus resultados.

A conclusão final é apresentada no capítulo 5. 


\section{Capítulo 2}

\section{Mercado de Cartões e Fraudes}

Um requisito para detectar fraudes em transações de cartões é compreender em detalhes o funcionamento do próprio mercado de cartões e suas nuances, o conceito de fraudes nesse domínio, assim como o ciclo das fraudes e os custos envolvidos. Esse capítulo é dedicado à compreensão desses assuntos.

\subsection{Organização e Funcionamento}

Por serem um meio de pagamento, os cartões funcionam como uma alternativa, por exemplo, ao papel-moeda e ao cheque. Os cartões são a base de um arranjo de pagamentos conhecido como Mercado de Cartões que, por sua vez, é constituído de diversas plataformas e seus membros. Cada plataforma tem a participação de cinco membros principais: a bandeira, os emissores, as credenciadoras, os estabelecimentos e os portadores.

Formalmente, o Mercado de Cartões pode ser compreendido como um mercado de dois lados (M2L) que, em geral, é estruturado a partir de uma plataforma que organiza e permite o encontro de dois grupos distintos de consumidores (BCdB10). No caso dos cartões, os dois grupos de consumidores são: (i) as pessoas que desejam realizar pagamentos com os cartões e (ii) os estabelecimentos que desejam aceitar pagamentos com cartões. Dessa forma, os outros membros das plataformas são responsáveis por viabilizar o acontecimento da transação financeira entre esses dois grupos. Portanto, o papel de cada membro do arranjo pode ser resumido nas seguintes funções:

- Bandeiras: as bandeiras são as proprietárias de cada plataforma. Suas funções são: criar as regras de operação, manter uma rede global de comunicação e, através de políticas e ações de marketing, manter a dinâmica do mercado, ou seja, convencer mais pessoas a realizarem pagamentos com cartões e mais estabelecimentos a aceitarem pagamentos com esse instrumento. As principais fontes de receitas das bandeiras são as taxas cobradas dos emissores e credenciadoras, além de multas aplicadas aos outros membros por descumprimento das regras. Exemplos de bandeiras são: Visa, MasterCard, American Express, Hipercard e Hiper.

- Emissores: os emissores são os responsáveis pela emissão do cartão e pelo relacionamento direto com os portadores; inclusive, oferecendo, na modalidade cartão de crédito, o crédito a eles. As maiores fontes de receitas dos emissores são as taxas cobradas das transações, os juros provenientes do financiamento rotativo dos portadores, as anuidades e os serviços agregados como seguros. Apesar dos bancos não serem as únicas instituições a assumirem o papel de emissores, em geral, são eles que desempenham essa função. 
- Credenciadoras: também conhecidas como adquirentes, são as empresas responsáveis por credenciar e manter o relacionamento com os estabelecimentos, capturar as transações, processá-las e fazer a liquidação delas nas contas bancárias dos estabelecimentos. As principais fontes de receita das credenciadoras são as taxas cobradas das transações, os aluguéis dos terminais e as taxas cobradas dos estabelecimentos pela antecipação dos recebíveis. Exemplos de credenciadoras são: a Rede (antiga Redecard), a Cielo, a GetNet e a FirstData.

- Estabelecimentos: são estabelecimentos comerciais, lojistas, prestadores de serviço e profissionais autônomos dispostos a aceitarem pagamentos com cartões e, para isso, se tornam clientes das credenciadoras. Após se tornarem clientes das credenciadoras, no caso das compras presenciais, os estabelecimentos recebem o terminal no qual as transações serão realizadas. No caso de transações no comércio eletrônico (e-commerce), eles recebem a permissão para acessar os servidores das credenciadoras, passando a fazer parte das plataformas.

- Portadores: são aqueles dispostos a realizarem pagamentos com cartões e, para isso, se tornam clientes dos emissores, passando a fazer parte das plataformas. Em geral, são pessoas físicas, mas há várias empresas que procuram os emissores para poderem pagar com cartões. Nesses casos, os emissores emitem os chamados cartões corporativos, que são cartões de crédito ou débito comum, mas emitidos em nome de pessoas jurídicas.

A partir dessa organização estrutural, as plataformas viabilizam a realização da transação financeira entre o estabelecimento e o portador para pagamento de uma transação comercial realizada entre o estabelecimento e o seu cliente, o comprador do produto, que portava o cartão. A Figura 2.1 ilustra a ocorrência de uma transação.

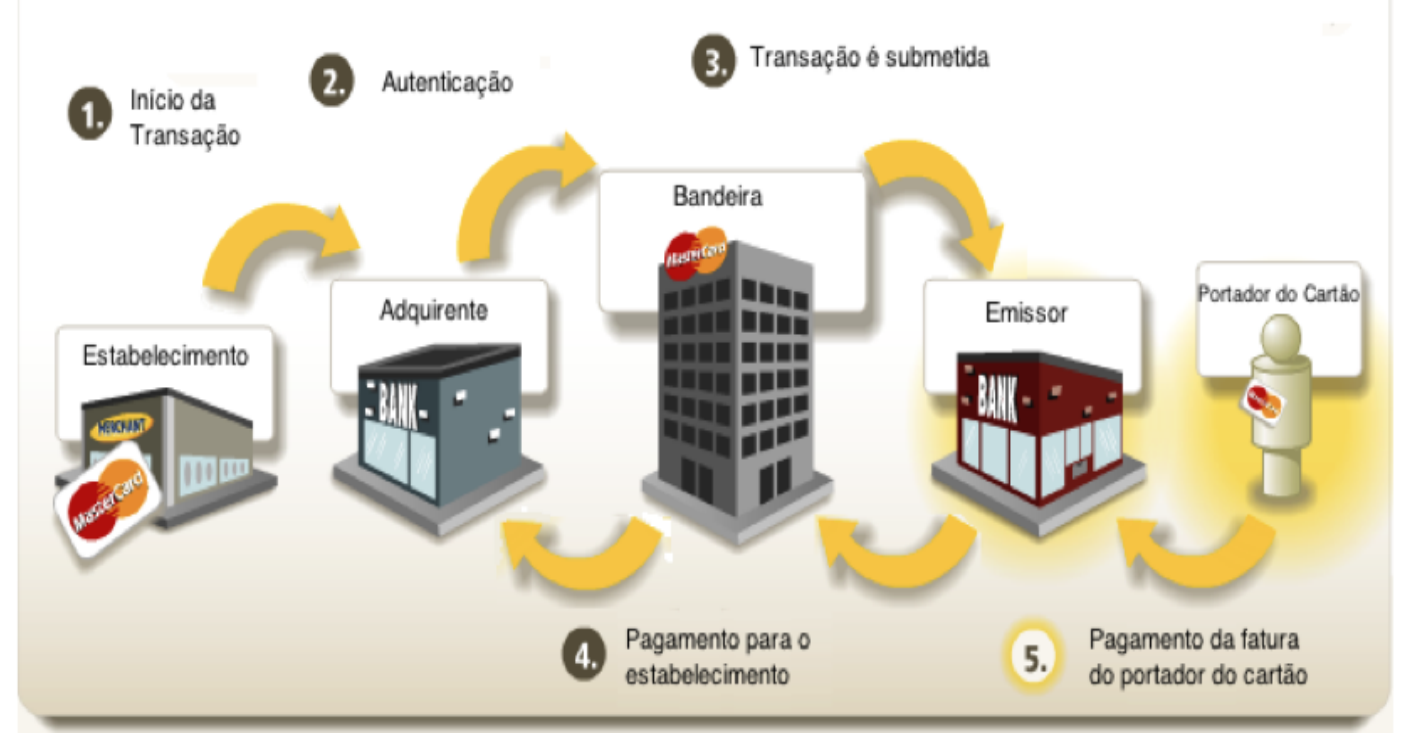

Figura 2.1: Os passos para uma transação de cartão. Fonte: MasterCard

Assim, os passos que envolvem a transação são:

1. Após concluir a transação comercial, o portador avisa o estabelecimento que pagará a compra ou prestação de serviço com o cartão. 
2. Os dados do cartão são inseridos - via leitura de chip, tarja magnética ou mesmo digitação - no terminal ou sistema de captura da adquirente que pode, ou não, solicitar alguma forma de autenticação do portador.

3. Os dados constituintes da transação são agrupados em uma mensagem, chamada de mensageria da transação, e enviados para as bandeiras.

4. As bandeiras, por sua vez, enviam a mensageria para os emissores que, baseados em critérios de crédito e/ou fraude, aprovam ou negam a transação.

5. Depois de um período de tempo, os emissores repassam os valores correspondentes às transações aprovadas às adquirentes e lançam o débito na fatura do portador.

6. Após mais algum período, as adquirentes creditam a conta do estabelecimento comercial.

7. O portador recebe, verifica e paga sua fatura.

No passo 2 descrito acima são colocadas as possibilidades da digitação de dados do cartão e da solicitação de alguma forma de autenticação do portador. Essas possibilidades são particularmente relevantes nas transações de cartões que acontecem no ambiente do comércio eletrônico (e-commerce), explicado em maiores detalhes nas próximas seções.

\subsection{Os Cartões no e-commerce}

Com o advento e a maturidade da Internet, as empresas perceberam a oportunidade de explorar mais um canal para encontrar seus consumidores e comercializar seus produtos e serviços. Porém, ao se disporem a participar do comércio eletrônico (e-commerce), as empresas têm que preparar sua infraestrutura não só em termos de tecnologia da informação (TI), mas também de logística - para entrega de produtos -, de marketing - para atrair público - e de meios de pagamentos.

Com relação aos meios de pagamento, apesar de existirem casos de empresas que aceitam papel-moeda em suas vendas no e-commerce (o pagamento é feito no momento da entrega do produto ou da prestação do serviço), uma boa parte delas oferece outros meios de pagamento como alternativas ao seus clientes. De acordo com as estimativas para o e-commerce contidas em (eCo14), os cartões de crédito são utilizados por $76 \%$ dos compradores, os boletos bancários por $12 \%$, as transferências eletrônicas de fundos (TEF) por $2 \%$ e os $10 \%$ restantes preferem outros meios.

Inicialmente, a necessidade dos estabelecimentos oferecerem vários meios de pagamento não foi percebida pelas credenciadoras, que se mantiveram especializadas nos cartões, mas foi percebida por outras empresas: os gateways e os facilitadores de pagamentos.

- Gateways de Pagamentos: os gateways de pagamento são empresas prestadoras de serviço que integram a infraestrutura computacional dos estabelecimentos à infraestrutura computacional das adquirentes. Logo, o estabelecimento contratante dos serviços de um gateway ainda deve se filiar às credenciadoras. Além desse papel, os gateways possibilitam que os estabelecimentos ofereçam aos consumidores finais os outros meios de pagamento - boleto, TEF, entre outros - não oferecidos pelas credenciadoras. Em geral, os gateways mantêm relações com mais de uma credenciadora com a promessa de oferecerem mais disponibilidade e quantidade de bandeiras aos estabelecimentos. Exemplos de gateways são: Braspag, CompreBem e CobreDireto. 
- Facilitadores de Pagamentos: também conhecidos como subadquirentes, os facilitadores de pagamentos têm um papel similar ao dos gateways com a diferença de que, ao optar por se filiar a um facilitador, o estabelecimento não precisa se filiar às credenciadoras, pois o facilitador, por si só, é o cliente da credenciadora. Logo, nesse caso, cria-se mais um nível na hierarquia de participantes do mercado de cartões. Exemplos de facilitadores são: MoIP, Pagamento Certo, PagSeguro e Global Collect.

Em adição à inclusão de novos participantes, o e-commerce trouxe mais peculiaridades ao mercado de cartões, principalmente na maneira como a transação é capturada e em questões relacionadas às fraudes e no combate a elas. No mundo físico, ou seja, fora do e-commerce, a maior parte das transações são capturadas em dois tipos de terminais: o POS (point of sale) e o pin-pad ilustrados nas Figuras 2.2 e 2.3. Quando a captura dos dados do cartão é feita por esses terminais com a presença do cartão no momento da transação, a transação é chamada de CP (cartão presente).

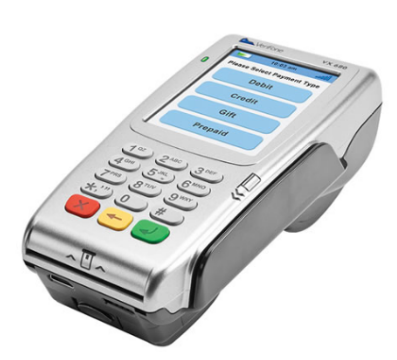

Figura 2.2: Terminal "POS"

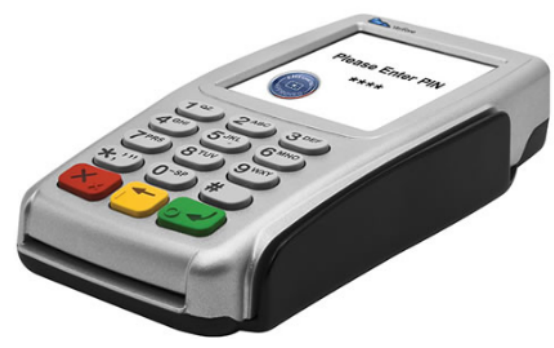

Figura 2.3: Terminal "Pinpad"

Esses terminais possibilitam que a captura dos dados do cartão seja feita ou através de um chip ou através da tarja magnética. Apesar de existirem modalidades de fraudes quando a captura é feita via esses dois modos, nesses casos, o mercado lida bem com os quesitos de confidencialidade, integridade e autenticação do portador. Por exemplo, para esses modos de captura, a autenticação do portador é feita com o uso de senhas ou assinaturas. Entretanto, no e-commerce, que é um dos canais nos quais a transação é chamada de CNP (cartão não presente), as questões de segurança da informação são mais desafiadoras, de modo que o mercado ainda não encontrou soluções que atendam concomitantemente fatores como custo, praticidade e escalabilidade.

Na próxima seção serão exibidos alguns números e estatísticas do mercado de cartões em geral e especificamente do e-commerce para, em seguida, serem tratados assuntos relacionados às fraudes.

\subsection{Números do Mercado de Cartões}

Após a compreensão da organização e do funcionamento do mercado de cartões e de algumas peculiaridades apresentadas por ele no e-commerce, é interessante a observação de alguns números e estatísticas sobre esse mercado para que a importância dele seja evidenciada.

\subsubsection{Números Gerais}

De acordo com os números e projeções da ABECS, Associação Brasileira de Empresas de Cartões de Crédito e Serviços, divulgados em (ABE14), o volume financeiro movimentado 
pelos cartões de crédito e débito atingiu cerca de $\mathrm{R} \$ 964$ bilhões em 2014, sendo que desde 2007, esse volume apresenta crescimento médio de mais de $21 \%$ ao ano. A Figura 2.4 mostra a evolução anual do volume financeiro movimentado e da quantidade de transações realizadas no período mencionado.

O Mercado de Cartões no Brasil (2007-2014)

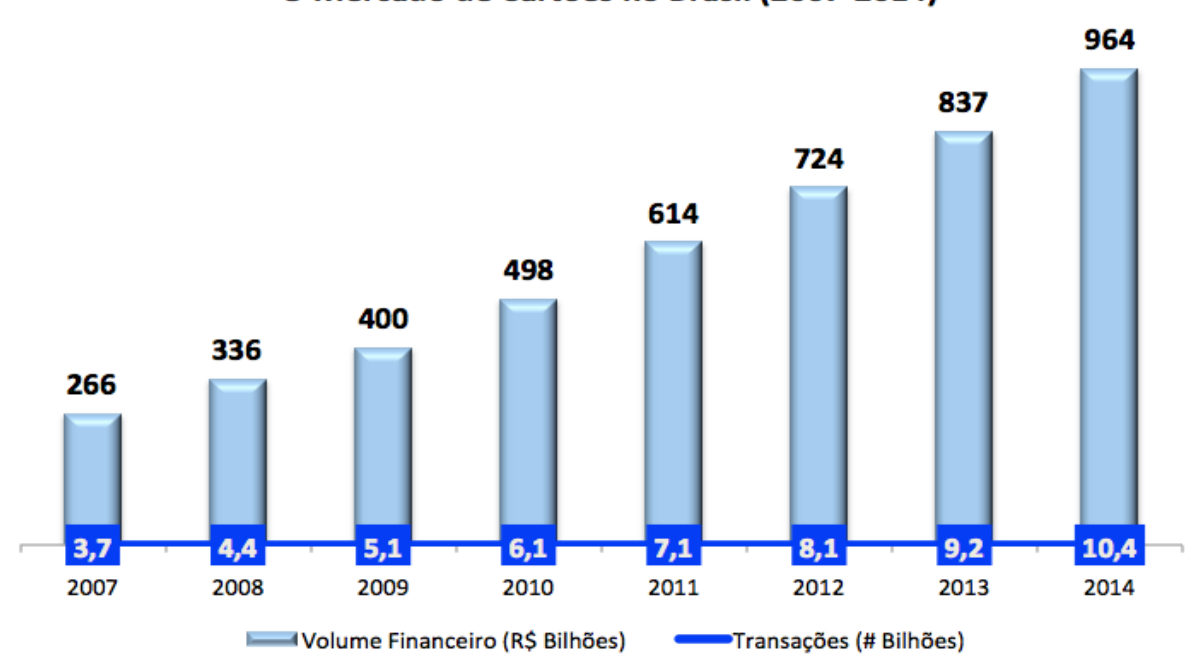

Figura 2.4: A evolução anual do mercado de cartões. Fonte: ABECS

Mesmo com essa evolução substancial, os analistas do mercado de cartões defendem que ainda há espaço para mais crescimento, pois ao se comparar a penetração desse meio de pagamento nas famílias brasileiras com a de outros países, verifica-se que a proporção de pagamentos realizados com cartões no Brasil chega a ser duas vezes menor que em outros países, como é mostrado no gráfico da Figura 2.5.

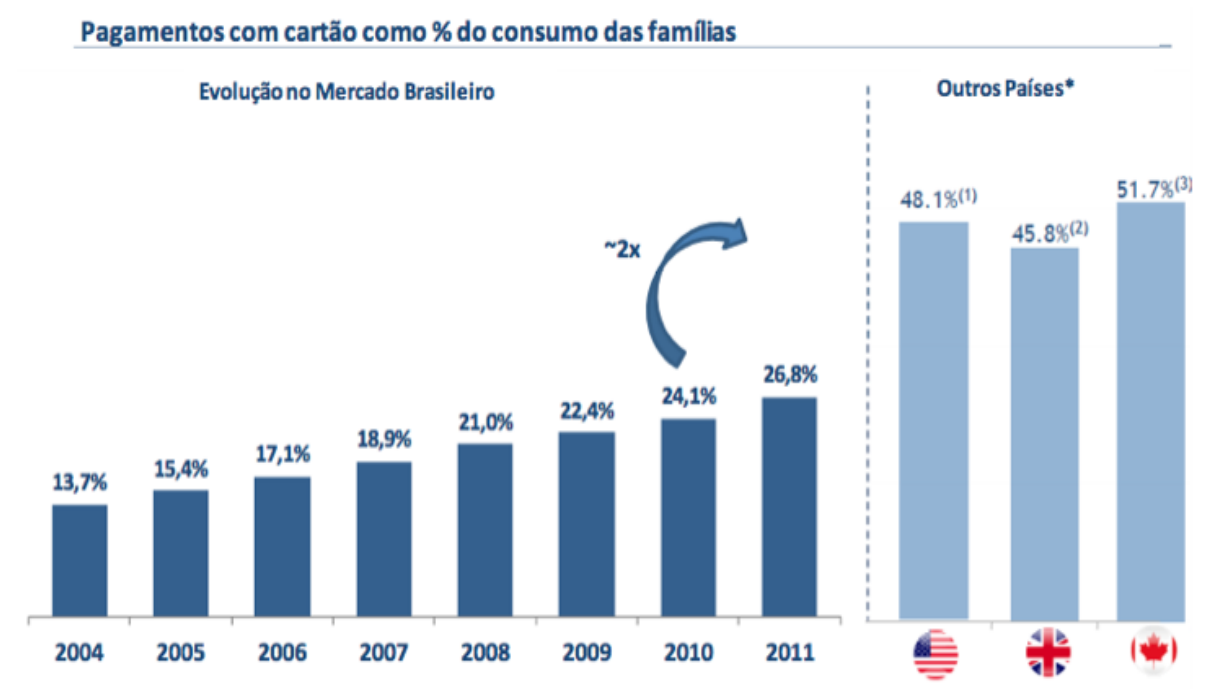

Figura 2.5: Proporção de pagamentos realizados com cartões em alguns países. Fonte: ABECS

Por fim, é interessante ter a ideia dos valores médios envolvidos em cada transação, que, no jargão do mercado, é chamado de ticket médio. A Figura 2.6 mostra essa estatística, dividindo as transações entre aquelas feitas com cartões de crédito e as feitas com cartões de débito.

Conforme mencionado, o e-commerce é um canal de vendas que vem se destacando nos últimos anos e a próxima seção discute alguns números específicos desse ambiente. 


\section{Valor Médio das Transações (2007 - 2014)}

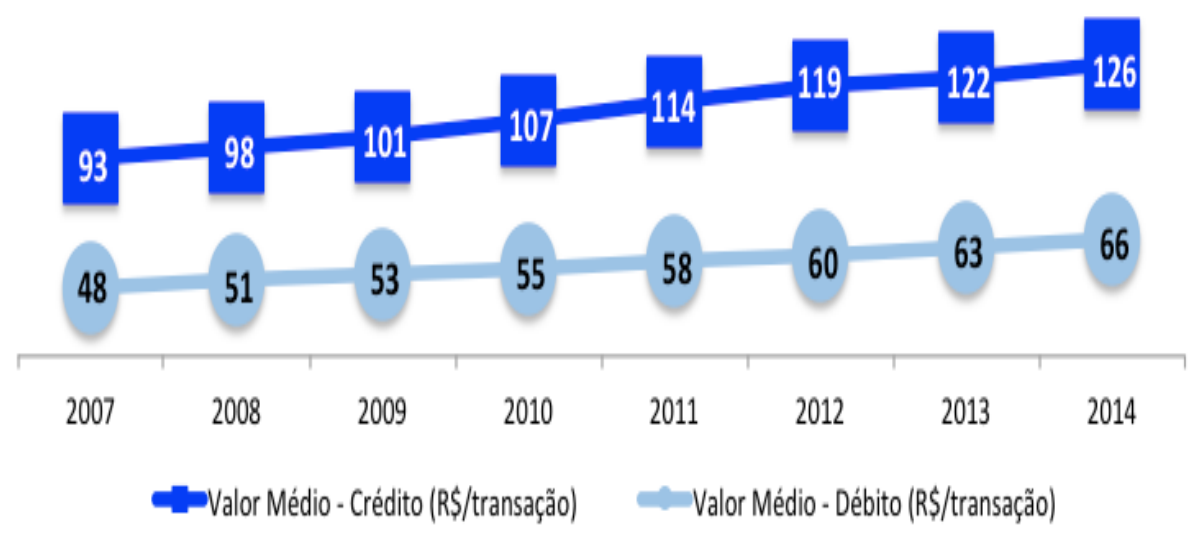

Figura 2.6: Evolução anual do ticket médio das transações de crédito e débito. Fonte: ABECS

\subsubsection{Números do e-commerce}

Considerando-se especificamente o e-commerce, é possível compreender os números desse canal através dos dados do relatório WebShoppers, produzido e divulgado semestralmente pela E-bit (Eb15). Em sua versão mais recente, do primeiro semestre de 2015, foram pesquisadas mais de 21.000 lojas virtuais. Alguns dos números mais relevantes apresentados no relatório são:

- O comércio eletrônico fechou o ano de 2014 com um faturamento de $\mathrm{R} \$ 35,8$ bilhões, um crescimento de $24 \%$ em relação à 2013.

- O valor médio de uma transação feita no e-commerce durante o ano de 2014 foi de $\mathrm{R} \$$ 347.

- A quantidade de pedidos feitos via web em 2014 aumentou 17\% se comparado à 2013, chegando a 103,4 milhões.

- O número total de e-consumidores que já fizeram ao menos um pedido via internet chegou a 51,4 milhões em 2014.

Através desses números, é possível compreender a relevância que o mercado de cartões tem na Economia do país e que há espaço para ele se tornar ainda mais relevante. O mesmo raciocínio pode ser aplicado ao e-commerce, um canal de negócios que já apresenta números consideráveis e taxas de crescimento robustas. Por razões de confidencialidade, dados sobre transações fraudulentas nesses mercados não são de fácil obtenção, mas como será visto na próxima seção, há diversas maneiras de se cometer fraudes em transações de cartões que culminam em perdas financeiras para as empresas envolvidas e torna as técnicas antifraude um assunto com teor estratégico para esses setores.

\subsection{Fraudes no Mercado de Cartões}

Pelo fato de ser um meio de pagamento, o mercado de cartões atrai muita atenção de fraudadores que tentam tirar proveito financeiro explorando vulnerabilidades e riscos assumidos pelas empresas participantes das plataformas. Sendo assim, o contexto das fraudes 
e algumas das modalidades presentes nesse mercado serão discutidos ao longo das próximas seções.

\subsubsection{Definição}

A definição do dicionário Houaiss da Língua Portuguesa para fraude é "qualquer ato ardiloso, enganoso, de má-fé, com o intuito de lesar ou ludibriar outrem, ou de não cumprir determinado dever; logro".

Em termos práticos para o mercado de cartões, o conceito de fraudes se materializa no momento em que o titular do cartão informa ao emissor do cartão o não reconhecimento de pelo menos uma das transações descritas em sua fatura. Quando isso acontece, o emissor dá início ao processo de disputa de chargeback.

\section{Chargeback}

Como mencionado anteriormente, transações realizadas com cartões são transações financeiras que sucedem transações comerciais de vendas de produtos ou prestação de serviços. Nos casos em que as transações financeiras já foram realizadas, mas, por quaisquer motivos, as transações comerciais não se concretizaram integralmente, é necessário reverter as transações realizadas com cartões. O instrumento criado pelas bandeiras para a efetivação dessa reversão é o chargeback. Logo, o chargeback, ou estorno, é o instrumento processual utilizado pelas bandeiras de cartões para reverter uma transação financeira que custeou uma transação comercial mal sucedida ou, em casos específicos, para reverter a própria transação financeira quando ela é mal sucedida, por exemplo, devido a erros sistêmicos. Em suma, há dois tipos de chargeback:

- Chargeback por desacordo comercial: são abertos para reverter transações financeiras que custeavam transações comerciais que foram desfeitas por não entrega de produtos, não prestação do serviço acordado, entrega de produtos com defeitos ou até mesmo expiração do prazo para entrega de produtos. Os métodos descritos nessa dissertação não tratam esse tipo de chargeback.

- Chargeback por fraude: uma das possíveis etapas de uma transação é o titular do cartão não reconhecer pelo menos uma das transações descritas em sua fatura. Quando isso acontece, ele entra em contato com o seu emissor para fazer essa alegação. Nesse momento, seguindo o regulamento mantido pelas bandeiras, o emissor deve abrir um processo de disputa do chargeback por motivos de fraude. Nesse caso, como houve uma perda financeira, ao final do processo, será determinado qual das partes envolvidas na transação arcará com o custo da fraude.

\subsubsection{Tipos de Fraudes}

Os tipos de fraudes mais comuns no mercado de cartões são:

- Invasão de conta: a fraude realizada através da invasão de conta é aquela na qual os criminosos obtêm informações pessoais de clientes, como número de contas e senhas, com o intuito de solicitar pagamentos, empréstimos e outros produtos bancários que estejam disponíveis. Para os cartões em específico, após invadir a conta da vítima, o fraudador realiza uma alteração de endereço e requisita um novo cartão para utilizá-lo em transações fraudulentas. Em outras palavras, na invasão de conta, a conta foi legitimamente criada por um usuário idôneo, mas após algum tempo, ela foi manipulada por um fraudador que se passa pela vítima para obter vantagens financeiras. 
- Roubo de identidade: é, na maioria dos casos, relacionado a grupos criminosos organizados que têm informações de pessoas idôneas e legítimas. De posse dessas informações, os fraudadores abrem contas novas para tirarem proveito financeiro. Basicamente, é o uso ilegal de informações de terceiros para realizar uma solicitação fraudulenta. As informações podem ser obtidas tanto de forma simples, como também por meios tecnologicamente elaborados, por exemplo: cavalos de tróia, phishing e engenharia social.

- Cartão perdido ou roubado: nesse tipo de fraude, os fraudadores tomam posse de um cartão perdido por seu verdadeiro titular, ou roubado dele pelo próprio fraudador ou outra pessoa, e realizam transações com ele.

- Extravio: acontece quando cartões e suas respectivas senhas são roubados no processo de envio do emissor do cartão para o portador. Os riscos nesse processo envolvem empresas de entregas conhecidas como couriers e os Correios;

- Falsificação de cartão (Skimming): falsificação, ou clonagem, de um cartão acontece quando um cartão é montado, sem a autorização do emissor, com os mesmos dados de um outro cartão que, por sua vez, foi emitido legitimamente. As informações para a criação desse cartão são muitas vezes obtidas através da trilha magnética do cartão verdadeiro ou da cópia manual de parte das informações contidas no plástico.

- E-commerce/Mail Order-Telephone Order (MOTO): além do e-commerce, mencionado anteriormente, as transações realizadas através de telefone, fax ou carta também são classificadas como CNP (cartão não presente), pois não necessariamente o portador do cartão tem a posse do cartão no momento da compra e, nesse caso, os dados do cartão não são lidos pelo terminal, mas sim digitados no meio de captura. Nesse tipo de transação, há dificuldade em se efetivar a autenticação do portador. Logo, os riscos de que haja uma fraude são maiores, pois o fraudador precisa apenas obter um conjunto de informações contidas no cartão (número do cartão, nome do titular, data de validade e código de segurança) e realizar a transação sem nem mesmo estar diante do vendedor. No caso de transações CNP, na prática, são os estabelecimentos que arcam com o ônus da fraude, pois no regulamento das bandeiras até está previsto que se o estabelecimento comprovar a autenticidade do portador, o lojista não será responsabilizado pelo ônus da fraude, mas como essa autenticação não é simples de se fazer, na maioria dos casos, o estabelecimento arca com o prejuízo.

- Autofraude: um tipo de fraude também comum em transações CNP é a autofraude, ou seja, o portador percebe as dificuldades enfrentadas pelas plataformas em autenticá-lo nesse tipo de transação e, após realizar uma compra e receber o produto em sua casa, o fraudador age de má fé e contata seu emissor com a alegação de que não fez a compra.

- Fraude amigável: também comum no e-commerce, a fraude amigável é parecida com a autofraude, com a diferença de que o titular do cartão realmente não se lembra de ter feito a compra, pois ela foi realizada por uma pessoa próxima do titular com ou sem a anuência dele.

\subsubsection{Custos Envolvidos e Combate às Fraudes}

Do ponto de vista de custos, as fraudes são encaradas como perdas operacionais que, em última instância, são repassadas para os consumidores finais. Logo, o efetivo e eficiente combate às fraudes acarreta em uma menor perda operacional que, por sua vez, pode se 
traduzir em menores preços para o consumidor final. Entretanto, para diminuir as perdas operacionais com fraudes, é essencial compreender todos os custos, tangíveis e intangíveis, relacionados a elas.

\section{Custos Financeiros da Fraude}

Os custos financeiros, ou tangíveis, das fraudes são aqueles facilmente mensuráveis em unidades monetárias. Entre eles, é possível citar:

- Perda financeira decorrente do uso indevido do cartão;

- Custo da investigação e prisão do fraudador;

- Reemissão do cartão e entrega;

- Chamadas no atendimento ao cliente;

- Intercâmbio (requisições e disputas com as bandeiras). Em alguns casos, é possível recuperar a perda financeira, mas esse processo tem um custo;

- Custo das transações referidas. É uma tarifa paga à bandeira para cada transação negada, por desconfiança de fraude, quando ultrapassa um certo ponto de corte;

- Custo de cancelamento de cartões. Clientes cancelam seus cartões e migram para concorrência;

- Custos de boletim de proteção com as bandeiras. Custo para inclusão e manutenção de números de cartões na "lista negativa" mantida pelas bandeiras;

- Potencial redução de receitas;

- Redução de market share. Redução do tamanho da instituição e perda de posição para algum concorrente.

\section{Custos Intangíveis da Fraude}

Os custos não financeiros, ou intangíveis, das fraudes são reconhecidos pelo mercado, mas são difíceis de serem mensurados em unidades monetárias. Entre eles, é possível citar:

- Insatisfação do cliente;

- Sentimento de violação e vulnerabilidade em relação à empresa. Em boa medida, a percepção de segurança é mais considerada que alguma métrica bem definida propriamente dita;

- Ameaça ao negócio e às pessoas ligadas a ele (funcionários e terceiros);

- Perda de lealdade à marca e às bandeiras;

- Custo de oportunidade: o investidor (sócio) da instituição poderia investir seu dinheiro em algo menos arriscado do ponto de vista de fraude e obter maior retorno sobre o capital investido. 


\section{Combate às Fraudes}

Para que o combate às fraudes em cartões seja efetivo, é necessário haver um entendimento global das fraudes em cartões, que consiste em compreender não só os custos envolvidos, mas também as condições que juntas culminam em uma fraude. O modelo do Triângulo da Fraude agrupa essas condições e argumenta que juntas elas seriam condições necessárias e suficientes para a ocorrência de uma fraude. Além disso, as práticas de combate podem ser compreendidas dentro do ciclo: prevenção, detecção e repressão. A seguir serão discutidos o Triângulo da Fraude e a relação dele com o ciclo de combate.

- Motivação: a motivação possui alto grau de subjetividade. Como consequência desse fato, as empresas têm pouca oportunidade de ação para utilizar esse pilar no combate às fraudes, pois elaborar estratégias para diminuir a motivação dos indivíduos exigiria alto grau de controle social por parte das empresas, e isso não é viável. Entretanto, a legislação mantida pelos governos atua nesse aspecto, pois espera-se que o indivíduo tenha menos motivação para cometer uma fraude ao reconhecer que, por exemplo, sofrerá sanções penais se praticar esse ato. Logo, dentro do Triângulo da Fraude, a legislação atua para diminuir a motivação dos fraudadores. Já no ciclo de combate às fraudes, a legislação interage com dois componentes: (i) prevenção, na medida em que é divulgada, a lei serve como fator educativo e de alerta e (ii) repressão: caso a fraude aconteça, as punições previstas na lei devem ser aplicadas.

- $\underline{\text { Conhecimento: }}$ anteriormente ao advento da Internet, o controle da informação era mais facilmente executado e, dessa forma, o conhecimento era suprimido. Ou seja, o grupo de pessoas que tinham know how para cometer uma fraude era mais restrito. Atualmente, não é raro que uma vulnerabilidade e os passos para explorá-la sejam divulgados na Internet e estejam ao alcance de qualquer indivíduo. Por outro lado, as empresas podem aproveitar a maior facilidade de veiculação e divulgar conteúdo para conscientizar os usuários legítimos sobre as melhores práticas para o uso de cartões, aumentando a vigilância sobre os fraudadores. Portanto, o conhecimento desempenha papeis tanto na prevenção quanto na detecção.

- Oportunidade: caso o fraudador possua motivação e conhecimento, restará a ele apenas ter e aproveitar uma oportunidade para cometer a fraude. É nesse pilar que as empresas têm maior poder de atuação, pois a posse dos sistemas e dos processos é delas, cabendo a elas o desenvolvimento e a implementação de sistemas seguros, processos controlados e políticas e normas que deixem claro como diminuir os riscos de fraudes e as melhores práticas a serem adotadas.

\section{Legislação Brasileira}

Como mostra (Cab12), a utilização fraudulenta de cartões envolve várias questões legais, como: a necessidade de tipificar corretamente o caso, o estabelecimento da competência jurisdicional e a atribuição da Polícia Judiciária.

A correta tipificação criminal de um caso é necessária, pois tipos penais diferentes podem acarretar processos penais e penalidades diferentes. No caso do uso fraudulento do cartão, principalmente a clonagem e o roubo/extravio, há duas tipificações penais comumente utilizadas: o furto mediante fraude (artigo 155, $\S 2^{\circ}$., II, Código Penal) e o estelionato (artigo 171, Código Penal). Para sanar eventuais divergências sobre a correta tipificação de um caso, os operadores do Direito fazem uso de doutrinas e da jurisprudência. Em suma, doutrinas 
são posições levantadas e defendidas por operadores do Direito que gozam de notável saber jurídico e, por isso, são seguidas pelo restante da comunidade jurídica. Entretanto, elas não têm força de lei. A jurisprudência, por sua vez, foi um posicionamento e entendimento efetuado durante um julgamento passado de mesmas características que o caso analisado.

Atualmente, a tipificação penal mais utilizada para o uso fraudulento dos cartões é o furto mediante fraude, crime no qual a participação da vítima é mais passiva quando comparado ao estelionato. Isso porque no furto mediante fraude, a vítima não concede o patrimônio ao meliante e o fraudador atua à revelia da vítima. Assim, a orientação jurisprudencial apresentada em (MF11) é:

"Distingue-se o furto mediante fraude, em que o engodo possibilita a subtração, do estelionato, em que o agente obtém a posse da coisa que lhe é transferida pela vítima por esta ter sido induzida a erro. Na jurisprudência, apontam-se as seguintes diferenças: no

primeiro há tirada contra a vontade da vítima; no segundo, a entrega é procedida livremente; no primeiro, há discordância da vítima; no segundo, o consentimento; no furto, há amortecimento da vigilância; no estelionato, engodo; naquele, o engano é concomitante

com a subtração; neste, é antecedente à entrega; a conduta do furto é de tirar, no estelionato é enganar para que a vítima entregue a coisa"

O estabelecimento da competência jurisdicional e a atribuição da Polícia Judiciária são aspectos importantes, pois determinarão o local onde deve-se fixar a competência para o processo e julgamento e, consequentemente, a atribuição para apuração da Polícia Judiciária, procedimentos requeridos pelo Código de Processo Penal. Essa discussão acontece, pois pode haver dúvidas onde efetivamente o crime ocorreu. Nesse caso, a posição mais adotada é que o prejuízo se dá no momento em que a instituição financeira realiza a compensação de valores, instante, então, que o crime ocorre (Kar02):

"Como induvidosamente expressa o disposto no artigo 70, do Código de Processo Penal, o lugar da alegada infração penal, que, em regra, determina o estabelecimento da competência territorial é, portanto, o lugar onde teria se dado sua consumação, ou seja, o lugar onde alegadamente se deu o resultado que integra a descrição típica, tanto quando este resultado é determinado e precisamente expresso, como quando se traduz na simples manifestação imediata da conduta no mundo exterior, pouco importando que, no primeiro caso, tenha este resultado ocorrido em lugar diferente daquele onde se desenvolveu a ação."

Apesar desses entendimentos serem aceitos pela maioria dos operadores do Direito no país e de estarem em processo de consenso, eles ainda não são unanimidade. Essa falta de clareza cria algumas dificuldades adicionais ao combate das fraudes, fazendo com que a relevância dos métodos de detecção seja ainda maior.

\section{Segurança da Informação e Detecção de Fraudes}

Enfim, ao considerar os custos e restrições envolvidos e as condições que impulsionam os fraudadores, para diminuir as chances dessas condições serem concomitantemente válidas, as empresas envolvidas devem implementar um ciclo de atividades. Como parte integrante desse ciclo, devem existir tanto políticas e processos de Segurança da Informação quanto sistemas e processos de Deteç̧ão e Análise de Fraudes. As atribuições dessas áreas não são as mesmas. Cada uma tem seus sistemas, processos, políticas e funções que, em alguns momentos, são complementares. 
Em suma, a área de Segurança da Informação zela pela confidencialidade, integridade e disponibilidade dos dados e executa políticas como, por exemplo, o PCI-DSS (Payment Card Industry - Data Security Standard) (PC15), cujos 12 requisitos estão listados abaixo.

O Payment Card Industry é um consórcio formado por várias empresas do Mercado de Cartões, inclusive em um contexto mais amplo que o abordado anteriormente, pois há a participação de fornecedores de equipamentos nesse consórcio. O Payment Card Industry mantém e divulga alguns padrões para aumentar a segurança dos dados, sendo o $P C I-D S S$ o mais difundido deles, cuja versão mais recente para o momento em que essa dissertação foi escrita é a v3.1 de abril de 2015. O PCI-DSS v3.1 é dividido em seis eixos principais que se subdividem em 12 requisitos.

- Construir e manter redes e sistemas seguros

1. Instalar e manter um firewall para proteger dados de cartão de crédito.

2. Não utilizar senhas padrão ou outras configurações de segurança dos softwares utilizados.

- Proteger os dados do titular do cartão

3. Proteger dados de cartões de crédito armazenados.

4. Utilizar criptografia na transmissão de dados de cartões de crédito.

- Manter um Programa de Gerenciamento de Vulnerabilidades

5. Utilizar regularmente programas antivírus.

6. Desenvolver e manter sistemas e aplicações seguras, implementar um forte controle de acesso.

- Implementar fortes medidas para controle de acesso

7. Restringir acesso a dados de cartões de crédito por negócio e por pessoas que realmente precisam acessá-los.

8. Designar um único ID para cada usuário da rede e sistemas.

9. Restringir acesso físico aos dados de cartão de crédito, testar e monitorar a rede regularmente.

- Monitorar e testar as redes regularmente

10. Rastrear e monitorar todos os acessos à rede e dados de cartões de crédito.

11. Testar a segurança de sistemas e processos regularmente.

- Manter uma Política de Segurança da Informação

12. Manter uma política para endereçar questões de Segurança da Informação.

Em geral, o papel da área de Segurança da Informação é garantir que os dados não sejam expostos. Na linguagem do mercado, dados de cartão expostos e posteriormente utilizados em transações fraudulentas são chamados de dados comprometidos. Uma instituição que foi local de comprometimento dos dados é chamada de Ponto de Comprometimento - POC e, quando são utilizadas corretamente e seguem as melhores práticas, as políticas de Segurança da Informação praticadas pelas instituições têm a função de evitar que a instituição se torne um POC. Caso isso aconteça, a instituição pode sofrer diversas penalidades impostas pelas bandeiras e perder credibilidade junto ao seu público. 
Como, na prática, não é possível garantir total segurança dos dados, a área de Detecção e Análise de Fraudes atua na contenção de operações fraudulentas que ocorrem quando a segurança dos dados falha. O passo seguinte executado pelos fraudadores após o comprometimento dos dados do cartão é a utilização dos dados para pagamento de uma compra ou serviço. Quando um estabelecimento tem um produto ou serviço seu pago com um cartão fraudado, ele é chamado de Ponto de Utilização - PUC. É para evitar que o estabelecimento se torne um PUC que a área de Detecção e Análise de Fraudes existe e é nesse âmbito que as técnicas discutidas nessa dissertação serão aplicadas, apesar de existirem aplicações de Aprendizagem de Máquina no contexto de Segurança da Informação como no problema de detecção de intrusos.

Como será visto no próximo capítulo, por tratar um universo vasto de transações e uma alta complexidade de dados e modelos, as técnicas de Aprendizagem de Máquina podem ser aplicadas como proposta de solução, ao menos parcial, para os problemas presentes na área de Detecção e Análise de Fraudes. 


\section{Capítulo 3}

\section{Fundamentação Teórica}

Dadas as necessidades e peculiaridades do mercado de cartões, o uso de técnicas de Aprendizagem de Máquina na detecção de fraudes nesse tipo de transação já foi estudado em diversos trabalhos: (MTVM93), (SFL $\left.{ }^{+} 97\right)$ e (GWdL08b). Devido à depreciação dos modelos de detecção de fraudes, as companhias especializadas no desenvolvimento deles geralmente permitem, através de acordos comerciais, que esses modelos sejam posteriormente complementados com o acréscimo de regras de detecção de fraudes. Essas novas regras são desenvolvidas manualmente por especialistas no domínio. Assim, a classificação baseada em regras se tornou uma das técnicas mais aplicadas na detecção de fraudes. Entretanto, um ponto de atenção da classificação baseada em regras é a manutenção do conjunto de regras, ou seja, as atividades de descoberta, geração, proposição e aferição do desempenho de cada uma das regras pertencentes ao conjunto de regras. Ao propor uma metodologia para algumas dessas atividades, essa dissertação pretende auxiliar o trabalho dos especialistas no domínio na execução delas. Sendo assim, esse capítulo tem por objetivo discutir a fundamentação teórica que serve de base para a técnica proposta. Então, a seguir, serão revisados tópicos como: Aprendizagem de Máquina e classificadores, regras de associação, análise sensível ao custo, desafios enfrentados ao se aplicar técnicas de Aprendizagem de Máquina e avaliação de desempenho.

Aprendizagem de Máquina, ou Machine Learning, pode ser definida como a área que pesquisa, estuda e propõe um conjunto de técnicas para, automaticamente, detectar padrões em dados e utilizar esses padrões descobertos para predizer acontecimentos futuros, ou até mesmo para realizar outros tipos de tomada de decisão relacionados a eventos não determinísticos (Mur12). Tipicamente, os problemas tratados pela área são: classificação, regressão e agrupamento. Com isso, é possível segmentar os algoritmos estudados em Aprendizagem de Máquina em três tipos (Mar09):

- Aprendizado supervisionado: um conjunto de treinamento contendo registros de exemplo com suas respectivas classes corretas e conhecidas é fornecido para o classificador. A partir daí, baseado nesses exemplos, o algoritmo generaliza as respostas recebidas e aplica essas generalizações a registros novos e de classes desconhecidas com a finalidade de determinar corretamente suas respectivas classes.

- Aprendizado não supervisionado: não há o fornecimento de registros de exemplo com classes conhecidas. Ao invés disso, o algoritmo tenta identificar similaridades entre os registros para atribuir a mesma classe aos registros parecidos.

- Aprendizado por reforço: pode se considerar um tipo de aprendizado situado no meiotermo entre os tipos anteriores. Isso porque o algoritmo é informado quando um registro 
é erroneamente classificado, mas o modo correto de classificar esse registro não é fornecido, e o algoritmo tem que aprender por si só, explorando algumas alternativas até encontrar a correta.

\subsection{Classificadores}

Há uma série de problemas estudados em Aprendizagem de Máquina que são denominados como problemas de classificação. Nesse tipo de problema, o objetivo é organizar os objetos em categorias, ou classes, previamente definidas. Assim, tem-se (i) um conjunto de classes, (ii) um conjunto de instâncias e (iii) um classificador. A partir disso, a classificação é a atividade, realizada pelo classificador, de atribuir uma classe a cada uma das instâncias.

Logo, para executar a tarefa de classificação, é necessário construir o classificador, ou método de classificação, que será responsável por fazer as atribuições entre os elementos do conjunto de amostras e os elementos do conjunto das classes. Para se construir o classificador, é preciso dispor de um conjunto de treinamento, ou seja, um conjunto de amostras cujas classes sejam previamente conhecidas. Após seu treinamento, o classificador é exposto a uma série de amostras cujas classes são desconhecidas para ele prever as classes dessas amostras.

No caso da detecção de fraudes em transações de cartões, o conjunto de classes é \{ "transação legítima"e "transação fraudulenta" \}; o conjunto de instâncias, ou amostras, é formado pelas transações em si; o conjunto de treinamento é formado por transações passadas que foram sabidamente tidas como fraudulentas ou legítimas; e, finalmente, o classificador deve atribuir uma e somente uma classe para cada nova transação.

Além dos classificadores baseados em regras, a utilização de outros métodos de classificação para detectar fraudes em transações de cartões já foi feita por diversos autores, como (AK12) e (Gad08). Ambos os textos apresentam explicações sobre o funcionamento de diferentes técnicas, mas o primeiro faz uma comparação qualitativa, enquanto o segundo compara as técnicas através de uma avaliação quantitativa de desempenho. Além disso, (Ber14) aplica a técnica Dynamic Model Averaging (DMA) ao problema. Alguns dos métodos de classificação serão brevemente revistos a seguir.

\subsection{1 Árvores de Decisão}

De acordo com (Mit97), um classificador baseado em árvore de decisão é aquele que expressa uma aproximação para os valores resultantes de uma função-alvo cuja imagem é formada por valores discretos e utiliza uma estrutura de árvore para representar essa aproximação.

A estratégia básica de aprendizado, ou construção, das árvores de decisão do tipo TDIDT (Top Down Induction Decision Trees) é a aprendizagem não-incremental através de exemplos (Qui86). Ou seja, na medida em que os registros de treinamento são apresentados, a árvore é construída de cima para baixo. Esse processo não é guiado pela ordem com que as informações aparecem, mas sim por um critério de frequência da informação cuja variante mais usada é o ganho de informação. Assim, inicialmente, o atributo que trouxer o maior ganho de informação é o que mais segmentará o conjunto de treinamento entre as classes e será o escolhido como nó raiz da árvore. Em seguida, cada valor desse atributo definido como nó raiz gera um ramo descendente da árvore. O processo é reiniciado para a definição de qual será o atributo que dará origem ao próximo nó da árvore.

O algoritmo ID3, (Qui86), é um processo iterativo cujo espaço de busca é formado pelas árvores de decisão possíveis para um dado conjunto de treinamento. Ou seja, seu foco está em determinar a melhor árvore entre todas as possíveis. 
Inicialmente, o ID3 escolhe aleatoriamente um subconjunto de instâncias pertencentes ao conjunto de treinamento e constrói uma árvore de decisão para classificar esse subconjunto. Posteriormente à sua construção, a árvore tenta classificar o restante do conjunto de treinamento. Caso todas as instâncias sejam classificadas corretamente, o processo termina. Caso contrário, uma parte aleatória das amostras incorretamente classificadas é adicionada ao subconjunto inicial e uma nova árvore é construída.

\subsubsection{Redes Neurais Artificiais}

Segundo (JMM96), as redes neurais artificiais são sistemas de computação massivamente paralelos formados por um grande número de unidades básicas de processamento conectadas entre si. A ideia por trás das redes neurais artificiais é criar um modelo computacional cuja organização remeta aos princípios do cérebro humano.

As primeiras unidades básicas de processamento, ou perceptrons, do modelo computacional foram propostas como funções matemáticas que calculam uma soma ponderada das variáveis de entrada e retornam 1 , caso essa soma exceda um determinado limiar; ou -1, caso ela não exceda.

Desse modo, o processo de aprendizado de uma rede neural artificial pode ser visto como o problema de atualizar a arquitetura da rede e os pesos das interconexões para que a rede possa realizar uma tarefa específica de modo eficiente.

Para o caso do perceptron, o aprendizado consiste em atribuir os pesos adequados aos atributos. O algoritmo mais utilizado para essa tarefa é chamado de gradiente descendente e, resumidamente, funciona da seguinte forma.

De início atribui-se um peso aleatório para cada atributo e aplica-se iterativamente o perceptron a cada amostra do conjunto de treinamento, modificando-se o peso dos atributos cada vez que um erro de classificação é cometido. A modificação dos pesos é regida pela diferença entre a classe desejada e a retornada pelo perceptron e por um parâmetro chamado taxa de aprendizado que controla o grau de mudança dos pesos em cada passo. Esse parâmetro é importante para diminuir o risco de uma otimização local ser considerada como a otimização global da função. Todo o processo é repetido até que todas as instâncias do conjunto de treinamento sejam corretamente classificadas.

Além desse modelo mais simples, há também as redes neurais multicamadas, que podem conter diversas camadas intermediárias entre as camadas de entrada e saída. Em uma rede neural com alimentação para frente, os nós de uma camadas somente estão ligados aos nós da camada seguinte; já em uma rede neural recorrente, os nós podem estar ligados a nós da camada seguinte, da mesma camada ou até mesmo de camadas anteriores. A função de ativação também pode ser diferente da descrita acima para permitir que os nós das camadas intermediárias produzam valores que não sejam lineares com seus parâmetros de saída. O algoritmo base de aprendizagem dos pesos mais utilizado para uma rede multicamada é chamado backpropagation e é uma extensão do algoritmo discutido acima para o caso do perceptron.

\subsubsection{Naive Bayes}

Em muitas ocasiões que envolvem problemas de classificação, o relacionamento entre o conjunto de atributos e a classe não é determinístico, ou seja, a classe não pode ser prevista com total margem de certeza mesmo que o conjunto de atributos de uma instância tenha os mesmos valores que algumas instâncias do conjunto de treinamento. Com isso, foram propostos os classificadores baseados em abordagens estatísticas, especialmente através do 
uso do Teorema de Bayes. Nesses classificadores, a classe atribuída à instância é aquela cuja probabilidade posterior é a maior possível. Dessa forma, se $X$ for o conjunto de atributos e $C$ for o conjunto de classes, a classe da instância será aquela que tiver maior valor de $P(C / X)$.

O Naive Bayes é um classificador também baseado no Teorema de Bayes, entretanto, ele supõe que os atributos que descrevem as instâncias sejam independentes entre si. Essa suposição pode parecer ingênua, mas produz bom desempenho prático, torna o cálculo de probabilidades viável e a técnica útil.

Ao esperar-se que a classe $c_{j} \in C$ esteja relacionada com as $n$ variáveis explicativas, tem-se $P\left(C \mid X_{1}, X_{2}, \ldots, X_{n}\right)$. Com a aplicação do Teorema de Bayes:

$$
P\left(C \mid X_{1}, X_{2}, \ldots, X_{n}\right)=\frac{P(C) P\left(X_{1}, X_{2}, \ldots, X_{n} \mid C\right)}{P\left(X_{1}, X_{2}, \ldots, X_{n}\right)}
$$

Para simplificar a equação acima, ignora-se o denominador por ele não depender de $C$, considera-se a suposição de independência feita pelo Naive Bayes e utiliza-se a definição de probabilidade condicional. O resultado é a expressão abaixo.

$$
P\left(C \mid X_{1}, X_{2}, \ldots, X_{n}\right)=P(C) \prod_{i=1}^{n} P\left(X_{i} \mid C\right)
$$

Por fim, o classificador atribuirá a classe com maior probabilidade à instância de entrada.

\subsubsection{Algoritmos Genéticos}

A aprendizagem de conceitos pode ser formulada como um problema de busca em um espaço de hipóteses potenciais para as generalizações que mais se encaixam no conjunto de treinamento. Então, algoritmos de buscas são frequentemente utilizados como proposta de solução para esse tipo de problema. Algoritmos Genéticos, (Mit97), são algoritmos de busca baseados na Teoria da Seleção Natural proposta por Darwin para a evolução biológica. Porém, ao invés de fazer buscas das amostras mais gerais para as mais específicas ou o inverso, essa classe de algoritmos gera as hipóteses através de operações particulares, como cruzamento e mutação, realizadas sobre as hipóteses vistas em passos anteriores.

Num primeiro momento, a técnica agrupa um conjunto de indivíduos, que funcionam como hipóteses, em um grupo denominado população. Dessa forma, a cada iteração, a técnica não manipula simples indivíduos, mas toda a população. Ao longo do processo, cada indivíduo recebe uma nota que serve como métrica de sua habilidade de adaptação. Alguns dos indivíduos mais adaptados são mantidos e darão origem aos seus descendentes. O processo é mantido até que uma solução plausível seja encontrada.

A nota que avalia os indivíduos é uma função objetivo que os algoritmos genéticos pretendem otimizar. Assim, essa função é utilizada como critério de ordenação das hipóteses potenciais e de seleção probabilística delas para a inclusão nas gerações futuras. Então, por exemplo, se o aprendizado envolve a geração de regras de classificação, tipicamente, a função objetivo seria uma métrica da qualidade do classificador.

Por sua vez, a importância dos operadores genéticos se dá pelas necessidades concomitantes de propagar a diversificação da população nas gerações futuras e manter determinadas características. Assim, o operador de mutação tem o papel de introduzir e estimular a diversidade genética da população. Em termos probabilísticos, esse operador tenta assegurar que a probabilidade de se chegar a qualquer ponto do espaço de busca não será zero e, ao proporcionar a alteração na direção da busca, tem a chance a contornar o problema dos mínimos locais. Enquanto isso, o operador de cruzamento tem o papel de recombinar, nos filhos, algumas características dos pais, num mecanismo de herança. 
Com a utilização de esquemas de codificação, os algoritmos genéticos podem servir de base para a geração de regras usadas em classificadores baseados em regras, que serão tema da próxima seção.

Os métodos e algoritmos vistos ao longo das seções anteriores constituem um considerável arcabouço de técnicas passíveis de serem utilizadas em tarefas de classificação, inclusive na detecção de fraudes em transações de cartões. Na prática, para definir qual classificador será utilizado, o especialista de domínio utiliza diversos fatores, entre eles o desempenho técnico dos classificadores, que pode ser bastante afetado pela escolha dos diferentes parâmetros envolvidos em suas implementações. Isso porque, de acordo com (Gad08), em termos de desempenho, os resultados apresentados pelos diferentes classificadores são intercambiáveis e uma boa escolha da parametrização pode ser a chave para o atingimento de bons resultados, principalmente quando se verifica que a manutenção dos valores padrão desses parâmetros pode degradar o desempenho dos métodos. Além disso, a utilização de técnicas como a Análise Sensivel ao Custo, que considera a diferença de custo nos erros dos classificadores e será vista nas próximas seções, mostrou-se um fator preponderante para o bom desempenho dos classificadores (GWdL08a).

Além do desempenho técnico, outros fatores são considerados na escolha de um classificador. Então, a Tabela 3.1, extraída de (AK12), resume vantagens e desvantagens de alguns métodos quando aplicados ao problema de detecção de fraudes em cartões, pois essa comparação pode variar para outros domínios. 


\begin{tabular}{|c|c|c|}
\hline Técnica & Vantagens & Desvantagens \\
\hline $\begin{array}{l}\text { Algoritmos } \\
\text { Genéticos }\end{array}$ & $\begin{array}{l}\text { Possibilidade de tratar dados com } \\
\text { ruído; facilidade de integração com } \\
\text { outros sistemas; usado para melho- } \\
\text { rar o desempenho de outras técnicas. }\end{array}$ & $\begin{array}{l}\text { Alta dependência de especialistas na } \\
\text { técnica; ao trabalhar com grandes } \\
\text { conjuntos de dados, exige alta capa- } \\
\text { cidade computacional. }\end{array}$ \\
\hline $\begin{array}{l}\text { Árvores de } \\
\text { Decisão }\end{array}$ & $\begin{array}{l}\text { Facilidade de uso, de interpretação e } \\
\text { na explicação dos resultados; escalá- } \\
\text { vel, alto grau de precisão. }\end{array}$ & $\begin{array}{l}\text { Dificuldade de tratar dados contí- } \\
\text { nuos ou faltantes; propensão a over- } \\
\text { fitting; ao trabalhar com grandes } \\
\text { conjuntos de dados, exige alta capa- } \\
\text { cidade computacional. }\end{array}$ \\
\hline $\begin{array}{l}\text { Programação } \\
\text { Lógica Indu- } \\
\text { tiva }\end{array}$ & $\begin{array}{l}\text { Linguagem com alto poder de ex- } \\
\text { pressão que pode ser usada em do- } \\
\text { mínios complexos. }\end{array}$ & $\begin{array}{l}\text { Baixo poder de predição; dificuldade } \\
\text { em tratar ruídos e outliers. }\end{array}$ \\
\hline $\begin{array}{l}\text { Redes Neu- } \\
\text { rais }\end{array}$ & $\begin{array}{l}\text { Possibilidade de tratar dados com } \\
\text { ruído; aplicável a problemas comple- } \\
\text { xos; altas precisão e rapidez na clas- } \\
\text { sificação. }\end{array}$ & $\begin{array}{l}\text { Dificuldade para configurar, operar } \\
\text { e explicar como os resultados foram } \\
\text { gerados; menos eficiente no proces- } \\
\text { samento de grandes conjuntos de da- } \\
\text { dos; sensível ao formato de dados } \\
\text { (diferentes representações de dados } \\
\text { podem produzir resultados diferen- } \\
\text { tes); dificuldade em tratar dados não } \\
\text { numéricos ou numéricos fora do in- } \\
\text { tervalo }[0,1] \text {. }\end{array}$ \\
\hline $\begin{array}{l}\text { Regressão Lo- } \\
\text { gística }\end{array}$ & $\begin{array}{l}\text { Facilidade em construir e explicar o } \\
\text { funcionamento; pode ter alto grau } \\
\text { de precisão, principalmente quando } \\
\text { aplicada a um conjunto pequeno de } \\
\text { dados. }\end{array}$ & $\begin{array}{l}\text { Dificuldade em tratar ruídos, outli- } \\
\text { ers ou dados não numéricos; pode } \\
\text { não ter alto grau de precisão para } \\
\text { conjuntos de dados grandes; dificul- } \\
\text { dade para ser aplicada à problemas } \\
\text { complexos. }\end{array}$ \\
\hline $\begin{array}{l}\text { Sistemas } \\
\text { Baseados em } \\
\text { Casos Passa- } \\
\text { dos (exemplo, } \\
k \text {-means) }\end{array}$ & $\begin{array}{l}\text { Facilidade de atualização e manu- } \\
\text { tenção; útil quando um grande nú- } \\
\text { mero de exemplos está disponível; } \\
\text { possibilidade de lidar com ruídos ou } \\
\text { dados incompletos; altas eficácia e } \\
\text { flexibilidade. }\end{array}$ & $\begin{array}{l}\text { Pode sofrer do problema de dados in- } \\
\text { completos ou com ruído; tempo re- } \\
\text { querido durante a classificação pode } \\
\text { ser alto. }\end{array}$ \\
\hline $\begin{array}{l}\text { Sistemas Ba- } \\
\text { seados em Re- } \\
\text { gras }\end{array}$ & $\begin{array}{l}\text { Facilidade em desenvolver, cons- } \\
\text { truir, implementar, modificar e ex- } \\
\text { plicar o funcionamento; alto grau de } \\
\text { precisão; alta flexibilidade; possibili- } \\
\text { dade de absorver regras provenientes } \\
\text { de outras técnicas. }\end{array}$ & $\begin{array}{l}\text { Dificuldade em tratar dados faltan- } \\
\text { tes ou valores inesperados; alta de- } \\
\text { pendência de especialistas no domí- } \\
\text { nio; propensão a underfiting. }\end{array}$ \\
\hline
\end{tabular}

Tabela 3.1: Quadro comparativo entre diversos classificadores (AK12).

\subsubsection{Classificação Baseada em Regras}

Sistemas baseados em regras são algoritmos de aprendizagem supervisionada cujo classificador é constituído por um conjunto de regras, cada uma com o formato:

Se (determinada condição é verdadeira) Então (faça determinada ação). 
O lado que contém a condição é chamado de antecedente da regra, o lado que contém a ação é chamado consequente da regra. É comum que haja mais de um atributo envolvido no antecedente. Uma regra $r$ cobre um registro $x$ se os atributos de $x$ satisfizerem as condições expressas no antecedente de $r$. Nesse caso, também é dito que a regra foi disparada. Com a geração de várias regras, cria-se um conjunto de regras que pode ter duas propriedades (TSK05):

- Conjunto de regras completo: os classificadores baseados em regras contêm essa propriedade quando cada um dos registros submetidos ao classificador dispara pelo menos uma regra.

- Regras mutuamente excludentes: um conjunto de regras é composto por regras mutuamente excludentes quando não houver nenhum registro que é coberto por mais de uma regra. Em outras palavras, cada instância dispara uma, e apenas uma, regra.

Uma dificuldade presente nos casos nos quais as regras não são mutuamente excludentes é que classes diferentes podem ser atribuídas a um mesmo registro. Há duas abordagens para contornar essa dificuldade.

- Ordenação das regras: ao utilizar essa estratégia, cria-se uma ordem dentro do conjunto de regras seguindo algum critério de ordenação. No momento em que um registro é exposto ao conjunto de regras, ele é testado contra as regras nessa ordem de prioridade, a primeira regra que ele disparar atribuirá a classe definida nela e o processo para. Portanto, não há como um registro ser rotulado como pertencente a duas classes distintas. Quando o critério de ordenação considera alguma métrica individual de qualidade das regras, a ordenação é conhecida como ordenação baseada em regras. Uma vantagem desse esquema é que, pelo menos a priori, o registro será classificado pela melhor - segundo um critério de qualidade previamente escolhido - regra disponível no conjunto. De outra forma, a ordenação pode ser feita baseada em classes, ou seja, primeiramente o registro é exposto a todas as regras que, se disparadas, atribuem, por exemplo, a classe transação legítima para, posteriormente, o registro ser exposto às regras que o classificam como transação fraudulenta.

- Não ordenação das regras (busca de consenso): com essa estratégia, aceita-se que diversas regras classifiquem uma instância, sendo que o disparo de uma regra funciona como um voto que, inclusive, pode ser ponderado. A instância recebe a classe que tiver mais votos. Uma vantagem é que essa estratégia pode diminuir os erros de classificação por considerar o parecer de várias regras.

A partir daí, parte significativa do trabalho passa a ser a construção do classificador e a determinação de quais serão as regras participantes do conjunto de regras. A extração das regras que subsidiam o classificador pode ser dividida em dois grupos de métodos: (i) métodos diretos: extraem as regras diretamente dos dados, e (ii) métodos indiretos: primeiramente utilizam outros métodos de classificação para, posteriormente, converter os resultados desses métodos em regras. Classificadores frequentemente utilizados nos métodos indiretos são as árvores de decisão e os algoritmos genéticos.

Há várias técnicas e implementações diferentes que foram propostas com o objetivo de determinar um conjunto de regras e representam os métodos diretos: $A Q$ (Mic69), CN2 (CN89), PRISM (Cen87) e RIPPER (Coh95). Apesar da aplicação principal do algoritmo ID3 (Qui86) não ser o aprendizado de conjunto de regras propriamente dito, mas sim a indução de árvores de decisão, ele é importante nesse contexto, pois serviu como fundamento 
para algumas das metodologias citadas anteriormente e é um representante dos métodos indiretos.

Os algoritmos $A Q$ e $C N 2$ são variações da abordagem de cobertura sequencial. Essa estratégia consiste em determinar uma regra, retirar as amostras cobertas por essa regra do conjunto de treinamento e, então, repetir o procedimento. O algoritmo extrai das regras uma classe por vez em conjuntos de dados que contenham mais de uma classe. A decisão de qual classe será explorada primeiro considera fatores como a representatividade das classes no conjunto de treinamento ou o custo acarretado pelo erro na classificação das amostras. Além disso, cada regra individual deve cobrir o máximo possível de amostras positivas e o mínimo possível de amostras negativas. Outro requisito é que a regra tenha alta precisão ou seja, as predições devem ser corretas -, mas não necessariamente alta cobertura - ou seja, cubra todos os exemplos.

De forma sucinta, o algoritmo de cobertura sequencial começa com uma lista de regras vazia. Então, é chamada uma função para extrair uma regra que cubra o máximo de amostras de treinamento positivas e o mínimo de amostras negativas. Ao verificar, segundo um critério de parada, que a regra formulada atingiu seu objetivo, a função retorna o controle para o módulo principal. Nesse ponto, os registros cobertos pela regra são removidos do conjunto de treinamento e a regra é adicionada à lista de regras. A função de extração de regras é novamente chamada e o processo todo se estende até que todas as amostras do conjunto de treinamento tenham sido analisadas.

No caso do algoritmo $A Q$, o método acima é aplicado com duas adaptações. A primeira faz com que ele aprenda tantos conjuntos disjuntos de regras quantas forem as classes, formando inicialmente todo o conjunto de regras para uma classe para depois formar o conjunto de regras que define outra e assim sucessivamente. A segunda propõe a utilização de apenas uma amostra positiva para guiar o aprendizado de cada regra individual. Então, para aprender uma nova regra, o algoritmo seleciona uma amostra positiva ainda não coberta para direcionar o aprendizado de uma nova regra.

Por sua vez, o algoritmo CN2 não depende de amostras específicas durante a busca e seu espaço de busca inclui regras cujo desempenho não é perfeito dentro do conjunto de treinamento.

O algoritmo RIPPER é a evolução de outro algoritmo para indução de regras chamado IREP. Ele também se utiliza da técnica de cobertura sequencial para gerar as regras, mas ele utiliza um conjunto de dados de validação para executar a poda das regras e quando há duas classes no conjunto de treinamento, o algoritmo define a classe com maior número de amostras como a classe padrão e descobre regras para detectar a classe que tenha um número menor de amostras. Dessa forma, ele é apropriado para os casos nos quais o conjunto de treinamento possui um desbalanceamento de classes ou quando há presença de ruído nos dados. Além disso, a complexidade computacional do RIPPER é linear ao número de amostras de treinamento.

\subsubsection{Modelos de Pontuação}

Os modelos de pontuação, ou modelos de scoring, são classificadores largamente utilizados pela indústria financeira devido à sua efetividade e por sua adequação operacional. Esses modelos utilizam técnicas para gerar uma pontuação para cada transação que, usualmente, quanto mais alta, maior a probabilidade da transação ser fraudulenta. Com isso, o que geralmente os especialistas no domínio fazem é criar duas notas de corte que segmentarão as transações em três grupos:

- Transações cuja pontuação foi menor ou igual à primeira nota de corte são aprovadas 
instantaneamente, pois considera-se que a probabilidade delas serem fraudulentas é baixa;

- Transações cuja pontuação foi maior que a primeira linha de corte, mas menor ou igual à segunda linha de corte são referidas para um time de especialistas no domínio para uma análise manual mais criteriosa;

- Transações cuja pontuação foi maior que a segunda linha de corte são negadas automaticamente, pois considera-se que elas excedem o apetite de risco do usuário.

Esse esquema de pontuação torna a operação antifraude bastante escalável, pois apesar de cada transação ser pontuada, somente algumas delas serão analisadas individualmente por especialistas. Isso não quer dizer que não há custos em pontuar cada transação, mas sim que essa estratégia permite calibrar o número de analistas responsáveis por analisar as transações, gerando um controle maior sobre os gastos com recursos humanos.

Algumas das técnicas discutidas anteriormente podem ser utilizadas para a geração dessa pontuação como as redes neurais ou árvores de decisão, mas o uso de regressão logística binária, técnica que será tratada mais adiante nessa dissertação, também é altamente disseminado.

Os modelos de pontuação podem, por exemplo, ser combinados com a classificação baseada em regras, seja atribuindo uma pontuação, ou peso, a cada regra, como discutido anteriormente, seja utilizando a pontuação como uma possível variável das regras para fazer a combinação da pontuação com outras características da transação. Por outro lado, a dificuldade encontrada pelas empresas para manter os modelos de pontuação é a duração da janela de tempo na qual esses modelos se mantêm atualizados e com alto poder de predição, já que há um alto custo envolvido em sua revisão. Essa dificuldade e uma abordagem para tratá-la são discutidas em (Ber14).

\subsection{Extração e Seleção de Características}

Independentemente da técnica de classificação que for escolhida como proposta de solução do problema, anteriormente à classificação em si e até mesmo ao treinamento do classificador, é necessário definir e descrever o conceito que será alvo do classificador. Como sugere (BL97), em um nível conceitual, essa tarefa pode ser subdividida em duas: (i) definir quais características, ou atributos, serão utilizadas para descrever e representar o conceito alvo e (ii) decidir como combinar essas características. Ainda, o texto sugere que a execução dessas tarefas deve ser guiada por uma métrica de relevância cujo objetivo é mensurar o poder que cada característica tem de discriminar as classes em questão. Uma das métricas mencionadas é a relevância ao alvo.

Relevância ao alvo: Um atributo $x_{i}$ é relevante em relação ao conceito alvo $c$ se existe, dentro do conjunto de instâncias, um par de instâncias A e B cujas classes c(A) e c(B) sejam diferentes e o único atributo, além da classe, para o qual elas tenham valores diferentes seja $x_{i}$.

Dessa forma, além da definição de quais atributos representarão o conceito alvo, a seleção e a extração de características são etapas primordiais na aplicação de técnicas de classificação e antecedem o treinamento do classificador. Segundo (ML02), elas podem ser definidas como:

- Seleção de Características: é o processo de escolha de um subconjunto de características pertencentes ao conjunto original de atributos para que o espaço de características seja otimamente reduzido de acordo com algum critério especificado previamente. 
- Extração de Características: é o processo de criação de novas características.

Por meio dessas atividades, busca-se: reduzir o volume de dados manipulado pelos algoritmos, ou seja, reduzir a dimensionalidade do conjunto de dados; encontrar um conjunto de dados relevante para a classificação; melhorar a qualidade dos dados disponíveis para consequentemente melhorar o desempenho dos algoritmos e aumentar o poder de compreensão sobre os resultados obtidos.

\subsection{Regras de Associação}

A mineração de regras de associação foi formalmente apresentada em (AIS93). Intuitivamente, essa tarefa consiste em encontrar regras que relacionam ou associam a presença conjunta de dois ou mais itens numa cestas de compras. Informalmente, uma cesta de compras é formada por uma série de registros, também chamados de transações, sendo que cada um desses registros contém um conjunto de itens. Para encontrar regras de associação, os algoritmos utilizam os dados obtidos de transações passadas e métricas de desempenho como confiança e suporte, definidos a seguir, cujos valores mínimos são definidos pelos usuários. As primeiras aplicações dessa técnica tinham o objetivo de direcionar ações conjuntas de vendas e marketing.

Para definirmos formalmente o problema, consideremos:

- Um conjunto de itens, $I=\left\{i_{1}, i_{2}, \ldots, i_{m}\right\}$;

- Um conjunto $D$ de transações, sendo que cada transação $T$, identificada unicamente por seu TID e pertencente ao conjunto $D$, contém uma série de itens tais que $T \subseteq I$;

- $X$, um conjunto de alguns itens de $I$. Onde é dito que uma transação $T$ contém $X$, se $X \subseteq T$.

Sendo assim, uma regra de associação é uma implicação $X \Longrightarrow Y$, na qual $X \subset I, Y \subset$ $I$ e $X \cap Y=\emptyset$.

Ainda, a regra $X \Longrightarrow Y$ terá confiança $c$ se c\% das transações de $D$ que contêm $X$ também contiverem $Y$.

Enquanto isso, o suporte $s$ da regra $X \Longrightarrow Y$ será o número de transações de $D$ que contêm $X \cup Y$. Onde, para os casos gerais, é permitido que $Y$ contenha mais de um item.

Dessa forma, para o conjunto $D$ de transações, o problema de mineração de regras de associação consiste em gerar todas as regras de associação que tenham suporte e confiança maiores ou iguais aos limites mínimos estabelecidos pelo usuário para cada uma dessas métricas.

Conforme (TSK05), a importância do suporte é dada pelo fato de que uma regra com baixo suporte tem alta probabilidade de ser gerada ao acaso. Logo, essa métrica é utilizada para se excluir regras possivelmente espúrias. Já a confiança mede a inferência feita por uma regra $X \Longrightarrow Y$. Portanto, quanto maior a confiança de uma regra, maior é a probabilidade do consequente, $Y$, estar presente em transações que contenham o antecedente, $X$. A confiança fornece uma estimativa da probabilidade condicional do consequente dado o antecedente.

Por fim, é interessante ressaltar que a inferência proposta por uma regra de associação não necessariamente revela uma relação de causalidade entre o antecedente e o consequente da regra. Ela sugere um forte relacionamento de co-ocorrência.

Há uma série de algoritmos que se propõem a resolver esse problema. Dois deles, Apriori e FP-Growth, serão abordados a seguir. 


\subsubsection{Algoritmo Apriori}

Uma abordagem para a mineração de regras de associação seria calcular o suporte e a confiança de cada regra possível. Entretanto, essa seria uma abordagem do tipo força bruta e seu custo computacional a inviabilizaria. Logo, há espaço para a aplicação de outras abordagens.

Uma abordagem utilizada por diversos algoritmos de mineração de regras é dividir o problema em dois subproblemas:

1. Geração de conjuntos de itens frequentes: nessa etapa, encontra-se todos os conjuntos de itens para os quais o suporte é maior ou igual a um suporte mínimo prefixado.

2. Geração de regras: nessa etapa, encontra-se todas as regras $X \Longrightarrow Y$ que tenham $X$ $\cup Y$ entre o conjunto de itens frequentes e para as quais a confiança é maior ou igual a uma confiança mínima preestabelecida.

O algoritmo Apriori, apresentado em (AS94), recebe um conjunto de transações como entrada e, respeitando os parâmetros estabelecidos pelo usuário, gera um conjunto de regras de associação como saída. Para que o espaço de busca seja reduzido e sua implementação se torne viável, ele se baseia em uma propriedade dos conjuntos de itens. Essa propriedade é conhecida como propriedade Apriori ou antimonotonia da relação $\subseteq$.

Propriedade Apriori ou Antimonotonia da Relação $\subseteq$ : se um conjunto de itens não é frequente, nenhum dos super conjuntos dele é frequente. Em outras palavras, para um conjunto de itens ser frequente, é necessário que todos os seus subconjuntos sejam frequentes.

Em termos práticos, essa propriedade quer dizer que, ao se fixar um conjunto de itens $S$ para verificar se ele é frequente, basta que um único subconjunto de $S$ não seja frequente para $S$ também não ser. Assim, seu suporte nem precisará ser calculado, pois $S$ não poderá ser frequente.

Conceitualmente, o algoritmo Apriori pode ser dividido em duas etapas: (i) determinação de todos os conjuntos de itens frequentes e (ii) geração de todas as regras de associação que satisfazem a confiança mínima.

Um conjunto de itens frequente é um conjunto de itens cujo suporte é maior ou igual ao suporte mínimo. A mineração dos conjuntos de itens frequentes é feita por níveis, sendo que conjuntos de itens de nível $k$ são aqueles conjuntos que possuem $k$ itens. Então, no nível 1, todos os conjuntos de itens frequentes de nível 1 são determinados e assim sucessivamente. Se um conjunto de itens não é frequente no nível $k$ - 1, ele é descartado, pois, segundo a propriedade Apriori, ele não poderá ser frequente em nenhum nível sucessivo. Após a determinação de todos os conjuntos de itens frequentes, as regras são geradas.

O algoritmo Apriori recebe o suporte mínimo e o conjunto de dados como parâmetros de entrada. De posse disso, ele gera uma lista de todos os conjuntos de itens candidatos que contenham apenas um item. A seguir, o conjunto de dados é varrido para verificar se esses conjuntos candidatos cumprem o requisito de suporte mínimo. Aqueles conjuntos candidatos que não cumprirem o requisito são descartados. Os conjuntos que cumpriram o requisito são combinados para formarem conjuntos de itens candidatos com dois elementos. Assim, o procedimento é repetido até que todos os conjuntos que não cumprem o requisito sejam descartados.

Após a geração dos conjuntos de itens frequentes, segue-se com a mineração de regras de associação, mas a métrica para avaliar regras de associação passa a ser a confiança. Assim, 
para encontrar as regras, uma lista de possíveis regras é gerada e a confiança de cada regra é calculada para verificar se ela ultrapassa o limite mínimo estabelecido pelo usuário.

\subsubsection{Algoritmo FP-Growth}

A partir da observação de que a geração dos conjuntos de itens candidatos feita no algoritmo Apriori é computacionalmente custosa, o trabalho de apresentado em (HPY00) propõe outro algoritmo para a mineração de regras de associação. Esse algoritmo, denominado FP-Growth, utiliza a técnica de dividir para conquistar aplicada à uma estrutura de dados eficiente, chamada FP-Tree, para eliminar a necessidade de criação dos conjuntos de itens candidatos.

Nesse algoritmo, bancos de dados extensos são condensados em uma estrutura de dados menor e o custo de se acessar esse banco de dados diversas vezes é evitado. Além disso, a técnica de dividir para conquistar decompõe a tarefa de mineração em subtarefas menores para proporcionar uma redução no espaço de busca. O algoritmo FP-Growth pode ser subdividido em duas etapas: (i) construção da FP-Tree e (ii) mineração de padrões frequentes contidos na FP-Tree.

$\mathrm{Na}$ primeira etapa, inicialmente, o algoritmo varre o banco de dados e conta o suporte de cada um dos itens contidos nele. Depois, o algoritmo analisa cada uma das transações contidas no banco de dados e, de cada uma delas, exclui os itens de baixo suporte (suporte menor que o suporte mínimo definido pelo usuário) e mantém os itens de alto suporte (suporte maior ou igual ao suporte mínimo definido pelo usuário). Ainda em cada transação, ordena-se os itens remanescentes em ordem decrescente de suporte.

Como exemplo, apresentado em (MM14), tem-se a seguinte situação:

- Conjunto de transações: $\{(\mathrm{A}$ B D E), (B C E), (A B D E), (A B C E), (A B C D E), (B C D)\}

- Suporte Mínimo: 3

Ao contar-se o suporte de cada item, o resultado é:

- Suporte de B: 6

- Suporte de E: 5

- Suporte de A: 4

- Suporte de C: 4

- Suporte de D: 4

Como o suporte de todos os itens é maior ou igual ao suporte mínimo, 3, estabelecido pelo usuário, todos os itens serão considerados na montagem da FP-Tree. Além disso, em cada uma das transações, os itens devem ser ordenados de forma decrescente pelo suporte. O resultado desse passo é:

- Conjunto de transações cujos itens estão ordenados: $\{(\mathrm{B}$ E A D), (B E C), (B E A D), (B E A C), (B E A C D), (B C D)\}

A partir daí, a árvore é construída. A raiz é um nó nulo e os ramos são formados com os itens das transações ordenadas no passo anterior. Para se formar os ramos, cada transação do banco de dados é analisada e seus itens vão sendo individualmente acrescentados à 
árvore. Caso os itens de uma determinada transação sejam idênticos aos itens de transações já analisadas, o ramo da árvore permanece o mesmo e os contadores dos itens são incrementados em uma unidade. Dessa forma, um novo ramo só é criado caso o próximo item da transação atual não seja compartilhado com as transações anteriores. A Figura 3.1 ilustra, como continuação do exemplo anteriormente iniciado, a construção da FP-Tree.

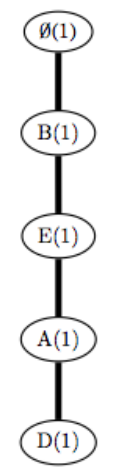

(a) $\langle 1, \mathrm{BEAD}\rangle$

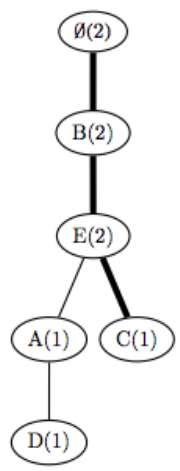

(b) $\langle 2, \mathrm{BEC}\rangle$

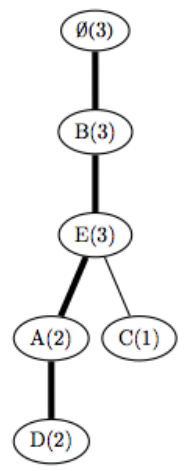

(c) $(3, \mathrm{BEAD})$

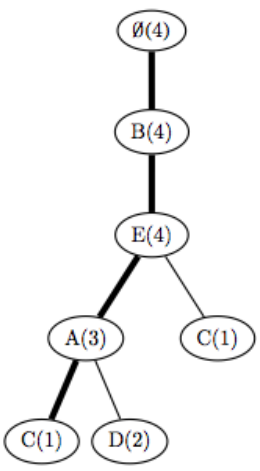

(d) $\langle 4, \mathrm{BEAC}\rangle$

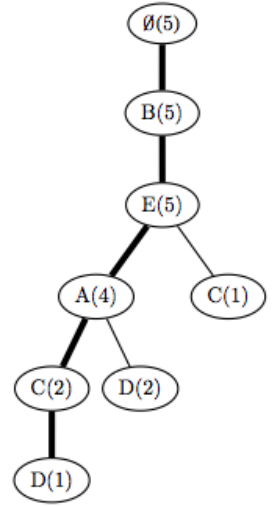

(e) $\langle 5, \mathrm{BEACD}\rangle$

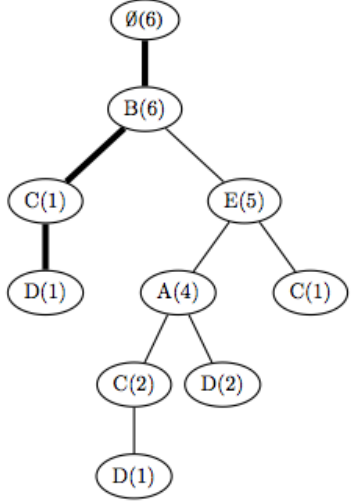

(f) $\langle 6, \mathrm{BCD}\rangle$

Figura 3.1: Os passos para a construção da FP-Tree. (MM14).

Assim, a FP-Tree é usada para armazenar a frequência com a qual os conjuntos de itens ocorrem. Nela, os conjuntos de itens são armazenados como caminhos da árvore. Dessa forma, conjuntos que possuam itens similares compartilham caminhos e, somente quando os itens se tornam diferentes, é que os caminhos são segmentados. Cada nó da árvore representa um item do conjunto de itens e contém o número de vezes que esse item participa da sequência. Ao se percorrer o caminho, tem-se, então, o número de vezes que a sequência ocorreu.

Então, é iniciada a segunda parte do algoritmo, cuja saída é o conjunto de itens frequentes. Essa segunda parte tem a FP-Tree como entrada e o processamento se inicia com os conjuntos de itens de apenas um item. Para cada um desses itens serão obtidos os padrões base condicionais, que são elementos do conjunto de caminhos que têm esse item em específico como último item. Os padrões base condicionais são utilizados na construção das FP-Tree condicionais. Cada caminho dessa árvore é chamado de caminho de prefixo, que nada mais é que um caminho intermediário existente entre o último nó (ou seja, o item em questão) e a raiz da árvore. Em outras palavras, caminhos de prefixo são os ramos da FP-Tree condicional, que é semelhante à FP-Tree, exceto por ser utilizada para encontrar conjuntos de itens frequentes terminados em um determinado sufixo. Uma FP-Tree condicional é obtida através dos passos:

1. Atualização dos contadores de suporte pelos caminhos de prefixo; 
2. Remoção dos nós previamente considerados;

3. Remoção dos itens que não satisfazem a condição de suporte mínimo.

Como sequência do exemplo, recebe-se a árvore da Figura 3.1(f) para que a construção das FP-Trees condicionais seja iniciada. Ao se considerar o item $D$, as transações $(B E C)$ e $(B E A C)$ são descartadas, pois elas não contêm o item em questão. A Figura 3.2 ilustra, em detalhes, a FP-Tree condicional para os conjuntos derivados do item $D$, que são: $D, D A$, $D E, D B, D A E, D A B, D E B$ e $D A E B$. Não há um conjunto $D C$, pois ao ser considerado no contexto do item $D$, o item $\mathrm{C}$ não atinge o critério de suporte mínimo.

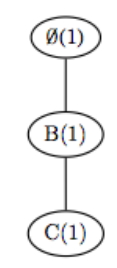

(a) Add BC, cnt $=1$

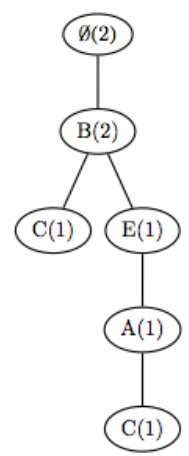

(b) Add BEAC, $c n t=1$

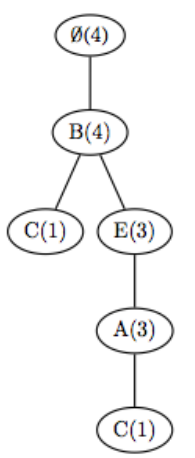

(c) Add BEA, $c n t=2$

Figura 3.2: As FP-Trees condicionais para o item D. (MM14).

Por sua vez, a Figura 3.3 ilustra, na forma de FP-Trees condicionais, os padrões base condicionais de todos os itens e, ao final da execução do algoritmo para todos os itens, tem-se, como resultado, o seguinte conjunto de itens frequentes: $\{D A, D B, D E, D A E, D A B, D E B$, $D A E B, C E, C B, C E B, A E, A B, A E B, E B\}$. Esse resultado é obtido através da enumeração de todas as combinações possíveis dos itens pertencentes ao subcaminho único resultante do processo de remoção dos itens não frequentes das FP-Trees condicionais. 


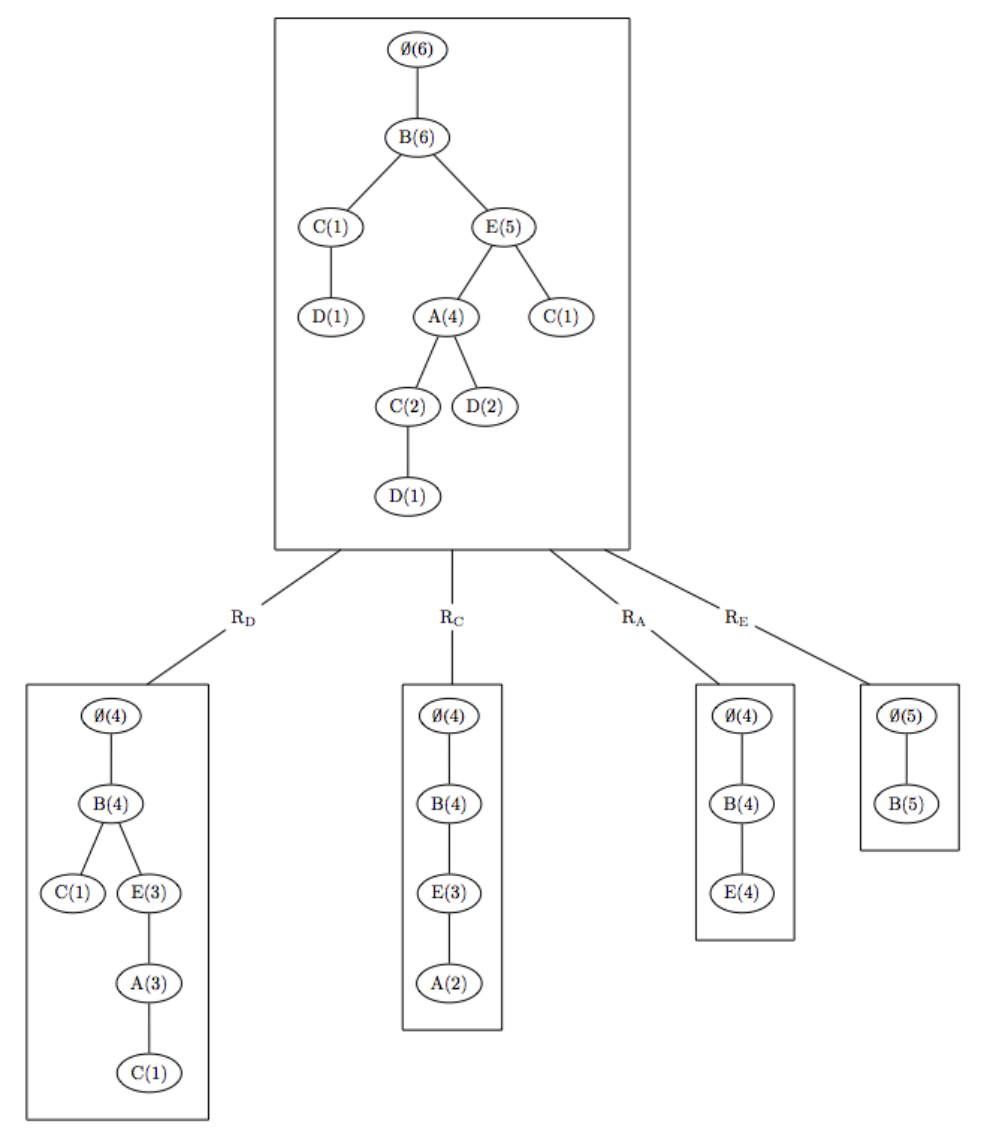

Figura 3.3: As diferentes FP-Trees condicionais. (MM14).

Um fator de atenção para o algoritmo FP-Growth é o caso no qual as FP-Tree condicionais forem resultantes de árvores de prefixo muito cheias, pois, quando isso acontecer, o algoritmo deve gerar um grande número de subproblemas e realizar a fusão dos resultados retornados de cada subproblema. Logo, o desempenho do algoritmo será degradado.

\subsection{Classificação Baseada em Associações}

Apesar de haver diferenças conceituais e de objetivos entre as técnicas de classificação e mineração de regras de associação, é possível fazer uso conjunto delas para fins de classificação. Para compreender como isso é feito, primeiramente é necessário reforçar as diferenças entre as técnicas e, posteriormente, discutir as oportunidades de integração.

Conforme apontado em (Fre00), existem diferenças sintáticas e semânticas entre as tarefas de classificação e mineração de regras de associação. Essas diferenças estão listadas abaixo.

- Quantidade de atributos no consequente da regra: dado o formato das regras, $X \Longrightarrow$ $Y$, é requisito da tarefa de classificação que o consequente da regra, ou seja, $Y$, tenha necessariamente apenas um atributo, a classe que se deseja prever. Por outro lado, as regras resultantes da tarefa de mineração de regras de associação podem ter um ou mais atributos em seus respectivos consequentes.

- Assimetria de atributos: na tarefa de classificação, o atributo classe deve ser determinado com base nos outros atributos do conjunto de dados e não pode aparecer no antecedente da regra. Logo, ele recebe uma maior importância e um tratamento diferenciado. Isso não acontece na mineração de regras de associação, pois todos os 
atributos têm a mesma importância e podem aparecer tanto no antecedente quanto no consequente das regras.

- Natureza semântica: na classificação, dados passados são utilizados para treinar o método com o objetivo de prever acontecimentos futuros. Logo, por natureza, essa tarefa é não determinística. Por sua vez, qualquer algoritmo aplicado à mineração de regras de associação deve retornar o mesmo conjunto de itens frequentes, ou seja, independentemente do algoritmo utilizado, o resultado retornado será o mesmo. Portanto, essa tarefa é determinística.

- Exposição à overfitting/underfitting: efeitos indesejados, como o overfitting e o underfitting, devem ser observados e prevenidos nas tarefas de classificação, mas não são fonte de preocupação para a mineração de regras de associação. Esses efeitos serão discutidos em maiores detalhes mais adiante.

- Presença de um viés indutivo: para cada classificador, o viés indutivo é a propriedade considerada pela técnica nos momentos em que é necessário optar por uma entre diversas hipóteses consistentes. Sem o viés indutivo, o classificador pode ser incapaz de fazer uma opção e prosseguir. Essa propriedade não é um requisito da mineração de regras de associação.

Mais especificamente, quando se discute diferenças entre as metodologias comuns de descoberta de regras para classificação - fundamentadas na cobertura sequencial - e a classificação baseada em associações, tem-se que as metodologias fundamentadas na cobertura sequencial, vista na seção 3.1.5, executam uma busca heurística, pois as regras são descobertas uma por vez, sendo que cada nova regra é descoberta após a exclusão das instâncias cobertas pela regra gerada anteriormente. Por outro lado, os classificadores baseados em associações fazem uma busca exaustiva utilizando todas as instâncias ao mesmo tempo. Dessa forma, a busca exaustiva pode determinar padrões não reconhecidos pela cobertura sequencial.

Apesar das diferenças, as dificuldades podem ser contornadas para viabilizar a utilização de regras de associação que sirvam de base para a construção de um classificador baseado em regras (LHM98). Uma das propostas apresentadas em (LMkW01) para contornar alguns problemas é: definição de um suporte mínimo para cada classe e a criação de um esquema de precedências de regras, apresentado abaixo, para que nem todas as regras descobertas sejam aplicadas no classificador.

Definição: dadas duas regras $r_{i}$ e $r_{j}, r_{i}$ tem precedência sobre $r_{j}$ se:

1. a confiança de $r_{i}$ é maior que a confiança de $r_{j}$, ou

2. a confiança de ambas as regras é a mesma, mas o suporte de $r_{i}$ é maior que o suporte de $r_{j}$, ou

3. a confiança e o suporte de ambas as regras são os mesmos, mas $r_{i}$ foi gerada antes de $r_{j}$.

A relação de precedência proposta pode ser utilizada para substituir o viés indutivo não existente na mineração de regras de associação, mas necessário na classificação. 


\subsection{Regressão Logística}

Em Estatística, os métodos de regressão têm o objetivo de entender a relação entre um conjunto de variáveis independentes (ou explicativas) e uma variável dependente (ou resposta) para construir um modelo para explicar essa associação. Com a construção do modelo, é possível prever o valor que a variável dependente terá diante dos valores das variáveis independentes, fazendo com que o método possa, diante de algumas circunstâncias, atuar como um classificador.

Dentre os métodos de regressão, há a Regressão Logística (HL00), que é adequada para situações nas quais:

- A variável resposta é categórica;

- As variáveis explicativas podem ser quantitativas ou qualitativas. Sendo que, no último caso, a representação será feita por variáveis indicadoras;

- Os erros não seguem uma distribuição de probabilidades do tipo normal.

Uma situação exemplo que satisfaz as condições acima é justamente a detecção de fraudes em transações de cartões, pois a variável resposta é binária, já que pode assumir um entre dois valores: transação fraudulenta ou transação legítima. Enquanto isso, as variáveis explicativas podem ser quantitativas ou qualitativas.

Assim, as próximas seções trazem, de uma forma sucinta, uma explanação sobre a Regressão Logística e algumas das principais questões na aplicação do modelo.

\subsubsection{A Função Resposta}

Na Regressão Logística Binária, a variável resposta, y, apresenta dois valores:

- Sucesso: quando o elemento possui a característica de interesse. Por exemplo, a transação é fraudulenta. Esse caso é representado pelo valor "1".

- Fracasso: quando o elemento não possui a característica de interesse. Por exemplo, a transação não é fraudulenta, ou seja, é legítima. Esse caso é representado pelo valor "0".

Ao se aplicar um método de regressão, um item chave é o valor médio da variável resposta dado valores para cada uma das variáveis do conjunto de variáveis independentes (aquelas que ajudam a explicar o fenômeno e das quais o valor médio da variável resposta depende). Esse valor médio é chamado de média condicional, ou $E(Y / x)$. Assim, tem-se, por exemplo:

$$
E(Y \mid x)=\beta_{0}+\vec{\beta}_{i} \vec{X}_{i}
$$

Onde:

- $\vec{X}_{i}$ é o vetor das variáveis explicativas;

- $\vec{\beta}_{i}$ é o vetor de coeficientes.

Com variáveis resposta categóricas, a média condicional deve ter um valor compreendido entre zero e um, ou seja, $0 \leq \mathrm{E}(\mathrm{Y} \mid \mathrm{x}) \leq 1$. Apesar de várias funções de distribuição já terem sido propostas para a análise de variáveis resposta categóricas, a distribuição logística possui duas vantagens significativas: facilidade e flexibilidade de manipulação matemática e facilidade de interpretação. Assim, se $\pi(x)=\mathrm{E}(\mathrm{Y} \mid \mathrm{x})$, então, o modelo de regressão logística será dado por: 


$$
\pi(x)=\frac{e^{\beta_{0}+\vec{\beta}_{i} \vec{X}_{i}}}{1+e^{\beta_{0}+\vec{\beta}_{i} \vec{X}_{i}}}
$$

Agora, ao se aplicar a transformação logit, $\mathrm{g}(\mathrm{x})$, em $\pi(x)$, obtém-se:

$$
g(x)=\ln \left[\frac{\pi(x)}{1-\pi(x)}\right]=\beta_{0}+\vec{\beta}_{i} \vec{X}_{i}
$$

O uso da transformação logit é interessante, pois ela se relaciona linearmente com seus parâmetros, pode ser contínua e varia de $-\infty$ a $\infty$ de acordo com os valores de $\mathrm{x}$.

Entretanto, é interessante ressaltar que o valor da variável resposta é, na verdade, a média condicional acrescida do erro existente entre essa média e o valor exato da amostra. Assim, $\mathrm{y}=E(Y \mid x)+\epsilon=\pi(x)+\epsilon$.

Em se tratando de variáveis resposta categóricas, o erro, $\epsilon$, pode assumir um entre dois valores. Se $\mathrm{y}=1$, então, $\epsilon=1-\pi(x)$ e isso tem probabilidade de ocorrência igual à $\pi(x)$. Já para o caso de $\mathrm{y}=0, \epsilon=-\pi(x)$, com probabilidade de ocorrência igual à $1-\pi(x)$. Portanto, $\epsilon$ tem uma distribuição binomial de média igual a 0 e variância igual à $\pi(x)[1-\pi(x)]$.

Em suma, se a variável resposta de um modelo de regressão é categórica, então:

1. A média condicional deve ser limitada ao intervalo $[0,1]$. O modelo de regressão logística satisfaz essa condição.

2. O erro não deve seguir uma distribuição normal, mas sim uma binomial.

A partir daí, é necessário que se determine os valores dos coeficientes $\beta_{0}, \ldots, \beta_{n}$. Porém, a determinação desses valores é dependente de métodos numéricos, o que faz com que os valores encontrados sejam, na verdade, estimativas. Então, o próximo passo para a construção do modelo é a estimação dos parâmetros.

\subsubsection{Estimação dos Parâmetros}

Na Regressão Linear, o método mais utilizado para a determinação do vetor de coeficientes é o Método dos Mínimos Quadrados (BM10). Porém, quando esse método é aplicado a um modelo cuja variável resposta é categórica, os estimadores não possuem as mesmas propriedades estatísticas da Regressão Linear. Logo, o método de estimação de coeficientes mais aplicado à Regressão Logística é o de Estimadores de Máxima Verossimilhança.

Ainda de acordo com (BM10), o princípio da máxima verossimilhança afirma que deve-se escolher os valores dos coeficientes de tal forma que eles maximizem a probabilidade de se obter a instância que está sendo observada naquele instante. Assim, no caso em estudo, onde:

- $Y_{i}$ são variáveis resposta independentes entre si e igualmente distribuídas.

- $\vec{X}_{i}$ é o vetor das covariáveis.

- A distribuição de $Y_{i} \mid \vec{X}_{i}$, ou seja, $\mathrm{P}\left(Y_{i}=y_{i} \mid \overrightarrow{x_{i}}\right)$, é uma distribuição Bernoulli com probabilidade de sucesso de $\pi(x)$

Tem-se que:

$$
P\left(Y_{i}=y_{i} \mid \overrightarrow{x_{i}}\right)=f\left(y_{i} \mid x_{i}\right)=\left(\pi\left(x_{i}\right)\right)^{y_{i}}\left(1-\pi\left(x_{i}\right)\right)^{1-y_{i}}, \text { com } y_{i}=0,1 \text { e i }=1,2, \ldots, \mathrm{n} .
$$

Enquanto isso, a função de verossimilhança, $L\left(\vec{\beta} ; \overrightarrow{x_{i}}\right)$, e seu logarítmo, $l\left(\vec{\beta} ; \overrightarrow{x_{i}}\right)$, são, respectivamente: 


$$
\begin{gathered}
L\left(\vec{\beta} ; \vec{x}_{i}\right)=\prod_{i=1}^{n} f\left(y_{i} \mid x_{i}\right)=\prod_{i=1}^{n}\left(\pi\left(x_{i}\right)\right)^{y_{i}}\left(1-\pi\left(x_{i}\right)\right)^{1-y_{i}} \\
l\left(\vec{\beta} ; \overrightarrow{x_{i}}\right)=\sum_{i=1}^{n}\left[y_{i} \ln \left(\frac{e^{\vec{\beta} \vec{x}}}{1+e^{\vec{\beta} \vec{x}}}\right)+\left(1-y_{i}\right) \ln \left(1-\frac{e^{\vec{\beta} \vec{x}}}{1+e^{\vec{\beta} \vec{x}}}\right)\right]
\end{gathered}
$$

Para se obter o valor de cada um dos coeficientes, basta maximizar a função de verossimilhança, ou seja, derivá-la com relação a cada um dos coeficientes, igualar os resultados a zero e resolver as equações. É nesse momento que a determinação dos coeficientes depende de métodos numéricos.

De acordo com (Mor08), as principais propriedades dos estimadores de máxima verossimilhança são:

- Não é nula a possibilidade desses valores estimados apresentarem alguma tendenciosidade que, todavia, pode ser eliminada com a multiplicação por uma constante apropriada.

- Essas estimativas possuem a propriedade das grandes amostras, ou seja, são assintóticas e sua aproximação pela distribuição Normal é boa. Disso, conclui-se que, se o tamanho da amostra for suficientemente grande, a estimativa será próxima do valor real do coeficiente.

- Dado que $\hat{H}$ é a estimativa de máxima verossimilhança de $\mathrm{H}$, então $\mathrm{h}(\hat{H})$ é a estimativa de máxima verossimilhança de uma função monótona contínua $\mathrm{h}(\mathrm{H})$.

\subsubsection{Seleção das Variáveis Explicativas}

Quando o modelo considera mais de uma variável explicativa na tentativa de prever a existência da condição de interesse, é desejável conhecer o quanto cada uma dessas variáveis contribui na formação do valor resposta para, inclusive, retirar uma ou mais dessas variáveis explicativas do modelo caso a contribuição dela seja baixa ou até mesmo nula, buscando respeitar o princípio da parcimônia.

De acordo com (HL00), na técnica de Regressão Logística, essa tarefa é mais usualmente realizada através do Teste da Razão de Verossimilhança. Esse teste consiste em uma série de etapas que calculam a importância das variáveis, suportando a inclusão ou exclusão delas do modelo mediante uma regra bem definida. Em termos práticos, a importância das variáveis é traduzida por uma medida de significância estatística dos coeficientes $\vec{\beta}$ que acompanham essas variáveis na função resposta. No caso da Regressão Linear, devido ao fato dos erros serem normalmente distribuídos, é utilizado um teste F. Entretanto, os erros da Regressão Logística seguem a distribuição binomial, logo, como dito anteriormente, é feito o uso do Teste da Razão de Verossimilhança. Portanto, em cada etapa do teste, a variável mais importante será a que produzir uma maior alteração no logaritmo da verossimilhança em relação ao modelo que não contém a variável.

Dessa forma, o Teste da Razão de Verossimilhança é baseado na estatística deviance, expressa por:

$$
D=-2 \log \left[\frac{\text { verossimilhança do modelo atual }}{\text { verossimilhança do modelo saturado }}\right]
$$

Para estimar a significância de uma covariável, calcula-se os valores da estatística $D$ para o modelo com e sem a variável desejada, obtendo-se, assim, a estatística $G$. 


$$
\mathrm{G}=\mathrm{D} \text { (modelo sem a covariável) - D(modelo com a covariável) }
$$

De outra forma,

$$
G=-2 \log \left[\frac{\text { verossimilhança sem a covariável }}{\text { verossimilhança com a covariável }}\right]
$$

Apesar da existência de outros testes para verificar a significância das variáveis explicativas como, por exemplo, o teste de Wald e o teste de Escore (HL00), o teste mais recomendado na literatura é o da Razão de Verossimilhança. Ainda, para os modelos multivariados, existem métodos para a seleção de variáveis que se apóiam no teste da Razão de Verossimilhança, alguns deles são: forward selection, backward selection e o stepwise selection, este último será discutido a seguir.

\subsubsection{O Método Stepwise}

Suponhamos que haja um total de $p$ variáveis independentes. O método começa com o ajuste do modelo que contém apenas o intercepto ( $\beta_{0}$ na regressão logística) e uma avaliação do logaritmo de sua verossimilhança $\left(L_{0}\right)$. A seguir, faz-se o ajuste para os $p$ modelos que conterão apenas o intercepto mais cada uma das $p$ variáveis e compara-se o logaritmo da verossimilhança de cada um desses modelos. Essa comparação é feita com o auxílio do valor-p da estatística $G$, sendo $G=L_{0}-L_{0}^{j}$, onde $j$ representa o número da iteração. Nessas condições, a variável mais importante será aquela para a qual a estatística $G$ tiver o menor valor-p. Contudo, mesmo o menor valor-p não necessariamente significa que a variável correspondente será estatisticamente significante, já que o menor valor-p pode ser maior que o nível de significância estabelecido para a modelagem. Dado isso, a boa escolha do valor para o nível de significância $\left(p_{e}\right)$ é crucial para um bom resultado do método stepwise, sendo que (HL00) recomenda um valor dentro do intervalo compreendido entre 0,15 e 0,20. Enfim, o método prosseguirá se houver pelo menos uma variável cujo valor-p de $G$ é menor que o nível de significância estabelecido. O valor do logaritmo da verossimilhança para essa variável será denominado $L_{e}$.

O passo seguinte inicia-se com o modelo contendo a variável de menor valor-p estatisticamente significante. A partir daí, são ajustados $p$ - 1 modelos contendo duas varíáveis: essa proveniente do passo anterior e cada uma das outras $p-1$ variáveis. Caso haja um modelo cujo valor-p de $G=L_{e}-L_{p-1}$ seja menor que o nível de significância estabelecido, mantém-se o modelo com duas variáveis (caso haja mais de um modelo, será mantido aquele cuja estatística G tenha o menor valor-p).

O próximo passo é iniciado com as duas variáveis, mas há a possibilidade que a inserção da segunda variável tenha feito a primeira variável perder seu efeito. Logo, é feito uma verificação com o método backward elimination. De forma geral, esse método é executado removendo-se variáveis incluídas em passos anteriores e ajustando-se o modelo para avaliar a importância da variável removida. A variável a ser removida é aquela que apresenta o maior valor-p, mas para avaliar se ela será realmente removida, define-se um segundo nível de significância $\left(p_{r}\right)$ - que deve, obviamente, ser mais alto que o primeiro - e, caso o valor-p da variável seja maior que esse segundo nível de significância, ela será efetivamente removida. Dessa forma, o processo de inclusão de variáveis é chamado de forward selection. Assim, o método stepwise segue incluindo variáveis via forward selection e averiguando sua real aderência via backward elimination. O critério de parada do método se dá quando: (i) todas as $p$ variáveis entraram no modelo ou (ii) quando todas as variáveis removidas do modelo têm valor-p menor que $p_{r}$ e todas as variáveis não incluídas no modelo têm valores-p que excederam $p_{e}$. 


\subsubsection{Multicolinearidade e Fator de Inflação de Variância}

Ao se aplicar modelos de regressão, em particular a regressão logística, um ponto de atenção é existência de relações de dependência entre as variáveis preditoras (explicativas). Essas correlações podem ocorrer entre duas ou mais variáveis preditoras e o nome que se dá a esse último caso é multicolinearidade (HL00). Conceitualmente, o fato de duas ou mais variáveis explicativas terem alta dependência entre si dificulta a obtenção de boas estimativas dos efeitos distintos que cada uma dessas variáveis tem sobre a variável resposta. Além disso, os coeficientes estimados se tornam mais instáveis. Como consequência, o erro padrão associado aos coeficientes aumenta e as variáveis explicativas que individualmente teriam um baixo efeito sobre a variável resposta passam, em grupo, a ter um efeito considerável (HL00). Dado esse cenário, a avaliação do grau de multicolinearidade entre as variáveis preditoras e a determinação do impacto desse fenômeno nos resultados do modelo é um passo importante da modelagem.

Um método formal e muito utilizado para detectar multicolinearidade é o Variance Inflation Factor - VIF ou Fator de Inflação de Variância. Esse fator, compreendido entre 0 e 1, mensura quanto das variâncias dos coeficientes estimados na regressão é distorcido quando comparados às variáveis preditoras que não são correlacionadas. Como discutido em (All99), quanto maior o valor da medida VIF, maior o grau de multicolinearidade. Uma outra medida, chamada Tolerância é recíproca à medida VIF. Logo, quanto menor o valor da tolerância, maior o grau de multicolinearidade. Como medida prática, (All99) menciona preocupação para valores de tolerância menores que 0,40.

\subsection{Análise Sensível ao Custo}

É possível que o classificador cometa erros ao classificar as instâncias submetidas a ele. Dependendo do domínio do problema, há mais um agravante: os erros podem ter custos diferentes. Por exemplo, na detecção de fraudes em transações de cartões, se o classificador diz que uma transação é fraudulenta, mas, na realidade, ela é legítima, houve um erro do tipo falso-positivo. Em suma, o custo do falso-positivo é o custo de oportunidade de barrar uma transação que aconteceria sem problemas e, caso a transação negada pelo sistema antifraude seja derivada para a análise manual de um recurso humano, há também o custo operacional de utilizar o recurso desnecessariamente. Agora, se o classificador afirma que a transação é legítima, mas, na realidade, ela é fraudulenta, houve um erro do tipo falso-negativo. Em suma, o custo do falso-negativo é o próprio chargeback. Há um consenso dos especialistas no domínio que o falso-negativo pode custar até cem vezes o falso-positivo (GWdL08a).

Portanto, é interessante que essa diferença nos custos dos erros de classificação seja considerada pelo classificador. A Análise Sensível ao Custo, apresentada em (Elk01), é uma técnica que tem por objetivo instruir o classificador a tomar decisões sobre a classificação das instâncias considerando diferenças nos custos dos erros de classificação. Ainda de acordo com (Elk01), a essência da Análise Sensível ao Custo é de que pode ser ótimo do ponto de vista do custo classificar uma instância como positiva em casos em que isso seja menos provável. Ainda, o texto propõe que a Análise Sensível ao Custo pode ser efetuada utilizando-se uma entre duas opções: (i) na iminência da classificação, com a consideração de uma matriz de custos e de probabilidades associadas a ela; e (ii) durante o treinamento do classificador, através da alteração da proporção das instâncias positivas e/ou negativas da amostras.

Ao se utilizar a primeira opção, deve-se construir uma matriz de confusão que descreva os custos de se fazer a atribuição das classes às amostras. Por convenção, cada uma das linhas da matriz contém cada classe passível de ser atribuída às instâncias pelo classificador, 
enquanto cada coluna contém cada classe à qual as amostras efetivamente pertencem. A Tabela 3.2 contém uma matriz de benefícios ilustrativa, nela, $x$ é o montante financeiro da transação.

\begin{tabular}{|l|l|l|}
\hline & Fraudulenta $(\$)$ & Legítima $(\$)$ \\
\hline \hline Negada (por suspeita) & 20 & -20 \\
\hline Aprovada & $-\mathrm{x}$ & $0,02 \mathrm{x}$ \\
\hline
\end{tabular}

Tabela 3.2: Um exemplo de matriz de benefícios.

O texto também faz algumas recomendações de como construir uma matriz coerente, como, por exemplo: os valores contidos em uma linha não devem ser sempre maiores ou menores que os da outra linha, pois, caso isso aconteça, o classificador sempre atribuirá apenas a classe menos custosa às amostras e a matriz deve ser encarada como uma matriz de benefícios e não de custos.

Já para o uso da opção do rebalanceamento das amostras do conjunto de treinamento, o texto fornece um teorema que ajuda a calcular o fator de multiplicação das instâncias negativas. Para compreender o cálculo desse fator, é necessário considerar que ao se utilizar métodos estatísticos em tarefas de classificação, a probabilidade retornada pelo método estatístico é confrontada com determinado limiar e, caso a probabilidade retornada pelo método seja maior que esse limiar, a amostra é classificada como positiva. Caso contrário, ela é classificada como negativa. No caso mais comum, esse limiar é igual a 0,5. Assim, caso a probabilidade retornada pelo método estatístico seja maior que 0,5, a amostra é tida como positiva. Caso essa probabilidade seja menor que 0,5 , a amostra é tida como negativa. Além disso, o teorema não sugere qual a metodologia deve ser utilizada para fazer esse rebalanceamento, mas cita como opções: sobreamostragem, subamostragem ou ponderação.

Teorema: Para fazer com que um limiar de probabilidade alvo, $p^{*}$, corresponda a um limiar de probabilidade dado, $p_{0}$, o número de instâncias negativas no conjunto de treinamento deve ser multiplicado por um fator tal que:

$$
\frac{p^{*}}{1-p^{*}} \cdot \frac{1-p_{0}}{p_{0}}
$$

onde:

- $p_{0}$ : é um limiar de referência comumente adotado quando a classificação não é baseada em análise sensível aos custos.

- $p^{*}$ : é o limiar ótimo para uma tomada de decisão baseada em custos de erros diferentes. Ele deve ser calculado segundo a fórmula:

$$
p^{*}=\frac{C_{F P}-C_{V N}}{C_{F P}-C_{V N}+C_{F N}-C_{V P}}
$$

- $C_{F P}$ : custo associado ao erro de classificação do tipo falso-positivo.

- $C_{V N}$ : custo associado ao acerto de classificação do tipo verdadeiro-negativo.

- $C_{F N}$ : custo associado ao erro de classificação do tipo falso-negativo.

- $C_{V P}$ : custo associado ao acerto de classificação do tipo verdadeiro-positivo. 


\subsection{Desafios Presentes em Aprendizagem de Máquina}

Os problemas que a área de Aprendizagem de Máquina estuda para propor soluções carregam dificuldades inerentes, seja do ponto de vista dos dados de entrada, seja para definir como se representa o conceito de interesse. Além disso, é interessante compreender algumas peculiaridades intrínsecas aos próprios métodos de classificação. Sendo assim, durante as próximas seções, o texto trata dessas dificuldades e peculiaridades visando um maior domínio teórico e, consequentemente, um alinhamento mais ajustado das expectativas para o experimento.

\subsubsection{Ruídos e Dados Ausentes}

É dito que o conjunto de dados possui ruídos em duas situações: (i) o valor para um ou mais atributos de uma ou mais instâncias foi erroneamente medido ou atribuído e (ii) duas ou mais instâncias possuem os mesmos valores para cada um de seus atributos, mas pertencem a classes diferentes. Quando os dados estão estruturados em forma de matriz ou tabela, a situação (ii) pode ser ilustrada por duas ou mais linhas que somente se diferem pelo valor das classes.

Enquanto isso, para uma ou mais instâncias, um dado é denominado ausente se o valor de um atributo não foi medido ou atribuído. Esse evento pode resultar em uma má seleção das características, sendo prejudicial para o resultado final do modelo.

Durante o tratamento dos dados e do desenvolvimento do modelo, é altamente recomendável identificar esses problemas com os dados e praticar estratégias para contorná-los.

\subsubsection{Maldição da Dimensionalidade}

O aumento do volume de dados não se refere apenas à quantidade de registros coletados ao longo do tempo, mas também ao número de atributos, ou características, coletados para cada um desses registros. O número de características que cada um dos registros possui é definido como a dimensionalidade do conjunto de dados. Logo, a maldição da dimensionalidade (TSK05) pode ser entendida como o aumento significativo da dificuldade em analisar os dados causado pelo aumento do espaço de busca que cresce exponencialmente com a dimensionalidade do conjunto de dados.

Assim, os dados ficam mais dispersos no espaço quando a dimensionalidade aumenta. Ademais, espaços de alta dimensionalidade possuem propriedades geométricas contra-intuitivas e diferentes daquelas observadas em espaços de duas ou três dimensões e as ferramentas de análise de dados, em sua maioria, são desenvolvidas considerando as propriedades intuitivas dos espaços de duas ou três dimensões, o que dificulta a análise de conjuntos de dados de alta dimensionalidade.

\subsubsection{Overfitting e Underfitting}

Os fenômenos conhecidos como overfitting e underfitting são dois efeitos indesejados enfrentados em problemas de Aprendizagem de Máquina e estão relacionados à complexidade do modelo construído. O overfitting acontece quando um classificador se ajusta perfeitamente aos dados de treinamento, mas falha ao classificar instâncias desconhecidas. Ou seja, levandose em consideração alguma medida de desempenho, verifica-se que o classificador apresenta taxas bastante altas de acerto para os dados de treinamento, mas taxas de acerto baixas para os dados de validação e teste. Por outro lado, quando o modelo é muito restritivo, ele não capta a essência do que se deseja representar e apresenta resultados ruins tanto para o 
conjunto de treinamento quanto para o conjunto de testes. Nesse caso, diz-se que ele sofreu underfitting.

Um exemplo didático do fenômeno de overfitting apresentado em (Fla12) é o do aluno que se prepara para uma prova decorando exatamente um conjunto de exercícios e respostas de um livro-texto sobre determinado assunto, mas que vai mal na prova, pois o professor cobra exercícios diferentes sobre o mesmo assunto.

Ao discutir o overfitting, (TSK05) argumenta que o erro de treinamento pode ser maior com o aumento da complexidade do modelo. Por exemplo, o antecedente das regras de associação poderia conter uma quantidade de itens suficiente para que o conjunto de regras seja perfeitamente apropriado aos dados de treinamento. Com essa medida, apesar do conjunto de regras se tornar extremamente complexo, o erro de treinamento seria zero, mas é provável que o erro de teste seja alto, pois existiriam regras que teriam captado ruídos presentes no conjunto de treinamento. Assim, tais regras degradariam o conjunto, diminuindo seu poder de generalização.

Duas causas comuns de overfitting são: (i) a presença de ruídos e (ii) a falta de uma quantidade suficiente de instâncias para treinamento do modelo.

\subsubsection{Variância e Viés}

Do ponto de vista matemático, os classificadores podem ser vistos como funções que têm o papel de estimar o mapeamento correto das variáveis de entrada, ou atributos, para o conjunto de classes. Aliado a isso, tem-se a natureza aleatória dos dados de entrada. Logo, o resultado da função de estimação pode ser caracterizado como uma variável aleatória governada por uma distribuição de probabilidade.

Nesse contexto, como mostra (FF97), a variância da função de estimação pode ser interpretada como a sensibilidade dessa função aos dados de treinamento, ou seja, quanto menor a variância, menos a função será instável à mudanças dos dados. Por sua vez, o viés reflete a sensibilidade não da função de estimação, mas sim da função-alvo, e pode ser interpretado como uma medida de quão bem a função de estimação se aproxima da função-alvo, pelo fato de que quanto menor o viés, mais a função de estimação se aproxima da função-alvo.

Do exposto acima, conclui-se que é desejável obter baixos valores tanto para a variância quanto para o viés. Entretanto, para se diminuir o viés, deve-se dispor de mais registros de treinamento, o que, por sua vez, aumenta a variância. Portanto, há um trade-off entre o viés e a variância.

\subsubsection{Classes Desbalanceadas}

Segundo (GdLM10), um conjunto de dados é perfeitamente balanceado quando cada uma das $n$ classes possui $100 / \mathrm{n} \%$ das instâncias do conjunto. Se a representatividade de uma ou mais classes difere significativamente das outras, esse conjunto de dados é denominado desbalanceado. Esse é o caso da deteç̧ão de fraudes em transações de cartões, pois diariamente há milhares de transações legítimas, mas apenas poucas fraudes.

Estudos apresentados em (CS98) mostram que a distribuição das classes no conjunto de treinamento podem afetar o desempenho do classificador. Disso, o texto sugere que não é recomendável manter a distribuição natural das amostras para o caso de classes desbalanceadas. 


\subsection{Avaliação de Desempenho}

Em praticamente toda tarefa de modelagem, somente criar o modelo e confrontá-lo com novos dados não é suficiente, pois é desejável avaliar a aderência do modelo ao fenômeno que ele pretende descrever. Para julgar se essa aderência se encontra dentro de padrões aceitáveis, é necessário calcular e avaliar métricas de desempenho. Há, na literatura, diversas métricas de avaliação de desempenho passíveis de serem consideradas na classificação de transações de cartões. Entretanto, em termos práticos, no momento em que a transação acontece e a classificação é feita, é difícil determinar se a classificação foi correta. Portanto, algumas métricas descritas são utilizadas na fase de treinamento e teste e outras na fase de produção do classificador.

\subsubsection{Razão de Chances}

Quando se executa a etapa de seleção de características, é interessante verificar qual o poder de discriminação cada característica tem, ou seja, o quanto os valores de determinada característica conseguem segmentar uma classe das outras (MNPL09). Assim, a razão de chances é definida como a razão entre a chance de um evento ocorrer em um grupo e a chance de ocorrer em outro grupo. Logo, se a probabilidade do evento ocorrer no primeiro grupo for $p_{1}$, e no segundo grupo for $p_{2}$, então, a razão de chances é calculada por:

$$
\mathrm{RC}=\frac{p_{1}\left(1-p_{2}\right)}{p_{2}\left(1-p_{1}\right)}
$$

\subsubsection{Precisão e Cobertura}

Conforme discutido na seção Análise Sensivel ao Custo, é possível extrair a seguinte tabela de uma tarefa de classificação:

\begin{tabular}{|l|l|l|}
\hline & Realmente Fraudulenta & Realmente Legítima \\
\hline \hline $\begin{array}{l}\text { Classificada como fraudu- } \\
\text { lenta }\end{array}$ & Verdadeiro Positivo (VP) & Falso Positivo (FP) \\
\hline Classificada como legítima & Falso Negativo (FN) & Verdadeiro Negativo (VN) \\
\hline
\end{tabular}

Tabela 3.3: Tabela descritiva dos erros e acertos da classificação.

Da tabela acima, é possível extrair algumas métricas de avaliação de desempenho:

Precisão: é a razão entre as transações corretamente classificadas como fraudulentas e todas as transações classificadas como fraudulentas, ou seja, VP / (VP + FP).

Cobertura ou Sensibilidade: é a razão entre as transações corretamente classificadas como fraudulentas e todas as transações fraudulentas, ou seja, VP / (VP + FN).

Especificidade (Taxa de Verdadeiro-Negativo): é a razão entre as transações corretamente classificadas como legítimas e todas as transações realmente legítimas, ou seja, $\mathrm{VN} /(\mathrm{VN}+\mathrm{FP})$.

Acurácia: é a razão entre a quantidade de casos corretamente classificados pelo modelo e todos os casos que passaram pelo classificador, ou seja, $(\mathrm{VP}+\mathrm{VN}) /(\mathrm{VP}+\mathrm{VN}+\mathrm{FP}+\mathrm{FN})$. 
Medida F: é a média harmônica entre a precisão $(\mathrm{P})$ e a cobertura $(\mathrm{C})$, ou seja, $(2 * \mathrm{P} * \mathrm{C}) /(\mathrm{P}+\mathrm{C})$

\subsubsection{Taxa de Negação}

Após o classificador ser treinado e testado, ele é implementado no ambiente de produção das empresas. A partir daí, as transações rotuladas como fraudulentas pelo classificador são negadas, e como as empresas, por razões históricas, não repassam para o comprador a informação de que determinada transação dele foi negada por suspeita de ser fraudulenta, em termos práticos, dificilmente se saberá se um falso-positivo ocorreu. Portanto, uma métrica de desempenho utilizada pelo mercado é a taxa de negação.

Taxa de negação: razão entre a quantidade de transações negadas por suspeita de fraude e o total de transações classificadas.

Idealmente, a taxa de negação deve ser baixa, pois, caso ela seja alta, há uma maior probabilidade do classificador ter um alto índice de falsos-positivos e, como consequência, os estabelecimentos deixam de realizar boas vendas e têm maiores custos operacionais. A taxa de aprovação, complemento da taxa de negação, também é frequentemente utilizada.

\subsection{4 Índice de Chargeback}

Outra métrica de alta utilização pelas empresas é o índice de chargeback. Esse indicador pode ser tratado como a versão prática e monetária do falso-negativo, pois quando uma transação fraudulenta é erroneamente rotulada pelos classificador como legítima e é aprovada, ela acarreta em uma fraude que será envolvida em uma disputa de chargeback. Idealmente, esse indicador deve ter um valor baixo.

Índice de chargeback: razão entre o volume financeiro envolvido em chargeback e o faturamento total do estabelecimento no período.

\subsection{5 Área sob a curva ROC}

O termo $R O C$, acrônimo de Receiver Operating Characteristic, tem suas raízes na área de Detecção de Sinais e é usado para designar a relação entre taxa de acerto e a taxa de falsos alarmes em um canal com ruídos. Sendo assim, a curva ROC é um gráfico no qual o eixo das ordenadas é dado pelo índice de verdadeiros positivos, enquanto o eixo das abcissas é dado pelo índice de falsos positivos. Logo, a área sob essa curva (AROC) é tida como uma medida de qualidade do classificador, pois quanto maior a área, melhor o desempenho do classificador. A Tabela 3.4, extraída de extraída de (HL00), fornece um mapa para, através do valor da AROC, definir o poder de classificação de um modelo.

\begin{tabular}{|l|l|}
\hline Valor AROC & Poder de Classificação \\
\hline \hline AROC $=0,5$ & Não há \\
$0,7 \leq \mathrm{AROC}<0,8$ & Aceitável \\
$0,8 \leq \mathrm{AROC}<0,9$ & Muito bom \\
$\mathrm{AROC} \geq 0,9$ & Excelente \\
\hline
\end{tabular}

Tabela 3.4: Poder de classificação de um modelo dado pela AROC. 
Um ponto levantado no uso da métrica AROC é sobre os classificadores que atingem valores muito altos para essa métrica, ou seja, têm, segundo ela, poder de classificação excelente. Quando um classificador atinge esse patamar de resultado, tem-se que aprofundar as análises - e buscar novas métricas e validações - para verificar se o classificador não foi acometido da Maldição da Dimensionalidade ou sofreu overfitting.

\subsection{A metodologia CRISP-DM (CRoss Industry Stan- dard Process for Data Mining)}

A metodologia CRISP-DM (CRoss Industry Standard Process for Data Mining), (Wir00), é a resultante de um esforço conjunto entre as empresas DaimlerChrysler, NCR e SPSS para produzir um processo padrão não proprietário, independente de indústria e livremente disponível para orientar o planejamento e a execução de projetos de mineração de dados. Dessa forma, a metodologia consiste em um conjunto de tarefas descritas em quatro níveis de abstração: fase, tarefa genérica, tarefa especializada e instância de processo. O documento que descreve a metodologia é composto de duas partes: um modelo de referência e um guia de usuário. Ambos são subdivididos em seis fases: compreensão do negócio, compreensão dos dados, preparação dos dados, modelagem, avaliação e implementação. O modelo de referência apresenta uma visão geral das fases de um projeto de mineração de dados, suas atividades e outputs. O guia de usuário, por sua vez, trata cada fase mais detalhadamente, inclusive, discutindo dicas e macetes práticos comuns a diferentes projetos.

A Figura 3.4 ilustra as diferentes fases propostas na metodologia e as interações entre elas. Essas fases estão no primeiro nível de abstração proposto pela metodologia.

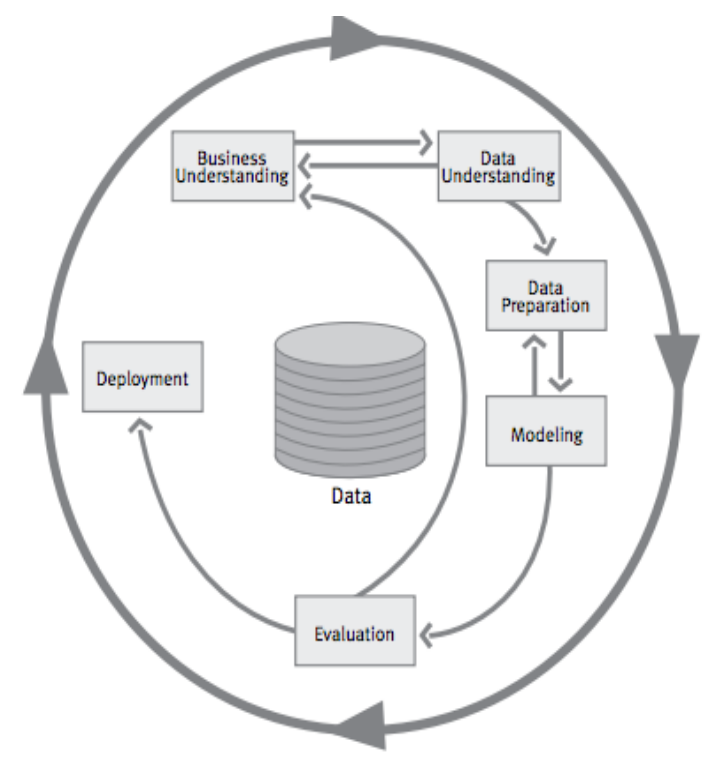

Figura 3.4: A interação e interdependência entre as fases do CRISP-DM. Fonte: (Wir00)

De forma resumida, cada uma das fases do CRISP-DM é caracterizada por:

- A fase de compreensão do negócio (business understanding) tem a finalidade de entender os objetivos e requisitos do negócio e, além disso, mapear esses requisitos em conceitos de mineração de dados. Dessa forma, o problema pode ser tratado com a utilização de ferramentas conceituais e práticas de mineração de dados. 
- Na fase de compreensão dos dados (data understanding) faz-se a coleta dos dados e algumas primeiras análises para aumentar a familiaridade do profissional com esses dados. É possível também que essas análises resultem na detecção de problemas com a qualidade do material.

- A preparação dos dados (data preparation) consiste em produzir, a partir dos dados iniciais - ou brutos -, o conjunto de dados que efetivamente servirá de base para a modelagem.

- A fase de modelagem (modeling) é aquela na qual a técnica de modelagem de dados definida pelo profissional é aplicada aos dados e seus parâmetros são calibrados para que se atinja patamares ótimos.

- Na etapa de avaliação de desempenho (evaluation), uma ou mais métricas de desempenho do modelo construído são coletadas e avaliadas. Assim, é possível concluir se as expectativas prévias sobre o modelo se confirmaram na prática. Além disso, é uma boa medida revisar as etapas executadas para garantir a correção e idoneidade do modelo.

- A implantação (deployment) é fase na qual o modelo é implementado nos sistemas de produção.

No segundo nível de abstração, o processo de mineração de dados é formado pelas tarefas genéricas, pois esse segundo nível precisa ser generalista o bastante para cobrir todas as situações de mineração de dados possíveis. A Figura 3.5 apresenta as tarefas genéricas de cada fase e suas saídas sugeridas.

Compreensão do
Negócio
Determinar os objetivos de
negócio
Listagem dos objetivos de
negócio
Critérios de sucesso de
negócio
Avaliar a situação
Inventório de recursos,
requisitos, premissos e
restriçöes
Riscos e contingências
Dicionórios de termos
Custos e beneficios
Determinar os objetivos
da mineraçäo de dados
Objetivos da mineroçōo
de dodos
Critérios de sucesso da
mineraçōo de dados
Produzir plano de projeto
Plono de projetos
Avolioçōo inicial de técnicos
e ferramentos

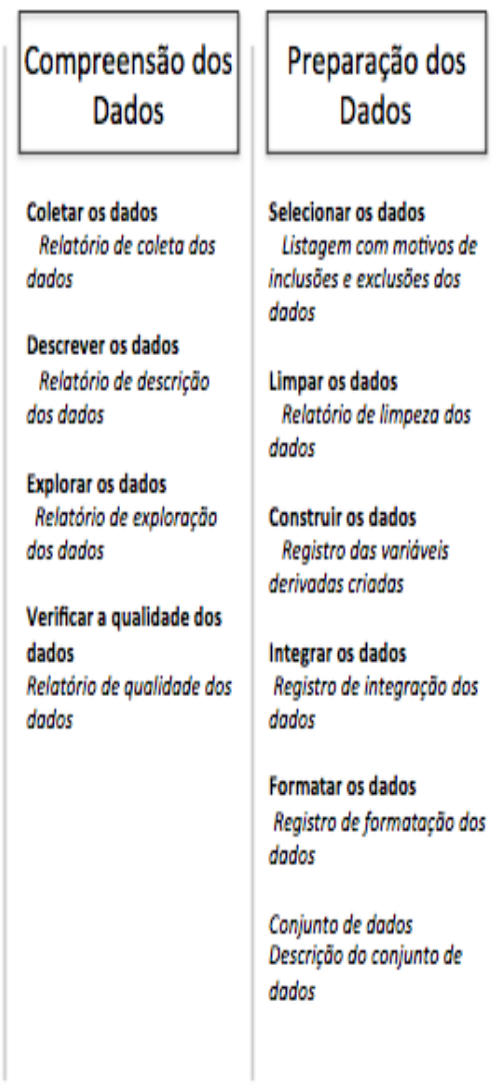

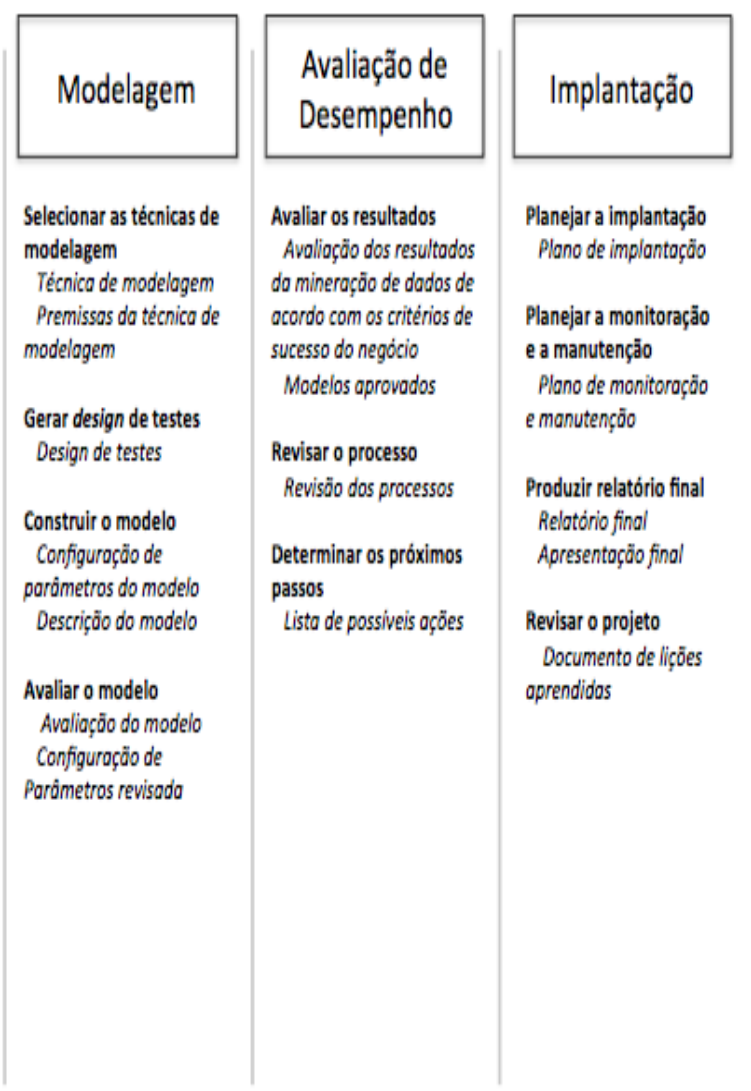

Figura 3.5: Fases, tarefas genéricas (negrito) e saídas sugeridas (itálico) do CRISP-DM. Fonte: (Wir00) 
Dessa forma, a metodologia segue descrevendo os detalhes de como conduzir um projeto de mineração de dados para que ele seja bem sucedido e, ao seu final, haja consistência entre os objetivos desejados e os realizados, além de dotar o projeto de uma documentação que facilite seu entendimento, manutenção e uso futuro. 


\section{Capítulo 4}

\section{Experimento e Metodologia}

Ao longo desse capítulo, a parte experimental do trabalho é discutida. Com o intuito de completar o experimento de forma bem sucedida, foi necessário compreender e definir as atividades constituintes do projeto. A metodologia CRISP-DM (CRoss Industry Standard Process for Data Mining) pretende descrever, conceitualmente, as fases que compõem um projeto de mineração de dados e foi utilizada como um guia no trabalho. Assim, as etapas do projeto serão detalhadas e discutidas à luz dessa metodologia.

\subsection{Introdução}

Previamente à explanação da parte experimental do projeto, fez-se a reunião e a exposição na Tabela 4.1 das atividades realizadas ao longo dessa fase do trabalho. Logo, nas seções seguintes será feito um detalhamento de cada uma dessas atividades.

1. Preparar banco de dados

1.1. Analisar banco de dados original e selecionar tabelas e campos;

1.2. Aplicar filtros e criar variáveis derivadas;

1.3. Obter base final para a modelagem;

2. Realizar análise descritiva dos dados e selecionar características de interesse

3. Obter amostra dos dados

3.1 Segmentar parte da amostra para treinamento dos classificadores;

3.2 Segmentar parte da amostra para validação dos classificadores;

4. Aplicar algoritmo FP-Growth para obter as regras de associação

4.1 Analisar a razão de chances das regras;

4.2 Analisar os grupos de confiança;

4.3 Analisar a distância semântica entre as regras;

4.4 Construir conjuntos de regras diferentes para realizar análise comparativa;

5. Realizar modelagem de regressão logística

5.1 Preparar os dados;

5.2 Ajustar os modelos;

5.3 Definir os limiares de classificação;

5.4 Validar os modelos;

5.5 Avaliar e comparar os indicadores de desempenho;

6. Extrair conclusões do trabalho

Tabela 4.1: Atividades desenvolvidas ao longo do trabalho. 


\subsection{Compreensão do Negócio}

A fase de compreensão do negócio foi realizada com a colaboração de profissionais experientes no mercado de cartões e especialistas na deteç̧ão de fraudes. Ela consistiu em entender o mercado de cartões, as fraudes desse mercado, a importância de combatê-las e as técnicas utilizadas nessa tarefa.

Mais especificamente, ao se acompanhar e estudar, na prática, as técnicas de detecção de fraudes no mercado de cartões, percebeu-se a intensa dependência que essa atividade têm dos especialistas de domínio e a oportunidade de se aplicar o método proposto nesse trabalho que, em suma, tem seus principais pontos em: (i) modelar a detecção de fraudes nas transações de cartões como um problema de classificação, (ii) enxergar a oportunidade de utilizar a técnica de regras de associação para minerar as regras e a regressão logística para fornecer a ponderação dessas regras e (iii) considerar a diferença de custos nos erros de classificação e aplicar a técnica de análise sensível ao custo para abordar essa característica. Em certa medida, os resultados da fase de compreensão do negócio foram discutidos no segundo capítulo dessa dissertação.

\subsection{Compreensão e Preparação dos Dados}

\subsubsection{Equipamentos}

Como o volume de dados utilizado no experimento é consideravelmente alto, a disponibilização de um equipamento composto de sistemas de hardware e software robustos é um ponto crucial para que o trabalho seja bem sucedido. Sendo assim, anteriormente à exposição das fases de compreensão e preparação dos dados, é válido descrever o equipamento no qual o trabalho foi realizado.

A empresa fornecedora dos dados disponibilizou um servidor, cujos acessos foram feitos remotamente, de configuração: processador Intel® E520 quad-core 2.4GHz, com $16 \mathrm{~GB}$ de $R A M$ que roda um sistema operacional Windows 7 de 64 bits. Enquanto isso, o sistema de software definido consiste em um Sistema Gerenciador de Banco de Dados (SGBD) MySqlFront versão 5.3, (MF15); na linguagem de programação Python, em sua versão 3.2 de 32 bits, (Pyt15), amplamente utilizada pela comunidade científica-acadêmica e reconhecida por sua adaptabilidade, extensão e eficiência. Sobre a instalação padrão do Python 3.2, foi feita a inclusão das bibliotecas: NumPy 1.8.1 rc, SciPy 0.13.3 e Pandas 0.13.1, especializadas em manipulação matricial de dados e computação científica; Matplotlib 1.2.0 para a visualização de gráficos; o uso da implementação Python do algoritmo FP-Growth discutida em (Har12), sendo que foi necessário migrar a implementação feita na versão 2.X do Python para a versão 3.2. Além disso, para executar o algoritmo de regressão e outras análises estatísticas, foi utilizado o SAS Enterprise Guide 5.1.

\subsubsection{Dados}

Para que fosse possível acessar os dados seguindo os padrões de segurança estabelecidos no PCI-DSS, foi assinado um acordo de não divulgação (NDA - Non Disclosure Agreement). Com a possibilidade de acesso aos dados, foi feito um extenso trabalho de análise do banco de dados original. Esse trabalho foi conduzido conjuntamente com Fidel Beraldi, também aluno do curso de Mestrado do Programa de Pós-Graduação em Ciência da Computação do IME-USP. Nas palavras do próprio Fidel, encontradas em (Ber14), o escopo da dissertação dele pode ser resumido da seguinte forma: 
"Como os fraudadores se adaptam rapidamente às medidas de prevenção, os modelos estatísticos para detecção de fraudes precisam ser adaptáveis e flexíveis para evoluir ao longo do tempo de maneira dinâmica. O método chamado Dynamic Model Averaging (DMA), ou Ponderação Dinâmica de Modelos implementa um processo de atualização contínuo ao longo do tempo. Nesta dissertação, desenvolvemos modelos DMA no espaço de transações eletrônicas oriundas do comércio eletrônico que incorporem as tendências e características de fraudes em cada periodo de análise. Também desenvolvemos modelos de regressão logística clássica com o objetivo de comparar as performances no processo de deteç̧ão de fraude."

Por sua vez, o trabalho de análise do banco de dados original consistiu nas seguintes fases:

1. Análise prévia do banco de dados original e seleção de tabelas e campos: a primeira atividade constituiu em analisar o banco de dados original, verificar quais campos e tabelas estavam dentro do escopo de interesse do trabalho e criar uma réplica dessas tabelas e campos para não precisar acessar a estrutura original frequentemente. Essa análise foi feita conjuntamente com os especialistas no domínio da empresa e resultou em 28 tabelas e 354 campos.

2. Aplicação de filtros e criação das variáveis derivadas: os filtros para selecionar o espaço de datas definido e as variáveis específicas foram aplicados. Além disso, foi feita a codificação para criação das variáveis derivadas, que estão detalhadas a seguir.

3. Base final para a modelagem: por fim, a base foi separada entre amostra de treinamento e amostra de validação e os registros foram aleatorizados.

Após esse trabalho prévio, o conjunto de dados passou a ter as seguintes características: os dados são provenientes de transações de cartões realizadas entre julho/2009 e janeiro/2014, foram selecionadas 43 variáveis originais e nele há 7.716.091 transações aprovadas (as transações negadas foram suprimidas) pelos emissores, contendo 22.615 fraudes. A listagem a seguir detalha as variáveis originais disponíveis.

1. Identificador da transação;

2. Data da transação;

3. Hora da transação;

4. IP Público do dispositivo no qual a transação foi realizada;

5. País do provedor para qual o IP está licenciado;

6. Estado do provedor para qual o IP está licenciado;

7. Cidade do provedor para qual o IP está licenciado;

8. Provedor para qual o IP está licenciado;

9. Valor da transação;

10. Status atual da transação na empresa detentora dos dados;

11. Meio de pagamento utilizado; 
12. Quantidade de parcelas em que a transação foi dividida;

13. BIN do cartão (6 primeiros dígitos - identificador do emissor);

14. Quatro últimos dígitos do cartão;

15. Data de validade do cartão;

16. Canal no qual a transação foi realizada;

17. Classe da transação (fraude/legítima);

18. Classe da transação (chargeback por desacordo/legítima);

19. Tipo do comprador;

20. Nome do comprador;

21. Email do comprador;

22. Identificador do comprador;

23. CEP do endereço de entrega do comprador;

24. Número do endereço de entrega do comprador;

25. Estado do endereço de entrega do comprador;

26. Telefone do comprador;

27. Nome de usuário do comprador;

28. Data de nascimento do comprador;

29. Data da filiação do comprador na empresa detentora dos dados;

30. Sinalização de verificação do CPF do comprador em bureaus especializados;

31. Detalhes do tipo do comprador;

32. Nome do titular do cartão;

33. Data de nascimento do titular do cartão;

34. CPF do titular do cartão;

35. Telefone do titular do cartão;

36. Identificador do estabelecimento;

37. Nome do proprietário do estabelecimento;

38. Tipo do estabelecimento;

39. CNPJ do estabelecimento;

40. Status atual do estabelecimento na empresa detentora dos dados;

41. Nome do estabelecimento;

42. Tipo do serviço utilizado pelo estabelecimento na empresa detentora dos dados;

43. Data da filiação do estabelecimento na empresa detentora dos dados. 


\section{Variáveis Independentes Derivadas}

Além dessas variáveis, durante o processo de preparação dos dados foram criadas 37 variáveis derivadas que se juntaram às outras 43 variáveis originais. Logo, o conjunto final de variáveis contém 80 variáveis. As variáveis independentes derivadas criadas são:

1. Dia da Semana da Transação: foi obtido o dia da semana correspondente à data da transação.

2. Período da Transação: através do horário da transação, registramos se a transação ocorreu pela manhã, tarde, noite ou madrugada.

3. Categoria Valor da Transação: os valores da transação foram categorizados conforme o nível de risco de transações fraudulentas.

4. Número de Parcelas da Transação: número de parcelas escolhido pelo comprador.

5. Categoria do BIN: o BIN do cartão foi classificado em grupos de acordo com o índice de fraude da quantidade das transações em pontos base - basis points - (\#Fraudes/\#Transações x 10.000).

6. Tempo de Validade do Cartão: diferença entre data de expiração do cartão e data da transação.

7. Ticket Médio do Estabelecimento: soma dos valores das transações dividida pela quantidade de transações.

8. Valor da Transação Maior que Ticket Médio: verifica se o valor da transação é maior que o valor do ticket médio das transações do estabelecimento.

9. Percentil 95 da Transação: verifica se o valor da transação é maior que o valor do percentil 95 das transações do estabelecimento.

10. Limite Superior da Transação: é o valor do ticket médio somado a três vezes o desvio padrão dividido pela raiz quadrada da quantidade de transações no período especificado do estabelecimento.

11. Diferença Valor Transação e Ticket Médio: diferença do valor da transação e o ticket médio do estabelecimento agrupados em categorias.

12. Diferença Valor Transação e Percentil 95: diferença do valor da transação e o percentil 95 do estabelecimento agrupados em categorias.

13. Diferença Valor Transação e Limite Superior: diferença do valor da transação e limite superior do estabelecimento agrupados em categorias.

14. Tempo de Filiação do Comprador: obtido pelo cálculo da diferença entre a data da transação e a data de filiação do comprador em dias.

15. Idade do Comprador: obtido pelo cálculo da diferença entre a data da transação e data de nascimento do comprador em anos.

16. Estado Comprador: os estados nos quais estavam localizados os compradores no momento da transação foram padronizados para evitar erros previsíveis de categorização, como, por exemplo, "SP"e "São Paulo"serem classificados em categorias distintas. Dessa maneira, temos 27 estados e uma categoria "NA"para dados faltantes. 
17. Estado do CPF do Comprador: estado de emissão do CPF do comprador obtido pela verificação do nono dígito do número de $\mathrm{CPF}$.

18. Estado do Telefone do Comprador: estado de registro do número de telefone informado pelo comprador e identificado pelos dois dígitos do número de telefone conforme tabela do DDD (discagem direta à distância) de cada cidade ou região.

19. Região do CEP: região a que pertence o CEP informado pelo comprador, obtido pela verificação do primeiro dígito do número que compõe o CEP.

20. Subregião do CEP: subregião a que pertence o CEP informado pelo comprador, obtido pela verificação do segundo dígito do número que compõe o CEP.

21. Setor do CEP: setor a que pertence o CEP informado pelo comprador, obtido pela verificação do terceiro dígito do número que compõe o CEP.

22. Tamanho do E-mail: número de caracteres do e-mail usado na compra.

23. Domínio do E-mail: domínio do e-mail utilizado pelo comprador.

24. Tamanho do E-mail Categorizado: tamanho do e-mail agrupado em categorias.

25. Idade do Titular do Cartão

26. Idade do Titular do Cartão Categorizado

27. Estado do CPF do Titular do Cartão

28. Estado do Telefone do Titular do Cartão

29. Tempo de Filiação do Estabelecimento por Período: obtido pelo cálculo da diferença entre a data da transação e a data de filiação do estabelecimento e categorizado em períodos mensais.

30. Tempo de Filiação do Estabelecimento em Dias: diferença entre a data da transação e a data de filiação do estabelecimento em dias agrupados em categorias.

31. Comparação CPF: comparação do CPF do comprador e do titular do cartão.

32. Comparação Datas de Nascimento: comparação entre as datas de nascimento do comprador e do titular do cartão.

33. Comparação Diferença Datas de Nascimento: diferença entre a data de nascimento do comprador e do titular do cartão em meses.

34. Comparação Telefone: comparação do telefone do comprador e do titular do cartão.

35. Comparação Telefone e CEP: verifica se o telefone e CEP informados pelo comprador estão na mesma região.

36. Comparação Telefone e CPF: verifica se o telefone e CPF informados pelo comprador estão na mesma região.

37. Comparação CEP e CPF: verifica se o CEP e CPF informado pelo comprador estão na mesma região. 


\subsubsection{Análise Descritiva e Amostragem}

A partir dessa coletânea de dados, seguiu-se com os processos de análise descritiva e amostragem para compreender os dados em maiores detalhes, definir quais valores específicos das variáveis seriam utilizados como entrada do algoritmo (FP-Growth) de mineração de regras - e, posterior e eventualmente, na regressão logística - e selecionar uma amostra que mantivesse a representatividade da população, mas tornasse a manipulação de dados factível.

\section{Análise Descritiva}

Nesse ponto, é bastante importante reiterar que o objetivo do trabalho é minerar regras de associação que mapeiem valores específicos (características) pertencentes ao domínio de cada variável à transações fraudulentas para que esses mapeamentos - ou regras mineradas - sejam incluídos como variáveis independentes do modelo de regressão logística. Em outras palavras, o objetivo não é que a variável Categoria do Valor da Transação, ilustrada na Tabela 4.2, com todos os valores de seu domínio sirva como variável independente no modelo de regressão logística, mas sim que, por exemplo, a característica "200.00-499.99" (sozinha ou acompanhada de outros valores específicos de outras variáveis) possa ser mapeada às transações fraudulentas e sirva como entrada do modelo de regressão logística. Aqui, definese característica como um valor específico pertencente ao domínio de uma variável. Sendo assim, para cada uma das variáveis discutidas, foi montada uma tabela como a Tabela 4.2.

\begin{tabular}{|c|c|c|c|c|c|c|}
\hline $\begin{array}{c}\text { Valor da } \\
\text { Característica }\end{array}$ & $\begin{array}{l}\text { Trxs Fraudulentas } \\
\text { (\#) }\end{array}$ & $\begin{array}{l}\text { Trxs Legítimas } \\
\text { (\#) }\end{array}$ & $\begin{array}{c}\text { Trxs Geral } \\
\text { (\#) }\end{array}$ & $\begin{array}{c}\text { Representatividade } \\
\text { Fraudulentas }\end{array}$ & $\begin{array}{c}\text { Representatividade } \\
\text { Legítimas }\end{array}$ & $\begin{array}{r}\text { Razão de } \\
\text { Chances }\end{array}$ \\
\hline 0 & 99 & 326.438 & 326.537 & $0,44 \%$ & $4,24 \%$ & 0,10 \\
\hline $10-49.99$ & 5.585 & 2.746 .747 & 2.752 .332 & $24,70 \%$ & $35,70 \%$ & 0,69 \\
\hline $50-99.99$ & 3.540 & 1.339 .320 & 1.342 .860 & $15,65 \%$ & $17,41 \%$ & 0,90 \\
\hline $100-199.99$ & 5.591 & 1.913 .739 & 1.919 .330 & $24,72 \%$ & $24,87 \%$ & 0,99 \\
\hline $200-499.99$ & 5.645 & 1.147 .613 & 1.153 .258 & $24,96 \%$ & $14,92 \%$ & 1,67 \\
\hline $500-999.99$ & 1.410 & 153.760 & 155.170 & $6,23 \%$ & $2,00 \%$ & 3,12 \\
\hline $1000+$ & 745 & 65.859 & 66.604 & $3,29 \%$ & $0,86 \%$ & 3,85 \\
\hline Total geral & 22.615 & 7.693 .476 & 7.716 .091 & $100,00 \%$ & $100,00 \%$ & 1,00 \\
\hline
\end{tabular}

Tabela 4.2: Um exemplo de tabela criada durante a análise descritiva dos dados para as categorias da variável "valor da transação".

Logo, com esse objetivo em mente, foi criada uma heurística para definir quais características de cada variável serviriam como entrada do algoritmo FP-Growth. A heurística consiste nos seguintes critérios:

1. Caso a razão de chances estimada entre as fraudes e as legítimas seja maior que 1, a característica será uma das escolhidas. Isso porque, essa medida faz com que características mais relacionadas com transações fraudulentas do que com transações legítimas sejam consideradas no algoritmo FP-Growth. O objetivo desse critério é levar para o FP-Growth características que tenham alta confiança.

2. Caso a razão de chances estimada entre as fraudes e as legítimas seja maior ou igual a 0,90 , mas a representatividade nas transações fraudulentas dessa característica seja relevante, a característica também será uma das escolhidas. Nesse critério, por representatividade relevante considera-se a característica que tenha representatividade percentual maior ou igual a $100 / \mathrm{n}$, onde $n$ é a quantidade de elementos do domínio da variável. Como exemplo, a variável Categoria do Valor da Transação tem 7 elementos em seu domínio ("0.00-9.99", "10.00-49.99", "50.00-99.99", "100.00-199.99", 
"200.00-499.99", "500.00-999.99" e "1000+"). Logo, a representatividade nas fraudes de uma característica será relevante se ela for maior ou igual a 14,29\% (100/7). O objetivo desse critério é levar para o FP-Growth características que tenham confiança razoável, mas alto suporte no conjunto de transações fraudulentas.

Como exemplo de aderência ao primeiro critério, podemos citar a característica "200.00499.99" da variável Categoria do Valor da Transação. A representatividade dessa característica nas transações fraudulentas é de $24,96 \%$, ou seja, o valor da transação para 5.645 das 22.615 fraudes estava nessa faixa. Por sua vez, a representatividade dessa característica nas transações legítimas é de 14,92\%, pois ela aparece em 1.147 .613 das 7.693 .476 transações legítimas. Assim, para essa característica, a razão entre a representatividade nas fraudes e a representatividade nas legítimas é de 24,96\%/14,92\%, ou seja, 1,67. Como esse valor é maior que 1, essa característica será uma das características consideradas no algoritmo FP-Growth. Outras características aderentes ao primeiro critério são: "500.00-999.99" e "1000+".

Já um exemplo de aderência ao segundo critério é a característica "50.00-99.99". Isso porque, a representatividade dessa característica nas transações fraudulentas é de cerca de $15,65 \%$, ou seja, o valor da transação para 3.540 das 22.615 fraudes estava nessa faixa. Por sua vez, a representatividade dessa característica nas transações legítimas é de cerca de 17,41\%, pois ela aparece em 1.339.320 das 7.693.476 transações legítimas. Com isso, para essa característica, a razão de chances estimada é de 15,65\%/17,41\%, ou seja, 0,90. Como a razão de chances estimada é menor ou igual a 1, essa característica não está aderente ao primeiro critério. Logo, é preciso verificar a aderência dela ao segundo critério. Dado que a representatividade nas transações fraudulentas dessa característica é de 15,65\% e, portanto, maior que 14,29\%, essa característica está aderente ao segundo critério. O mesmo raciocínio é válido para a característica "100.00-199.99".

Finalmente, como exemplos de características da variável valor da transação que não são aderentes a nenhum dos critérios da heurística e, por isso, não serão consideradas no algoritmo FP-Growth são: "0.00-9.99", "10.00-49.99".

Com a utilização dessa heurística, foi possível selecionar 141 características que servirão de base para a mineração de regras de associação, ou seja, as regras de associação mineradas pelo algoritmo FP-Growth serão compostas das associações entre uma ou mais dessas características. Nesse contexto, uma decisão de projeto importante foi eliminar as características cujos valores eram ausentes, pois elas degradam o desempenho do algoritmo. Sendo assim, as características selecionadas estão detalhadas no Apêndice A. Uma análise sobre esses critérios é feita na seção Validação dos Critérios Utilizados na Análise Descritiva.

\section{Amostragem}

Como era preciso determinar na própria população quais seriam as características selecionadas, a análise descritiva foi feita para toda a população dos dados. Em seguida à análise descritiva e à seleção das características, fez-se a amostragem, ou seja, a seleção de algumas transações que serviram de base para o FP-Growth. O processo de amostragem se faz necessário, pois é preciso reduzir o volume de dados para que o trabalho seja factível tanto em termos de recursos computacionais quanto temporais.

Segundo (GdLM10) e (CS98), quando se trabalha em modelos de transações fraudulentas é frequente nos depararmos com o fenômeno de classes desbalanceadas, ou skewed data. Esse fenômeno significa que há relativamente poucas transações fraudulentas para muitas transações legítimas. No caso da população estudada, há cerca de 340 transações legítimas para cada fraude (7.693.476 legítimas para 22.615 fraudes). Entretanto, esses textos também sugerem que os modelos terão melhores resultados ao se alterar, na amostragem, essa 
proporção. A partir dessas recomendações e com o objetivo de construir um classificador sensível ao custo, seguiu-se a fórmula de cálculo para a proporção apresentada em (Elk01).

As estimativas de custos utilizadas na análise sensível ao custo foram discutidas com especialistas no domínio e concluiu-se que: (i) o custo aproximado do falso-positivo $\left(C_{F P}\right)$ é de $6 \%$ do valor da transação $(\mathrm{x})$, (ii) o custo aproximado do falso-negativo $\left(C_{F N}\right)$ é de 1,2 vez o valor da transação $(\mathrm{x})$, (iii) os custos do verdadeiro-negativo $\left(C_{V N}\right)$ e do verdadeiropositivo $\left(C_{V P}\right)$ poderiam ser aproximados a zero. A partir daí, ao se considerar um limiar a priori de classificação para transações fraudulentas igual a 0,5 , tem-se como resultado que o número de amostras negativas deve ser multiplicado por 5\%. Logo, o número total de amostras negativas deve ser 384.674 (7.693.476 * 5\%). Isso dará uma proporção de cerca de 17 legítimas para cada fraude $(384.674 / 22.615)$. Esses custos são ilustrados na Tabela 4.3, mas é válido observar que ao montar a tabela de acordo com o sugerido por (Elk01), os custos são representados por benefícios de valor negativo.

\begin{tabular}{|l|l|l|}
\hline & Fraudulenta $(\$)$ & Legítima $(\$)$ \\
\hline \hline Negada (por suspeita) & 0 & $-0,06 \mathrm{x}$ \\
\hline Aprovada & $-1,2 \mathrm{x}$ & 0 \\
\hline
\end{tabular}

Tabela 4.3: A matriz de benefícios utilizada no trabalho.

Utilizando-se dos dados da Tabela 4.3, chega-se ao fator multiplicativo de $5 \%$ para as amostras negativas (transações legítimas), pois a quantidade delas, segundo o teorema apresentado em (Elk01), deve ser multiplicado por:

$$
\frac{C_{F P}}{C_{F N}}=\frac{-0,06 x}{-1,2 x}=5 \%
$$

Onde $x$ é o valor da transação.

Portanto, como a Figura 4.1 ilustra, a amostra final utilizada no trabalho é composta de 407.289 transações, sendo 384.674 legítimas e 22.615 fraudes. Essa amostra foi separada entre amostra de treinamento (80\%) e amostra de teste (20\%). Logo, as composições dos conjuntos de treinamento e teste eram de:

- Treinamento: 307.739 legítimas e 18.092 fraudes;

- Teste/Validação: 76.935 legítimas e 4.523 fraudes. 


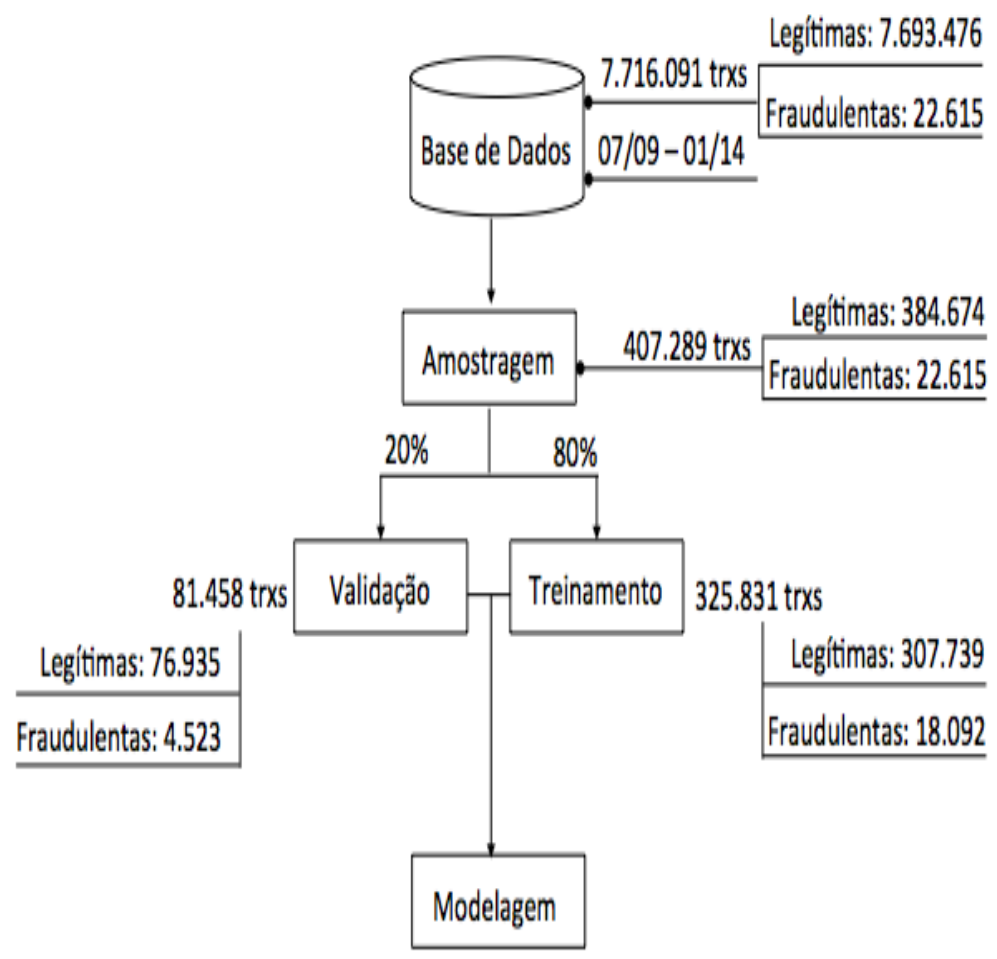

Figura 4.1: Processo de amostragem de dados

Após a definição da quantidade de transações que consistiria cada quebra, fez-se uma amostragem aleatória, usando o identificador da transação como base.

\subsection{Modelagem e Validação dos Modelos}

Agora tratamos da modelagem do classificador baseado em mineração de regras de associação e regressão logística. Ou seja, descrevemos como o algoritmo FP-Growth foi aplicado à amostra de dados e como o conjunto de regras resultante desse algoritmo foi submetido à regressão logística para, ao final do processo, termos a comparação de diversos conjuntos de regras nos quais cada regra foi ponderada. Ao final, os resultados da modelagem são discutidos juntamente com a validação do modelo.

\subsubsection{Aplicação do FP-Growth - Obtenção de Regras}

O passo seguinte à segmentação dos dados entre amostra de treinamento e amostra de validação foi a execução do algoritmo FP-Growth. Como objetivo inicial era encontrar regras de associação que levassem determinadas características das transações às fraudes, nesse estágio da modelagem não foram utilizadas instâncias negativas, ou seja, transações legítimas. Dessa forma, apenas transações fraudulentas foram utilizadas como entrada do algoritmo FP-Growth. Na versão implementada, além do conjunto de transações, o algoritmo pede o suporte mínimo, min_sup, como parâmetro de entrada. Como explicado na Fundamentação Teórica, na prática, o suporte mínimo é uma medida utilizada para que nenhuma regra dispare menos do que min_sup transações fraudulentas. O valor escolhido como min_sup foi 466 e a razão para isso é que esse é o valor do primeiro quartil da medida quantidade de transações fraudulentas das características resultantes da análise descritiva discutida na seção Análise Descritiva. A Figura 4.2 ilustra conceitualmente a aplicação, os parâmetros e os resultados do FP-Growth. 


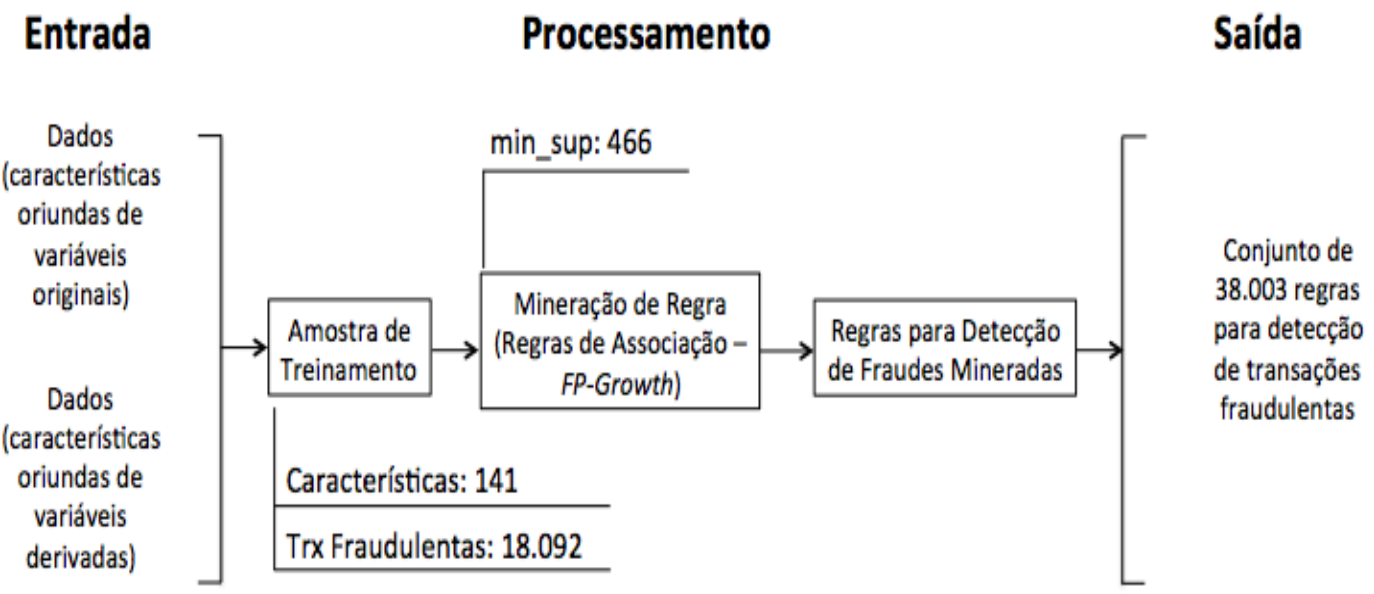

Figura 4.2: Diagrama conceitual para ilustrar a aplicação do algoritmo FP-Growth.

Com algumas pequenas modificações, a implementação do algoritmo FP-Growth teve por base o código apresentado em (Har12). Esse código base, presente no Apêndice B, é constituído de uma classe que implementa o nó da árvore $F P$-Tree e diversas funções para criar, atualizar a árvore e a header table, incluir nós e manipular a árvore em geral, além das funções para determinar os caminhos de prefixo e minerar a árvore em busca de padrões frequentes.

Como resultado da aplicação do algoritmo no conjunto de treinamento somente com transações fraudulentas foram geradas 38.003 regras. A partir daí, foi preciso disparar cada uma dessas regras no conjunto de treinamento contendo somente transações legítimas. Isso porque, a quantidade de transações legítimas disparadas por cada regra é um valor necessário para o cálculo da métrica confiança, já que, conforme discutido na seção Fundamentação Teórica, a regra $X \Longrightarrow Y$ terá confiança $c$ se c\% das transações de $D$ que contêm $X$ também contiverem $Y$. Ou seja, as transações de $D$ que contêm $X$ e também contêm $Y$ é um valor retirado do conjunto de treinamento contendo apenas transações fraudulentas. No entanto, para saber a quantidade de todas as transações de $D$ que contêm $X$, é preciso contar também as transações legítimas que são disparadas por $X$. A Tabela 4.4 traz alguns exemplos de regras mineradas pelo algoritmo FP-Growth, sendo que as características e suas respectivas variáveis são separadas pelo marcador $\_C_{-}$. Assim, a característica 500 999.99 pertence à variável $C A T_{-} V A L O R_{-} T R X$ ou a característica $M A D R U G A D A$ pertence à variável TRX_PERIODO.

\begin{tabular}{|c|c|c|c|c|}
\hline ID da Regra & Características da Regra & Itens (\#) & Suporte & Confiança \\
\hline regra04290 & 500-999.99_C_CAT_VALOR_TRX & 1 & 1.138 & $15,64 \%$ \\
\hline regra21214 & GOIAS_C_COMPR_ESTADO & 1 & 570 & $9,08 \%$ \\
\hline regra17239 & QUINTA_C_TRX_DIA_SEMANA, B1_C_GRUPO_BIN & 2 & 588 & $10,00 \%$ \\
\hline regra25454 & 200-499.99_C_CAT_VALOR_TRX, 2_C_REGIAO_CEP, INTERM_C_TAMANHO_EMAIL & 3 & 617 & $7,83 \%$ \\
\hline regra27952 & 0_C_REGIAO_CEP, BRASIL_C_TRX_IP_PAIS, 1_C_TRX_NUM_PARCELAS & 3 & 1.007 & $7,06 \%$ \\
\hline regra00981 & $\begin{array}{l}\text { BRASIL_C_TRX_IP_PAIS, MADRUGADA_C_TRX_PERIODO, INTERM_C_TAMANHO_EMAIL, } \\
\text { TRX VALLR MAIOR QUE LIM SUPERIOR_C_TRX_VALOR_LIM_SUPERIOR }\end{array}$ & 4 & 589 & $23,36 \%$ \\
\hline regra36871 & INTERM_C_TAMANHO_EMAIL, 2_C_REGIAO_CEP, BRASIL_C_TRX_IP_PAIS, IGUAL LOCAL & 5 & 486 & $4,90 \%$ \\
\hline
\end{tabular}

Tabela 4.4: Exemplos de regras mineradas pelo FP-Growth e suas respectivas métricas de suporte e confiança. 
A quantidade de regras mineradas, 38.003, foi grande o suficiente para inviabilizar uma análise regra à regra. Logo, foi preciso criar estratégias para diminuir o conjunto de regras. Três estratégias foram implementadas e serão discutidas a seguir.

Estratégia \#1 - Analisar a Razão de Chances das Regras: além dessas duas métricas (suporte e confiança), foi possível calcular também uma aproximação para a razão de chances de cada regra. Como também citado na Fundamentação Teórica, a razão de chances é definida como a razão entre a chance de um evento ocorrer em um grupo (transações fraudulentas) e a chance de ocorrer em outro grupo (transações legítimas). A relevância dessa métrica se dá pelo fato de que ela tem grande importância conceitual nos modelos de regressão logística e calcular uma aproximação para ela pode direcionar melhor a compreensão e a seleção de variáveis no modelo de regressão. Sendo assim, sabendo-se que o total de transações fraudulentas no conjunto de treinamento era de 18.092 e o total de transações legítimas nesse mesmo conjunto era de 307.739, para cada uma das regras fez-se o cálculo da razão de chance estimada $(R C)$ :

$$
\mathrm{RC}=\frac{\frac{S_{F}}{18.092}}{\frac{S_{L}}{307.739}},
$$

Onde:

- $S_{F}$ : é a quantidade de transações que a regra $X$ dispara no conjunto de treinamento de transações fraudulentas, ou seja, suporte nas fraudes.

- $S_{L}$ : é a quantidade de transações que a regra $X$ dispara no conjunto de treinamento de transações legítimas, ou seja, suporte nas legítimas.

Com isso, esperou-se obter, através de uma abordagem frequentista, uma estimação para a razão de chances de cada regra.

A partir do cálculo estimado da razão de chances, foi possível desconsiderar as regras que tinham valor compreendido entre zero e um para essa medida, já que, na prática, essas regras provavelmente levariam o classificador às transações legítimas. Esse passo fez com que a quantidade de regras fosse reduzida de 38.003 para 34.400 , uma redução de $9,48 \%$ do total de regras.

Estratégia \#2 - Analisar os Grupos de Confiança: Em seguida, ao se continuar com a análise das regras geradas, foi possível observar, como ilustrado na Tabela 4.5, que regras diferentes tinham suportes equivalentes tanto nas transações fraudulentas quanto nas transações legítimas, portanto, tinham a mesma confiança. Sendo assim, foi possível criar grupos de regras diferentes, mas com mesmo valor de confiança. Esses casos consistiam em regras cujas características não eram idênticas, mas eram semelhantes ou a diferença consistia na presença de uma característica menos relevante. Um exemplo contido na Tabela 4.5 é o das regras (regra00001 e regra00002). A regra regra00001 contém seis características e se difere da regra regra00002, pois essa contém cinco elementos, sendo que a regra regra00002 é um subconjunto da regra regra00001. Entretanto, apesar da regra regra00002 ter uma característica a menos, a confiança de ambas é $61,93 \%$. O mesmo raciocínio vale para as regras regra00004 e regra00005, pois a regra regra00005 é um subconjunto da regra regra00004 e tem uma característica a menos que ela, mas ambas têm confiança $61,71 \%$. Nesses casos, verifica-se que o conjunto de características de uma das regras está contido no da outra e, baseando-se no princípio da parcimônia, desconsiderou-se a regra que possuía a maior quantidade de elementos, no caso do exemplo, a regra regra00001. Por fim, essa 
heurística resultou na desconsideração de 10.256 regras, uma redução de $29,81 \%$. Ou seja, o conjunto passou a ter 24.144 regras.

\begin{tabular}{crrrr}
$\begin{array}{c}\text { Identificador } \\
\text { da Regra }\end{array}$ & $\begin{array}{c}\text { Quantidade de } \\
\text { Elementos da Regra }\end{array}$ & $\begin{array}{c}\text { Suporte } \\
\text { Fraudulentas (\#) }\end{array}$ & $\begin{array}{c}\text { Suporte } \\
\text { Legítimas (\#) }\end{array}$ & Confiança \\
\hline \hline regra00002 & 5 & 623 & 383 & $61,93 \%$ \\
\hline regra00001 & 6 & 623 & 383 & $61,93 \%$ \\
\hline regra00003 & 5 & 623 & 384 & $61,87 \%$ \\
\hline regra00005 & 6 & 593 & 368 & $61,71 \%$ \\
\hline regra00004 & 7 & 593 & 368 & $61,71 \%$ \\
\hline regra00006 & 6 & 593 & 369 & $61,64 \%$ \\
\hline regra00007 & 5 & 466 & 321 & $59,21 \%$ \\
\hline
\end{tabular}

Tabela 4.5: Tabela com exemplos dos grupos de confiança.

Com a finalidade de descrever quantitativamente o conjunto de 24.144 regras, a Tabela 4.6 traz algumas estatísticas de resumo (valores mínimo, máximo, médio, primeiro quartil, mediana e terceiro quartil) de algumas métricas de interesse (quantidade de elementos de cada regra, suporte nas transações fraudulentas e legítimas, confiança, medida F e razão de chances).

\begin{tabular}{lrrrrrr} 
Estatística & $\begin{array}{c}\text { Itens das } \\
\text { Regras (\#) }\end{array}$ & $\begin{array}{c}\text { Suporte } \\
\text { Fraudulentas (\#) }\end{array}$ & $\begin{array}{c}\text { Métrica } \\
\text { Suporte } \\
\text { Legítimas (\#) }\end{array}$ & $\begin{array}{r}\text { Confiança Medida F } \\
\text { Razão de } \\
\text { Chances }\end{array}$ \\
\hline \hline Mínimo & 1 & 466 & 321 & $5,55 \%$ & $3,54 \%$ & 1,0003 \\
\hline Máximo & 8 & 15.822 & 266.587 & $61,93 \%$ & $17,80 \%$ & 27,6685 \\
\hline Média & 4,32 & 866,30 & $8.785,82$ & $10,74 \%$ & $5,88 \%$ & 2,1225 \\
\hline 1o Quartil & 4 & 538 & 4.457 & $7,28 \%$ & $4,56 \%$ & 1,3358 \\
\hline Mediana & 4 & 659 & 6.582 & $9,70 \%$ & $5,27 \%$ & 1,8269 \\
\hline 3o Quartil & 5 & 920 & 9.908 & $12,39 \%$ & $6,58 \%$ & 2,4058 \\
\hline
\end{tabular}

Tabela 4.6: Estatísticas de resumo para métricas de interesse do conjunto de 24.144 regras.

Estratégia \#3 - Analisar a Distância Semântica entre as Regras: Por fim, como o conjunto de regras ainda possuía dezenas de milhares de regras, decidiu-se por filtrar as regras utilizando-se alguma métrica que fornecesse uma medida da distância semântica entre as regras. Para isso, foram utilizadas mais duas novas métricas: a medida $F$ e o coeficiente de Jaccard. Aqui, a medida $F$ foi definida como a média harmônica entre o suporte e a confiança, ou seja,

$$
\text { Medida } \mathrm{F}=\frac{2 * \text { suporte }^{*} \text { confiança }}{\text { suporte }+ \text { confiança }}
$$

Enquanto isso, o coeficiente de Jaccard foi usado propriamente como uma medida da distância semântica entre as regras, pois cada regra em si é um conjunto de elementos e essa estatística mede a similaridade entre conjuntos. Dados dois conjuntos A e B, sua definição é a razão entre a interseç̧ão e a união dos conjuntos. Sendo assim, o coeficiente de Jaccard é calculado por:

$$
\mathrm{J}(\mathrm{A}, \mathrm{B})=\frac{|A \cap B|}{|A \cup B|}
$$


Observe que $0 \leq J(A, B) \leq 1$, sendo que $\mathrm{J}(\mathrm{A}, \mathrm{B})=0$ se os conjuntos são disjuntos; e $\mathrm{J}(\mathrm{A}, \mathrm{B})=1$, se eles são idênticos.

Para exemplificar a aplicação do coeficiente de Jaccard, retomemos parte do exemplo tratado na seção 3.3.2 Algoritmo FP-Growth da Fundamentação Teórica. Suponha que A = $\{\mathrm{C}, \mathrm{E}\}$ e $\mathrm{B}=\{\mathrm{D}, \mathrm{E}\}$. Então,

$$
\mathrm{J}(\mathrm{A}, \mathrm{B})=\frac{|A \cap B|}{|A \cup B|}=\frac{|\{C, E\} \cap\{D, E\}|}{|\{C, E\} \cup\{D, E\}|}=\frac{|\{E\}|}{|\{C, D, E\}|}=\frac{1}{3}
$$

A partir disso, o uso do coeficiente de Jaccard se deu do seguinte modo: como os valores de suporte e confiança de cada regra já tinham sido extraídos, calculou-se, a partir deles, a medida F de cada regra. Em seguida, do conjunto das 24.144 regras foram obtidas três ordenações, todas de forma decrescente: (i) uma pelo critério de suporte, da regra de maior suporte para a de menor suporte; (ii) outra pelo critério de confiança, da regra de maior para a de menor confiança e (iii) pelo critério da maior para a menor medida F. Para cada um desses conjuntos ordenados, fez-se o seguinte procedimento:

- Tomar como entrada: (i) um conjunto vazio, $V$, (ii) uma ordenação de regras, $O$, e (iii) j, um limiar máximo para o coeficiente de Jaccard;

- Incluir, em $V$, a primeira regra da ordenação;

- Para cada regra seguinte, $r$, da ordenação, $O$, percorrer o conjunto $O$ e calcular o coeficiente de Jaccard entre $r$ e as regras já pertencentes ao conjunto $V$. Caso o coeficiente de Jaccard entre $r$ e cada regra pertencente ao conjunto $V$ seja MENOR OU IGUAL A $j$, a regra $r$ é incluída em $V$.

Dessa forma, a saída desse procedimento será o conjunto final $V$ que, por sua vez, só será composto de regras que tenham, entre si, similaridade máxima igual à $j$. Em outras palavras, o conjunto de regras final é composto de regras cuja distância semântica tenha um valor mínimo definido e específico. O procedimento acima foi conduzido com cinco combinações de parâmetros:

1. Suporte 050: Regras ordenadas pelo suporte decrescente e coeficiente de Jaccard, $j$, igual a $0, \overline{5}$. Resultado: conjunto final de 412 regras.

2. MedidaF_050: Regras ordenadas pela medida F decrescente e coeficiente de Jaccard, $j$, igual a $0, \overline{5}$. Resultado: conjunto final de 930 regras.

3. Confiança_050: Regras ordenadas pela confiança decrescente e coeficiente de Jaccard, $j$, igual a 0,5. Resultado: conjunto final de 1.285 regras.

4. Confiança_040: Regras ordenadas pela confiança decrescente e coeficiente de Jaccard, $j$, igual a 0,4. Resultado: conjunto final de 966 regras.

5. Confiança_030: Regras ordenadas pela confiança decrescente e coeficiente de Jaccard, $j$, igual a 0,3. Resultado: conjunto final de 174 regras.

Com a finalidade de descrever quantitativamente cada um dos cinco conjuntos acima citados, as Tabelas de 4.7 à 4.11 trazem algumas estatísticas de resumo (valores mínimo, máximo, médio, primeiro quartil, mediana e terceiro quartil) de algumas métricas de interesse (quantidade de elementos de cada regra, suporte nas transações fraudulentas e legítimas, confiança, medida $\mathrm{F}$ e razão de chances) para os conjuntos de entrada dos modelos de 
regressão logística.

\begin{tabular}{lrrrrrr} 
Estatística & $\begin{array}{c}\text { Itens das } \\
\text { Regras (\#) }\end{array}$ & $\begin{array}{c}\text { Muporte } \\
\text { Fraudulentas (\#) }\end{array}$ & $\begin{array}{c}\text { Suporte } \\
\text { Legítimas (\#) }\end{array}$ & Confiança Medida F & $\begin{array}{c}\text { Razão de } \\
\text { Chances }\end{array}$ \\
\hline \hline Mínimo & 1 & 466 & 1.457 & $5,57 \%$ & $3,59 \%$ & 1,0039 \\
\hline Máximo & 7 & 15.822 & 266.587 & $34,58 \%$ & $17,80 \%$ & 8,9892 \\
\hline Média & 3,20 & $1.526,22$ & $18.037,48$ & $9,29 \%$ & $7,03 \%$ & 1,7793 \\
\hline 1o Quartil & 3 & 621 & 6.514 & $6,48 \%$ & $4,85 \%$ & 1,1781 \\
\hline Mediana & 4 & 907 & 10.420 & $8,45 \%$ & $6,38 \%$ & 1,5691 \\
\hline 3o Quartil & 4 & 1.685 & 18.780 & $10,62 \%$ & $8,47 \%$ & 2,0201 \\
\hline
\end{tabular}

Tabela 4.7: Estatísticas de resumo para métricas de interesse do conjunto Suporte_050 na entrada da regressão logística. Esse conjunto tem 412 regras.

\begin{tabular}{lrrrrrr}
\multicolumn{1}{c}{ Estatística } & $\begin{array}{c}\text { Métrica } \\
\text { Itens das } \\
\text { Regras (\#) }\end{array}$ & $\begin{array}{c}\text { Suporte } \\
\text { Fraudulentas (\#) }\end{array}$ & $\begin{array}{c}\text { Suporte } \\
\text { Legítimas (\#) }\end{array}$ & $\begin{array}{r}\text { Confiança Medida F } \\
\text { Razão de } \\
\text { Chances }\end{array}$ \\
\hline \hline Mínimo & 1 & 466 & 552 & $5,56 \%$ & $3,59 \%$ & 1,0013 \\
\hline Máximo & 5 & 13.994 & 237.237 & $49,91 \%$ & $17,80 \%$ & 16,9480 \\
\hline Média & 2,88 & $1.472,51$ & $17.533,92$ & $9,11 \%$ & $7,09 \%$ & 1,7486 \\
\hline 1o Quartil & 2 & 654 & 6.870 & $6,34 \%$ & $5,06 \%$ & 1,1520 \\
\hline Mediana & 2 & 1.011 & 11.379 & $8,07 \%$ & $6,50 \%$ & 1,4940 \\
\hline 3o Quartil & 5 & 1.631 & 19.755 & $10,32 \%$ & $8,43 \%$ & 1,9573 \\
\hline
\end{tabular}

Tabela 4.8: Estatísticas de resumo para métricas de interesse do conjunto MedidaF_050 na entrada da regressão logística. Esse conjunto tem 930 regras.

\begin{tabular}{lrrrrrr} 
Estatística & $\begin{array}{c}\text { Métrica } \\
\text { Itens das } \\
\text { Regras (\#) }\end{array}$ & $\begin{array}{c}\text { Suporte } \\
\text { Sraudulentas (\#) }\end{array}$ & $\begin{array}{c}\text { Suporte } \\
\text { Legítimas (\#) }\end{array}$ & Confiança Medida F $\begin{array}{c}\text { Razão de } \\
\text { Chances }\end{array}$ \\
\hline \hline Mínimo & 1 & 466 & 321 & $5,56 \%$ & $3,59 \%$ & 1,0005 \\
\hline Máximo & 8 & 8.043 & 117.775 & $61,93 \%$ & $11,89 \%$ & 27,6685 \\
\hline Média & 3,04 & 774,88 & $8.538,51$ & $11,01 \%$ & $5,41 \%$ & 2,2471 \\
\hline 1o Quartil & 2 & 520 & 3.919 & $6,86 \%$ & $4,47 \%$ & 1,2531 \\
\hline Mediana & 2 & 612 & 6.361 & $9,12 \%$ & $5,07 \%$ & 1,7061 \\
\hline 3o Quartil & 5 & 833 & 10.205 & $12,56 \%$ & $6,06 \%$ & 2,4439 \\
\hline
\end{tabular}

Tabela 4.9: Estatísticas de resumo para métricas de interesse do conjunto Confiança_050 na entrada da regressão logística. Esse conjunto tem 1.285 regras. 


\begin{tabular}{lrrrrrr} 
Estatística & $\begin{array}{c}\text { Métrica } \\
\text { Itens das } \\
\text { Regras (\#) }\end{array}$ & $\begin{array}{c}\text { Suporte } \\
\text { Sraudulentas (\#) }\end{array}$ & $\begin{array}{c}\text { Suporte } \\
\text { Legítimas (\#) }\end{array}$ & Confiança Medida F F $\begin{array}{c}\text { Razão de } \\
\text { Chances }\end{array}$ \\
\hline \hline Mínimo & 1 & 466 & 383 & $5,56 \%$ & $3,59 \%$ & 1,0005 \\
\hline Máximo & 7 & 2.798 & 46.666 & $61,93 \%$ & $10,47 \%$ & 27,6685 \\
\hline Média & 2,54 & 754,62 & $8.455,97$ & $10,40 \%$ & $5,38 \%$ & 2,0918 \\
\hline 1o Quartil & 2 & 529 & 4.433 & $6,64 \%$ & $4,51 \%$ & 1,2102 \\
\hline Mediana & 2 & 643 & 7.242 & $8,64 \%$ & $5,10 \%$ & 1,6083 \\
\hline 3o Quartil & 3 & 850 & 10.735 & $11,51 \%$ & $6,06 \%$ & 2,2117 \\
\hline
\end{tabular}

Tabela 4.10: Estatísticas de resumo para métricas de interesse do conjunto Confiança_040 na entrada da regressão logística. Esse conjunto tem 966 regras.

\begin{tabular}{lrrrrrr} 
Estatística & $\begin{array}{c}\text { Itens das } \\
\text { Regras (\#) }\end{array}$ & $\begin{array}{c}\text { Suporte } \\
\text { Fraudulentas (\#) }\end{array}$ & $\begin{array}{c}\text { Suporte } \\
\text { Legítimas (\#) }\end{array}$ & Confiança & $\begin{array}{c}\text { Redida Fazo de } \\
\text { Chances }\end{array}$ \\
\hline \hline Mínimo & 1 & 466 & 383 & $5,57 \%$ & $3,61 \%$ & 1,0039 \\
\hline Máximo & 6 & 2.125 & 32.828 & $61,93 \%$ & $8,11 \%$ & 27,6685 \\
\hline Média & 2,97 & 648,65 & $6.101,55$ & $13,97 \%$ & $5,11 \%$ & 3,1004 \\
\hline 1o Quartil & 2 & 494 & 2.691 & $7,73 \%$ & $4,33 \%$ & 1,4246 \\
\hline Mediana & 3 & 551 & 4.989 & $9,93 \%$ & $4,87 \%$ & 1,8746 \\
\hline 3o Quartil & 4 & 660 & 7.284 & $16,64 \%$ & $5,70 \%$ & 3,3948 \\
\hline
\end{tabular}

Tabela 4.11: Estatisticas de resumo para métricas de interesse do conjunto Confiança_030 na entrada da regressão logística. Esse conjunto tem 174 regras.

Para todos os conjuntos, o primeiro quartil da métrica suporte nas transações fraudulentas é, no mínimo, 11\% maior que o suporte mínimo de 466. Disso, conclui-se que as estratégias para diminuir a quantidade de regras que serão analisadas nos próximos passos do trabalho cumpriram seu papel e mantiveram as premissas anteriores.

Ao longo da construção dos cinco conjuntos, surgiu o interesse em verificar se havia intersecção entre as regras participantes de cada um deles. Assim, ao final do trabalho será possível comparar o quanto cada um desses conjuntos possuía regras que persistiram por todas as restrições que foram impostas na modelagem de regressão logística e, de certa forma, determinar qual das métricas (confiança, suporte e medida F) - aliada ao coeficiente de Jaccard - impõe um conjunto de regras mais robusto. A tabela contida na Tabela 4.12 mostra todas as combinações de conjuntos possíveis e a quantidade de regras existente somente nesse conjunto. Para citar um exemplo, o conjunto Confiança_050 tem 1.285 regras, porém apenas 514 regras são exclusivas dele. As outras 771, além de pertencerem a ele, pertencem a outros conjuntos. Da tabela, também é possível extrair a informação de que, ao final do processo de mineração de regras de associação, chegou-se a um conjunto de 2.567 regras únicas. 


\begin{tabular}{|c|c|c|}
\hline Conjuntos de Regras & Regras (\#) & Representatividade \\
\hline "CONFIANÇA_050 & 514 & $20 \%$ \\
\hline SUPORTE_050 & 327 & $13 \%$ \\
\hline MEDIDAF_050 & 480 & $19 \%$ \\
\hline CONFIANÇA_030 & 100 & $4 \%$ \\
\hline CONFIANÇA_040 & 250 & $10 \%$ \\
\hline CONFIANÇA_050, SUPORTE_050 & 1 & $0 \%$ \\
\hline CONFIANÇA_050, MEDIDAF_050 & 103 & $4 \%$ \\
\hline CONFIANÇA_050, CONFIANÇA_030 & 7 & $0 \%$ \\
\hline CONFIANÇA_050, CONFIANÇA_040 & 400 & $16 \%$ \\
\hline SUPORTE_050, MEDIDAF_050 & 38 & $1 \%$ \\
\hline SUPORTE_050, CONFIANÇA_030 & 6 & $0 \%$ \\
\hline SUPORTE_050, CONFIANÇA_040 & 6 & $0 \%$ \\
\hline MEDIDAF_050, CONFIANÇA_030 & 2 & $0 \%$ \\
\hline MEDIDAF_050, CONFIANÇA_040 & 41 & $2 \%$ \\
\hline CONFIANÇA_030, CONFIANÇA_040 & 8 & $0 \%$ \\
\hline CONFIANÇA_050, SUPORTE_050, MEDIDAF_050 & 1 & $0 \%$ \\
\hline CONFIANÇA_050, SUPORTE_050, CONFIANÇA_030 & 0 & $0 \%$ \\
\hline CONFIANÇA_050, SUPORTE_050, CONFIANÇA_040 & 0 & $0 \%$ \\
\hline CONFIANÇA_050, MEDIDAF_050, CONFIANÇA_030 & 1 & $0 \%$ \\
\hline CONFIANÇA_050, MEDIDAF_050, CONFIANÇA_040 & 224 & $9 \%$ \\
\hline CONFIANÇA_050, CONFIANÇA_030, CONFIANÇA_040 & 18 & $1 \%$ \\
\hline SUPORTE_050, MEDIDAF_050, CONFIANÇA_030 & 20 & $1 \%$ \\
\hline SUPORTE_050, MEDIDAF_050, CONFIANÇA_040 & 2 & $0 \%$ \\
\hline MEDIDAF_050, CONFIANÇA_030, CONFIANÇA_040 & 2 & $0 \%$ \\
\hline CONFIANÇA_050, SUPORTE_050, MEDIDAF_050, CONFIANÇA_030 & 1 & $0 \%$ \\
\hline CONFIANÇA_050, SUPORTE_050, MEDIDAF_050, CONFIANÇA_040 & 6 & $0 \%$ \\
\hline CONFIANÇA_050, MEDIDAF_050, CONFIANÇA_030, CONFIANÇA_040 & 5 & $0 \%$ \\
\hline CONFIANÇA_050, SUPORTE_050, CONFIANÇA_030, CONFIANÇA_040 & 0 & $0 \%$ \\
\hline SUPORTE_050, MEDIDAF_050, CONFIANÇA_030,CONFIANÇA_040 & 0 & $0 \%$ \\
\hline SUPORTE_050, MEDIDAF_050, CONFIANÇA_050, CONFIANÇA_040, CONFIANÇA_030 & 4 & $0 \%$ \\
\hline Total & 2.567 & $100 \%$ \\
\hline
\end{tabular}

Tabela 4.12: Tabela com a quantidade de regras pertencentes a cada combinação de conjuntos para entrada da regressão logística.

Com isso, encerrou-se a mineração de regras de associação e cada um dos conjuntos de regras resultante do procedimento acima foi submetido à modelagem com utilização da técnica de regressão logística. Ou seja, ao final do processo de modelagem, descrito na próxima seção, obteve-se cinco conjuntos de regras baseados em mineração de regras de associação e regressão logística cujos resultados foram comparados.

\subsubsection{Modelos de Regressão Logística}

Como fase final do trabalho experimental, os cinco conjuntos selecionados de regras resultantes da aplicação do algoritmo FP-Growth de mineração de regras de associação foram individualmente submetidos ao modelo de regressão logística. Nesse experimento, para o qual foi utilizado o software SAS Enterprise Guide 5.1, a modelagem de regressão logística consistiu nas seguintes atividades:

1. Preparar os dados;

2. Ajustar os modelos;

3. Definir os limiares de classificação;

4. Validar os modelos;

5. Avaliar e comparar os indicadores de desempenho; 
A Figura 4.3 contém um diagrama conceitual da fase de modelagem de regressão logística executada no experimento.

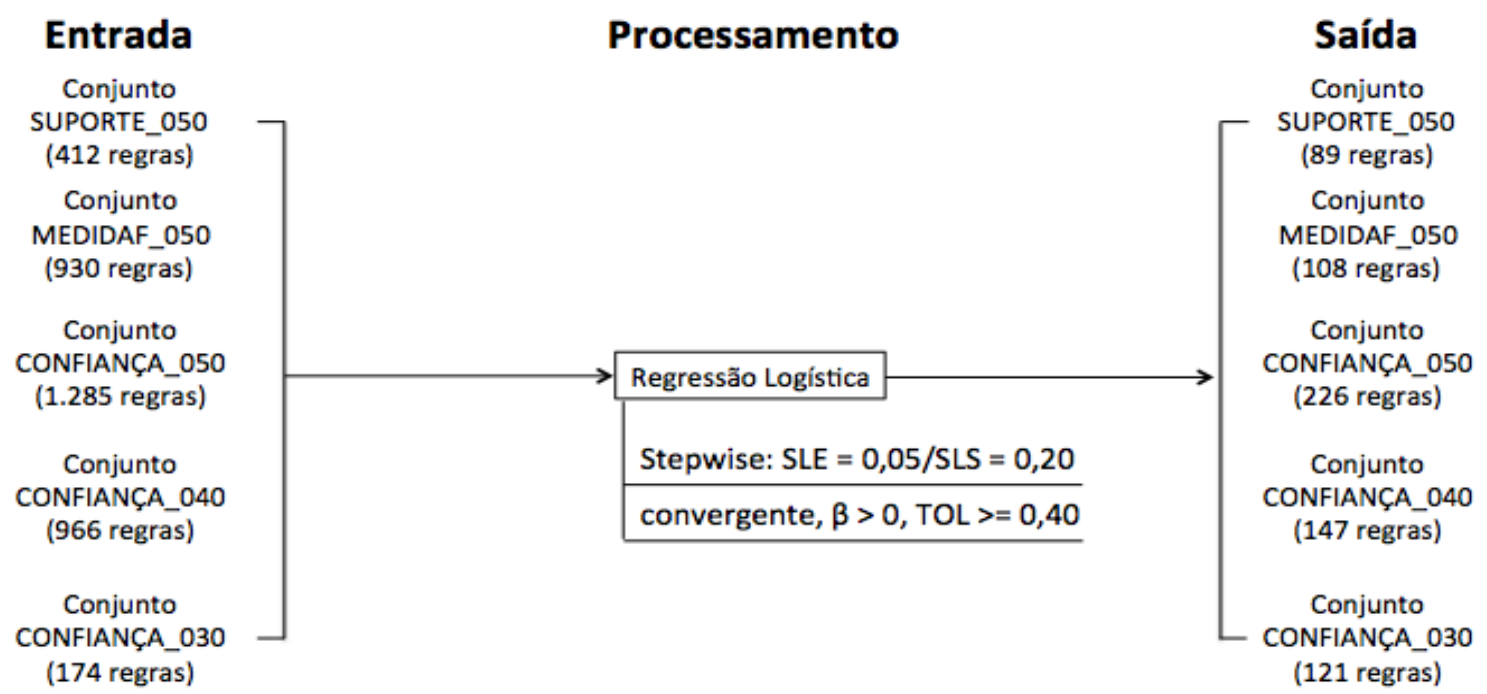

Figura 4.3: Diagrama conceitual para ilustrar a aplicação do modelo de regressão logística.

\section{Preparação dos Dados}

A preparação dos dados consistiu em construir cinco conjunto de dados, um para cada conjunto de regras. Cada um desses conjuntos de dados tinha como base a amostra de treinamento (325.831 transações, sendo 307.739 transações legítimas e 18.902 fraudulentas) e a construção deles se deu pela submissão de cada transação da amostra de treinamento ao disparo de cada uma das regras do conjunto de regras. Assim, se a regra disparou a transação, a variável de marcação recebeu o valor "1". Por outro lado, se a regra não disparou a transação, a variável de marcação recebeu o valor " 0 ". Logo, ao final do processo, tem-se os dados dispostos em uma estrutura matricial, com 325.831 linhas (uma para cada transação) e diversas colunas: uma contendo o identificador da transação, outra contendo sua classe (fraude/legítima) e as outras contendo um dentre dois valores $(0 / 1)$ que representa se a transação foi disparada por cada regra. Um aspecto válido de ser mencionado é que essa estrutura de dados forma uma matriz esparsa e, idealmente, o software utilizado na análise de dados deve ter mecanismos para trabalhar esse tipo de estrutura de dados para permitir um uso mais eficiente dos recursos. A Tabela 4.13 ilustra o resultado da fase de preparação dos dados.

\begin{tabular}{|c|c|c|c|c|c|c|c|c|}
\hline (4) id transacaso & (4) classe & (2i) regra00210 (2) & regra00492 (2) & regra00521 (2i) & regra00036 (2i) & regra00735 (28) & regra01196 (2) & regra01592 \\
\hline 66276 & FRAUDE & 0 & 0 & 0 & 1 & 0 & 1 & 0 \\
\hline 66333 & FRAUDE & 0 & 1 & 1 & 0 & 0 & 0 & 0 \\
\hline 66342 & NAO FRAUDE & 1 & 0 & 0 & 0 & 0 & 0 & 0 \\
\hline 66388 & NAO FRAUDE & 0 & 0 & 0 & 1 & 0 & 0 & 0 \\
\hline 66402 & NAO FRAUDE & 1 & 0 & 0 & 0 & 0 & 0 & 0 \\
\hline 66420 & FRAUDE & 0 & 1 & 0 & 0 & 1 & 1 & 0 \\
\hline 66427 & FRAUDE & 0 & 0 & 0 & 0 & 0 & 0 & 0 \\
\hline 66713 & NAO FRAUDE & 0 & 0 & 1 & 0 & 0 & 0 & 0 \\
\hline
\end{tabular}

Tabela 4.13: Um exemplo da base de dados resultado da preparação de dados para a regressão logistica.

A propósito, a atividade de preparação dos dados para cada um desses cinco conjuntos 
de regras também foi feita para a amostra de dados de validação. Ou seja, foram gerados cinco conjuntos de dados em formato matricial com base na amostra de validação.

\section{Ajuste dos Modelos}

Com os dados prontos, seguiu-se com o ajuste do modelo. Para ajustar as regras de cada conjunto de regras ao modelo de regressão logística, foram utilizados quatro critérios: (i) aderência aos critérios de convergência do software, (ii) aderência ao nível descritivo (valor-p), (iii) valor do coeficiente $\beta$ e (iv) comportamento diante do teste de multicolinearidade. Esses quatro critérios foram utilizados como forma de garantir que cada regra do modelo final: (i) possua relevância estatística dentro de valores definidos, (ii) se disparada, efetivamente, contribua para que a transação seja fraudulenta e (iii) não possua relação de dependência com outras variáveis que seja prejudicial ao modelo como um todo.

O método stepwise para seleção de variáveis explicativas foi usado para escolher as regras que permaneceriam no modelo. O nível descritivo, valor-p, máximo para entrada da variável no modelo foi de 0,05, enquanto que o valor-p máximo para a permanência da variável no modelo foi de 0,20. Assim, após a inclusão de uma nova variável no modelo, testa-se o modelo para verificar se as variáveis que já estavam no modelo devem permanecer nele. Além disso, foram retiradas do modelo as regras cujos valores estimados dos coeficientes $\beta$ fossem negativos ou que não respeitassem os critérios de convergência de modelo impostos pelo software. Isso porque a interpretação para um valor negativo para o $\beta$ é que a modelagem de regressão logística considerou que a regra tem razão de chance entre 0 e 1 , ou seja, é mais provável que a transação disparada por essa regra seja legítima (e não fraudulenta). Aparentemente, esse resultado contrasta com os passos anteriores do trabalho, mas esse risco já era esperado, pois a modelagem inferencial não necessariamente confirma exatamente tudo o que foi capturado no modelo descritivo.

Por fim, o teste de multicolinearidade, discutido na seção Fundamentação Teórica, foi aplicado e foram mantidas no modelo as variáveis cujos valores de tolerância eram maiores ou iguais a 0,40. Em suma, todos os modelos de regressão logística foram rodados novamente e somente possuíam variáveis que: (i) respeitassem os critérios de convergência de modelo, (ii) cujo valor-p pertencesse ao intervalo $[0 ; 0,20]$, (iii) o valor estimado do coeficiente $\beta$ fosse positivo e (iv) tinham o valor de tolerância, dado pelo teste da multicolinearidade, maior ou igual a 0,40. Desse modo, todas as regras de todos os modelos têm relevância estatística aceitável, têm maiores chances de dispararem em transações fraudulentas e não têm relação de dependência com outras regras num nível que prejudique o resultado final do modelo. As Tabelas de 4.14 à 4.18 trazem algumas estatísticas de resumo (valores mínimo, máximo, médio, primeiro quartil, mediana e terceiro quartil) de algumas métricas de interesse (quantidade de elementos de cada regra, suporte nas transações fraudulentas e legítimas, confiança, medida $\mathrm{F}$ e razão de chances) para as saídas dos modelos de regressão logística. 


\begin{tabular}{lrrrrrr} 
Estatística & $\begin{array}{c}\text { Itens das } \\
\text { Regras (\#) }\end{array}$ & $\begin{array}{c}\text { Métrica } \\
\text { Fraudulentas (\#) }\end{array}$ & $\begin{array}{c}\text { Suporte } \\
\text { Legítimas (\#) }\end{array}$ & Confiança Medida F & $\begin{array}{c}\text { Razão de } \\
\text { Chances }\end{array}$ \\
\hline \hline Mínimo & 1 & 486 & 1457 & $5,62 \%$ & $3,70 \%$ & 1,0125 \\
\hline Máximo & 6 & 9.424 & 135.816 & $34,58 \%$ & $17,80 \%$ & 8,9892 \\
\hline Média & 2,47 & 1563,69 & 17003,62 & $11,02 \%$ & $7,72 \%$ & 2,1911 \\
\hline 1o Quartil & 1 & 686 & 5.883 & $7,07 \%$ & $5,66 \%$ & 1,2947 \\
\hline Mediana & 3 & 1047 & 9.751 & $9,55 \%$ & $7,20 \%$ & 1,7959 \\
\hline 3o Quartil & 4 & 1999 & 21.216 & $12,74 \%$ & $8,97 \%$ & 2,4837 \\
\hline
\end{tabular}

Tabela 4.14: Estatísticas de resumo para métricas de interesse do conjunto Suporte_050 na saída da regressão logística. Esse conjunto tem 89 regras.

\begin{tabular}{lrrrrrr} 
Estatística & $\begin{array}{c}\text { Itens das } \\
\text { Regras (\#) }\end{array}$ & $\begin{array}{c}\text { Suporte } \\
\text { Fraudulentas (\#) }\end{array}$ & $\begin{array}{c}\text { Métrica } \\
\text { Luporte } \\
\text { Legítimas (\#) }\end{array}$ & Confiança Medida F $\begin{array}{c}\text { Razão de } \\
\text { Chances }\end{array}$ \\
\hline \hline Mínimo & 1 & 467 & 1493 & $5,82 \%$ & $3,80 \%$ & 1,0508 \\
\hline Máximo & 5 & 5.714 & 67.647 & $27,87 \%$ & $17,80 \%$ & 6,5737 \\
\hline Média & 2,36 & 1456,35 & 14468,33 & $11,35 \%$ & $7,73 \%$ & 2,2405 \\
\hline 1o Quartil & 2 & 638,25 & 5.207 & $7,78 \%$ & $5,56 \%$ & 1,4341 \\
\hline Mediana & 2 & 1041,5 & 8.730 & $9,79 \%$ & $7,22 \%$ & 1,8456 \\
\hline 3o Quartil & 3 & 1641 & 17.793 & $13,17 \%$ & $9,20 \%$ & 2,5811 \\
\hline
\end{tabular}

Tabela 4.15: Estatísticas de resumo para métricas de interesse do conjunto MedidaF_050 na saída da regressão logística. Esse conjunto tem 108 regras.

\begin{tabular}{lrrrrrr} 
Estatística & $\begin{array}{c}\text { Itens das } \\
\text { Regras (\#) }\end{array}$ & $\begin{array}{c}\text { Suporte } \\
\text { Fraudulentas (\#) }\end{array}$ & $\begin{array}{c}\text { Métrica } \\
\text { Luporte } \\
\text { Legítimas (\#) }\end{array}$ & Confiança Medida F & $\begin{array}{c}\text { Razão de } \\
\text { Chances }\end{array}$ \\
\hline \hline Mínimo & 1 & 466 & 681 & $5,57 \%$ & $3,66 \%$ & 1,0027 \\
\hline Máximo & 8 & 2.600 & 40.986 & $40,63 \%$ & $10,49 \%$ & 11,6395 \\
\hline Média & 2,95 & 703,88 & 6254,35 & $12,94 \%$ & $5,46 \%$ & 2,6450 \\
\hline 1o Quartil & 2 & 506 & 2.971 & $8,83 \%$ & $4,59 \%$ & 1,6471 \\
\hline Mediana & 2 & 591,5 & 4.853 & $10,85 \%$ & $5,15 \%$ & 2,0710 \\
\hline 3o Quartil & 4 & 748 & 7.256 & $16,14 \%$ & $6,06 \%$ & 3,2742 \\
\hline
\end{tabular}

Tabela 4.16: Estatísticas de resumo para métricas de interesse do conjunto Confiança_050 na saída da regressão logística. Esse conjunto tem 226 regras.

\begin{tabular}{lrrrrrr} 
Estatística & $\begin{array}{c}\text { Itens das } \\
\text { Regras (\#) }\end{array}$ & $\begin{array}{c}\text { Suporte } \\
\text { Fraudulentas (\#) }\end{array}$ & $\begin{array}{c}\text { Métrica } \\
\text { Luporte } \\
\text { Legítimas (\#) }\end{array}$ & Confiança Medida F & $\begin{array}{c}\text { Razão de } \\
\text { Chances }\end{array}$ \\
\hline \hline Mínimo & 1 & 466 & 383 & $5,64 \%$ & $3,78 \%$ & 1,0175 \\
\hline Máximo & 6 & 1.805 & 19.905 & $61,93 \%$ & $9,93 \%$ & 27,6685 \\
\hline Média & 2,78 & 661,62 & 5921,15 & $13,36 \%$ & $5,30 \%$ & 2,8863 \\
\hline 1o Quartil & 2 & 509,5 & 3.021 & $8,15 \%$ & $4,49 \%$ & 1,5084 \\
\hline Mediana & 2 & 574 & 4.991 & $10,63 \%$ & $5,09 \%$ & 2,0232 \\
\hline 3o Quartil & 4 & 729 & 7.565 & $15,82 \%$ & $5,81 \%$ & 3,1963 \\
\hline
\end{tabular}

Tabela 4.17: Estatísticas de resumo para métricas de interesse do conjunto Confiança_040 na saída da regressão logística. Esse conjunto tem 147 regras. 


\begin{tabular}{lrrrrrr} 
Estatística & $\begin{array}{c}\text { Itens das } \\
\text { Regras (\#) }\end{array}$ & $\begin{array}{c}\text { Fuporte } \\
\text { Fraudulentas (\#) }\end{array}$ & $\begin{array}{c}\text { Métrica } \\
\text { Luporte } \\
\text { Legítimas (\#) }\end{array}$ & Confiança Medida Fazão de \\
\hline \hline Mínimo & 1 & 466 & 383 & $5,73 \%$ & $3,61 \%$ & 1,0334 \\
\hline Máximo & 6 & 2.125 & 32.828 & $61,93 \%$ & $8,11 \%$ & 27,6685 \\
\hline Média & 2,99 & 659,06 & 5922,00 & $14,68 \%$ & $5,21 \%$ & 3,2786 \\
\hline 1o Quartil & 2 & 502 & 2.470 & $8,16 \%$ & $4,45 \%$ & 1,5108 \\
\hline Mediana & 3 & 556 & 4.437 & $11,54 \%$ & $4,93 \%$ & 2,2190 \\
\hline 3o Quartil & 4 & 673 & 6.965 & $17,58 \%$ & $5,84 \%$ & 3,6280 \\
\hline
\end{tabular}

Tabela 4.18: Estatísticas de resumo para métricas de interesse do conjunto Confiança_030 na saída da regressão logística. Esse conjunto tem 121 regras.

A seguir, as Tabelas 4.19 à 4.23 destacam as regras finais pertencentes a cada modelo, seus coeficientes estimados, o erro padrão de cada estimativa e seus valores-p.

\begin{tabular}{|c|c|c|c|c|c|c|c|c|c|c|c|}
\hline \# Variável & 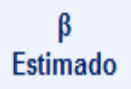 & $\begin{array}{l}\text { rro } \\
\text { drão }\end{array}$ & falor & \# Variável & $\begin{array}{c}\beta \\
\text { timado } F\end{array}$ & $\begin{array}{l}\text { Erro } \\
\text { Padrão }\end{array}$ & ralor & \# Variável & $\begin{array}{c}\beta \\
\text { Estimado }\end{array}$ & $\begin{array}{c}\text { Erro } \\
\text { Padrão }\end{array}$ & - -va \\
\hline 0 Inter & & & 001 & 30 re & & & 0001 & $60 \mathrm{re}$ & & & 1 \\
\hline 1 regra00210 & 2150 & 61 & 0001 & $31 r$ & 23 & & 0001 & 80 & & & (1) \\
\hline 2 regra & & & 001 & 32 & & & 001 & & & 510 & 0001 \\
\hline 3 regra & & 38 & 001 & & & 0,0277 & 001 & & & 20 & 000 \\
\hline 4 regra00636 & $3<0$ & 695 & 001 & 34 & 19 & 0,0301 & 0001 & &, , JJLE & 267 & , \\
\hline 5 regra01196 & 153 & 679 & 0001 & $35 r$ & 944 & 0,0421 & 0001 & 389 & 0,6458 & 0407 & $<, 0001$ \\
\hline $\begin{array}{l}6 \text { regra01592 } \\
\end{array}$ & 4796 & 0618 & 0001 & $36 \mathrm{re}$ & 0799 & 0,0286 & 0001 & 114 & 2435 & 0328 & $<, 0001$ \\
\hline 7 regra01595 & 7143 & 0595 & 0001 & 37 re & 5173 & 0,0299 & 0001 & 67 & 3912 &, 0552 & $<, 0001$ \\
\hline 8 regra & 794 & 559 & 0001 & $38 \mathrm{r}$ & 3026 & 0,0337 & 0001 & 031 & 3857 & 0317 & $<, 0001$ \\
\hline 9 regra & 3299 & 50 & 001 & & 84 & 0,0408 & 001 & & 43 & 477 & 0001 \\
\hline & & 2 & 01 & & & & 01 & & & 4 & $\overline{11}$ \\
\hline & & & 01 & & & & 05 & & & 6 & $\overline{1}$ \\
\hline regra03431 & & 7 & 380 & & & 0,0414 & 01 & & & 3 & $<, 0001$ \\
\hline regra04034 & 14 & 513 & 0001 & $43 r$ & 73 & 0,0404 & 001 & & 07 & 887 & $<, 0001$ \\
\hline regra04140 & 1594 & 362 & $<, 0001$ & & 050 & 0,0461 & $<, 0001$ & & 009 &, 0464 & $<, 0001$ \\
\hline 4290 & 1625 & 0411 & $<, 0001$ & $45 \mathrm{re}$ & 6309 & 0,0424 & $<, 0001$ & & 3587 &, 0279 & $<, 0001$ \\
\hline regral & 4250 & 0371 & $<, 0001$ & 46 re & 6592 & 0,0447 & $<, 0001$ & $76 r$ & 1477 &, 0407 & 0,0003 \\
\hline regra05256 & 1712 & 0431 & $<, 0001$ & 47 re & 5737 & 0,0492 & $<, 0001$ & 77 r & 764 &, 0220 & $<, 0001$ \\
\hline 3 regra06237 & 0,2306 & 39 & 0001 & $48 \mathrm{re}$ & 53 & 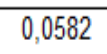 & $<, 0001$ & & 00 & 0,0267 & $<, 0001$ \\
\hline 07645 & 4576 & 44 & 0001 & 49 r & 00 & 1 & $<, 0001$ & & 35 & 0,0287 & $<, 0001$ \\
\hline 50 & 0 & 436 & $<, 0001$ & $50 r$ & 259 & 0,0271 & $<, 0001$ & 80 & 243 &, 0260 & $<, 0001$ \\
\hline 475 & 413 & 560 & $<, 0001$ & 51 & 572 & 0,0634 &, 0001 & & 2821 &, 0305 & $<, 0001$ \\
\hline 591 & 059 & 546 & $<, 0001$ & $52 r$ & 13 & 0,0340 & $<, 0001$ & 82 & 765 &, 0330 & $<, 0001$ \\
\hline 8593 & 789 & 372 & $<, 0001$ & $53 \mathrm{re}$ & 663 & 0,0301 & $<, 0001$ & & 613 &, 0223 & $<, 0001$ \\
\hline regra08637 & 705 & 270 & $<, 0001$ & & & 0,0530 & 0,0012 & & 3740 &, 0285 & $<, 0001$ \\
\hline regra10159 & $0,2<\sqrt{0}$ & 0,0496 & $<, 0001$ & $55 \mathrm{rec}$ & 0,2480 & 0,0369 & $<, 0001$ & $85 \mathrm{re}$ & 0,1328 & 0,0489 & 0,0066 \\
\hline 0858 & 0,1507 & 0,0575 & 0,0087 & 56 re & 0,5516 & 0,0435 & $<, 0001$ & 3574 & 0,4871 & 0,0315 & $<, 0001$ \\
\hline regra10883 & 0,1797 & 0,0501 & 0,0003 & 57 reg & 0,7525 & 0,0413 & $<, 0001$ & 33749 & 0,1212 & 0,0305 & $<, 0001$ \\
\hline 3 regra11758 & 2580 & 0,0659 & $<, 0001$ & $58 \mathrm{re}$ & 1312 & 0,0553 & 0,0177 & 33908 & 0,1868 & 0,0539 & 0,0005 \\
\hline 12735 & 150 & 563 & 000 & 63 & 353 & 0,0373 & 00 & 106 & 0,3052 & 0,0325 & $<, 00$ \\
\hline
\end{tabular}

Tabela 4.19: Regras selecionadas e estimativas do modelo utilizando a técnica stepwise para o conjunto Suporte_050. Esse conjunto tem 89 regras. 


\begin{tabular}{|c|c|c|c|c|c|c|c|c|c|c|c|c|}
\hline \# & $\begin{array}{c}\beta \\
\text { timado }\end{array}$ & rro & $\mathrm{F}$ & \# & $\begin{array}{c}\boldsymbol{\beta} \\
\text { Estimado }\end{array}$ & $\begin{array}{l}\text { irro } \\
\text { drão }\end{array}$ & or & \# & r & $\begin{array}{c}\beta \\
\text { Estimado }\end{array}$ & $\begin{array}{c}\text { Erro } \\
\text { Padrão }\end{array}$ & \\
\hline 0 Inter & & & 0001 & $37 \mathrm{re}$ & & & $<<, 0001$ & 73 & & & 36 & $\overline{000}$ \\
\hline 1 regr & 91 & 36 & 0001 & $38 \mathrm{re}$ & & & 0001 & 74 & & 752 & 540 & 0001 \\
\hline 2 regra0 & 602 & 1 & 0001 & 072 & 11 & 06 & 0001 & 75 & 4 & 46 & 53 & 0001 \\
\hline 3 regra0 & 665 & 05 & 0001 & $40 r$ & & 404 & $<, 0001$ & 6 & & 45 & 0412 & 0001 \\
\hline 4 regra01007 & 958 & 555 & 0001 & 41 & 227 & 511 & 0,0163 & . & & 435 & 0351 & 0001 \\
\hline 5 regral & 201 & 0691 & 0015 & 42 r & 670 & 0345 & $<, 0001$ & 78 & 761 & 030 & 0548 & 0001 \\
\hline 6 regra & 934 & 0643 & 0001 & 43 & 253 & 2341 & $<, 0001$ & 79 & & 543 & 0419 & $<, 0001$ \\
\hline 7 regra0 & 1725 & 0534 & 0001 & 5010 & 384 & 0388 & 0,0004 & 80 & 508 & 1597 & 0293 & $<, 0001$ \\
\hline 8 regra0 & 3475 & 0513 & 0001 & $45 r$ & & 352 & $<, 0001$ & 1 & & & 309 & $<, 0001$ \\
\hline 9 regra & 4497 & 0614 & 0001 & 46 & 791 & 0,0307 & 0,0101 & 2 & & 1810 & 0391 & 0001 \\
\hline regra & 531 & 0635 & 0001 & 47 & 008 & 0418 & $<, 0001$ & 83 & & 2622 & 0397 & 0001 \\
\hline res & 859 & 44 & 0001 & 48 & & 485 & 0001 & 84 & & 365 & 466 & 0001 \\
\hline regr & 9773 & 0899 & 0001 & $49 \mathrm{res}$ & 2269 & 0,0413 & $<, 0001$ & 85 & 7011 & 4850 & 0,0574 & $<, 0001$ \\
\hline reg & 2495 & 0549 & 0001 & $50 \mathrm{r}$ & & 0290 & 0,0002 & 86 & & 757 & 0571 & 0021 \\
\hline 27 & 287 & 653 & 001 & 61 & 34 & 0,0383 & $<, 0001$ & 87 & 499 & 0,2344 & 0,0652 & 0,0003 \\
\hline reg & 289 & 0403 & 0001 & $52 \mathrm{r}$ & 272 & 0426 & $<, 0001$ & 88 & & 0987 & 0,0396 & 0,0126 \\
\hline 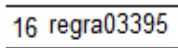 & 797 & 33 & 01 & & & & 001 & 9 & & 663 & 25 & 0001 \\
\hline reg & 1867 & 0,0720 & 0095 & 54 re & 1802 & 0,0386 & $<, 0001$ & 90 & 679 & 2242 & 0,0532 & $<, 0001$ \\
\hline res & 369 & 0524 & 0001 & $55 \mathrm{r}$ & 457 & 0470 & $<, 0001$ & 91 & & 129 & 0265 & 0001 \\
\hline & 200 & 0,0362 &, 0001 & $56 \mathrm{re}$ & 1781 & 0,0468 & 0,0001 & 92 & & 0,1782 & 0,0356 & $<, 0001$ \\
\hline 290 & 0444 & 0416 & 0001 & $57 \mathrm{re}$ & 3126 & 0,0501 & $<, 0001$ & 93 & 441 & 2789 & 0,0331 & $<, 0001$ \\
\hline & & & 001 & 58 & & & 0045 & 4 & & 48 & & 01 \\
\hline 373 & 3230 & 0,0487 & 0001 & $59 \mathrm{r}$ & 037 & 0,0437 & 0,0175 & 95 & & 1037 & 0,0377 & 0,0059 \\
\hline 993 & 4273 & 1,0576 & 0001 & $60 \mathrm{r}$ & 155 & 0,0424 & $<, 0001$ & 96 & 72 & 3422 & 0,0301 &, 0001 \\
\hline reg & 620 & 0,0738 & $<, 0001$ & $61 \mathrm{re}$ & 345 & 0,0431 & $<, 0001$ & \begin{tabular}{|l|}
97 \\
\end{tabular} & & 0,2009 & 0,0399 & $<, 0001$ \\
\hline 783 & 2750 & 0,0594 & 0001 & $62 \mathrm{re}$ & 6692 & 0,0453 & $<, 0001$ & 98 & 3997 & 1873 & 0,0392 & $<, 0001$ \\
\hline 0 & & 520 & 0001 & $63 \mathrm{re}$ & 64 & 0,0299 & $<, 0001$ & 99 & & 1802 & 0,0365 & $<, 0001$ \\
\hline 91 & 691 & 0,0543 & 0001 & $64 \mathrm{re}$ & 30 & 0,0585 & $<, 0001$ & $100 \mathrm{r}$ & & 2196 & 0,0323 & $<, 0001$ \\
\hline & 571 & 0484 & 0001 & $65 \mathrm{r}$ & 261 & 0,0605 & $<, 0001$ & $1 \mathrm{r}$ & 61 & 1270 & 0,0432 & 0,0033 \\
\hline reg & 3597 & 0,0557 & 0001 & $66 \mathrm{re}$ & 197 & 0,0531 & $<, 0001$ & 102 & & 0,1797 & 0,0422 & $<, 0001$ \\
\hline reg & 973 & 0,0291 & $<, 0001$ & $67 \mathrm{re}$ & 1798 & 0,0336 & $<, 0001$ & 103 & 255 & 0,2483 & 0,0349 & $<, 0001$ \\
\hline reg & 2575 & 0,0423 & $<, 0001$ & $68 \mathrm{reg}$ & 0,6849 & 0,0536 & $<, 0001$ & 104 & 074 & 0,0733 & 0,0303 & 0,0154 \\
\hline res & 3517 & 0,0532 & $<, 0001$ & 69 regra21708 & 0,7244 & 0,0511 & $<, 0001$ & $105 \mathrm{r}$ & 561 &, 2786 & 0,0415 & $<, 0001$ \\
\hline 33 ге & 379 & 0,0524 & 0,0086 & 70 regra & 143 & 0,0298 & $<, 0001$ & $106 \mathrm{r}$ & 25 & 0,2724 & 0,0280 & $<, 0001$ \\
\hline 560 & 0,4690 & 0,0520 & $<, 0001$ & 71 regr & 0,1742 & 0,0621 & 0,0050 & $107 r$ & 2977 & 0,3205 & 0,0280 & $<, 0001$ \\
\hline 5 regr & 4948 & 0,0509 & $<, 0001$ & 72 regra22326 & 355 & 0,0367 & 0001 & 81 & & 0,1691 & 0,0255 & $<, 0001$ \\
\hline & 271 & 444 & 0001 & & & & & & & & & \\
\hline
\end{tabular}

Tabela 4.20: Regras selecionadas e estimativas do modelo utilizando a técnica stepwise para o conjunto MedidaF_050. Esse conjunto tem 108 regras. 


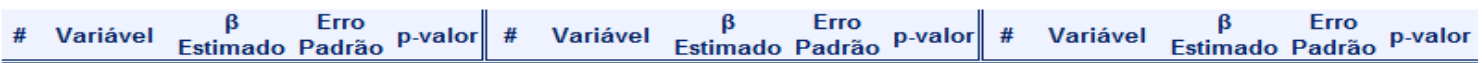

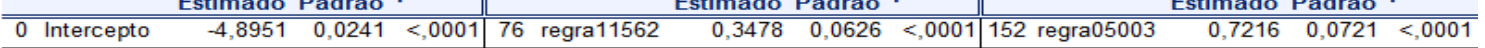
\begin{tabular}{lllllllllllllll}
\hline 1 regra28511 & 0,3243 & 0,0525 & $<, 0001$ & 77 & regra00391 & 0,6168 & 0,0782 & $<, 0001$ & 153 regra13502 & 0,3995 & 0,0570 & $<, 0001$ \\
\hline
\end{tabular} \begin{tabular}{lllllllllllllll}
\hline 2 & regra21119 & 0,6524 & 0,0478 & $<, 0001$ & 78 & regra01491 & 0,8601 & 0,0718 & $<, 0001$ & 154 regra01007 & 0,9634 & 0,0544 & $<, 0001$ \\
\hline 3 & regra & &
\end{tabular} \begin{tabular}{lllllllll|lllll}
\hline 3 regra26133 & 0,1268 & 0,0445 & 0,0044 & 79 & regra24465 & 0,1573 & 0,0523 & 0,0026 & 155 regra19776 & 0,1597 & 0,0581 & 0,0060 \\
\hline
\end{tabular} \begin{tabular}{lllll|lllllllll}
4 & regra28541 & 0,1887 & 0,0547 & 0,0006 & 80 & regra19652 & 0,2343 & 0,0507 & $<, 0001$ & 156 regra27786 & 0,1106 & 0,0452 & 0,0144 \\
\hline
\end{tabular} \begin{tabular}{llllllllllllll}
\hline 5 & regra27622 & 0,1618 & 0,0424 & 0,0001 & 81 & regra02555 & 0,1608 & 0,0686 & 0,0190 & 157 regra14607 & 0,2302 & 0,0510 & $<, 0001$ \\
\hline 6
\end{tabular} \begin{tabular}{lllllllll|llllll}
\hline 6 & regra02385 & 1,5201 & 0,0558 & $<, 0001$ & 82 & regra02454 & 0,2504 & 0,0699 & 0,0003 & 158 regra15747 & 0,1082 & 0,0466 & 0,0203 \\
\hline 7
\end{tabular} \begin{tabular}{lllllllllllllll}
\hline 7 & regra20502 & 0,2624 & 0,0544 & $<, 0001$ & 83 & regra13993 & 0,1783 & 0,0532 & 0,0008 & 159 regra03600 & 0,2292 & 0,0628 & 0,0003 \\
\hline 8
\end{tabular} \begin{tabular}{lllllllllllllll}
\hline 8 & regra25415 & 0,3161 & 0,0526 & $<, 0001$ & 84 & regra00187 & 0,4479 & 0,0778 & $<, 0001$ & 160 regra01034 & 0,1636 & 0,0797 & 0,0402 \\
\hline
\end{tabular} \begin{tabular}{llllllllllllll}
\hline 9 & regra29299 & 0,1318 & 0,0580 & 0,0231 & 85 & regra29642 & 0,3365 & 0,0471 & $<, 0001$ & 161 regra09644 & 0,2793 & 0,0532 & $<, 0001$ \\
\hline
\end{tabular} \begin{tabular}{rlll|llllllllll}
\hline 10 regra25923 & 0,3064 & 0,0389 & $<, 0001$ & 86 & regra27583 & 0,3537 & 0,0549 & $<, 0001$ & 162 regra03688 & 1,0817 & 0,0657 & $<, 0001$ \\
\hline 11 regras
\end{tabular} \begin{tabular}{lllllllllllll}
\hline 11 regra05344 & 0,5211 & 0,0560 & $<, 0001$ & 87 & regra02332 & 0,1938 & 0,0620 & 0,0018 & 163 regra22915 & 0,2021 & 0,0631 & 0,0014 \\
\hline 12 regra
\end{tabular} \begin{tabular}{lllllllllllll}
\hline 12 regra29289 & 0,1637 & 0,0562 & 0,0036 & 88 & regra11660 & 0,4780 & 0,0574 & $<, 0001$ & 164 regra21410 & 0,2874 & 0,0605 & $<, 0001$ \\
\hline
\end{tabular} \begin{tabular}{llll|llllllllll}
\hline 13 regra01304 & 0,7380 & 0,0651 & $<, 0001$ & 89 & regra22503 & 0,4101 & 0,0607 & $<, 0001$ & 165 regra14103 & 0,1747 & 0,0641 & 0,0064 \\
\hline 14 regra
\end{tabular} \begin{tabular}{lllllllllllll}
\hline 14 regra03388 & 0,2184 & 0,0651 & 0,0008 & 90 & regra12460 & 0,5255 & 0,0666 & $<, 0001$ & 166 regra20037 & 0,7597 & 0,0577 & $<, 0001$ \\
\hline
\end{tabular} \begin{tabular}{lllllllllllll}
\hline 15 regra03073 & 0,3621 & 0,0618 & $<, 0001$ & 91 & regra27512 & 0,1806 & 0,0619 & 0,0035 & 167 regra03665 & 0,2804 & 0,0705 & $<, 0001$ \\
\hline 16 regra
\end{tabular} \begin{tabular}{lllllllllllllll}
\hline 16 regra07697 & 0,6038 & 0,0635 & $<, 0001$ & 92 & regra16335 & 0,2041 & 0,0558 & 0,0003 & 168 regra09839 & 0,6523 & 0,0732 & $<, 0001$ \\
\hline
\end{tabular} \begin{tabular}{llllllllllllll}
\hline 17 regra20009 & 0,8220 & 0,0464 & $<, 0001$ & 93 & regra14655 & 0,2232 & 0,0631 & 0,0004 & 169 regra23711 & 0,2493 & 0,0390 & $<, 0001$ \\
\hline
\end{tabular} \begin{tabular}{lllllllllllllll}
\hline 18 regra23761 & 0,3031 & 0,0577 & $<, 0001$ & 94 & regra03395 & 0,2468 & 0,0669 & 0,0002 & 170 regra11315 & 0,2770 & 0,0562 & $<, 0001$ \\
\hline
\end{tabular} \begin{tabular}{lllllllllllll}
\hline 19 regra27983 & 0,2542 & 0,0490 & $<, 0001$ & 95 & regra25850 & 0,3101 & 0,0554 & $<, 0001$ & 171 regra08876 & 0,1698 & 0,0627 & 0,0067 \\
\hline
\end{tabular} \begin{tabular}{lllllllllllll}
\hline 20 regra26998 & 0,1875 & 0,0540 & 0,0005 & 96 & regra13639 & 0,1752 & 0,0644 & 0,0065 & 172 regra06413 & 0,2039 & 0,0695 & 0,0033 \\
\hline
\end{tabular} \begin{tabular}{llllllllllllll}
\hline 21 regra19857 & 0,6218 & 0,0602 & $<, 0001$ & 97 & regra25813 & 0,3483 & 0,0603 & $<, 0001$ & 173 regra22707 & 0,1687 & 0,0659 & 0,0105 \\
\hline
\end{tabular} \begin{tabular}{lllllllllllll}
\hline 22 regra05319 & 0,4820 & 0,0677 & $<, 0001$ & 98 & regra03160 & 0,6148 & 0,0728 & $<, 0001$ & 174 regra29715 & 0,1518 & 0,0498 & 0,0023 \\
\hline
\end{tabular} \begin{tabular}{llll|lllll|lllll}
\hline 23 regra25978 & 0,2712 & 0,0414 & $<, 0001$ & 99 & regra14692 & 0,1443 & 0,0514 & 0,0050 & 175 regra03086 & 0,7478 & 0,0715 & $<, 0001$ \\
\hline
\end{tabular}

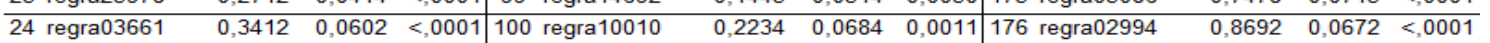
\begin{tabular}{lllllllllllll}
\hline 25 regra19827 & 0,2541 & 0,0468 & $<, 0001$ & 101 regra07486 & 0,5492 & 0,0665 & $<, 0001$ & 177 regra12827 & 0,1936 & 0,0720 & 0,0071 \\
\hline
\end{tabular} \begin{tabular}{llll|llllllllll}
\hline 26 regra20621 & 0,1213 & 0,0337 & 0,0003 & 102 regra31879 & 0,1266 & 0,0602 & 0,0354 & 178 regra13055 & 0,0968 & 0,0541 & 0,0733 \\
\hline
\end{tabular} \begin{tabular}{lllllllllllll}
\hline 27 regra19731 & 0,5709 & 0,0590 & $<, 0001$ & 103 regra14566 & 0,3447 & 0,0536 & $<, 0001$ & 179 regra27683 & 0,2381 & 0,0499 & $<, 0001$ \\
\hline
\end{tabular} \begin{tabular}{lllllllllllll}
28 regra00394 & 0,8455 & 0,0738 & $<, 0001$ & 104 regra09249 & 0,2912 & 0,0676 & $<, 0001$ & 180 regra10486 & 0,1854 & 0,0695 & 0,0076 \\
\hline
\end{tabular} \begin{tabular}{llllllllllllll}
\hline 29 regra09968 & 0,2690 & 0,0635 & $<, 0001$ & 105 regra12758 & 0,3186 & 0,0579 & $<, 0001$ & 181 regra18609 & 0,1977 & 0,0526 & 0,0002 \\
\hline
\end{tabular} \begin{tabular}{lllllllllllll}
\hline 30 regra05225 & 0,9075 & 0,0659 & $<, 0001$ & 106 regra03005 & 0,2949 & 0,0643 & $<, 0001$ & 182 regra15844 & 0,1234 & 0,0483 & 0,0107 \\
\hline
\end{tabular} \begin{tabular}{llllllllllllll}
\hline 31 regra06990 & 0,4253 & 0,0572 & $<, 0001$ & 107 regra13665 & 0,1606 & 0,0622 & 0,0099 & 183 regra08589 & 0,2748 & 0,0709 & 0,0001 \\
\hline
\end{tabular} \begin{tabular}{llllllll|lllll}
\hline 32 regra24633 & 0,2952 & 0,0524 & $<, 0001$ & 108 regra17530 & 0,5239 & 0,0503 & $<, 0001$ & 184 regra00122 & 1,3161 & 0,1095 & $<, 0001$ \\
\hline
\end{tabular} \begin{tabular}{llllllllllllll}
\hline 33 regra15275 & 0,1635 & 0,0610 & 0,0074 & 109 regra17134 & 0,2044 & 0,0497 & $<, 0001$ & 185 regra00229 & 0,6980 & 0,0838 & $<, 0001$ \\
\hline
\end{tabular} \begin{tabular}{llllllllllllll}
\hline 34 regra33396 & 0,2083 & 0,0546 & 0,0001 & 110 regra02109 & 0,6450 & 0,0716 & $<, 0001$ & 186 regra00346 & 0,2550 & 0,0897 & 0,0045 \\
\hline 35
\end{tabular} \begin{tabular}{lllllllllllll}
\hline 35 regra03430 & 0,3790 & 0,0672 & $<, 0001$ & 111 regra23743 & 0,2945 & 0,0488 & $<, 0001$ & 187 regra20145 & 0,6246 & 0,0572 & $<, 0001$ \\
\hline
\end{tabular} \begin{tabular}{llllllllllllll}
\hline 36 regra23643 & 0,4892 & 0,0634 & $<, 0001$ & 112 regra01681 & 0,3343 & 0,0676 & $<, 0001$ & 188 regra04406 & 0,2588 & 0,0769 & 0,0008 \\
\hline
\end{tabular} \begin{tabular}{lllllllllllll}
\hline 37 regra01657 & 0,2974 & 0,0721 & $<, 0001$ & 113 regra06850 & 0,4345 & 0,0685 & $<, 0001$ & 189 regra03503 & 0,1778 & 0,0722 & 0,0137 \\
\hline 38 regra
\end{tabular} \begin{tabular}{lllllllllllll}
\hline 38 regra02193 & 0,9449 & 0,0592 & $<, 0001$ & 114 regra19308 & 0,4629 & 0,0408 & $<, 0001$ & 190 regra19056 & 0,3061 & 0,0677 & $<, 0001$ \\
\hline
\end{tabular} \begin{tabular}{lllllllllllll}
\hline 39 regra20878 & 0,2519 & 0,0528 & $<, 0001$ & 115 regra21944 & 0,2253 & 0,0473 & $<, 0001$ & 191 regra01542 & 0,2656 & 0,0730 & 0,0003 \\
\hline
\end{tabular} \begin{tabular}{llllllllllllll}
\hline 40 regra24676 & 0,2034 & 0,0616 & 0,001 & 116 regra00237 & 0,6513 & 0,0753 & $<, 0001$ & 192 regra22247 & 0,2621 & 0,0548 & $<, 0001$
\end{tabular} \begin{tabular}{llllllll|lllll}
\hline 41 regra14285 & 0,2179 & 0,0540 & $<, 0001$ & 117 regra09127 & 0,2128 & 0,0548 & 0,0001 & 193 regra09259 & 0,1709 & 0,0699 & 0,0144 \\
\hline
\end{tabular} \begin{tabular}{lllllllllllll}
\hline 42 regra34352 & 0,1463 & 0,0523 & 0,0051 & 118 regra04754 & 0,4057 & 0,0684 & $<, 0001$ & 194 regra04504 & 0,3165 & 0,0826 & 0,0001 \\
\hline
\end{tabular} \begin{tabular}{lllllllll|llll}
\hline 43 regra04348 & 0,7007 & 0,0558 & $<, 0001$ & 119 regra29461 & 0,1695 & 0,0482 & 0,0004 & 195 regra19910 & 0,4055 & 0,0634 & $<, 0001$ \\
\hline
\end{tabular}

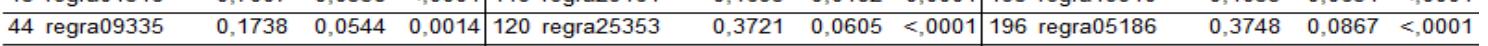
\begin{tabular}{lllllllllllll}
44 regra11264 & 0,7424 & 0,0639 & $<, 0001$ & 121 regra24525 & 0,3772 & 0,0633 & $<, 0001$ & 197 regra20642 & 0,5480 & 0,0513 & $<, 0001$ \\
\hline
\end{tabular} \begin{tabular}{llllllllllllll}
\hline 46 regra00235 & 0,7168 & 0,0816 & $<, 0001$ & 122 regra06797 & 0,4626 & 0,0507 & $<, 0001$ & 198 regra21418 & 0,2603 & 0,0606 & $<, 0001$ \\
\hline
\end{tabular} \begin{tabular}{lllllllllllllll}
\hline 47 regra15224 & 0,1925 & 0,0539 & 0,0004 & 123 regra00994 & 0,2175 & 0,0724 & 0,0027 & 199 regra15109 & 0,4419 & 0,0710 & $<, 0001$ \\
\hline
\end{tabular} \begin{tabular}{lllllllllllll}
\hline 48 regra12431 & 0,1545 & 0,0644 & 0,0164 & 124 regra01169 & 0,3372 & 0,0726 & $<, 0001$ & 200 regra12477 & 0,1803 & 0,0609 & 0,0031
\end{tabular} \begin{tabular}{llllllllllllll}
\hline 49 regra32315 & 0,1317 & 0,0499 & 0,0083 & 125 regra16498 & 0,2617 & 0,0657 & $<, 0001$ & 201 regra00574 & 1,7915 & 0,0740 & $<, 0001$ \\
\hline
\end{tabular} \begin{tabular}{lllllllllllll}
\hline 50 regra22793 & 0,3183 & 0,0538 & $<, 0001$ & 126 regra03423 & 0,1593 & 0,0692 & 0,0214 & 202 regra00378 & 0,5135 & 0,0943 & $<, 0001$ \\
\hline
\end{tabular} \begin{tabular}{llllllllllllll}
\hline 51 regra26899 & 0,2046 & 0,0643 & 0,0015 & 127 regra29296 & 0,1639 & 0,0550 & 0,0029 & 203 regra10341 & 0,4566 & 0,0773 & $<, 0001$ \\
\hline
\end{tabular} \begin{tabular}{lllllllllllll}
\hline 52 regra12317 & 0,4525 & 0,0567 & $<, 0001$ & 128 regra21289 & 0,1839 & 0,0462 & $<, 0001$ & 204 regra28936 & 0,1693 & 0,0563 & 0,0026 \\
\hline 5
\end{tabular} \begin{tabular}{llllllll|llll}
\hline 53 regra14685 & 0,1679 & 0,0576 & 0,0036 & 129 regra11277 & 0,2753 & 0,0608 & $<, 0001$ & 205 regra12740 & 0,1533 & 0,0770 & 0,0464 \\
\hline
\end{tabular} \begin{tabular}{llllllllllllll}
53 regra14685 & 0,1679 & 0,0576 & 0,0036 & 129 & regra11277 & 0,2753 & 0,0608 & $<, 0001$ & 205 regra12740 & 0,1533 & 0,0770 & 0,0464 \\
\hline 54 regra00243 & 0,5238 & 0,0724 & $<, 0001$ & 130 regra24714 & 0,3395 & 0,0350 & $<, 0001$ & 206 regra01021 & 0,2265 & 0,0666 & 0,0007 \\
\hline
\end{tabular} \begin{tabular}{llllllllllllll}
\hline 55 regra20373 & 0,2803 & 0,0567 & $<, 0001$ & 131 regra22403 & 0,2283 & 0,0629 & 0,0003 & 207 regra31406 & 0,1899 & 0,0364 & $<, 0001$ \\
\hline
\end{tabular} \begin{tabular}{lllllllllllllll}
\hline 56 regra20263 & 0,3474 & 0,0623 & $<, 0001$ & 132 regra24417 & 0,4009 & 0,0407 & $<, 0001$ & 208 regra24849 & 0,4402 & 0,0564 & $<, 0001$ \\
\hline
\end{tabular} \begin{tabular}{llllllllllllll}
\hline 57 regra07087 & 0,2042 & 0,0634 & 0,0013 & 133 regra03884 & 0,6170 & 0,0678 & $<, 0001$ & 209 regra21219 & 0,4199 & 0,0557 & $<, 0001$ \\
\hline 58 regras
\end{tabular} \begin{tabular}{lllllllllllll}
\hline 58 regra30835 & 0,0945 & 0,0410 & 0,0212 & 134 regra21214 & 0,3325 & 0,0602 & $<, 0001$ & 210 regra28772 & 0,3258 & 0,0451 & $<, 0001$ \\
\hline
\end{tabular} \begin{tabular}{llllllllllll}
\hline 59 regra19349 & 0,2546 & 0,0580 & $<, 0001$ & 135 regra00870 & 0,3806 & 0,0634 & $<, 0001$ & 211 regra15462 & 0,4681 & 0,0797 & $<, 0001$ \\
\hline
\end{tabular} \begin{tabular}{lllllllllllll}
\hline 60 regra17142 & 0,6254 & 0,0641 & $<, 0001$ & 136 regra01078 & 0,3816 & 0,0762 & $<, 0001$ & 212 regra15777 & 0,5319 & 0,0712 & $<, 0001$ \\
\hline
\end{tabular} \begin{tabular}{llllllll|lllll}
\hline 61 regra01533 & 0,4168 & 0,0611 & $<, 0001$ & 137 regra03026 & 1,2068 & 0,0694 & $<, 0001$ & 213 regra18058 & 0,1216 & 0,0518 & 0,0189 \\
\hline
\end{tabular} \begin{tabular}{lllllllllllll}
\hline 62 regra01291 & 0,6105 & 0,0725 & $<, 0001$ & 138 regra08525 & 0,5233 & 0,0672 & $<, 0001$ & 214 regra28684 & 0,1169 & 0,0484 & 0,0156 \\
\hline
\end{tabular} \begin{tabular}{llllllllllllll}
\hline 63 regra10070 & 0,2050 & 0,0648 & 0,0016 & 139 regra22923 & 0,2006 & 0,0564 & 0,0004 & 215 regra03300 & 0,5610 & 0,0873 & $<, 0001$ \\
\hline
\end{tabular} \begin{tabular}{llllllllllllll}
\hline 64 regra03709 & 0,3050 & 0,0669 & $<, 0001$ & 140 regra18465 & 0,1192 & 0,0496 & 0,0163 & 216 regra13943 & 0,5167 & 0,0704 & $<, 0001$ \\
\hline
\end{tabular} \begin{tabular}{lllllllllllll}
\hline 65 regra26124 & 0,1420 & 0,0560 & 0,0113 & 141 regra06767 & 0,2933 & 0,0718 & $<, 0001$ & 217 regra09232 & 0,5185 & 0,0862 & $<, 0001$ \\
\hline
\end{tabular} \begin{tabular}{llllllllllllll}
\hline 66 regra01243 & 0,7220 & 0,0693 & $<, 0001$ & 142 regra13487 & 0,5189 & 0,0641 & $<, 0001$ & 218 regra13645 & 0,5671 & 0,0742 & $<, 0001$ \\
\hline
\end{tabular} \begin{tabular}{lllllllllllll}
\hline 67 regra01404 & 0,5441 & 0,0702 & $<, 0001$ & 143 regra18627 & 0,2559 & 0,0466 & $<, 0001$ & 219 regra01886 & 0,6632 & 0,0957 & $<, 0001$ \\
\hline
\end{tabular} \begin{tabular}{llllllllllll}
\hline 68 regra18001 & 0,3097 & 0,0539 & $<, 0001$ & 144 regra33245 & 0,1576 & 0,0344 & $<, 0001$ & 220 regra32316 & 0,1074 & 0,0386 & 0,0053 \\
\hline
\end{tabular} \begin{tabular}{lllllllllllll}
\hline 69 regra02055 & 0,1298 & 0,0620 & 0,0362 & 145 regra01589 & 0,4126 & 0,0723 & $<, 0001$ & 221 regra00571 & 0,3720 & 0,0999 & 0,0002 \\
\hline
\end{tabular} \begin{tabular}{lllllllllllll}
\hline 70 regra27189 & 0,2492 & 0,0550 & $<, 0001$ & 146 regra15030 & 0,3868 & 0,0618 & $<, 0001$ & 222 regra03138 & 0,4754 & 0,0944 & $<, 0001$ \\
\hline 71 regra
\end{tabular} \begin{tabular}{lllllllllllll}
\hline 71 regra07050 & 0,4224 & 0,0675 & $<, 0001$ & 147 regra05744 & 0,2940 & 0,0535 & $<, 0001$ & 223 regra01768 & 0,3462 & 0,0785 & $<, 0001$ \\
\hline 72
\end{tabular} \begin{tabular}{llllllllllllll}
\hline 72 regra11966 & 0,2951 & 0,0649 & $<, 0001$ & 148 regra19257 & 0,1189 & 0,0401 & 0,0030 & 224 regra02682 & 0,8221 & 0,0993 & $<, 0001$ \\
\hline 73
\end{tabular} \begin{tabular}{lllllllllllll}
\hline 73 regra07355 & 0,3292 & 0,0628 & $<, 0001$ & 149 regra28682 & 0,1477 & 0,0322 & $<, 0001$ & 225 regra19071 & 0,7290 & 0,0673 & $<, 0001$ \\
\hline 74
\end{tabular} \begin{tabular}{lllllllllllll}
\hline 74 regra27702 & 0,1555 & 0,0397 & $<, 0001$ & 150 regra04613 & 0,1818 & 0,0637 & 0,0043 & 226 regra21561 & 0,4614 & 0,0551 & $<, 0001$ \\
\hline
\end{tabular} \begin{tabular}{llll|l}
74 regra17046 & 0,3896 & 0,0619 & $<, 0001$ & 151 regra34136 \\
\hline
\end{tabular} $\begin{array}{llll}0,2977 & 0,0424 & <, 0001\end{array}$ 


\begin{tabular}{|c|c|c|c|c|c|c|c|c|c|c|c|c|}
\hline ariável & $\begin{array}{c}\beta \\
\text { stimado }\end{array}$ & $\begin{array}{c}\text { Erro } \\
\text { Padrão }\end{array}$ & alor & \# & ariá & $\begin{array}{c}\beta \\
\text { stimado }\end{array}$ & $\begin{array}{c}\text { Erro } \\
\text { Padrão }\end{array}$ & or & \# Variável & $\begin{array}{c}\beta \\
\text { Estimado }\end{array}$ & $\begin{array}{c}\text { Erro } \\
\text { Padrão }\end{array}$ & 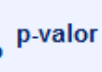 \\
\hline 0 Inter & & & $\overline{0001}$ & 50 & 7050 & & & Tor & 99 & & $\begin{array}{l}777 \\
\end{array}$ & 0 \\
\hline 1 regra000002 & 8913 & 1031 & $<, 0001$ & 1 & regra07413 & 807 & 731 & 0001 & $100 r$ & 409 & 557 & 0001 \\
\hline 2 regra00092 & 7091 & 1041 & $<, 0001$ & 2 & regra07508 & 3732 & 0717 & $<, 0001$ & 221904 & 1697 & 0600 & 0,0047 \\
\hline 3 regra00122 & 450 & 1044 & $<, 0001$ & 3 & 8152 & 1474 & 0582 & 0,0114 & $102 r$ & 5157 & 0597 & $<<, 0001$ \\
\hline 4 regra00146 & 9285 &, 0693 & $<, 0001$ & 54 & regra08331 & 2317 & 0553 & $<, 0001$ & $103 r$ & 5773 &, 0454 & $<<, 0001$ \\
\hline 5 regra00186 & 0813 &, 0733 & $<, 0001$ & 5 & regra08799 & 3542 & 0,0506 & $<, 0001$ & 2503 & 4136 &, 0621 & $<, 0001$ \\
\hline 6 regra00187 & 732 & 0760 & $<, 0001$ & 6 & 9232 & 443 & 0851 & $<, 0001$ & $105 r$ & 3119 & 0590 & $<, 0001$ \\
\hline 7 regra00237 & 4682 & 0,0655 & $<, 0001$ & 57 & regra09259 & 3370 & 0,0612 & $<, 0001$ & $106 r$ & 1940 & 0,0662 & 2. 0,0034 \\
\hline 8 regra00394 & 1115 & 0,0705 & $<, 0001$ & 8 & 9644 & 4499 & 0,0510 & $<, 0001$ & $107 \mathrm{re}$ & 2368 &, 0540 & $<<, 0001$ \\
\hline 9 regra00400 & 073 & 0,0738 & $<, 0001$ & 59 & 881 & 5654 & 0511 & $<, 0001$ & $108 \mathrm{r}$ & 2801 &, 0502 & $2<, 0001$ \\
\hline 10 regra00458 & 1227 & 0,0582 & $<, 0001$ & 60 & regra10165 & 6972 & 0,0590 & $<, 0001$ & $109 r$ & 1691 & 0,0673 & 30,0120 \\
\hline 11 regra00718 & 6617 & 0,0522 & $<, 0001$ & 1 & 8883 & 4270 & 0,0478 & $<, 0001$ & 479 & 5850 & 0,0555 & $6<, 0001$ \\
\hline 12 regra & 736 & 0,0758 & $<, 0001$ & 62 & 991 & 1640 & 0666 & 0,0138 & $111 \mathrm{r}$ & 506 & 537 & $<<, 0001$ \\
\hline 13 regra00931 & 6119 & 0,0576 & $<<, 0001$ & 63 & regra11566 & 4443 & 0,0547 & $<, 0001$ & $112 \mathrm{r}$ & 4271 & 0,0507 & $<, 0001$ \\
\hline 14 regr & 5603 & 0,0625 & $<, 0001$ & 64 & 1595 & 2044 & 0,0559 & 0,0003 & 702 & 1821 & 0,0522 & 20,0005 \\
\hline 15 regr & 917 & 0,0577 & $<, 0001$ & 65 & & 2042 & 467 & $<, 0001$ & $114 \mathrm{r}$ & 247 & 521 & $<<, 0001$ \\
\hline 16 regr & 8583 & 0,0652 & $<, 0001$ & 66 & regra & 1694 & 0677 & 0,0124 & $115 r$ & 3212 & 0,0536 & $<<, 0001$ \\
\hline 278 & 0,9504 & 0,0633 & $<, 0001$ & 67 & 2679 & 4195 & 0,0731 & $<, 0001$ & $116 r$ & 3244 & 0,0573 & $3<, 0001$ \\
\hline 18 regr & 8678 & 0,0663 & $<, 0001$ & 68 & & 188 & 0,0714 & $<, 0001$ & $117 \mathrm{r}$ & 716 & 499 & $<, 0001$ \\
\hline 19 reg & 871 & 0,0621 & $<, 0001$ & 69 & 055 & 3580 & 0476 & $<, 0001$ & $118 \mathrm{r}$ & 1749 & 0,0574 & 0,0023 \\
\hline 20 regr & 8040 & 0,0673 & $<, 0001$ & 70 & 3502 & 0,4569 & 0,0537 & $<, 0001$ & $119 \mathrm{r}$ & 2034 & 0,0602 & 20,0007 \\
\hline 1 regr & 2183 & 0,0607 & $<, 0001$ & 71 & 45 & 5856 & 0,0656 & $<, 0001$ & $120 r$ & 224 & 503 & $3<, 0001$ \\
\hline 2 reg & 9935 & 0,0622 & $<, 0001$ & 72 & regra & 3242 & 0,0560 & $<, 0001$ & $121 \mathrm{r}$ & 2021 & 0,0488 & $3<, 0001$ \\
\hline 3 regr & 7928 & 0,0803 & $<<, 0001$ & 3 & 465 & 0,3256 & 0,0568 & $<, 0001$ & $122 r$ & 2481 & 0,0531 & $<, 0001$ \\
\hline 4 regr & 3527 & 0,0549 & $<, 0001$ & 74 & 692 & 2876 & 0,0483 & $<, 0001$ & $123 r$ & 276 & 488 & $3<, 0001$ \\
\hline $5 \mathrm{reg}$ & 2638 & 0,0536 & $<, 0001$ & 75 & 224 & 161 & 0513 & $<, 0001$ & 124 & 391 & 0,0544 & 0,0106 \\
\hline $6 \mathrm{reg}$ & 6974 & 0,0561 & $<, 0001$ & 76 & 457 & 4730 & 0,0416 & $<, 0001$ & $125 \mathrm{r}$ & 1284 & 0,0562 & 0,0222 \\
\hline 27 regr & 6158 & 0612 & $<, 0001$ & 77 & 462 & 5196 & 0,0775 & $<, 0001$ & $126 r$ & 193 & 502 & $2<, 0001$ \\
\hline 025 & 7443 & 0,0666 & $<, 0001$ & 78 & 491 & 6004 & 0675 & $<, 0001$ & 127 & 817 & 0,0379 & $<, 0001$ \\
\hline 9 regr & 2911 & 0,0568 & $<, 0001$ & 9 & 777 & 4811 & 0,0696 & $<, 0001$ & $128 \mathrm{r}$ & 1785 & 0,0382 & $2<, 0001$ \\
\hline 3073 & 847 & 0608 & $<, 0001$ & 80 & 221 & 3483 & 0,0512 & $<, 0001$ & $129 \mathrm{r}$ & 1548 & 0558 & 0,0055 \\
\hline 086 & 145 & 0,0664 & $<, 0001$ & 81 & 237 & 5018 & 378 & $<, 0001$ & 130 & 867 & 0,0508 & $3<, 0001$ \\
\hline $2 \mathrm{reg}$ & 737 & 0,0572 & $<, 0001$ & 82 & reg & 1838 & 0,0484 & 0,0001 & $131 \mathrm{r}$ & , 1455 & 0,0386 & 0,0002 \\
\hline 3 regr & 0809 & 0,0537 & $<, 0001$ & 83 & 439 & 1724 & 0595 & 0,0037 & $132 r$ & 2276 &, 0439 & $<, 0001$ \\
\hline 718 & 007 & 0,0529 & $<, 0001$ & 84 & 558 & 778 & 0,0647 & $<, 0001$ & $133 \mathrm{r}$ & 052 & 0,0458 & 0,0217 \\
\hline $35 \mathrm{reg}$ & 0,1580 & 0,0557 & 0,0045 & 85 & 142 & 7163 & 0,0591 & $<, 0001$ & $134 \mathrm{r}$ & 0,2799 & 0,0404 & $<<, 0001$ \\
\hline 6 regr & 7248 & 0,0592 & $<, 0001$ & 86 & 275 & 7380 & 0,0504 & $<, 0001$ & $135 \mathrm{r}$ & 2577 & 0,0341 & $<, 0001$ \\
\hline 37 regr & 284 & 0,0728 & $<, 0001$ & 87 & regra17530 & 0,5597 & 0,0487 & $<, 0001$ & $136 r$ & 2731 & 0,0485 & $<<, 0001$ \\
\hline $8 \mathrm{reg}$ & 0,7742 & 0,0537 & $<, 0001$ & 88 & reg & 0,2468 & 0,0397 & $<, 0001$ & 137 re & 0,2390 & 0,0411 & $<, 0001$ \\
\hline 9 regr & 5350 & 0,0670 & $<, 0001$ & 89 & 260 & 1556 & 0,0608 & 0,0105 & $138 \mathrm{r}$ & .0960 & 0,0343 & 0,0051 \\
\hline 10 regr & 5976 & 0,0658 & $<, 0001$ & 90 & regra19086 & 0,1927 & 0,0564 & 0,0006 & $139 \mathrm{re}$ & 0,1895 & 0,0398 & $<<, 0001$ \\
\hline 1 regr & 0,1740 & 0,0824 & 0,0347 & 91 & reg & 0,1216 & 0,0594 & 0,0406 & $140 \mathrm{re}$ & 0,1643 & 0,0451 & 0,0003 \\
\hline 42 regra05098 & 0,4640 & 0,0654 & $<, 0001$ & 92 & regra19827 & 0,2896 & 0,0451 & $<, 0001$ & $141 \mathrm{re}$ & 0,2208 & 0,0390 & $<, 0001$ \\
\hline 43 regr & 0,3655 & 0,0648 & $<, 0001$ & 93 & regra19844 & 0,3055 & 0,0528 & $<, 0001$ & $142 \mathrm{reg}$ & 0,0901 & 0,0368 & 0,0143 \\
\hline 44 regr & 0,7118 & 0,0700 & $<, 0001$ & 94 & 9987 & 0,2949 & 0,0646 & $<, 0001$ & 143 re & 0,1651 & 0,0510 & 0,0012 \\
\hline 45 regra05343 & 0,5461 & 0,0738 & $<, 0001$ & 95 & regra20317 & 0,1796 & 0,0550 & 0,0011 & 144 re & 0,2408 & 0,0395 & $<<, 0001$ \\
\hline 46 regra05827 & 0,4773 & 0,0606 & $<, 0001$ & 96 & regra20380 & 0,3053 & 0,0454 & $<, 0001$ & 145 regra33375 & 0,1394 & 0,0411 & 0,0007 \\
\hline 47 regr & 0,2433 & 0,0723 & 0,0008 & 97 & 956 & 0,2952 & 0,0554 & $<, 0001$ & $146 \mathrm{re}$ & 0,1229 & 0,0497 & 0,0134 \\
\hline 48 regra06191 & 0,5450 & 0,0575 & $<, 0001$ & 98 & regra21011 & 1985 & 0,0525 & 0,0002 & 009 & 1412 & 0,0488 & 0,0038 \\
\hline 49 regra06956 & 0,7345 & 0628 & 0001 & & & & & & & & & \\
\hline
\end{tabular}

Tabela 4.22: Regras selecionadas e estimativas do modelo utilizando a técnica stepwise para o conjunto Confiança_040. Esse conjunto tem 147 regras. 


\begin{tabular}{|c|c|c|c|c|c|c|c|c|c|c|c|c|c|c|}
\hline \# & iável & $\begin{array}{c}\beta \\
\text { timado }\end{array}$ & $\begin{array}{l}\text { Erro } \\
\text { Padrão }\end{array}$ & 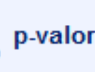 & \# & riá & $\begin{array}{c}\beta \\
\text { stimado }\end{array}$ & $\begin{array}{l}\text { Irro } \\
\text { drão }\end{array}$ & & \# & Variável & $\begin{array}{c}\boldsymbol{\beta} \\
\text { Estimado }\end{array}$ & $\begin{array}{l}\text { Er } \\
\text { Pad }\end{array}$ & \\
\hline 0 & ercepto & & & $=$ & & regra04721 & $\overline{0,6452}$ & 8 & 2001 & 82 & 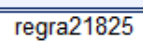 & & & 5 \\
\hline 1 & & & & 001 & & & & & 001 & 3 & & & & 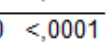 \\
\hline 2 & gra00073 & 80 & 0848 & 0001 & & 82 & 328 & 85 & 0001 & 84 & regra22359 & 299 & 569 & $\overline{0001}$ \\
\hline 3 & gra00122 & & 0956 & 0001 & & & & 75 & 0001 & 85 & 738 & & 60 &, 0001 \\
\hline 4 & regra00147 & & & 00 & & & & & 0001 & 86 & & & & 0001 \\
\hline 5 & gra00164 & & 0 & 0001 & & & & & 0001 & 87 & & & 32 & $\overline{0001}$ \\
\hline 6 & regra00177 & 312 & 0868 & 0001 & & re & 552 & 0610 & 0001 & 88 & regra23719 & 217 & 558 &, 0001 \\
\hline & regra00198 & & 9 & 0001 & & & 84 & 25 & $<, 0001$ & 89 & & & 52 & $<<, 0001$ \\
\hline & 10 & & 3 & 0001 & & & & 97 & $<, 0001$ & 0 & & & 23 & $\overline{58}$ \\
\hline & 246 & & 3 & 0001 & & & 62 & 53 & $<, 0001$ & 91 & & 49 & 360 & $\overline{01}$ \\
\hline & regral & 95 & 0670 & 0001 & & re & 866 & 0609 & $<, 0001$ & 92 & 631 & 355 & 0488 & $\overline{0001}$ \\
\hline & & & & 0001 & & & & & 0001 & 3 & & & 24 & $\overline{0015}$ \\
\hline & & 58 & 0758 & 0001 & & & 14 & 15 & $<, 0001$ & 4 & & & 0526 & $\overline{11}$ \\
\hline & regr & 004 & 0766 & 0001 & & re & 479 & 523 & $<, 0001$ & 95 & 873 & 50 & 0428 & $\overline{001}$ \\
\hline & regr & & 0700 & 0001 & & re & 849 & 880 & $<, 0001$ & 96 & regr & 92 & 0863 & $\overline{0003}$ \\
\hline & & & 3 & 0001 & & & & & 0001 & 97 & & & 0443 & $\overline{0009}$ \\
\hline & & & 0666 & $<, 0001$ & & & 2 & 50 & $<, 0001$ & 98 & & & 332 & $\overline{11}$ \\
\hline & reg & 889 & 0569 & $<, 0001$ & & & 20 & 38 & $<, 0001$ & 99 & 886 & 877 & 0578 & $\overline{0006}$ \\
\hline & & & $\overline{06}$ & 0001 & & & 39 & 82 & $<, 0001$ & & & & 0,0875 & $\overline{0325}$ \\
\hline & & & 4 & 0001 & & & & & $<, 0001$ & & & & 50 & $\overline{15}$ \\
\hline & reg & & 58 & 0001 & & & & 60 & 0,0041 & & & & 0445 & 15 \\
\hline & & 335 & 0601 & $<, 0001$ & & & 653 & 572 & 0,0039 & & 25 & 270 & 0,0519 & $\overline{0001}$ \\
\hline & & & 6 & 0001 & & & 29 & 83 & $<, 0001$ & & & & 0,0387 & $\overline{, 0066}$ \\
\hline & 42 & & 9 & 0001 & & & 14 & & $<, 0001$ & & & & 35 & $\overline{0001}$ \\
\hline & 565 & & & 001 & & & & & $<, 0001$ & & & & 0,0545 & 0144 \\
\hline & & 58 & 5668 & 0001 & & & 327 & 108 & $<, 0001$ & & & 586 & 0,0467 & $<, 0001$ \\
\hline & & & 8 & 0001 & & & 39 & 87 & $<, 0001$ & & & & 0,0528 & 0,0035 \\
\hline & & 278 & 0552 & $<, 0001$ & & & 2657 & & $<, 0001$ & & & & 0497 & $\overline{0047}$ \\
\hline & 109 & 29 & 0621 & 0001 & & & 2086 & & $<, 0001$ & & & 777 & 0,0556 & .0001 \\
\hline & & & 676 & 0001 & & & 284 & 84 & $<, 0001$ & & & 365 & 0,0316 & $\overline{, 0062}$ \\
\hline & & & 579 & 0001 & & & 08 & 89 & $<, 0001$ & & & 03 & 0261 & $<<, 0001$ \\
\hline & & & $054 \pi$ & 0,0137 & & & & 0,0553 & $<, 0001$ & & & & 0,0305 &, 0003 \\
\hline & & & 0613 & 0001 & & & 6493 & 0,0422 & $<, 0001$ & & & & 0,0321 &, 0098 \\
\hline & & & 0565 & 0001 & & & 5629 & 424 & $<, 0001$ & & 993 & 219 & 0,0286 & $<<, 0001$ \\
\hline & & 96 & 8 & 0001 & & & 344 & 539 & \begin{tabular}{|c|}
0,0127 \\
\end{tabular} & & 003 & 264 & 0,0321 & $<<, 0001$ \\
\hline & & & 0656 & 0,0008 & & & & & $<, 0001$ & & & & 0,0526 & 0,0218 \\
\hline & & 885 & 0600 & $<, 0001$ & 7 & & 8096 & 0,0513 & $<, 0001$ & & & 650 & 0,0502 & $<<, 0001$ \\
\hline & & 229 & 0683 & 0001 & 78 & 326 & 2228 & 0,0552 & $<, 0001$ & & 497 & 1466 & 0,0493 & 0,0029 \\
\hline & & & 74 & 0001 & & & 97 & 70 & $<, 0001$ & & 513 & 339 & 0,0521 & $<<, 0001$ \\
\hline & & & & $<, 0001$ & & & & & $<, 0001$ & & 592 & 70 & 0,0282 & 0,0001 \\
\hline & 13 & 698 & 525 & 18 & & 708 & 102 & st & $<, 0001$ & & & & & \\
\hline
\end{tabular}

Tabela 4.23: Regras selecionadas e estimativas do modelo utilizando a técnica stepwise para o conjunto Confiança_030. Esse conjunto tem 121 regras.

\section{Medidas de Ajuste dos Modelos}

Para avaliar o ajuste dos modelos, é possível verificar as medidas de ajuste dos modelos expostas na Tabela 4.24. Em suma, todos os modelos satisfizeram os critérios de convergência do software, os erros padrão atribuídos à estimação dos parâmetros $\beta$ tiveram bom comportamento e, como atestado pelos resultados dos testes de máxima verossimilhança, score, Wald e pela estatística Deviance, os modelos apresentaram ajuste adequado aos dados.

Com relação ao teste de Hosmer e Lemershow, os modelos não apresentaram o ajuste desejado. Entretanto, esse teste, de forma geral, segmenta os valores observados e os esperados em diversas faixas de casos e calcula uma estatística comparando esses valores. Porém, para modelos de regressão logística nos quais as variáveis explicativas são contínuas, as classes são desbalanceadas ou o tamanho da amostra é muito grande, o uso dessa estatística vem 
sendo repensado (HL00).

Uma observação relacionada à estatística Deviance é que, em suma, o teste de hipótese avaliado nela é de que o modelo é bem ajustado se comparado ao modelo saturado. Logo, o desejável é não rejeitar o teste, ou seja, para essa estatística, busca-se um valor-p maior que 0,05 .

\begin{tabular}{|c|c|c|c|c|c|c|}
\hline \multirow{2}{*}{\multicolumn{2}{|c|}{ Teste/Estatística }} & \multicolumn{5}{|c|}{ CONJUNTO DE REGRAS } \\
\hline & & \multirow{2}{*}{$\begin{array}{r}\text { SUPORTE_050 } \\
26.195,7494 \\
\end{array}$} & \multirow{2}{*}{$\begin{array}{r}\text { MEDIDAF_050 } \\
26.169,4231\end{array}$} & \multirow{2}{*}{$\begin{array}{r}\text { CONFIANÇA_050 } \\
29.367,2000\end{array}$} & \multirow{2}{*}{$\begin{array}{r}\text { CONFIANÇA_040 } \\
25.784,0324 \\
\end{array}$} & \multirow{2}{*}{$\begin{array}{r}\text { CONFIANÇA_030 } \\
23.874,7728\end{array}$} \\
\hline & Qui-Quadrado & & & & & \\
\hline \multirow[t]{3}{*}{ Máxima Verossimilhança } & Graus de Liberdade & 89 & 108 & 226 & 147 & 121 \\
\hline & P-valor & $<0,0001$ & $<0,0001$ & $<0,0001$ & $<0,0001$ & $<0,0001$ \\
\hline & Qui-Quadrado & $34.697,5416$ & $35.581,7740$ & 44304,5722 & $41.922,4771$ & $40.463,3412$ \\
\hline \multirow[t]{2}{*}{ Score } & Graus de Liberdade & 89 & 108 & 226 & 147 & 121 \\
\hline & P-valor & $<0,0001$ & $<0,0001$ & $<0,0001$ & $<0,0001$ & $<0,0001$ \\
\hline \multirow{3}{*}{ Wald } & Qui-Quadrado & $22.620,3355$ & $22.765,5636$ & 24765,1829 & $23.079,2670$ & $21.602,5165$ \\
\hline & Graus de Liberdade & 89 & 108 & 226 & 147 & 121 \\
\hline & P-valor & $<0,0001$ & $<0,0001$ & $<0,0001$ & $<0,0001$ & $<0,0001$ \\
\hline \multirow{3}{*}{ Hosmer e Lemeshow } & $\begin{array}{l}\text { Qui-Quadrado } \\
\end{array}$ & 24,5891 & 34,4364 & 62,2356 & 136,1408 & 166,8878 \\
\hline & Graus de Liberdade & 8 & 8 & 8 & 8 & 8 \\
\hline & P-valor & 0,0018 & $<0,0001$ & $<0,0001$ & $<0,0001$ & $<0,0001$ \\
\hline \multirow{3}{*}{ Deviance } & Valor & $100.099,4950$ & $97.320,2795$ & $99.596,9423$ & $80.274,4256$ & $68.990,6598$ \\
\hline & Graus de Liberdade & 200.000 & 180.000 & 200.000 & 120.000 & 89.000 \\
\hline & P-valor & 1,0000 & 1,0000 & 1,0000 & 1,0000 & 1,0000 \\
\hline \multicolumn{2}{|c|}{ Área sob a Curva ROC (AROC) } & 0,805 & 0,807 & 0,820 & 0,801 & 0,788 \\
\hline
\end{tabular}

Tabela 4.24: Quadro comparativo contendo as métricas de ajuste dos modelos para os diferentes conjuntos de regras.

\section{Área sob a Curva ROC (AROC)}

Além das medidas de ajuste do modelo, a Tabela 4.24 traz a área sob a curva ROC (AROC) de cada um dos cinco conjuntos de regras. A AROC não é propriamente uma medida de ajuste do modelo, mas sim uma métrica para aferir a capacidade de predição dos modelos, ou seja, deles conseguirem classificar (ou discriminar) as instâncias entre as classes \{fraude e legítima\} corretamente. A Tabela 4.25, discutida na Fundamentação Teórica, fornece um mapa para, através do valor da AROC, definir o poder de classificação de um modelo.

\begin{tabular}{|l|l|}
\hline Valor AROC & Poder de Classificação \\
\hline \hline AROC $=0,5$ & Não há \\
$0,7 \leq$ AROC $<0,8$ & Aceitável \\
$0,8 \leq$ AROC $<0,9$ & Muito bom \\
AROC $\geq 0,9$ & Excelente \\
\hline
\end{tabular}

Tabela 4.25: Poder de classificação de um modelo dado pela AROC.

Ao se comparar a AROC dos modelos expostos na Tabela 4.24 com a Tabela 4.25, é possível concluir que quatro (Suporte_050, MedidaF_050, Confiança_050, Confiança_040) dos cinco modelos apresentam um poder de classificação Muito bom, enquanto que apenas um modelo (Confiança_030) apresenta poder de classificação Aceitável. Dessa métrica, é possível discutir, também, como os modelos se comportaram diante da Maldição da Dimensionalidade. Como discutido na seção Fundamentação Teórica, esse fenômeno faz com que modelos com muitas variáveis se ajustem perfeitamente aos dados de treinamento e não apresentem bons resultados em dados desconhecidos pelo classificador. Segundo (HL00), 
modelos cujos valores da área sob a curva ROC sejam maiores ou iguais a 0,90 mostram uma maior tendência a sofrerem desse fenômeno. Enfim, como a AROC dos modelos não está nessa faixa de valor, há um indicativo de que, apesar deles possuírem uma quantidade considerável de variáveis, eles não sofreram da Maldição da Dimensionalidade. Entretanto, esse tópico será observado e discutido em mais detalhes adiante durante a validação dos modelos, pois nessa etapa, os classificadores serão submetidos a dados não utilizados durante a fase de treinamento.

A Tabela 4.26, por sua vez, contém todas as combinações possíveis e a quantidade de regras que cada combinação possui. Ela é um espelho da Tabela $4.12 \mathrm{com}$ a diferença que a última mostra a quantidade de regras que cada combinação continha antes da modelagem de regressão logística e a Tabela 4.26 mostra o mesmo conceito, porém após a regressão logística. Assim, é possível observar que, ao final do processo, as combinações nas quais os conjuntos ordenados pela métrica confiança estavam presentes ganharam representatividade na quantidade de regras únicas ao final do processo. Por exemplo, antes da regressão logística, as regras existentes unicamente no conjunto Confiança_050 representavam 20\% das regras únicas, mas, ao final do processo, as regras que permaneceram nesse conjunto passaram a representar $28 \%$ das regras únicas.

\begin{tabular}{|c|c|c|}
\hline Conjuntos de Regras & Regras (\#) & Representatividade \\
\hline "CONFIANÇA_050 & 156 & $28 \%$ \\
\hline SUPORTE_050 & 59 & $10 \%$ \\
\hline MEDIDAF_050 & 53 & $9 \%$ \\
\hline CONFIANÇA_030 & 94 & $17 \%$ \\
\hline CONFIANÇA_040 & 92 & $16 \%$ \\
\hline CONFIANÇA_050, SUPORTE_050 & 0 & $0 \%$ \\
\hline CONFIANÇA_050, MEDIDAF_050 & 20 & $4 \%$ \\
\hline CONFIANÇA_050, CONFIANÇA_030 & 7 & $1 \%$ \\
\hline CONFIANÇA_050, CONFIANÇA_040 & 35 & $6 \%$ \\
\hline SUPORTE_050, MEDIDAF_050 & 19 & $3 \%$ \\
\hline SUPORTE_050, CONFIANÇA_030 & 4 & $1 \%$ \\
\hline SUPORTE_050, CONFIANÇA_040 & 2 & $0 \%$ \\
\hline MEDIDAF_050, CONFIANÇA_030 & 2 & $0 \%$ \\
\hline MEDIDAF_050, CONFIANÇA_040 & 6 & $1 \%$ \\
\hline CONFIANÇA_030, CONFIANÇA_040 & 4 & $1 \%$ \\
\hline CONFIANÇA_050, SUPORTE_050, MEDIDAF_050 & 0 & $0 \%$ \\
\hline CONFIANÇA_050, SUPORTE_050, CONFIANÇA_030 & 0 & $0 \%$ \\
\hline CONFIANÇA_050, SUPORTE_050, CONFIANÇA_040 & 0 & $0 \%$ \\
\hline CONFIANÇA_050, MEDIDAF_050, CONFIANÇA_030 & 0 & $0 \%$ \\
\hline CONFIANÇA_050, MEDIDAF_050, CONFIANÇA_040 & 2 & $0 \%$ \\
\hline CONFIANÇA_050, CONFIANÇA_030, CONFIANÇA_040 & 4 & $1 \%$ \\
\hline SUPORTE_050, MEDIDAF_050, CONFIANÇA_030 & 4 & $1 \%$ \\
\hline SUPORTE_050, MEDIDAF_050, CONFIANÇA_040 & 0 & $0 \%$ \\
\hline MEDIDAF_050, CONFIANÇA_030, CONFIANÇA_040 & 0 & $0 \%$ \\
\hline CONFIANÇA_050, SUPORTE_050, MEDIDAF_050, CONFIANÇA_030 & 0 & $0 \%$ \\
\hline CONFIANÇA_050, SUPORTE_050, MEDIDAF_050, CONFIANÇA_040 & 0 & $0 \%$ \\
\hline CONFIANÇA_050, MEDIDAF_050, CONFIANÇA_030, CONFIANÇA_040 & 1 & $0 \%$ \\
\hline CONFIANÇA_050, SUPORTE_050, CONFIANÇA_030, CONFIANÇA_040 & 0 & $0 \%$ \\
\hline SUPORTE_050, MEDIDAF_050, CONFIANÇA_030, CONFIANÇA_040 & 0 & $0 \%$ \\
\hline SUPORTE_050, MEDIDAF_050, CONFIANÇA_050, CONFIANÇA_040, CONFIANÇA_030 & 1 & $0 \%$ \\
\hline $\begin{array}{l}\text { Total } \\
\end{array}$ & 565 & $100 \%$ \\
\hline
\end{tabular}

Tabela 4.26: Tabela com a quantidade de regras pertencentes a cada combinação de conjuntos na saída da regressão logística. 


\section{Definição dos Limiares de Classificação}

Após o treinamento e ajuste dos modelos de regressão logística e antes de se fazer a validação deles, é necessário determinar qual será o nível de probabilidade acima do qual as transações serão consideradas fraudulentas. Esse nível, conhecido, entre outros nomes, como limiar de fraude, score de fraude ou threshold de fraude é utilizado pelo classificador para definir se a transação será classificada como fraudulenta ou legítima. A Figura 4.4 ilustra o momento no qual o limiar de fraude é usado no processo de classificação.

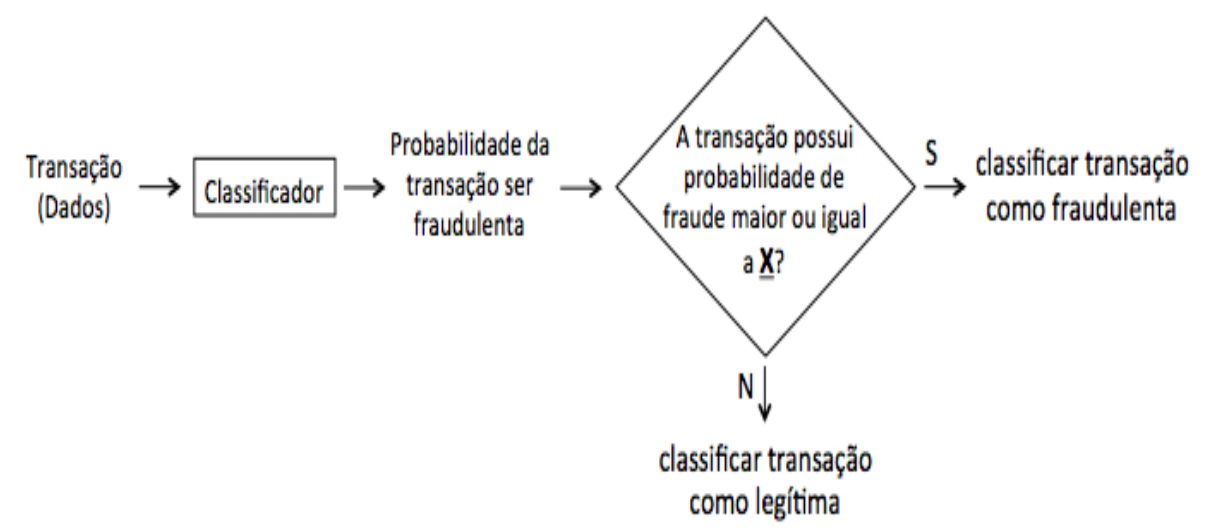

Figura 4.4: Um esquema visual para facilitar a compreensão do uso do score de fraude.

A abordagem usada nesse trabalho para a definição de cada um dos limiares de fraudes de cada um dos conjuntos de regras foi a comparação das métricas cobertura/sensibilidade e especificidade discutidas na seção Fundamentação Teórica. Nos modelos de classificação, a cobertura/sensibilidade é uma métrica para mensurar a capacidade do classificador detectar corretamente as amostras positivas (fraudes) e é dada pela razão entre as transações corretamente classificadas como fraudulentas e todas as transações fraudulentas. Já a especificidade é a métrica análoga para as amostras negativas (legítimas) e é dada pela razão entre as transações corretamente classificadas como legítimas e todas as transações realmente legítimas.

A comparação entre as duas métricas citadas foi feita de forma gráfica e busca o resultado ótimo entre a cobertura das transações fraudulentas e a classificação correta das transações legítimas. Para que a comparação fosse feita, utilizou-se as tabelas de classificação produzidas como saída do SAS Enterprise Guide 5.1. A partir dos números expostos nelas, foram construídos diversos gráficos (um para cada conjunto de regras) cujas séries de dados eram a sensibilidade e a especificidade resultantes do treinamento da regressão logística de cada conjunto de regras. Como essas duas métricas, em geral, são inversamente proporcionais, o ponto no qual as séries de dados se cruzam é tido como o ponto ótimo e ele foi escolhido para ser o limiar de fraude. Para todos os cinco conjuntos de regras, essa análise indicou o nível de probabilidade igual à 0,05 como o limiar de fraude. Assim, as Tabelas de 4.27 à 4.31 mostram as tabelas de classificação de cada conjunto de regras e as Figuras 4.5 à 4.9 os seus respectivos gráficos sensibilidade $x$ especificidade. 


\begin{tabular}{|c|c|c|c|c|c|c|c|c|c|}
\hline \multirow{3}{*}{$\begin{array}{c}\text { Nivel de } \\
\text { Probabilidade }\end{array}$} & \multicolumn{8}{|c|}{ Tabela de Classificação } & \multirow[b]{3}{*}{ Falso Negativo } \\
\hline & \multirow{2}{*}{\multicolumn{2}{|c|}{\begin{tabular}{|c||} 
Corretas \\
Fraudes Legítimas
\end{tabular}}} & \multicolumn{2}{|c|}{ Incorretas } & \multicolumn{4}{|c|}{ Percentagens } & \\
\hline & & & Fraudes & Legítimas & Corretas & Sensibilidade & Especificidade & Falso Positivo & \\
\hline$\overline{0,00}$ & 18.092 & - & 308.000 & - & 5,60 & 100,00 & - & 94,40 & - \\
\hline 0,02 & 16.595 & 120.000 & 187.000 & 1.497 & 42,00 & 91,70 & 39,10 & 91,90 & 1,20 \\
\hline 0,04 & 14.144 & 203.000 & 105.000 & 3.948 & 66,60 & 78,20 & 65,90 & 88,10 & 1,90 \\
\hline 0,06 & 12.244 & 241.000 & 66.838 & 5.848 & 77,70 & 67,70 & 78,30 & 84,50 & 2,40 \\
\hline 0,08 & 10.765 & 262.000 & 45.966 & 7.327 & 83,60 & 59,50 & 85,10 & 81,00 & 2,70 \\
\hline 0,10 & 9.545 & 274.000 & 33.471 & 8.547 & 87,10 & 52,80 & 89,10 & 77,80 & 3,00 \\
\hline 0,12 & 8.510 & 282.000 & 25.443 & 9.582 & 89,30 & 47,00 & 91,70 & 74,90 & 3,30 \\
\hline 0,14 & 7.706 & 288.000 & 19.821 & 10.386 & 90,70 & 42,60 & 93,60 & 72,00 & 3,50 \\
\hline 0,16 & 7.002 & 292.000 & 15.613 & 11.090 & 91,80 & 38,70 & 94,90 & 69,00 & 3,70 \\
\hline 0,18 & 6.331 & 295.000 & 12.650 & 11.761 & 92,50 & 35,00 & 95,90 & 66,60 & 3,80 \\
\hline 0,20 & 5.746 & 297.000 & 10.362 & 12.346 & 93,00 & 31,80 & 96,60 & 64,30 & 4,00 \\
\hline 0,22 & 5.272 & 299.000 & 8.565 & 12.820 & 93,40 & 29,10 & 97,20 & 61,90 & 4,10 \\
\hline 0,24 & 4.849 & 301.000 & 7.204 & 13.243 & 93,70 & 26,80 & 97,70 & 59,80 & 4,20 \\
\hline 0,26 & 4.453 & 302.000 & 6.040 & 13.639 & 94,00 & 24,60 & 98,00 & 57,60 & 4,30 \\
\hline 0,28 & 4.113 & 303.000 & 5.085 & 13.979 & 94,10 & 22,70 & 98,30 & 55,30 & 4,40 \\
\hline 0,30 & 3.808 & 303.000 & 4.357 & 14.284 & 94,30 & 21,00 & 98,60 & 53,40 & 4,50 \\
\hline 0,32 & 3.480 & 304.000 & 3.737 & 14.612 & 94,40 & 19,20 & 98,80 & 51,80 & 4,60 \\
\hline 0,34 & 3.161 & 305.000 & 3.218 & 14.931 & 94,40 & 17,50 & 99,00 & 50,40 & 4,70 \\
\hline 0,36 & 2.938 & 305.000 & 2.772 & 15.154 & 94,50 & 16,20 & 99,10 & 48,50 & 4,70 \\
\hline 0,38 & 2.710 & 305.000 & 2.392 & 15.382 & 94,50 & 15,00 & 99,20 & 46,90 & 4,80 \\
\hline 0,40 & 2.513 & 306.000 & 2.053 & 15.579 & 94,60 & 13,90 & 99,30 & 45,00 & 4,80 \\
\hline 0,42 & 2.303 & 306.000 & 1.785 & 15.789 & 94,60 & 12,70 & 99,40 & 43,70 & 4,90 \\
\hline 0,44 & 2.151 & 306.000 & 1.548 & 15.941 & 94,60 & 11,90 & 99,50 & 41,80 & 4,90 \\
\hline 0,46 & 1.957 & 306.000 & 1.337 & 16.135 & 94,60 & 10,80 & 99,60 & 40,60 & 5,00 \\
\hline 0,48 & 1.784 & 307.000 & 1.161 & 16.308 & 94,60 & 9,90 & 99,60 & 39,40 & 5,10 \\
\hline 0,50 & 1.645 & 307.000 & 1.009 & 16.447 & 94,60 & 9,10 & 99,70 & 38,00 & 5,10 \\
\hline 0,52 & 1.497 & 307.000 & 856 & 16.595 & 94,60 & 8,30 & 99,70 & 36,40 & 5,10 \\
\hline 0,54 & 1.369 & 307.000 & 741 & 16.723 & 94,60 & 7,60 & 99,80 & 35,10 & 5,20 \\
\hline 0,56 & 1.239 & 307.000 & 652 & 16.853 & 94,60 & 6,80 & 99,80 & 34,50 & 5,20 \\
\hline 0,58 & 1.121 & 307.000 & 552 & 16.971 & 94,60 & 6,20 & 99,80 & 33,00 & 5,20 \\
\hline 0,60 & 1.011 & 307.000 & 470 & 17.081 & 94,60 & 5,60 & 99,80 & 31,70 & 5,30 \\
\hline 0,62 & 900 & 307.000 & 406 & 17.192 & 94,60 & 5,00 & 99,90 & 31,10 & 5,30 \\
\hline 0,64 & 807 & 307.000 & 342 & 17.285 & 94,60 & 4,50 & 99,90 & 29,80 & 5,30 \\
\hline 0,66 & 725 & 307.000 & 275 & 17.367 & 94,60 & 4,00 & 99,90 & 27,50 & 5,30 \\
\hline 0,68 & 648 & 308.000 & 231 & 17.444 & 94,60 & 3,60 & 99,90 & 26,30 & 5,40 \\
\hline 0,70 & 570 & 308.000 & 193 & 17.522 & 94,60 & 3,20 & 99,90 & 25,30 & 5,40 \\
\hline 0,72 & 503 & 308.000 & 160 & 17.589 & 94,60 & 2,80 & 99,90 & 24,10 & 5,40 \\
\hline 0,74 & 448 & 308.000 & 127 & 17.644 & 94,50 & 2,50 & 100,00 & 22,10 & 5,40 \\
\hline 0,76 & 392 & 308.000 & 98 & 17.700 & 94,50 & 2,20 & 100,00 & 20,00 & 5,40 \\
\hline 0,78 & 332 & 308.000 & 79 & 17.760 & 94,50 & 1,80 & 100,00 & 19,20 & 5,50 \\
\hline 0,80 & 292 & 308.000 & 71 & 17.800 & 94,50 & 1,60 & 100,00 & 19,60 & 5,50 \\
\hline 0,82 & 244 & 308.000 & 59 & 17.848 & 94,50 & 1,30 & 100,00 & 19,50 & 5,50 \\
\hline 0,84 & 207 & 308.000 & 46 & 17.885 & 94,50 & 1,10 & 100,00 & 18,20 & 5,50 \\
\hline 0,86 & 170 & 308.000 & 36 & 17.922 & 94,50 & 0,90 & 100,00 & 17,50 & 5,50 \\
\hline 0,88 & 135 & 308.000 & 25 & 17.957 & 94,50 & 0,70 & 100,00 & 15,60 & 5,50 \\
\hline 0,90 & 102 & 308.000 & 17 & 17.990 & 94,50 & 0,60 & 100,00 & 14,30 & 5,50 \\
\hline 0,92 & 77 & 308.000 & 13 & 18.015 & 94,50 & 0,40 & 100,00 & 14,40 & 5,50 \\
\hline 0,94 & 46 & 308.000 & 6 & 18.046 & 94,50 & 0,30 & 100,00 & 11,50 & 5,50 \\
\hline 0,96 & 22 & 308.000 & 2 & 18.070 & 94,50 & 0,10 & 100,00 & 8,30 & 5,50 \\
\hline 0,98 & 5 & 308.000 & 1 & 18.087 & 94,40 & - & 100,00 & 16,70 & 5,60 \\
\hline 1,00 & - & 308.000 & - & 18.092 & 94,40 & - & 100,00 & - & 5,60 \\
\hline
\end{tabular}

Tabela 4.27: Tabela de classificação da regressão logística do conjunto Suporte_050.

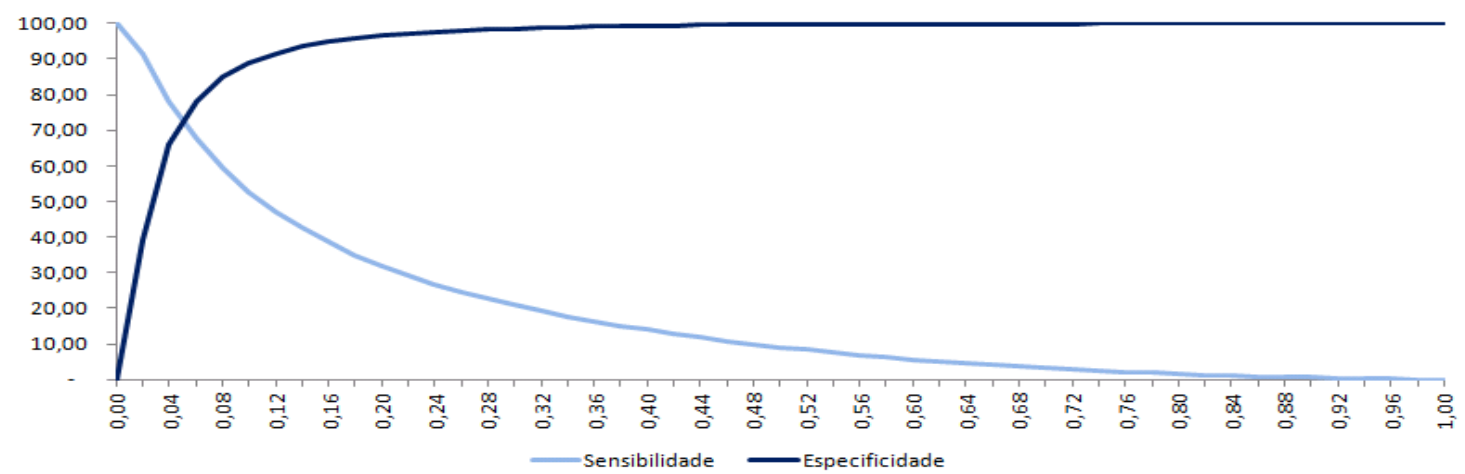

Figura 4.5: Gráfico sensibilidade $x$ especificidade do conjunto Suporte_050. 


\begin{tabular}{|c|c|c|c|c|c|c|c|c|c|}
\hline & & & & Tabe & ela de Cla & assificação & & & \\
\hline Nível de & Cor & rretas & Inco & rretas & & & Percentage & ens & \\
\hline Probabilidade & Fraudes & Legítimas & Fraudes & Legítimas & Corretas & Sensibilidade & Especificidade & Falso Positivo & Falso Negativo \\
\hline$\overline{0,00}$ & 18.092 & - & 308.000 & - & 25,60 & 100,00 & - & 94,40 & - \\
\hline 0,02 & 16.638 & 120.000 & 187.000 & 1.454 & 42,10 & 92,00 & 39,20 & 91,80 & 1,20 \\
\hline 0,04 & 14.214 & 203.000 & 105.000 & 3.878 & 66,70 & 78,60 & 66,00 & 88,00 & 1,90 \\
\hline$\overline{0,06}$ & 12.157 & 241.000 & 66.686 & 5.935 & 77,70 & 67,20 & 78,30 & 84,60 & 2,40 \\
\hline 0,08 & 10.594 & 262.000 & 45.774 & 7.498 & 83,70 & 58,60 & 85,10 & 81,20 & 2,80 \\
\hline 0,10 & 9.325 & 275.000 & 33.115 & 8.767 & 87,10 & 51,50 & 89,20 & 78,00 & 3,10 \\
\hline 0,12 & 8.353 & 283.000 & 24.964 & 9.739 & 89,30 & 46,20 & 91,90 & 74,90 & 3,30 \\
\hline 0,14 & 7.476 & 288.000 & 19.370 & 10.616 & 90,80 & 41,30 & 93,70 & 72,20 & 3,60 \\
\hline 0,16 & 6.783 & 292.000 & 15.385 & 11.309 & 91,80 & 37,50 & 95,00 & 69,40 & 3,70 \\
\hline$\overline{0,18}$ & 6.167 & 295.000 & 12.421 & 11.925 & 92,50 & 34,10 & 96,00 & 66,80 & 3,90 \\
\hline 0,20 & 5.665 & 298.000 & 10.153 & 12.427 & 93,10 & 31,30 & 96,70 & 64,20 & 4,00 \\
\hline 0,22 & 5.165 & 299.000 & 8.420 & 12.927 & 93,40 & 28,50 & 97,30 & 62,00 & 4,10 \\
\hline 0,24 & 4.781 & 301.000 & 7.092 & 13.311 & 93,70 & 26,40 & 97,70 & 59,70 & 4,20 \\
\hline 0,26 & 4.384 & 302.000 & 6.027 & 13.708 & 93,90 & 24,20 & 98,00 & 57,90 & 4,30 \\
\hline 0,28 & 4.067 & 303.000 & 5.109 & 14.025 & 94,10 & 22,50 & 98,30 & 55,70 & 4,40 \\
\hline 0,30 & 3.729 & 303.000 & 4.346 & 14.363 & 94,30 & 20,60 & 98,60 & 53,80 & 4,50 \\
\hline 0,32 & 3.471 & 304.000 & 3.745 & 14.621 & 94,40 & 19,20 & 98,80 & 51,90 & 4,60 \\
\hline 0,34 & 3.205 & 305.000 & 3.214 & 14.887 & 94,40 & 17,70 & 99,00 & 50,10 & 4,70 \\
\hline 0,36 & 2.967 & 305.000 & 2.759 & 15.125 & 94,50 & 16,40 & 99,10 & 48,20 & 4,70 \\
\hline 0,38 & 2.711 & 305.000 & 2.410 & 15.381 & 94,50 & 15,00 & 99,20 & 47,10 & 4,80 \\
\hline 0,40 & 2.517 & 306.000 & 2.091 & 15.575 & 94,60 & 13,90 & 99,30 & 45,40 & 4,80 \\
\hline 0,42 & 2.312 & 306.000 & 1.831 & 15.780 & 94,60 & 12,80 & 99,40 & 44,20 & 4,90 \\
\hline 0,44 & 2.142 & 306.000 & 1.584 & 15.950 & 94,60 & 11,80 & 99,50 & 42,50 & 5,00 \\
\hline$\overline{0,46}$ & 1.987 & 306.000 & 1.389 & 16.105 & 94,60 & 11,00 & 99,50 & 41,10 & 5,00 \\
\hline 0,48 & 1.831 & 307.000 & 1.214 & 16.261 & 94,60 & 10,10 & 99,60 & 39,90 & 5,00 \\
\hline 0,50 & 1.691 & 307.000 & 1.057 & 16.401 & 94,60 & 9,30 & 99,70 & 38,50 & 5,10 \\
\hline 0,52 & 1.571 & 307.000 & 910 & 16.521 & 94,70 & 8,70 & 99,70 & 36,70 & 5,10 \\
\hline 0,54 & 1.449 & 307.000 & 789 & 16.643 & 94,60 & 8,00 & 99,70 & 35,30 & 5,10 \\
\hline 0,56 & 1.342 & 307.000 & 690 & 16.750 & 94,60 & 7,40 & 99,80 & 34,00 & 5,20 \\
\hline 0,58 & 1.255 & 307.000 & 593 & 16.837 & 94,70 & 6,90 & 99,80 & 32,10 & 5,20 \\
\hline 0,60 & 1.152 & 307.000 & 518 & 16.940 & 94,60 & 6,40 & 99,80 & 31,00 & 5,20 \\
\hline 0,62 & 1.049 & 307.000 & 448 & 17.043 & 94,60 & 5,80 & 99,90 & 29,90 & 5,30 \\
\hline 0,64 & 951 & 307.000 & 389 & 17.141 & 94,60 & 5,30 & 99,90 & 29,00 & 5,30 \\
\hline 0,66 & 861 & 307.000 & 339 & 17.231 & 94,60 & 4,80 & 99,90 & 28,30 & 5,30 \\
\hline 0,68 & 762 & 307.000 & 282 & 17.330 & 94,60 & 4,20 & 99,90 & 27,00 & 5,30 \\
\hline 0,70 & 653 & 308.000 & 237 & 17.439 & 94,60 & 3,60 & 99,90 & 26,60 & 5,40 \\
\hline 0,72 & 580 & 308.000 & 195 & 17.512 & 94,60 & 3,20 & 99,90 & 25,20 & 5,40 \\
\hline 0,74 & 503 & 308.000 & 162 & 17.589 & 94,60 & 2,80 & 99,90 & 24,40 & 5,40 \\
\hline 0,76 & 450 & 308.000 & 131 & 17.642 & 94,50 & 2,50 & 100,00 & 22,50 & 5,40 \\
\hline 0,78 & 391 & 308.000 & 99 & 17.701 & 94,50 & 2,20 & 100,00 & 20,20 & 5,40 \\
\hline 0,80 & 324 & 308.000 & 67 & 17.768 & 94,50 & 1,80 & 100,00 & 17,10 & 5,50 \\
\hline 0,82 & 274 & 308.000 & 53 & 17.818 & 94,50 & 1,50 & 100,00 & 16,20 & 5,50 \\
\hline 0,84 & 219 & 308.000 & 40 & 17.873 & 94,50 & 1,20 & 100,00 & 15,40 & 5,50 \\
\hline 0,86 & 168 & 308.000 & 27 & 17.924 & 94,50 & 0,90 & 100,00 & 13,80 & 5,50 \\
\hline 0,88 & 119 & 308.000 & 17 & 17.973 & 94,50 & 0,70 & 100,00 & 12,50 & 5,50 \\
\hline 0,90 & 88 & 308.000 & 13 & 18.004 & 94,50 & 0,50 & 100,00 & 12,90 & 5,50 \\
\hline 0,92 & 59 & 308.000 & 9 & 18.033 & 94,50 & 0,30 & 100,00 & 13,20 & 5,50 \\
\hline 0,94 & 36 & 308.000 & 8 & 18.056 & 94,50 & 0,20 & 100,00 & 18,20 & 5,50 \\
\hline 0,96 & 15 & 308.000 & 3 & 18.077 & 94,50 & 0,10 & 100,00 & 16,70 & 5,50 \\
\hline 0,98 & 2 & 308.000 & - & 18.090 & 94,40 & - & 100,00 & - & 5,60 \\
\hline 1,00 & - & 308.000 & - & 18.092 & 94,40 & - & 100,00 & - & 5,60 \\
\hline
\end{tabular}

Tabela 4.28: Tabela de classificação da regressão logística do conjunto MedidaF_050.

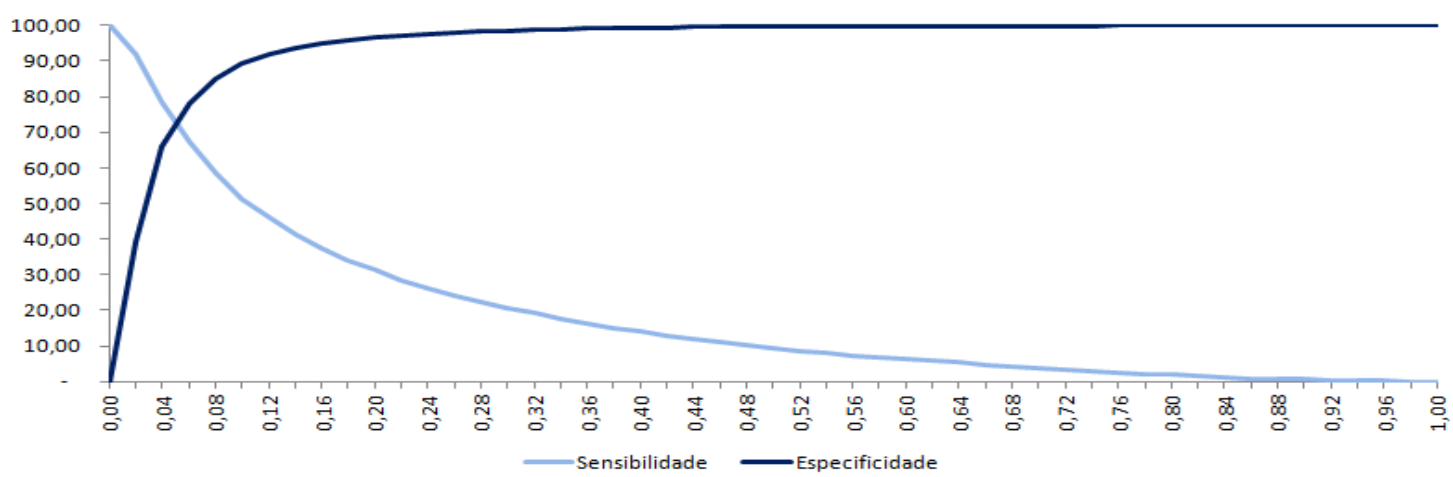

Figura 4.6: Gráfico sensibilidade $x$ especificidade do conjunto MedidaF_050. 


\begin{tabular}{|c|c|c|c|c|c|c|c|c|c|}
\hline \multirow{3}{*}{$\begin{array}{c}\text { Nivel de } \\
\text { Probabilidade }\end{array}$} & \multicolumn{8}{|c|}{ Tabela de Classificação } & \multirow[b]{3}{*}{ Falso Negativo } \\
\hline & \multirow{2}{*}{\multicolumn{2}{|c|}{\begin{tabular}{|c||} 
Corretas \\
Fraudes Legítimas
\end{tabular}}} & \multicolumn{2}{|c|}{ Incorretas } & \multicolumn{4}{|c|}{ Percentagens } & \\
\hline & & & Fraudes & Legítimas & Corretas & Sensibilidade & Especificidade & Falso Positivo & \\
\hline$\overline{0,00}$ & 18.092 & - & 308.000 & - & 5,60 & 100,00 & - & 94,40 & - \\
\hline 0,02 & 16.654 & 127.000 & 181.000 & 1.438 & 44,10 & 92,10 & 41,30 & 91,60 & 1,10 \\
\hline 0,04 & 14.127 & 212.000 & 96.002 & 3.965 & 69,30 & 78,10 & 68,80 & 87,20 & 1,80 \\
\hline 0,06 & 12.216 & 248.000 & 60.175 & 5.876 & 79,70 & 67,50 & 80,40 & 83,10 & 2,30 \\
\hline 0,08 & 10.774 & 266.000 & 41.644 & 7.318 & 85,00 & 59,60 & 86,50 & 79,40 & 2,70 \\
\hline 0,10 & 9.668 & 277.000 & 30.761 & 8.424 & 88,00 & 53,40 & 90,00 & 76,10 & 3,00 \\
\hline 0,12 & 8.704 & 284.000 & 23.542 & 9.388 & 89,90 & 48,10 & 92,40 & 73,00 & 3,20 \\
\hline 0,14 & 7.906 & 289.000 & 18.644 & 10.186 & 91,20 & 43,70 & 93,90 & 70,20 & 3,40 \\
\hline 0,16 & 7.271 & 293.000 & 15.106 & 10.821 & 92,00 & 40,20 & 95,10 & 67,50 & 3,60 \\
\hline 0,18 & 6.712 & 295.000 & 12.356 & 11.380 & 92,70 & 37,10 & 96,00 & 64,80 & 3,70 \\
\hline 0,20 & 6.197 & 297.000 & 10.269 & 11.895 & 93,20 & 34,30 & 96,70 & 62,40 & 3,80 \\
\hline 0,22 & 5.758 & 299.000 & 8.650 & 12.334 & 93,60 & 31,80 & 97,20 & 60,00 & 4,00 \\
\hline 0,24 & 5.388 & 300.000 & 7.369 & 12.704 & 93,80 & 29,80 & 97,60 & 57,80 & 4,10 \\
\hline 0,26 & 5.014 & 301.000 & 6.322 & 13.078 & 94,00 & 27,70 & 97,90 & 55,80 & 4,20 \\
\hline 0,28 & 4.691 & 302.000 & 5.489 & 13.401 & 94,20 & 25,90 & 98,20 & 53,90 & 4,20 \\
\hline 0,30 & 4.403 & 303.000 & 4.763 & 13.689 & 94,30 & 24,30 & 98,50 & 52,00 & 4,30 \\
\hline 0,32 & 4.123 & 304.000 & 4.153 & 13.969 & 94,40 & 22,80 & 98,70 & 50,20 & 4,40 \\
\hline 0,34 & 3.862 & 304.000 & 3.628 & 14.230 & 94,50 & 21,30 & 98,80 & 48,40 & 4,50 \\
\hline 0,36 & 3.645 & 305.000 & 3.172 & 14.447 & 94,60 & 20,10 & 99,00 & 46,50 & 4,50 \\
\hline 0,38 & 3.418 & 305.000 & 2.786 & 14.674 & 94,60 & 18,90 & 99,10 & 44,90 & 4,60 \\
\hline 0,40 & 3.217 & 305.000 & 2.464 & 14.875 & 94,70 & 17,80 & 99,20 & 43,40 & 4,60 \\
\hline 0,42 & 3.023 & 306.000 & 2.184 & 15.069 & 94,70 & 16,70 & 99,30 & 41,90 & 4,70 \\
\hline 0,44 & 2.842 & 306.000 & 1.920 & 15.250 & 94,70 & 15,70 & 99,40 & 40,30 & 4,70 \\
\hline 0,46 & 2.665 & 306.000 & 1.718 & 15.427 & 94,70 & 14,70 & 99,40 & 39,20 & 4,80 \\
\hline 0,48 & 2.490 & 306.000 & 1.511 & 15.602 & 94,70 & 13,80 & 99,50 & 37,80 & 4,80 \\
\hline 0,50 & 2.348 & 306.000 & 1.330 & 15.744 & 94,80 & 13,00 & 99,60 & 36,20 & 4,90 \\
\hline 0,52 & 2.187 & 307.000 & 1.171 & 15.905 & 94,80 & 12,10 & 99,60 & 34,90 & 4,90 \\
\hline 0,54 & 2.038 & 307.000 & 1.042 & 16.054 & 94,80 & 11,30 & 99,70 & 33,80 & 5,00 \\
\hline 0,56 & 1.884 & 307.000 & 911 & 16.208 & 94,70 & 10,40 & 99,70 & 32,60 & 5,00 \\
\hline 0,58 & 1.765 & 307.000 & 814 & 16.327 & 94,70 & 9,80 & 99,70 & 31,60 & 5,10 \\
\hline 0,60 & 1.647 & 307.000 & 714 & 16.445 & 94,70 & 9,10 & 99,80 & 30,20 & 5,10 \\
\hline 0,62 & 1.522 & 307.000 & 635 & 16.570 & 94,70 & 8,40 & 99,80 & 29,40 & 5,10 \\
\hline 0,64 & 1.401 & 307.000 & 557 & 16.691 & 94,70 & 7,70 & 99,80 & 28,40 & 5,20 \\
\hline 0,66 & 1.295 & 307.000 & 495 & 16.797 & 94,70 & 7,20 & 99,80 & 27,70 & 5,20 \\
\hline 0,68 & 1.204 & 307.000 & 433 & 16.888 & 94,70 & 6,70 & 99,90 & 26,50 & 5,20 \\
\hline 0,70 & 1.099 & 307.000 & 368 & 16.993 & 94,70 & 6,10 & 99,90 & 25,10 & 5,20 \\
\hline 0,72 & 1.000 & 307.000 & 304 & 17.092 & 94,70 & 5,50 & 99,90 & 23,30 & 5,30 \\
\hline 0,74 & 907 & 307.000 & 261 & 17.185 & 94,60 & 5,00 & 99,90 & 22,30 & 5,30 \\
\hline 0,76 & 822 & 308.000 & 228 & 17.270 & 94,60 & 4,50 & 99,90 & 21,70 & 5,30 \\
\hline 0,78 & 728 & 308.000 & 198 & 17.364 & 94,60 & 4,00 & 99,90 & 21,40 & 5,30 \\
\hline 0,80 & 652 & 308.000 & 158 & 17.440 & 94,60 & 3,60 & 99,90 & 19,50 & 5,40 \\
\hline 0,82 & 580 & 308.000 & 128 & 17.512 & 94,60 & 3,20 & 100,00 & 18,10 & 5,40 \\
\hline 0,84 & 503 & 308.000 & 111 & 17.589 & 94,60 & 2,80 & 100,00 & 18,10 & 5,40 \\
\hline 0,86 & 426 & 308.000 & 82 & 17.666 & 94,60 & 2,40 & 100,00 & 16,10 & 5,40 \\
\hline 0,88 & 358 & 308.000 & 63 & 17.734 & 94,50 & 2,00 & 100,00 & 15,00 & 5,40 \\
\hline 0,90 & 275 & 308.000 & 47 & 17.817 & 94,50 & 1,50 & 100,00 & 14,60 & 5,50 \\
\hline 0,92 & 223 & 308.000 & 29 & 17.869 & 94,50 & 1,20 & 100,00 & 11,50 & 5,50 \\
\hline 0,94 & 160 & 308.000 & 16 & 17.932 & 94,50 & 0,90 & 100,00 & 9,10 & 5,50 \\
\hline 0,96 & 93 & 308.000 & 2 & 17.999 & 94,50 & 0,50 & 100,00 & 2,10 & 5,50 \\
\hline 0,98 & 32 & 308.000 & 1 & 18.060 & 94,50 & 0,20 & 100,00 & 3,00 & 5,50 \\
\hline 1,00 & - & 308.000 & - & 18.092 & 94,40 & - & 100,00 & - & 5,60 \\
\hline
\end{tabular}

Tabela 4.29: Tabela de classificação da regressão logística do conjunto Confianca_050.

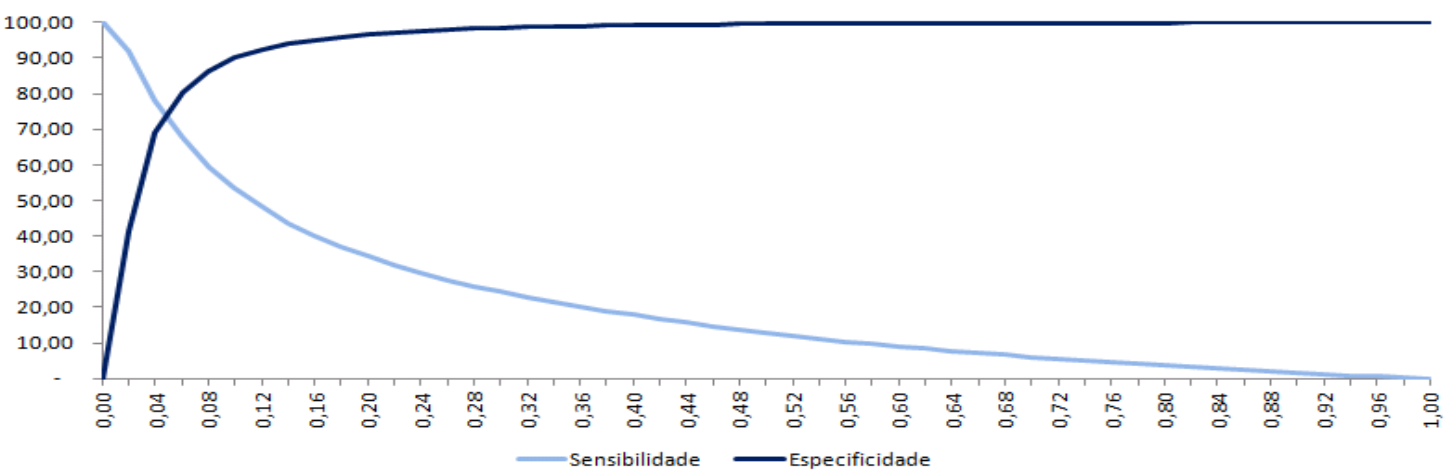

Figura 4.7: Gráfico sensibilidade x especificidade do conjunto Confianca_050. 


\begin{tabular}{|c|c|c|c|c|c|c|c|c|c|}
\hline & & & & Tabe & ela de Cla & assificação & & & \\
\hline Nível de & Cor & rretas & Inco & rretas & & & Percentage & ens & \\
\hline Probabilidade & Fraudes & Legítimas & Fraudes & Legítimas & Corretas & Sensibilidade & Especificidade & Falso Positivo & Falso Negativo \\
\hline$\overline{0,00}$ & 18.092 & - & 308.000 & - & 5,60 & 100,00 & - & 94,40 & - \\
\hline 0,02 & 16.770 & 104.000 & 204.000 & 1.322 & 37,00 & 92,70 & 33,80 & 92,40 & 1,30 \\
\hline 0,04 & 13.875 & 208.000 & 99.611 & 4.217 & 68,10 & 76,70 & 67,60 & 87,80 & 2,00 \\
\hline 0,06 & 11.551 & 249.000 & 58.548 & 6.541 & 80,00 & 63,80 & 81,00 & 83,50 & 2,60 \\
\hline 0,08 & 9.956 & 269.000 & 39.044 & 8.136 & 85,50 & 55,00 & 87,30 & 79,70 & 2,90 \\
\hline 0,10 & 8.846 & 280.000 & 28.174 & 9.246 & 88,50 & 48,90 & 90,80 & 76,10 & 3,20 \\
\hline 0,12 & 7.942 & 286.000 & 21.305 & 10.150 & 90,30 & 43,90 & 93,10 & 72,80 & 3,40 \\
\hline 0,14 & 7.167 & 291.000 & 16.692 & 10.925 & 91,50 & 39,60 & 94,60 & 70,00 & 3,60 \\
\hline 0,16 & 6.540 & 294.000 & 13.440 & 11.552 & 92,30 & 36,10 & 95,60 & 67,30 & 3,80 \\
\hline 0,18 & 5.977 & 297.000 & 11.044 & 12.115 & 92,90 & 33,00 & 96,40 & 64,90 & 3,90 \\
\hline 0,20 & 5.483 & 299.000 & 9.218 & 12.609 & 93,30 & 30,30 & 97,00 & 62,70 & 4,10 \\
\hline 0,22 & 5.100 & 300.000 & 7.801 & 12.992 & 93,60 & 28,20 & 97,50 & 60,50 & 4,20 \\
\hline 0,24 & 4.756 & 301.000 & 6.713 & 13.336 & 93,80 & 26,30 & 97,80 & 58,50 & 4,20 \\
\hline 0,26 & 4.427 & 302.000 & 5.788 & 13.665 & 94,00 & 24,50 & 98,10 & 56,70 & 4,30 \\
\hline 0,28 & 4.136 & 303.000 & 4.996 & 13.956 & 94,20 & 22,90 & 98,40 & 54,70 & 4,40 \\
\hline 0,30 & 3.865 & 303.000 & 4.348 & 14.227 & 94,30 & 21,40 & 98,60 & 52,90 & 4,50 \\
\hline 0,32 & 3.615 & 304.000 & 3.755 & 14.477 & 94,40 & 20,00 & 98,80 & 50,90 & 4,50 \\
\hline 0,34 & 3.359 & 304.000 & 3.307 & 14.733 & 94,50 & 18,60 & 98,90 & 49,60 & 4,60 \\
\hline 0,36 & 3.127 & 305.000 & 2.936 & 14.965 & 94,50 & 17,30 & 99,00 & 48,40 & 4,70 \\
\hline 0,38 & 2.948 & 305.000 & 2.609 & 15.144 & 94,60 & 16,30 & 99,20 & 46,90 & 4,70 \\
\hline 0,40 & 2.790 & 305.000 & 2.304 & 15.302 & 94,60 & 15,40 & 99,30 & 45,20 & 4,80 \\
\hline 0,42 & 2.620 & 306.000 & 2.025 & 15.472 & 94,60 & 14,50 & 99,30 & 43,60 & 4,80 \\
\hline 0,44 & 2.481 & 306.000 & 1.804 & 15.611 & 94,70 & 13,70 & 99,40 & 42,10 & 4,90 \\
\hline 0,46 & 2.352 & 306.000 & 1.620 & 15.740 & 94,70 & 13,00 & 99,50 & 40,80 & 4,90 \\
\hline 0,48 & 2.208 & 306.000 & 1.456 & 15.884 & 94,70 & 12,20 & 99,50 & 39,70 & 4,90 \\
\hline 0,50 & 2.075 & 306.000 & 1.305 & 16.017 & 94,70 & 11,50 & 99,60 & 38,60 & 5,00 \\
\hline 0,52 & 1.949 & 307.000 & 1.162 & 16.143 & 94,70 & 10,80 & 99,60 & 37,40 & 5,00 \\
\hline 0,54 & 1.814 & 307.000 & 1.012 & 16.278 & 94,70 & 10,00 & 99,70 & 35,80 & 5,00 \\
\hline 0,56 & 1.726 & 307.000 & 915 & 16.366 & 94,70 & 9,50 & 99,70 & 34,60 & 5,10 \\
\hline 0,58 & 1.605 & 307.000 & 813 & 16.487 & 94,70 & 8,90 & 99,70 & 33,60 & 5,10 \\
\hline 0,60 & 1.502 & 307.000 & 711 & 16.590 & 94,70 & 8,30 & 99,80 & 32,10 & 5,10 \\
\hline 0,62 & 1.390 & 307.000 & 631 & 16.702 & 94,70 & 7,70 & 99,80 & 31,20 & 5,20 \\
\hline 0,64 & 1.276 & 307.000 & 566 & 16.816 & 94,70 & 7,10 & 99,80 & 30,70 & 5,20 \\
\hline 0,66 & 1.183 & 307.000 & 502 & 16.909 & 94,70 & 6,50 & 99,80 & 29,80 & 5,20 \\
\hline 0,68 & 1.096 & 307.000 & 451 & 16.996 & 94,60 & 6,10 & 99,90 & 29,20 & 5,20 \\
\hline 0,70 & 1.016 & 307.000 & 394 & 17.076 & 94,60 & 5,60 & 99,90 & 27,90 & 5,30 \\
\hline 0,72 & 944 & 307.000 & 336 & 17.148 & 94,60 & 5,20 & 99,90 & 26,30 & 5,30 \\
\hline 0,74 & 874 & 307.000 & 290 & 17.218 & 94,60 & 4,80 & 99,90 & 24,90 & 5,30 \\
\hline 0,76 & 797 & 307.000 & 245 & 17.295 & 94,60 & 4,40 & 99,90 & 23,50 & 5,30 \\
\hline 0,78 & 713 & 308.000 & 200 & 17.379 & 94,60 & 3,90 & 99,90 & 21,90 & 5,30 \\
\hline 0,80 & 630 & 308.000 & 170 & 17.462 & 94,60 & 3,50 & 99,90 & 21,30 & 5,40 \\
\hline 0,82 & 549 & 308.000 & 145 & 17.543 & 94,60 & 3,00 & 100,00 & 20,90 & 5,40 \\
\hline 0,84 & 464 & 308.000 & 109 & 17.628 & 94,60 & 2,60 & 100,00 & 19,00 & 5,40 \\
\hline 0,86 & 394 & 308.000 & 87 & 17.698 & 94,50 & 2,20 & 100,00 & 18,10 & 5,40 \\
\hline 0,88 & 319 & 308.000 & 74 & 17.773 & 94,50 & 1,80 & 100,00 & 18,80 & 5,50 \\
\hline 0,90 & 265 & 308.000 & 49 & 17.827 & 94,50 & 1,50 & 100,00 & 15,60 & 5,50 \\
\hline 0,92 & 182 & 308.000 & 36 & 17.910 & 94,50 & 1,00 & 100,00 & 16,50 & 5,50 \\
\hline 0,94 & 126 & 308.000 & 20 & 17.966 & 94,50 & 0,70 & 100,00 & 13,70 & 5,50 \\
\hline 0,96 & 72 & 308.000 & 3 & 18.020 & 94,50 & 0,40 & 100,00 & 4,00 & 5,50 \\
\hline 0,98 & 30 & 308.000 & 1 & 18.062 & 94,50 & 0,20 & 100,00 & 3,20 & 5,50 \\
\hline 1,00 & - & 308.000 & - & 18.092 & 94,40 & - & 100,00 & - & 5,60 \\
\hline
\end{tabular}

Tabela 4.30: Tabela de classificação da regressão logística do conjunto Confiança_040.

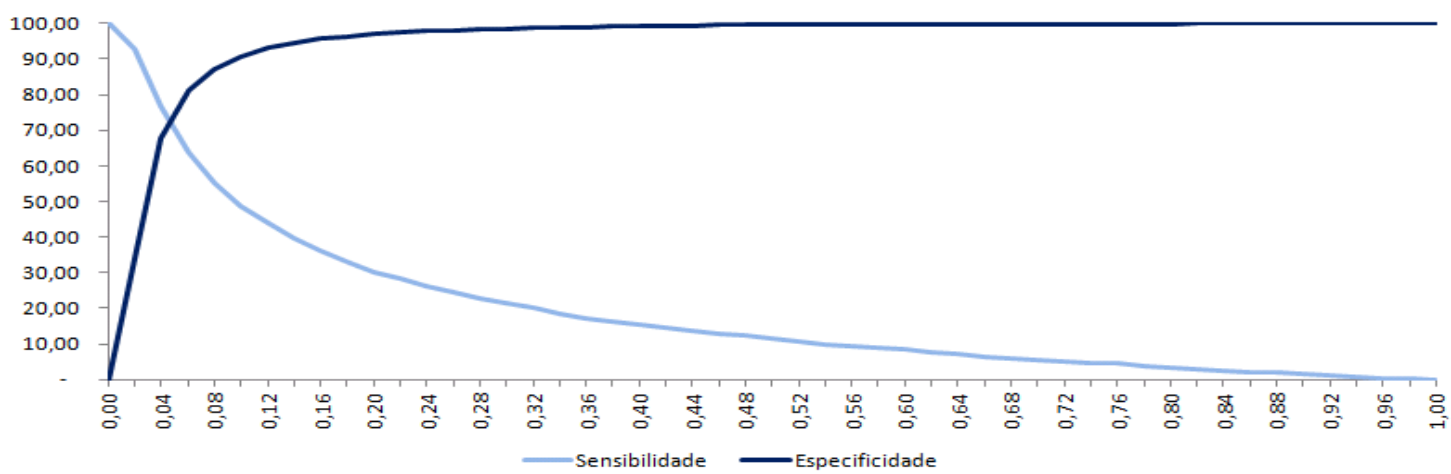

Figura 4.8: Gráfico sensibilidade x especificidade do conjunto Confiança_040. 


\begin{tabular}{|c|c|c|c|c|c|c|c|c|c|}
\hline \multirow{3}{*}{$\begin{array}{c}\text { Nível de } \\
\text { Probabilidade } \\
\end{array}$} & \multicolumn{8}{|c|}{ Tabela de Classificação } & \multirow[b]{3}{*}{ Falso Negativo } \\
\hline & \multicolumn{2}{|c|}{ Corretas } & \multicolumn{2}{|c|}{ Incorretas } & \multicolumn{4}{|c|}{ Percentagens } & \\
\hline & Fraudes & Legítimas & Fraudes & Legitimas & Corretas & Sensibilidade & Especificidade & Falso Positivo & \\
\hline 0,00 & 18.092 & - & 308.000 & - & 5,60 & 100,00 & - & 94,40 & - \\
\hline 0,02 & 16.824 & 89.402 & 218.000 & 1.268 & 32,60 & 93,00 & 29,10 & 92,80 & 1,40 \\
\hline 0,04 & 13.519 & 206.000 & 102.000 & 4.573 & 67,40 & 74,70 & 67,00 & 88,30 & 2,20 \\
\hline 0,06 & 11.179 & 250.000 & 57.640 & 6.913 & 80,20 & 61,80 & 81,30 & 83,80 & 2,70 \\
\hline 0,08 & 9.506 & 270.000 & 37.635 & 8.586 & 85,80 & 52,50 & 87,80 & 79,80 & 3,10 \\
\hline 0,10 & 8.349 & 281.000 & 26.483 & 9.743 & 88,90 & 46,10 & 91,40 & 76,00 & 3,30 \\
\hline 0,12 & 7.412 & 288.000 & 19.931 & 10.680 & 90,60 & 41,00 & 93,50 & 72,90 & 3,60 \\
\hline 0,14 & 6.662 & 292.000 & 15.453 & 11.430 & 91,70 & 36,80 & 95,00 & 69,90 & 3,80 \\
\hline 0,16 & 6.083 & 295.000 & 12.391 & 12.009 & 92,50 & 33,60 & 96,00 & 67,10 & 3,90 \\
\hline 0,18 & 5.615 & 298.000 & 10.189 & 12.477 & 93,00 & 31,00 & 96,70 & 64,50 & 4,00 \\
\hline 0,20 & 5.154 & 299.000 & 8.401 & 12.938 & 93,50 & 28,50 & 97,30 & 62,00 & 4,10 \\
\hline 0,22 & 4.788 & 301.000 & 7.118 & 13.304 & 93,70 & 26,50 & 97,70 & 59,80 & 4,20 \\
\hline 0,24 & 4.459 & 302.000 & 6.011 & 13.633 & 94,00 & 24,60 & 98,00 & 57,40 & 4,30 \\
\hline 0,26 & 4.151 & 303.000 & 5.141 & 13.941 & 94,10 & 22,90 & 98,30 & 55,30 & 4,40 \\
\hline 0,28 & 3.870 & 303.000 & 4.474 & 14.222 & 94,30 & 21,40 & 98,50 & 53,60 & 4,50 \\
\hline 0,30 & 3.610 & 304.000 & 3.890 & 14.482 & 94,40 & 20,00 & 98,70 & 51,90 & 4,50 \\
\hline 0,32 & 3.349 & 304.000 & 3.457 & 14.743 & 94,40 & 18,50 & 98,90 & 50,80 & 4,60 \\
\hline 0,34 & 3.143 & 305.000 & 3.033 & 14.949 & 94,50 & 17,40 & 99,00 & 49,10 & 4,70 \\
\hline 0,36 & 2.934 & 305.000 & 2.700 & 15.158 & 94,50 & 16,20 & 99,10 & 47,90 & 4,70 \\
\hline 0,38 & 2.763 & 305.000 & 2.408 & 15.329 & 94,60 & 15,30 & 99,20 & 46,60 & 4,80 \\
\hline 0,40 & 2.598 & 306.000 & 2.123 & 15.494 & 94,60 & 14,40 & 99,30 & 45,00 & 4,80 \\
\hline 0,42 & 2.468 & 306.000 & 1.866 & 15.624 & 94,60 & 13,60 & 99,40 & 43,10 & 4,90 \\
\hline 0,44 & 2.319 & 306.000 & 1.673 & 15.773 & 94,60 & 12,80 & 99,50 & 41,90 & 4,90 \\
\hline 0,46 & 2.174 & 306.000 & 1.505 & 15.918 & 94,70 & 12,00 & 99,50 & 40,90 & 4,90 \\
\hline 0,48 & 2.050 & 306.000 & 1.363 & 16.042 & 94,70 & 11,30 & 99,60 & 39,90 & 5,00 \\
\hline 0,50 & 1.926 & 307.000 & 1.203 & 16.166 & 94,70 & 10,60 & 99,60 & 38,40 & 5,00 \\
\hline 0,52 & 1.816 & 307.000 & 1.077 & 16.276 & 94,70 & 10,00 & 99,70 & 37,20 & 5,00 \\
\hline 0,54 & 1.719 & 307.000 & 963 & 16.373 & 94,70 & 9,50 & 99,70 & 35,90 & 5,10 \\
\hline 0,56 & 1.613 & 307.000 & 881 & 16.479 & 94,70 & 8,90 & 99,70 & 35,30 & 5,10 \\
\hline 0,58 & 1.524 & 307.000 & 791 & 16.568 & 94,70 & 8,40 & 99,70 & 34,20 & 5,10 \\
\hline 0,60 & 1.423 & 307.000 & 689 & 16.669 & 94,70 & 7,90 & 99,80 & 32,60 & 5,10 \\
\hline 0,62 & 1.319 & 307.000 & 619 & 16.773 & 94,70 & 7,30 & 99,80 & 31,90 & 5,20 \\
\hline 0,64 & 1.231 & 307.000 & 551 & 16.861 & 94,70 & 6,80 & 99,80 & 30,90 & 5,20 \\
\hline 0,66 & 1.152 & 307.000 & 482 & 16.940 & 94,70 & 6,40 & 99,80 & 29,50 & 5,20 \\
\hline 0,68 & 1.079 & 307.000 & 428 & 17.013 & 94,60 & 6,00 & 99,90 & 28,40 & 5,20 \\
\hline 0,70 & 996 & 307.000 & 386 & 17.096 & 94,60 & 5,50 & 99,90 & 27,90 & 5,30 \\
\hline 0,72 & 922 & 307.000 & 344 & 17.170 & 94,60 & 5,10 & 99,90 & 27,20 & 5,30 \\
\hline 0,74 & 851 & 307.000 & 312 & 17.241 & 94,60 & 4,70 & 99,90 & 26,80 & 5,30 \\
\hline 0,76 & 770 & 307.000 & 274 & 17.322 & 94,60 & 4,30 & 99,90 & 26,20 & 5,30 \\
\hline 0,78 & 715 & 307.000 & 249 & 17.377 & 94,60 & 4,00 & 99,90 & 25,80 & 5,30 \\
\hline 0,80 & 653 & 308.000 & 206 & 17.439 & 94,60 & 3,60 & 99,90 & 24,00 & 5,40 \\
\hline 0,82 & 586 & 308.000 & 169 & 17.506 & 94,60 & 3,20 & 99,90 & 22,40 & 5,40 \\
\hline 0,84 & 523 & 308.000 & 138 & 17.569 & 94,60 & 2,90 & 100,00 & 20,90 & 5,40 \\
\hline 0,86 & 470 & 308.000 & 119 & 17.622 & 94,60 & 2,60 & 100,00 & 20,20 & 5,40 \\
\hline 0,88 & 394 & 308.000 & 95 & 17.698 & 94,50 & 2,20 & 100,00 & 19,40 & 5,40 \\
\hline 0,90 & 314 & 308.000 & 74 & 17.778 & 94,50 & 1,70 & 100,00 & 19,10 & 5,50 \\
\hline 0,92 & 249 & 308.000 & 52 & 17.843 & 94,50 & 1,40 & 100,00 & 17,30 & 5,50 \\
\hline 0,94 & 190 & 308.000 & 32 & 17.902 & 94,50 & 1,10 & 100,00 & 14,40 & 5,50 \\
\hline 0,96 & 123 & 308.000 & 20 & 17.969 & 94,50 & 0,70 & 100,00 & 14,00 & 5,50 \\
\hline 0,98 & 50 & 308.000 & 8 & 18.042 & 94,50 & 0,30 & 100,00 & 13,80 & 5,50 \\
\hline 1,00 & - & 308.000 & - & 18.092 & 94,40 & - & 100,00 & - & 5,60 \\
\hline
\end{tabular}

Tabela 4.31: Tabela de classificação da regressão logística do conjunto Confiança_030.

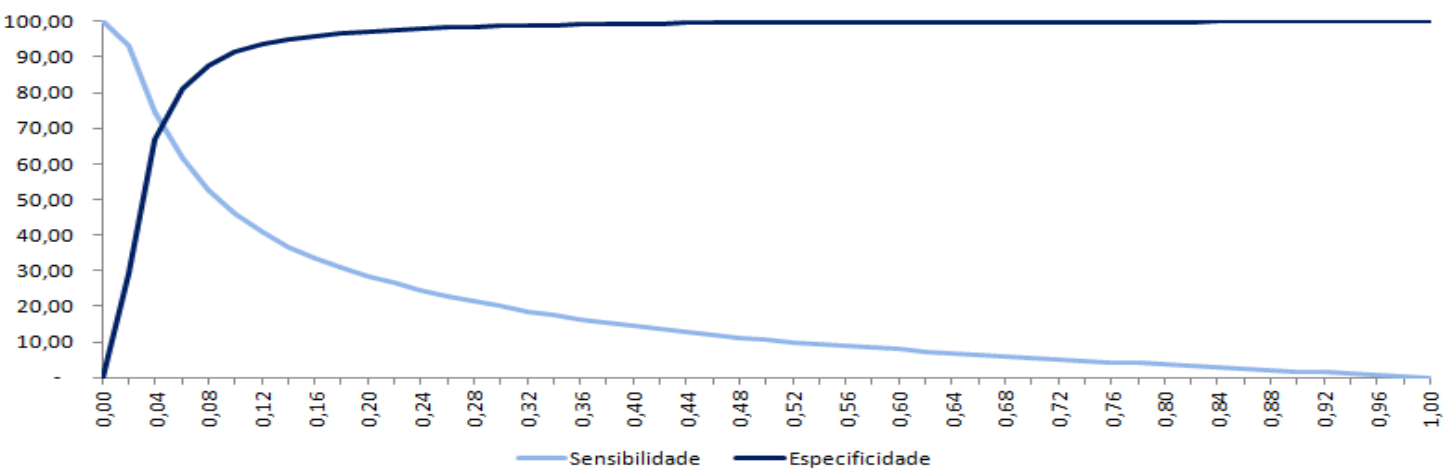

Figura 4.9: Gráfico sensibilidade x especificidade do conjunto Confiança_030. 


\subsubsection{Validação dos Modelos}

A fase de validação dos modelos foi a seguinte após o ajuste dos modelos e a definição dos limiares de fraude. Nessa fase, cada um dos modelos ajustados foi submetido à amostra de validação, que é formada pelo equivalente à $20 \%$ da amostra original e continha 76.935 transações legítimas e 4.523 fraudulentas. O objetivo dessa fase é verificar a capacidade de generalização dos modelos, pois a amostra de validação não foi apresentada a eles durante o treinamento (ajuste). Em outras palavras, se as métricas de desempenho dos modelos diante da amostra de validação forem boas, pode-se atestar que a capacidade de generalização dos modelos (classificação de dados desconhecidos) é satisfatória e o trabalho de modelagem foi bem sucedido. A Figura 4.10 retrata as matrizes de confusão para a classificação das amostras de validação de cada um dos cinco conjuntos de regras discutidos ao longo do trabalho.

\begin{tabular}{l||cc}
\multicolumn{4}{c}{ Quadro Teórico } \\
\multicolumn{1}{c|}{ CLASSIFICADA } & \multicolumn{2}{c}{ REAL } \\
& FRAUDE LEGITIMA \\
\hline \hline FRAUDE & VP & FP \\
\hline LEGITIMA & FN & VN \\
\hline \multicolumn{4}{c}{ Confiança_050 } \\
CLASSIFICADA & REAL \\
\hline \hline FRAUDE & FRAUDE LEGÍTIMA \\
\hline LEGÍTIMA & 3.063 & 15.166 \\
\hline
\end{tabular}

\begin{tabular}{l|cr}
\multicolumn{3}{c}{ Suporte_050 } \\
CLASSIFICADA & \multicolumn{2}{c}{ REAL } \\
& FRAUDE LEGITIMA \\
\hline \hline FRAUDE & 3.292 & 20.278 \\
\hline LEGÍTIMA & 1.231 & 56.657 \\
\hline
\end{tabular}

\begin{tabular}{|c|c|c|}
\hline \multicolumn{3}{|c|}{ MedidaF_050 } \\
\hline \multirow{2}{*}{ CLASSIFICADA } & \multicolumn{2}{|c|}{ REAL } \\
\hline & FRAUDE & LEGÍTIMA \\
\hline FRAUDE & 3.999 & 39.422 \\
\hline LEGÍTIMA & 524 & 37.513 \\
\hline
\end{tabular}

\begin{tabular}{l|cr}
\multicolumn{3}{c}{ Confiança_040 } \\
CLASSIFICADA & \multicolumn{2}{c}{ REAL } \\
& FRAUDE LEGÍTIMA \\
\hline \hline FRAUDE & 3.130 & 18.378 \\
\hline LEGÍTIMA & 1.393 & 58.557 \\
\hline
\end{tabular}

\begin{tabular}{l|rr}
\multicolumn{3}{c}{ Confiança_030 } \\
CLASSIFICADA & \multicolumn{2}{c}{ REAL } \\
& FRAUDE & LEGITIMA \\
\hline \hline FRAUDE & 3.019 & 18.197 \\
\hline LEGÍTIMA & 1.504 & 58.738 \\
\hline
\end{tabular}

Figura 4.10: As matrizes de confusão para os dados de validação dos cinco conjuntos de regras.

A matriz de confusão consolida a quantidade de amostras realmente pertencentes a cada uma das classes e também a quantidade de amostras classificadas pelo classificador nas classes $\{$ fraude e legítima $\}$. Com isso, é possível calcular uma série de indicadores de desempenho do classificador. Dentre esses indicadores estão a cobertura/sensibilidade e a especificidade. Como esses indicadores foram calculados para a amostra de treinamento e mensuram a capacidade do classificador classificar corretamente, respectivamente, as amostras positivas e negativas, eles foram calculados para a amostra de validação. Logo, se para cada um dos cinco conjuntos de regras, os resultados desses indicadores para as amostras de treinamento e validação forem equivalentes, há indicações de validade dos modelos e de suas capacidades de generalização. A Tabela 4.32 contém esses dados.

\begin{tabular}{ccc|cr}
\multirow{2}{*}{ Métrica } & \multicolumn{2}{c}{$\begin{array}{c}\text { Cobertura/Sensibilidade } \\
\text { Treinamento Validação }\end{array}$} & \multicolumn{2}{c}{ Especificidade } \\
& Treinamento & \multicolumn{1}{c}{ Validação } \\
\hline \hline SUPORTE_050 & $67,7 \%$ & $72,8 \%$ & $78,3 \%$ & $73,6 \%$ \\
\hline MEDIDAF_050 & $67,2 \%$ & $88,4 \%$ & $78,3 \%$ & $48,8 \%$ \\
\hline CONFIANÇA_050 & $67,5 \%$ & $67,7 \%$ & $80,4 \%$ & $80,3 \%$ \\
\hline CONFIANÇA_040 & $63,8 \%$ & $69,2 \%$ & $81,0 \%$ & $76,1 \%$ \\
\hline CONFIANÇA_030 & $61,8 \%$ & $66,7 \%$ & $81,3 \%$ & $76,3 \%$ \\
\hline
\end{tabular}

Tabela 4.32: As métricas cobertura/sensibilidade e a especificidade para as amostras de treinamento e validação para cada um dos cinco conjuntos de regras.

A análise dos dados da Tabela 4.32 mostra, num geral, um grau de equivalência aceitável entre os resultados das amostras de treinamento e de validação para os classificadores. A exceção é o conjunto MedidaF_050 que para o indicador cobertura/sensibilidade apresentou 
um descolamento positivo (de $67,2 \%$ na amostra de treinamento para $85,5 \%$ na amostra de validação) e um descolamento negativo (de 78,3\% para 56,0\%) para o indicador especificidade.

Esse grau de equivalência geral permite concluir que os modelos apresentaram um comportamento válido para conjuntos de instâncias (amostras) diferentes daquelas apresentados aos modelos durante a fase de treinamento. Logo, é possível dizer que não houve nem um super ajustamento dos dados (overfitting) nem um ajuste que prejudicasse a capacidade de predição (underfitting). Além disso, juntamente com a observação da medida AROC discutida na seção Medidas de Ajuste dos Modelos, os resultados obtidos pelos classificadores a partir dos dados de validação permite concluir que os classificadores realmente não foram atingidos pelo fenômeno da Maldição da Dimensionalidade.

\subsubsection{Avaliação e Comparação dos Indicadores de Desempenho}

Após o ajuste e a validação dos modelos, foi feita uma comparação dos resultados obtidos por eles. Essa comparação é uma ferramenta importante para a fase de conclusão do projeto e é suportada por uma série de indicadores de desempenho calculados a partir das matrizes de confusão da Figura 4.10.

Para algumas dessas métricas (cobertura/sensibilidade, precisão (fraudes), precisão (legítimas), acurácia, especificidade e medida $F$ ), quanto maiores os valores delas, melhor é o resultado final. Por outro lado, para outras (relação legítimas/fraudes e taxa de falsopositivo), quanto menores seus valores, melhor. A Tabela 4.33 contém o quadro comparativo das métricas referentes aos cinco conjuntos de regras desenvolvidos no trabalho.

\begin{tabular}{|c|c|c|c|c|c|}
\hline Métrica & SUPORTE_050 & MEDIDAF_050 & CONFIANÇA_050 & CONFIANÇA_040 & CONFIANÇA_030 \\
\hline Cobertura & $72,8 \%$ & $88,4 \%$ & $67,7 \%$ & $69,2 \%$ & $66,7 \%$ \\
\hline Precisão (Fraudes) & $14,0 \%$ & $9,2 \%$ & $16,8 \%$ & $14,6 \%$ & $14,2 \%$ \\
\hline Legítimas / Fraudes & 6,2 & 9,9 & 5,0 & 5,9 & 6,0 \\
\hline Precisão (Legítimas) & $97,9 \%$ & $98,6 \%$ & $97,7 \%$ & $97,7 \%$ & $97,5 \%$ \\
\hline Acurácia & $73,6 \%$ & $51,0 \%$ & $79,6 \%$ & $75,7 \%$ & $75,8 \%$ \\
\hline Especificidade & $73,6 \%$ & $48,8 \%$ & $80,3 \%$ & $76,1 \%$ & $76,3 \%$ \\
\hline Medida F & $23,4 \%$ & $16,7 \%$ & $26,9 \%$ & $24,0 \%$ & $23,5 \%$ \\
\hline Taxa de Falso Positivo & $26,4 \%$ & $51,2 \%$ & $19,7 \%$ & $23,9 \%$ & $23,7 \%$ \\
\hline
\end{tabular}

Tabela 4.33: Quadro comparativo contendo os indicadores de desempenho dos modelos frente à amostra de validação.

Devido aos diversos fatores envolvidos na tarefa de classificação de amostras, é aconselhável observar diversos aspectos antes de se concluir qual classificador é o mais adequado para determinada tarefa. Ao se avaliar os dois tipos de erros (falso-positivo e falso-negativo) e os acertos (verdadeiro-positivo e verdadeiro-negativo) cometidos pelo classificador na execução de sua tarefa, temos que o conjunto MedidaF_050 tem os melhores resultados para cobertura e precisão nas transações legítimas, mas o fato de seu resultado ser o pior para a precisão nas transações fraudulentas, faz com que seu resultado para a métrica medida $F$ também seja o mais baixo. Esse mesmo conjunto teve os piores resultados para os indicadores relação legitimas/fraudes, taxa de falso-positivo, acurácia e especificidade. Esses resultados indicam que para se obter uma cobertura extrema, deve-se pagar o preço nos outros indicadores.

O conjunto Confiança_050 teve um resultado intermediário para os indicadores cobertura e precisão nas transações legítimas, mas em todos os outros indicadores, ele foi o modelo mais bem pontuado. A importância das métricas relação legítimas/fraudes e medida $F$ é 
que elas mostram um bom equilíbrio entre os aspectos mais importantes na avaliação de classificadores. Por sua vez, o conjunto MedidaF_050 apresenta os melhores resultados para as métricas cobertura e precisão nas transações legítimas.

Duas métricas relevantes para se discutir diante de todos os modelos são as métricas de relação legítimas/fraudes e taxa de falso-positivo. Isso porque, no uso prático dos classificadores de deteç̧ão de transações fraudulentas no mercado de cartões, essas métricas são importantes, pois elas norteiam o custo de análise manual das transações. Num geral, as empresas não trabalham com um único limiar de fraude para definir se uma transação é fraudulenta ou não, elas trabalham com dois limiares. Geralmente, caso o score da transação fique abaixo do limiar mais baixo, ela é aprovada automaticamente, ou seja, ela é automaticamente considerada legítima. Se o score da transação fica acima do segundo limiar, ela é negada automaticamente, ou seja, ela é automaticamente considerada fraudulenta. Entretanto, se o score da transação fica numa faixa de valores compreendida entre os dois limiares, a transação é avaliada manualmente por um especialista no domínio e ele decide se a transação deve ser aprovada ou rejeitada. Dessa forma, na prática, as duas métricas citadas norteiam o tamanho da equipe de especialistas do domínio. Para os resultados apresentados em todos os modelos, a relação legítimas/fraudes apresentou valores considerados bons ou muito bons. Entretanto, a taxa de falso-positivo apresentou valores ligeiramente mais altos que os praticados, porém esses resultados são esperados - e até previsíveis - para o trabalho, pois ao se considerar a utilização da análise sensível ao custo, é previsto que, se o classificador cometer um erro, esse erro deve ser o menos custoso. Portanto, ainda na fase de amostragem, determinou-se que o falso-positivo era menos custoso que o falso-negativo. Logo, para os modelos terem uma cobertura maior, eles também terão uma maior taxa de falso-positivo.

Por fim, os conjuntos Suporte_050, Confiança_040 e Confiança_030 demonstraram resultados razoáveis e aceitáveis para todos os indicadores, porém sem destaques.

\subsubsection{Validação dos Critérios Utilizados na Análise Descritiva}

Na fase de Análise Descritiva, uma das fases iniciais do experimento e na qual era preciso selecionar as características que serviriam de entrada para o algoritmo FP-Growth, foi utilizada a heurística constituída dos dois critérios a seguir.

1. Caso a razão de chances estimada entre as fraudes e as legítimas seja maior que 1, a característica será uma das escolhidas. Isso porque, essa medida faz com que características mais relacionadas com transações fraudulentas do que com transações legítimas sejam consideradas no algoritmo FP-Growth. O objetivo desse critério é levar para o FP-Growth características que tenham alta confiança.

2. Caso a razão de chances estimada entre as fraudes e as legítimas seja maior ou igual a 0,90, mas a razão de chances estimada dessa característica seja relevante, a característica também será uma das escolhidas. Nesse critério, por representatividade relevante considera-se a característica que tenha representatividade percentual maior ou igual a $100 / \mathrm{n}$, onde $n$ é a quantidade de elementos do domínio da variável. Como exemplo, a variável Categoria do Valor da Transação tem 7 elementos em seu domínio ( "0.00-9.99", "10.00-49.99", "50.00-99.99", "100.00-199.99", "200.00-499.99", "500.00-999.99" e "1000+"). Logo, a representatividade nas fraudes de uma característica será relevante se ela for maior ou igual a 14,29\% (100/7). O objetivo dessa regra é levar para o FPGrowth características que tenham confiança razoável, mas alto suporte no conjunto de transações fraudulentas. 
Após a realização do experimento, para atestar a validade dos critérios e a robustez dos resultados obtidos, fizemos uma análise de como as características - e, por consequência, os critérios de seleção das características - se comportaram ao longo das diversas fases do experimento. Essa análise é baseada na Tabela 4.34.

Boa parte das análises e discussões das seções anteriores foram feitas na granularidade das regras. Em contraste, a análise a seguir desce um nível de granularidade e discute as características que são elementos formadores de regras, pois cada regra é uma conjunção de uma ou mais características.

\begin{tabular}{|c|c|c|c|}
\hline Estatística & $\begin{array}{l}\text { Razão de Chances (estimativa) - } \\
\text { Antes FP.Growth } \\
\end{array}$ & $\begin{array}{l}\text { Razão de Chances (estimativa) - } \\
\text { Antes Regressão Logistica } \\
\end{array}$ & $\begin{array}{c}\text { Razão de Chances (estimativa) } \\
\text { Depois Regressão Logistica } \\
\end{array}$ \\
\hline Mínimo & 0,90 & 0,90 & 0,90 \\
\hline Máximo & 31,67 & 6,68 & 6,68 \\
\hline Média & 1,95 & 1,56 & 1,56 \\
\hline 10 Quartil & 1,07 & 1,03 & 1,02 \\
\hline Mediana & 1,32 & 1,25 & 1,27 \\
\hline 30 Quartil & 1,80 & 1,69 & 1,69 \\
\hline Características do 10 critério (\#) & $125(88,7 \%)$ & $84(84,0 \%)$ & $79(83,2 \%)$ \\
\hline Caracteristicas do 20 critério (\#) & $16(11,3 \%)$ & $16(16,0 \%)$ & $16(16,8 \%)$ \\
\hline Total de Caracteristicas (\#) & $141(100 \%)$ & $100(100 \%)$ & $95(100 \%)$ \\
\hline
\end{tabular}

Tabela 4.34: Estatísticas das características nos diferentes estágios do experimento.

A análise da Tabela 4.34 mostra, através de diversas estatísticas, como a razão de chances estimada variou ao longo do experimento. Como exemplo, é feito um acompanhamento do valor médio da razão de chance estimada. No primeiro estágio (assim que as características foram selecionadas, ou seja, antes do FP-Growth), esse valor médio é de 1,95. No segundo estágio (após o FP-Growth e antes da regressão logística), esse valor médio é de 1,56. Já no último estágio (após a regressão logística), esse valor médio é de 1,56. Isso mostra que os critérios da heurística podem selecionar características de altíssimo valor estimado de razão de chances - como é o caso da característica DOAÇÕES da variável EC_TIPO_SERVICO, que tem razão de chance estimada de 31,67 (essa característica eleva a média das razões de chance estimada) -, porém, pelo fato do algoritmo FP-Growth considerar somente a métrica suporte, se a característica não tiver o suporte mínimo exigido (como é o caso da característica $D O A C ̧ \widetilde{O E S}$ ), ela é descartada. Esse aspecto no algoritmo faz com que a média - e as outras estatísticas - da razão de chances estimada caia. Por fim, como a regressão logística é uma técnica sensível à razão de chances mais altas, ela tende a manter, no modelo final, as regras que contenham características de razão de chance estimada mais alta, por isso as estatísticas da razão de chances estimadas tiveram uma alta, mesmo que marginal. Sendo assim, o primeiro critério de seleção de característica é útil como esperado e seu uso foi válido.

Para analisar a robustez do segundo critério, é possível verificar a segunda parte da Tabela 4.34. Ela mostra que, apesar do primeiro estágio do experimento ter 141 características e o estágio final ter apenas 95, nenhuma característica selecionada pelo segundo critério foi descartada. Em outras palavras, as 16 características selecionadas por esse critério permaneceram, em algum grau, durante todo o experimento. Ainda, com a observação das tabelas do apêndice $\mathrm{C}$, vemos que se multiplicarmos a quantidade de regras pela quantidade de características que cada regra contém, teremos 1.651 elementos. Desses, 395, ou cerca de 24\%, se referem a características selecionadas pelo segundo critério. Como informação complementar, o suporte médio das características que foram excluídas ao longo de todo o processo é 
de 325 .

\subsubsection{Ponderação com Regressão Logística versus Abordagens Usu- ais}

Após verificar a validade dos critérios balizadores da seleção das características, há interesse em discutir se o resultado do uso da regressão logística para ponderar as regras é uma boa estratégia. Essa discussão pode ser feita através da comparação dos resultados obtidos com a regressão logística com aqueles que seriam obtidos com a utilização de outras estratégias. Em particular, a regressão logística será comparada com duas abordagens geralmente utilizadas:

1. As regras do classificador não têm diferença de pesos. A partir daí, como o interesse do classificador é detectar transações fraudulentas, se pelo menos uma das regras disparar a transação, essa transação é classificada como fraudulenta. Na análise a seguir, essa abordagem será chamada de usual_score0.

2. As regras do classificador não têm diferença de pesos. Entretanto, a quantidade de regras que disparam uma transação é considerada. Dessa forma, uma transação só será classificada como fraudulenta se a quantidade de regras que a dispararem for superior a um determinado limiar. Na análise a seguir, essa abordagem terá dois representantes, chamados de usual_score37 e usual_score47.

Para implementar essas abordagens, utilizou-se o conjunto de regras Confiança_050. Isso porque, esse conjunto foi o vencedor dentre aqueles resultantes da aplicação da técnica de regressão logística. Assim, o processo de comparação consistiu em:

- Utilizar o conjunto de dados de treinamento para determinar quais seriam os limiares de fraude para a segunda abordagem. Esse passo pode ser visto na Figura 4.11.

- Disparar as 1.285 regras do conjunto de regras Confiança_050 no conjunto de dados de validação e simular a classificação para os limiares determinados na primeira e na segunda abordagem.

- Comparar os resultados obtidos nos dados de validação pelas quatro abordagens: (i) conjunto Confiança_050 ponderado pela regressão logística, (ii) conjunto Confiança_050 com regras sem peso e bastando apenas um disparo para a transação ser considerada fraudulenta (usual_score0), (iii) conjunto Confiança_050 com regras sem peso e limiar igual a 37, ou seja, é preciso que mais de 37 regras disparem a transação para ela ser considerada fraudulenta (usual_score37) e (iv) conjunto Confiança_050 com regras sem peso e limiar igual a 47, ou seja, é preciso que mais de 47 regras disparem a transação para ela ser considerada fraudulenta (usual_score47).

Com a finalidade de determinar a quantidade de regras disparadas por uma transação para ela ser considerada fraudulenta, disparou-se todas as 1.285 regras contra o conjunto de treinamento e depois contou-se quantas regras tinham disparado cada transação. Em seguida, um gráfico do tipo box-plot foi construído e analisado. Esse gráfico está representado na Figura 4.11. 


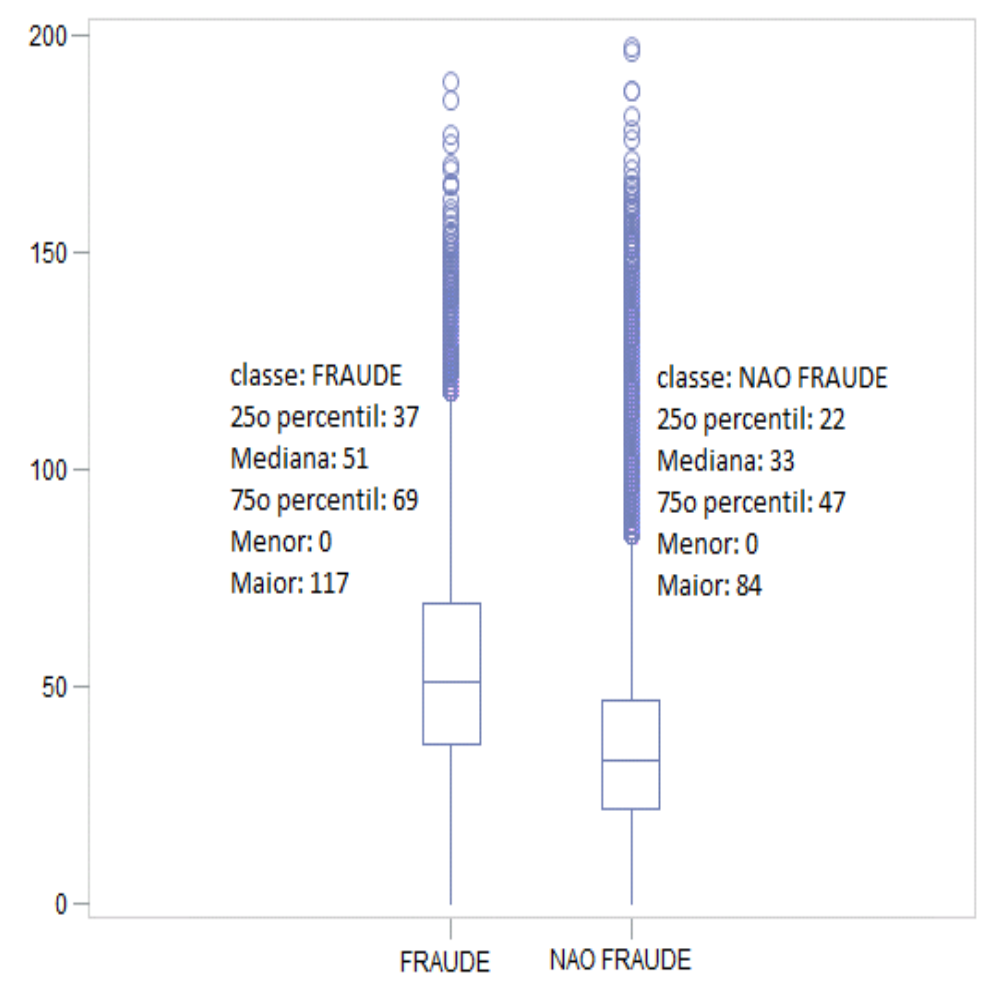

Figura 4.11: Box-plot utilizado para se definir os limiares de fraude da segunda abordagem usual.

A análise do box-plot mostra que há valores para a variável quantidade de regras disparadas pela transação que estabelecem uma boa segmentação entre as classes FRAUDE e NÃO FRAUDE. Dois desses possíveis valores são 37 (primeiro quartil da classe FRAUDE) e 47 (terceiro quartil da classe $N \widetilde{A} O F R A U D E$ ). Caso o valor 37 seja escolhido, privilegia-se o disparo de transações fraudulentas ao custo de se classificar algumas amostras legítimas erroneamente. Assim, a classificação deve apresentar maior cobertura, mas maior taxa de falso-positivo. Por outro lado, ao se definir o valor 47 , a expectativa é que amostras fraudulentas sejam classificadas como legítimas, ou seja, espera-se que haverá uma menor taxa de falso-positivo, mas também uma menor cobertura. Enfim, decidiu-se testar os dois valores.

As tabelas expostas na Figura 4.12 mostram as matrizes de confusão obtidas com o disparo dos classificadores nas transações do conjunto de dados de validação. Por sua vez, a Tabela 4.35 mostra os indicadores de desempenho obtidos com esse exercício.

\begin{tabular}{|c|c|c|c|c|c|}
\hline \multicolumn{3}{|c|}{ Confiança_050 } & \multicolumn{3}{|c|}{ Usual_Scoreo } \\
\hline \multirow{2}{*}{ CLASSIFICADA } & \multirow{2}{*}{\multicolumn{2}{|c|}{$\begin{array}{c}\text { REAL } \\
\text { FRAUDE LEGÍTIMA }\end{array}$}} & \multirow{2}{*}{ CLASSIFICADA } & \multicolumn{2}{|c|}{ REAL } \\
\hline & & & & FRAUDE & LEGÍTIMA \\
\hline FRAUDE & 3.063 & 15.166 & FRAUDE & 4.522 & 76.507 \\
\hline LEGÍTIMA & 1.460 & 61.769 & LEGÍTIMA & 1 & 428 \\
\hline \multicolumn{3}{|c|}{ Usual_Score37 } & \multicolumn{3}{|c|}{ Usual_Score47 } \\
\hline \multirow{2}{*}{ CLASSIFICADA } & \multicolumn{2}{|c|}{ [ REAL } & \multirow{2}{*}{ CLASSIFICADA } & \multicolumn{2}{|c|}{ REAL } \\
\hline & FRAUDE & LEGÍTIMA & & FRAUDE & LEGÍTIMA \\
\hline FRAUDE & 3.506 & 33.063 & FRAUDE & 2.611 & 18.241 \\
\hline LEGÍTIMA & 1.017 & 43.872 & LEGÍTIMA & 1.912 & 58.694 \\
\hline
\end{tabular}

Figura 4.12: As matrizes de confusão para comparar as abordagens usuais com a regressão logística. 


\begin{tabular}{lrrrr}
\multicolumn{1}{c}{ Métrica } & CONFIANÇA_050 & USUAL_SCORE0 & USUAL_SCORE37 & USUAL_SCORE47 \\
\hline \hline Cobertura & $67,7 \%$ & $\mathbf{1 0 0 , 0} \%$ & $77,5 \%$ & $57,7 \%$ \\
\hline Precisão (Fraudes) & $\mathbf{1 6 , 8} \%$ & $5,6 \%$ & $9,6 \%$ & $12,5 \%$ \\
\hline Legítimas / Fraudes & $\mathbf{5 , 0}$ & 16,9 & 9,4 & 7,0 \\
\hline Precisão (Legítimas) & $\mathbf{9 7 , 7} \%$ & $\mathbf{9 9 , 8} \%$ & $97,7 \%$ & $96,8 \%$ \\
\hline Acurácia & $\mathbf{7 9 , 6 \%}$ & $6,1 \%$ & $58,2 \%$ & $75,3 \%$ \\
\hline Especificidade & $\mathbf{8 0 , 3} \%$ & $0,6 \%$ & $57,0 \%$ & $76,3 \%$ \\
\hline Medida F & $\mathbf{2 6 , 9 \%}$ & $10,6 \%$ & $17,1 \%$ & $20,6 \%$ \\
\hline Taxa de Falso Positivo & $\mathbf{1 9 , 7} \%$ & $99,4 \%$ & $43,0 \%$ & $23,7 \%$ \\
\hline
\end{tabular}

Tabela 4.35: Quadro comparativo contendo os indicadores de desempenho das abordagens usuais frente à amostra de validação.

Ao se interpretar os dados obtidos na Tabela 4.35, verificamos que o uso da regressão logística para ponderar as regras se mostrou uma boa estratégia, pois essa abordagem teve resultados melhores que os obtidos pelas abordagens usuais em seis dos oito indicadores de desempenho, inclusive, na métrica medida $F$. Observe-se que o melhor dos métodos usuais (usual_score47) perde na métrica medida $F$ não somente para o melhor (Confiança_050) daqueles conjuntos de regras ponderados pela regressão logística como também para os conjuntos Confiança_040, Confiança_030 e Suporte_050.

\subsection{Sumário da Parte Experimental}

Antes do encerramento deste capítulo, é válido realizar um breve resumo da metodologia utilizada no experimento e dos resultados obtidos com ele para consolidar essa parte do trabalho.

A metodologia conceitual usada na parte experimental do trabalho foi a CRISP-DM (CRoss Industry Standard Process for Data Mining). Para o executor de um trabalho de mineração de dados ser bem sucedido em sua tarefa, essa metodologia orienta a passagem por seis estágios: compreensão do negócio, compreensão dos dados, preparação dos dados, modelagem, avaliação de desempenho e implantação. Os dois primeiros estágios foram conduzidos pelo autor em conjunto com especialistas no domínio e com integrantes da empresa que concedeu os dados e equipamentos. Os outros estágios foram conduzidos pelo autor, que contou com a colaboração de seu orientador.

Durante os estágios de compreensão e preparação dos dados, cujo conjunto era composto de 7.716.091 transações aprovadas, sendo 22.615 transações fraudulentas e 7.693.476 transações legítimas, chegou-se a um conjunto de 80 variáveis independentes (43 variáveis originais mais 37 variáveis derivadas). Cada variável dessas possui um domínio próprio (valores específicos), sendo alguns desses valores específicos (características) a matéria prima para a criação das regras de detecção de transações fraudulentas. Assim, a primeira etapa do estágio de modelagem consistiu numa análise descritiva que selecionou 141 características de maior interesse a partir do método descrito na seção 3.2 .

Partindo dessas 141 características e das mais de sete milhões de transações, o estágio de modelagem prosseguiu com a amostragem que, baseada na técnica de análise sensível ao custo, separou aleatoriamente 407.289 transações (384.674 legítimas e 22.615 fraudulentas) para serem utilizadas no experimento. Dessa amostra, $80 \%$ foram utilizados durante o treinamento dos modelos e o restante foi utilizado para a validação deles. Em seguida, as transações fraudulentas da amostra de treinamento serviram como entrada do algoritmo 
FP-Growth, usado na mineração de regras de associação. Como saída do algoritmo, foram geradas 38.003 regras. Dado que esse conjunto de regras era demasiadamente grande, foram criadas três heurísticas para sua diminuição: (i) análise da razão de chances das regras, (ii) análise dos grupos de confiança e (iii) análise da distância semântica entre as regras. Com essas heurísticas, formou-se cinco conjuntos diferentes de regras: Suporte_050, MedidaF_050, Confiança_050, Confiança_040 e Confiança_030. Cada um deles, separadamente, foi submetido à técnica de regressão logística. Na regressão logística, as regras permaneceram nos modelos que respeitaram quatro condições: (i) aderência aos critérios de convergência do software, (ii) aderência ao nível descritivo (valor-p), (iii) valor do coeficiente $\beta$ positivo e (iv) passaram pelo teste de multicolinearidade, ou seja, tinham baixa correlação com as outras regras. Com isso, todas as regras de todos os modelos tiveram valores-p baixos (valor-p < 0,05), erros padrão controlados e todos os modelos foram bem ajustados de acordo com testes estatísticos (máxima verossimilhança, score, Wald e pelas estatística Deviance e AROC), falhando apenas no teste Hosmer e Lemershow, que tem aplicação controversa para as características desse trabalho.

Com relação à avaliação de desempenho. Nessa etapa, os modelos foram validados e a capacidade de generalização deles para dados não usados durante o treinamento foi atestada. Além disso, os resultados desses cinco classificadores foram avaliados, comparados e discutidos diante de diversas métricas (cobertura/sensibilidade, precisão (fraudes), precisão (legítimas), acurácia, especificidade, medida $F$, relação legítimas/fraudes e taxa de falsopositivo). Através dessa análise, foi possível demonstrar a consistência do trabalho inicialmente proposto e pudemos observar na seção 4.4.6 que o uso da regressão logística mostrou ser uma contribuição efetiva com resultados melhores que as abordagens usuais de contagem de evidências de fraude.

Conforme verificado na seção 4.4.5, tanto o primeiro critério quanto o segundo se mostraram úteis e proveitosos já que das 95 características finais, 16 foram obtidas pelo segundo critério, com participação em $24 \%$ dos elementos das regras e 79 foram obtidos pelo primeiro critério, com $76 \%$ dos elementos. 


\section{Capítulo 5}

\section{Conclusões}

Esse capítulo trata do encerramento do trabalho. Nele, os objetivos do trabalho serão revistos para discutir se eles foram alcançados e as considerações finais com conclusões tanto do ponto de vista prático quanto metodológico serão detalhadas. Além disso, as oportunidades identificadas para embasar novas pesquisas e trabalhos serão apresentadas.

\subsection{Considerações Finais}

Conforme mencionado na introdução, o objetivo desse trabalho era propor o desenvolvimento de uma arquitetura de mineração de regras de associação ponderadas por regressão logística para produzir conjuntos de regras de detecção de transações fraudulentas e auxiliar o trabalho do especialista de domínio na identificação de padrões de fraudes em cartões num menor tempo possível. Nessa atividade corre-se o risco do especialista somente identificar esses padrões após muitas fraudes terem acontecido. Partindo desse ponto, o trabalho conseguiu cumprir o que foi proposto e mostrou que a combinação das técnicas é vantajosa, já que elas têm funções complementares entre si, obtendo-se modelos coesos, bem ajustados e com boa capacidade de generalização.

Do ponto de vista teórico, vale destacar que durante o levantamento bibliográfico, não foi identificado nenhum outro trabalho de extração de regras de fraudes que fizesse a utilização conjunta das técnicas utilizadas na arquitetura proposta para abordar problemas de classificação nem na deteç̧ão de transações fraudulentas no mercado de cartões, tampouco em outros contextos. Sozinha, a regressão logística é altamente utilizada nesse domínio, mas, nesse caso, as variáveis das transações são as entradas do modelo e componentes de regras de associação. Assim, esse trabalho traz uma contribuição para seu campo de pesquisa acadêmica ao mostrar, de forma bem sucedida, que a arquitetura proposta pode ser utilizada em problemas de classificação e, mais especificamente, em detecção de transações fraudulentas no mercado de cartões.

Para viabilizar a implementação da arquitetura, mostrou-se importante realizarmos um processo de filtragem das regras devolvidas pelo FP-Growth antes de pondera-las pela regressão logística. O uso proposto da distância semântica baseada no coeficiente de Jaccard revelou-se fundamental nessa etapa de forma a reduzir as 38.003 regras originalmente devolvidas pelo FP-Growth para 1.285 no caso do conjunto Confiança_050, que apresentou os melhores resultados obtidos.

Do ponto de vista prático, o trabalho demonstrou sua viabilidade técnica nas fases de modelagem e de avaliação. Ademais, fizemos também uma comparação com algumas abordagens usuais no mercado e os modelos obtidos com a arquitetura proposta foram significativamente mais bem avaliados que a melhor aplicação das abordagens usuais, pois a medida $F$ foi de 
$26,9 \%$ para o melhor modelo da arquitetura e de 20,6\% para o melhor modelo da abordagem usual. Sendo assim, ao utilizar a técnica proposta, os especialistas do domínio podem ter ganhos de eficiência e escala operacional, pois a mineração de regras através do uso dos algoritmos propostos complementa o trabalho do especialista trazendo um alto volume de regras mineradas, aumentando a abrangência dos padrões identificados e, mais ainda, com resultados na predição bastante razoáveis.

\subsection{Sugestões para Pesquisas Futuras}

Ao longo do trabalho, foi possível identificar algumas frentes de trabalho que podem ser abordadas no futuro.

- Amostragem: há diversas alternativas para se executar a amostragem dos dados (estratificada, não sensível ao custo, entre outras...). Assim, seria interessante explorar essas diferentes alternativas e comparar os resultados obtidos.

- Heurísticas e Métricas: o uso do algoritmo FP-Growth para mineração de regras resulta num volume de regras mineradas bastante alto. Por isso, é preciso utilizar heurísticas que reduzam o número de regras para um patamar administrável. A partir daí, pode-se trabalhar com heurísticas diferentes das utilizadas nesse trabalho. O mesmo raciocínio vale para as métricas e os valores de métricas utilizadas tanto no FP-Growth quanto na regressão logística, pois a possibilidade de se fazer ajustes paramétricos pode culminar em resultados diferentes dos obtidos.

- Modelagem Dinâmica no Tempo: esse trabalho não utilizou a variável tempo em seu contexto, ou seja, as transações foram consideradas igualmente, independentemente da data de sua ocorrência. Os especialistas sabem que o fator temporal é importante no domínio. Logo, essa informação poderia ser introduzida na modelagem e, por exemplo, ponderar as regras de alguma forma que leve o fator temporal em consideração. 


\section{Apêndice A}

\section{Características Base para a Mineração de Regras de Associação}

\begin{tabular}{|c|c|c|c|c|}
\hline Varíavel & Característica & $\begin{array}{c}\text { Razão de Chances } \\
\text { (estimativa) }\end{array}$ & $\begin{array}{c}\text { Trxs Fraudulentas } \\
\text { (\#) }\end{array}$ & $\begin{array}{c}\text { Critério Aderente } \\
\text { (Heurística) }\end{array}$ \\
\hline C_CAT_VALOR_TRX & $1000+$ & 3,85 & 745 & 10 critério \\
\hline C_CAT_VALOR_TRX & $100-199.99$ & 0,99 & 5.591 & 20 critério \\
\hline C_CAT_VALOR_TRX & $200-499.99$ & 1,67 & 5.645 & 10 critério \\
\hline C_CAT_VALOR_TRX & $500-999.99$ & 3,12 & 1.410 & 10 critério \\
\hline C_CAT_VALOR_TRX & $50-99.99$ & 0,90 & 3.540 & 20 critério \\
\hline C_CEP_CPF_MATCH & DIFERENTE LOCAL CEP e CPF & 2,45 & 2.017 & 10 critério \\
\hline C_CLASSIF_EMAIL_COMPR & bol.com.br & 1,80 & 1.159 & 1o critério \\
\hline C_CLASSIF_EMAIL_COMPR & globomail.com & 6,03 & 127 & 10 critério \\
\hline C_CLASSIF_EMAIL_COMPR & hotmail.com & 1,19 & 11.812 & 1o critério \\
\hline C_CLASSIF_EMAIL_COMPR & hotmail.com.br & 3,32 & 263 & 1o critério \\
\hline C_CLASSIF_EMAIL_COMPR & live.com & 6,46 & 1.059 & 10 critério \\
\hline C_CLASSIF_EMAIL_COMPR & outlook.com & 3,11 & 145 & 10 critério \\
\hline C_CLASSIF_EMAIL_COMPR & pop.com.br & 1,06 & 41 & 10 critério \\
\hline C_CLASSIF_EMAIL_COMPR & r7.com & 3,76 & 155 & 10 critério \\
\hline C_CLASSIF_EMAIL_COMPR & yahoo.com & 2,68 & 375 & 10 critério \\
\hline C_CLASSIF_EMAIL_COMPR & yahoo.com.br & 1,01 & 2.527 & 10 critério \\
\hline C_CLASSIF_EMAIL_COMPR & ymail.com & 2,71 & 128 & 10 critério \\
\hline C_COMPR_DATA_FILIACAO_TRX & $0-30$ & 1,80 & 1.012 & 10 critério \\
\hline C_COMPR_ESTADO & ALAGOAS & 1,80 & 422 & 10 critério \\
\hline C_COMPR_ESTADO & AMAPÁ & 1,05 & 73 & 10 critério \\
\hline C_COMPR_ESTADO & AMAZONAS & 1,81 & 360 & 10 critério \\
\hline C_COMPR_ESTADO & BAHIA & 1,66 & 1.298 & 10 critério \\
\hline C_COMPR_ESTADO & CEARÁ & 1,52 & 912 & 10 critério \\
\hline C_COMPR_ESTADO & GOIÁS & 1,79 & 736 & 10 critério \\
\hline C_COMPR_ESTADO & MARANHÅO & 2,58 & 475 & 10 critério \\
\hline C_COMPR_ESTADO & MATO GROSSO & 1,21 & 237 & 10 critério \\
\hline C_COMPR_ESTADO & PARÁ & 1,89 & 567 & 10 critério \\
\hline C_COMPR_ESTADO & PARAÍBA & 1,19 & 282 & 10 critério \\
\hline C_COMPR_ESTADO & PERNAMBUCO & 1,27 & 1.011 & 10 critério \\
\hline C_COMPR_ESTADO & PIAUÍ & 1,15 & 168 & 10 critério \\
\hline C_COMPR_ESTADO & RIO DE JANEIRO & 1,05 & 3.331 & 10 critério \\
\hline C_COMPR_ESTADO & RIO GRANDE DO NORTE & 1,79 & 435 & 10 critério \\
\hline C_COMPR_ESTADO & RONDÔNIA & 1,47 & 193 & 10 critério \\
\hline C_COMPR_ESTADO & TOCANTINS & 1,87 & 141 & 10 critério \\
\hline C_CPF_COMPR_CARD_MATCH & $1 \mathrm{CPF}$ INFORMADO $\gg$ NULL & 0,95 & 12.611 & 1o critério \\
\hline C_CPF_COMPR_CARD_MATCH & CPFs DIFERENTES & 1,63 & 5.941 & 10 critério \\
\hline C_DIF_DTA_NASC_COMPR_CARD & 1-3 MESES & 1,49 & 29 & 10 critério \\
\hline C_DIF_DTA_NASC_COMPR_CARD & 4-6 MESES & 1,79 & 19 & 10 critério \\
\hline C_DIF_DTA_NASC_COMPR_CARD & MAIOR 7 MESES & 1,94 & 1.214 & 10 critério \\
\hline C_DTA_NASC_COMPR_CARD & DIFERENTE & 1,90 & 1.272 & 10 critério \\
\hline
\end{tabular}

Tabela A.1: Características selecionadas para o algoritmo FP-Growth. Parte 01 de 03. 


\begin{tabular}{|c|c|c|c|c|}
\hline Varíavel & Característica & $\begin{array}{l}\text { Razão de Chances } \\
\text { (estimativa) }\end{array}$ & $\begin{array}{l}\text { Trxs Fraudulentas } \\
\text { (\#) }\end{array}$ & $\begin{array}{l}\text { Critério Aderente } \\
\text { (Heurística) }\end{array}$ \\
\hline C_EC_DATA_FILIACAO_TRX & $0-30$ & 2,90 & 1.089 & 10 critério \\
\hline C_EC_DATA_FILIACAO_TRX & $121-150$ & 1,20 & 747 & 10 critério \\
\hline C_EC_DATA_FILIACAO_TRX & $151-180$ & 1,00 & 652 & 10 critério \\
\hline C_EC_DATA_FILIACAO_TRX & $31-60$ & 2,09 & 923 & 10 critério \\
\hline C_EC_DATA_FILIACAO_TRX & $61-90$ & 1,77 & 965 & 10 critério \\
\hline C_EC_DATA_FILIACAO_TRX & $91-120$ & 1,59 & 912 & 10 critério \\
\hline C_GRUPO_BIN & B1 & 1,98 & 4.796 & 10 critério \\
\hline C_IDADE_COMPR_CARD_TRX & $07-17$ & 2,12 & 116 & 10 critério \\
\hline C_IDADE_COMPR_CARD_TRX & $18-29$ & 1,00 & 6.172 & 10 critério \\
\hline C_IDADE_COMPR_CARD_TRX & $30-39$ & 0,97 & 6.224 & 20 critério \\
\hline C_IDADE_COMPR_CARD_TRX & $40-49$ & 1,20 & 4.589 & 10 critério \\
\hline C_IDADE_COMPR_CARD_TRX & $50-59$ & 1,18 & 2.774 & 10 critério \\
\hline C_IDADE_COMPR_CARD_TRX & $60-69$ & 1,51 & 1.384 & 10 critério \\
\hline C_IDADE_COMPRADOR_TRX & $07-17$ & 1,04 & 18 & 10 critério \\
\hline C_IDADE_COMPRADOR_TRX & $18-29$ & 1,30 & 1.256 & 10 critério \\
\hline C_IDADE_COMPRADOR_TRX & $70-99$ & 2,43 & 51 & 10 critério \\
\hline C_IDADE_COMPRADOR_TRX & Maior 100 & 2,13 & 3 & 10 critério \\
\hline C_REGIAO_CEP & 0 & 1,12 & 4.429 & 10 critério \\
\hline C_REGIAO_CEP & 2 & 1,04 & 3.678 & 10 critério \\
\hline C_REGIAO_CEP & 4 & 1,49 & 1.412 & 10 critério \\
\hline C_REGIAO_CEP & 5 & 1,43 & 2.154 & 10 critério \\
\hline C_REGIAO_CEP & 6 & 1,66 & 2.610 & 10 critério \\
\hline C_REGIAO_CEP & 7 & 1,27 & 2.138 & 10 critério \\
\hline C_SETOR_CEP & SETOR 1 & 1,16 & 2.497 & 10 critério \\
\hline C_SETOR_CEP & SETOR 2 & 1,00 & 2.336 & 10 critério \\
\hline C_SETOR_CEP & SETOR 3 & 1,11 & 1.890 & 10 critério \\
\hline C_SETOR_CEP & SETOR 5 & 1,01 & 1.840 & 10 critério \\
\hline C_SETOR_CEP & SETOR 6 & 1,09 & 1.691 & 10 critério \\
\hline C_SETOR_CEP & SETOR 8 & 1,14 & 1.788 & 10 critério \\
\hline C_SETOR_CEP & SETOR 9 & 1,16 & 1.632 & 10 critério \\
\hline C_SUBREGIAO_CEP & SUBREGIAO 0 & 0,98 & 2.374 & 20 critério \\
\hline C_SUBREGIAO_CEP & SUBREGIAO 1 & 0,92 & 2.226 & 20 critério \\
\hline C_SUBREGIAO_CEP & SUBREGIAO 2 & 1,02 & 2.414 & 10 critério \\
\hline C_SUBREGIAO_CEP & SUBREGIAO 3 & 0,94 & 2.076 & 20 critério \\
\hline C_SUBREGIAO_CEP & SUBREGIAO 4 & 1,10 & 2.646 & 10 critério \\
\hline C_SUBREGIAO_CEP & SUBREGIAO 5 & 1,10 & 2.450 & 10 critério \\
\hline C_SUBREGIAO_CEP & SUBREGIAO 6 & 1,21 & 1.910 & 10 critério \\
\hline C_SUBREGIAO_CEP & SUBREGIAO 7 & 1,30 & 1.729 & 10 critério \\
\hline C_SUBREGIAO_CEP & SUBREGIAO 8 & 1,15 & 2.455 & 10 critério \\
\hline C_TAMANHO_EMAIL & $01-03$ & 1,03 & 66 & 10 critério \\
\hline C_TAMANHO_EMAIL & 04-19 & 0,98 & 21.409 & 20 critério \\
\hline C_TAMANHO_EMAIL & MAIOR 19 & 2,05 & 1.061 & 10 critério \\
\hline C_TEL_CEP_MATCH & DIFERENTE LOCAL TEL e CEP & 3,17 & 1.777 & 10 critério \\
\hline C_TEL_CEP_MATCH & IGUAL LOCAL TEL e CEP & 0,99 & 20.077 & 20 critério \\
\hline C_TEL_CPF_MATCH & DIFERENTE LOCAL TEL e CPF & 2,57 & 2.086 & 10 critério \\
\hline C_TELEFONE_COMPR_CARD_MATCH & TEL COMPR E CARD DIFERENTES & 2,02 & 1.586 & 10 critério \\
\hline C_TRX_DIA_SEMANA & QUARTA & 0,97 & 3.583 & 20 critério \\
\hline C_TRX_DIA_SEMANA & QUINTA & 1,08 & 3.919 & 10 critério \\
\hline C_TRX_DIA_SEMANA & SABADO & 1,09 & 2.579 & 10 critério \\
\hline C_TRX_DIA_SEMANA & SEGUNDA & 0,93 & 3.375 & 20 critério \\
\hline
\end{tabular}

Tabela A.2: Características selecionadas para o algoritmo FP-Growth. Parte 02 de 03. 


\begin{tabular}{|c|c|c|c|c|}
\hline Varíavel & Característica & $\begin{array}{l}\text { Razão de Chances } \\
\text { (estimativa) }\end{array}$ & $\begin{array}{l}\text { Trxs Fraudulentas } \\
\text { (\#) }\end{array}$ & $\begin{array}{l}\text { Critério Aderente } \\
\text { (Heurística) }\end{array}$ \\
\hline C_TRX_DIA_SEMANA & SEXTA & 0,99 & 3.365 & 20 critério \\
\hline C_TRX_DIA_SEMANA & TERCA & 0,98 & 3.554 & 20 critério \\
\hline C_TRX_IP_PAIS & BRASIL & 1,19 & 10.200 & 10 critério \\
\hline C_TRX_IP_PAIS & EUA & 1,32 & 389 & 10 critério \\
\hline$\overline{\text { C_TRX_IP_PAIS }}$ & OUTROS & 14,85 & 360 & 10 critério \\
\hline C_TRX_NUM_PARCELAS & 1 & 0,93 & 12.547 & 20 critério \\
\hline $\bar{C}$ C_TRX_NUM_PARCELAS & 2 & 1,14 & 2.321 & 10 critério \\
\hline C_TRX_NUM_PARCELAS & 4 & 1,05 & 961 & 10 critério \\
\hline C_TRX_NUM_PARCELAS & 5 & 1,01 & 748 & 10 critério \\
\hline C_TRX_NUM_PARCELAS & 6 & 1,29 & 826 & 10 critério \\
\hline C_TRX_NUM_PARCELAS & 7 & 1,16 & 173 & 10 critério \\
\hline $\bar{C}$ C_TRX_NUM_PARCELAS & 8 & 1,49 & 275 & 10 critério \\
\hline C_TRX_NUM_PARCELAS & 9 & 1,57 & 115 & 10 critério \\
\hline$\overline{\text { C_TRX_NUM_PARCELAS }}$ & 10 & 1,47 & 1.273 & 10 critério \\
\hline C_TRX_NUM_PARCELAS & 11 & 2,94 & 90 & 10 critério \\
\hline$\overline{\text { C_TRX_NUM_PARCELAS }}$ & 12 & 1,28 & 1.164 & 10 critério \\
\hline C_TRX_PERIODO & MADRUGADA & 1,94 & 2.919 & 10 critério \\
\hline C_TRX_PERIODO & NOITE & 1,07 & 8.043 & 10 critério \\
\hline C_TRX_PERIODO & TARDE & 0,99 & 8.110 & 20 critério \\
\hline C_TRX_VALOR_LIM_SUPERIOR & TRX VALOR MAIOR QUE LIM SUPERIOR & 1,69 & 12.496 & 10 critério \\
\hline C_TRX_VALOR_MEDIA & TRX VALOR MAIOR QUE MEDIA & 1,73 & 13.555 & 10 critério \\
\hline C_TRX_VALOR_PERC95 & TRX VALOR MAIOR QUE PERC 95 & 3,17 & 3.329 & 10 critério \\
\hline C_UF_CPF_COMPR_CARD & 1 & 1,23 & 1.726 & 10 critério \\
\hline C_UF_CPF_COMPR_CARD & 2 & 1,43 & 1.056 & 10 critério \\
\hline C_UF_CPF_COMPR_CARD & 3 & 1,37 & 1.366 & 10 critério \\
\hline C_UF_CPF_COMPR_CARD & 4 & 1,34 & 2.187 & 10 critério \\
\hline C_UF_CPF_COMPR_CARD & 5 & 1,44 & 1.503 & 10 critério \\
\hline C_UF_CPF_COMPR_CARD & 6 & 1,05 & 2.496 & 10 critério \\
\hline C_UF_CPF_COMPR_CARD & 7 & 0,99 & 3.423 & 20 critério \\
\hline C_UF_CPF_COMPRADOR & 1 & 1,29 & 608 & 10 critério \\
\hline C_UF_CPF_COMPRADOR & 2 & 1,07 & 341 & 10 critério \\
\hline C_UF_CPF_COMPRADOR & 3 & 1,21 & 484 & 10 critério \\
\hline C_UF_CPF_COMPRADOR & 4 & 1,49 & 800 & 10 critério \\
\hline C_UF_CPF_COMPRADOR & 5 & 1,49 & 436 & 10 critério \\
\hline COMPR_CLASSE & CONSUMER & 1,01 & 19.771 & 10 critério \\
\hline COMPR_TIPO_MEMBER & CONTA DE NEGOCIOS & 1,47 & 590 & 10 critério \\
\hline COMPR_TIPO_MEMBER & CONTA PROFISSIONAL & 1,21 & 13 & 10 critério \\
\hline COMPR_VERIFICACAO_ID & ID COMPRADOR VERIFICADO E INVALIDO & 1,70 & 318 & 10 critério \\
\hline COMPR_VERIFICACAO_ID & ID COMPRADOR VERIFICADO E VALIDO & 1,46 & 294 & 10 critério \\
\hline EC_CNPJ_STATUS & ID COMPRADOR NAO VERIFICADO & 1,43 & 7.824 & 10 critério \\
\hline EC_CNPJ_STATUS & ID COMPRADOR VERIFICADO E INVALIDO & 2,01 & 1.634 & 10 critério \\
\hline EC_TIPO & CONTA PROFISSIONAL & 1,25 & 11.320 & 10 critério \\
\hline$\overline{\text { EC_TIPO_SERVICO }}$ & CARRINHO DE COMPRAS & 2,40 & 144 & 10 critério \\
\hline EC_TIPO_SERVICO & COBRANÇA & 6,68 & 719 & 10 critério \\
\hline EC_TIPO_SERVICO & DOAÇÕES & 31,67 & 413 & 10 critério \\
\hline EC_TIPO_SERVICO & INTEGRAÇÃO HTML & 1,63 & 3.996 & 10 critério \\
\hline EC_TIPO_SERVICO & PAGAMENTO SIMPLES & 3,13 & 772 & 10 critério \\
\hline EC_TIPO_SERVICO & VENDA PRODUTOS DIGITAIS & 1,79 & 298 & 10 critério \\
\hline TRX_TIPO_PAGTO_DETALHE & MASTERCARD CRÉDITO & 1,04 & 9.509 & 10 critério \\
\hline TRX_TIPO_PAGTO_DETALHE & VISA CRÉDITO & 1,05 & 12.157 & 10 critério \\
\hline TRX_TIPO_TERMINAL & 1-CHECKOUT & 0,91 & 5.415 & 20 critério \\
\hline
\end{tabular}

Tabela A.3: Características selecionadas para o algoritmo FP-Growth. Parte 03 de 03. 


\section{Apêndice B}

\section{Implementação em Python do algoritmo FP-Growth}

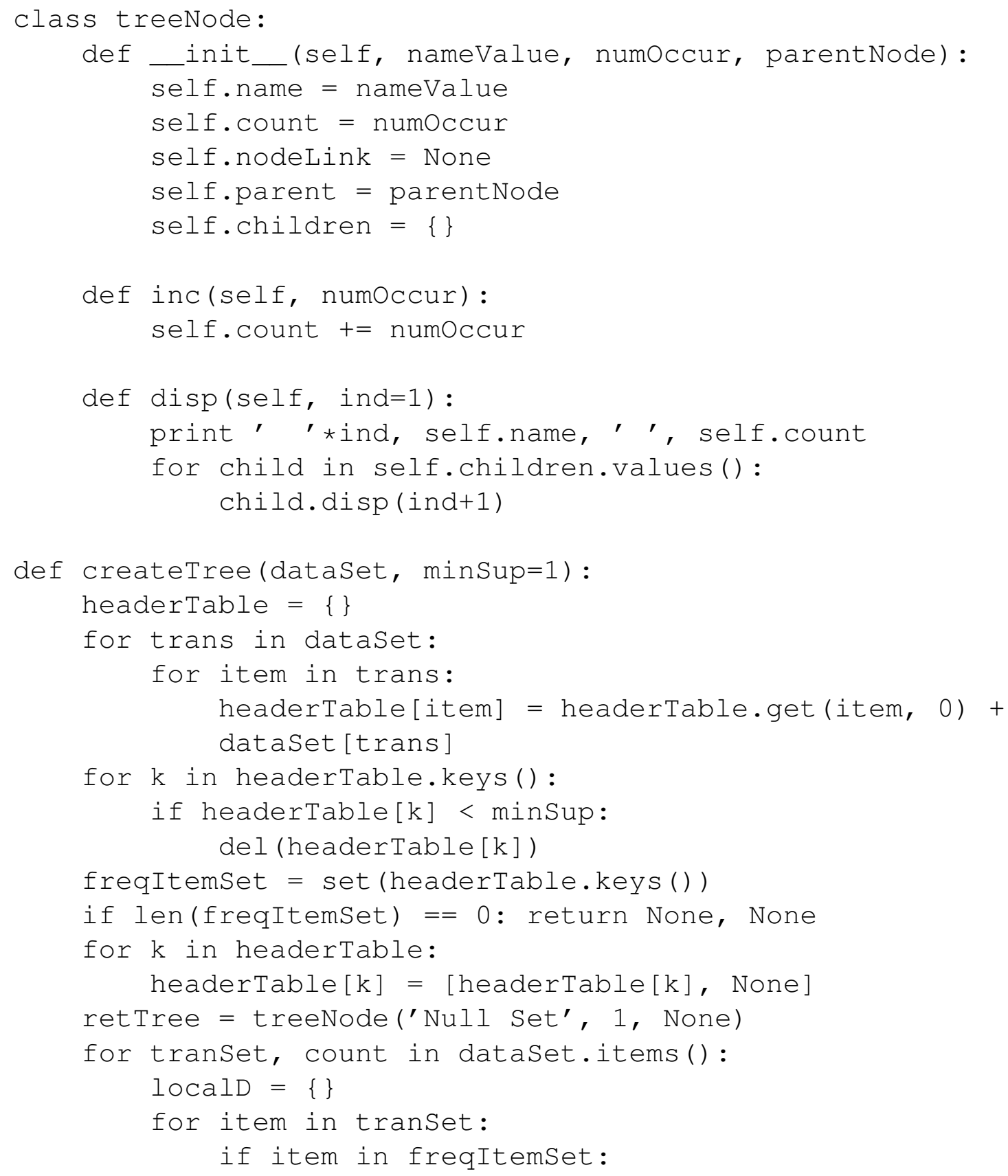




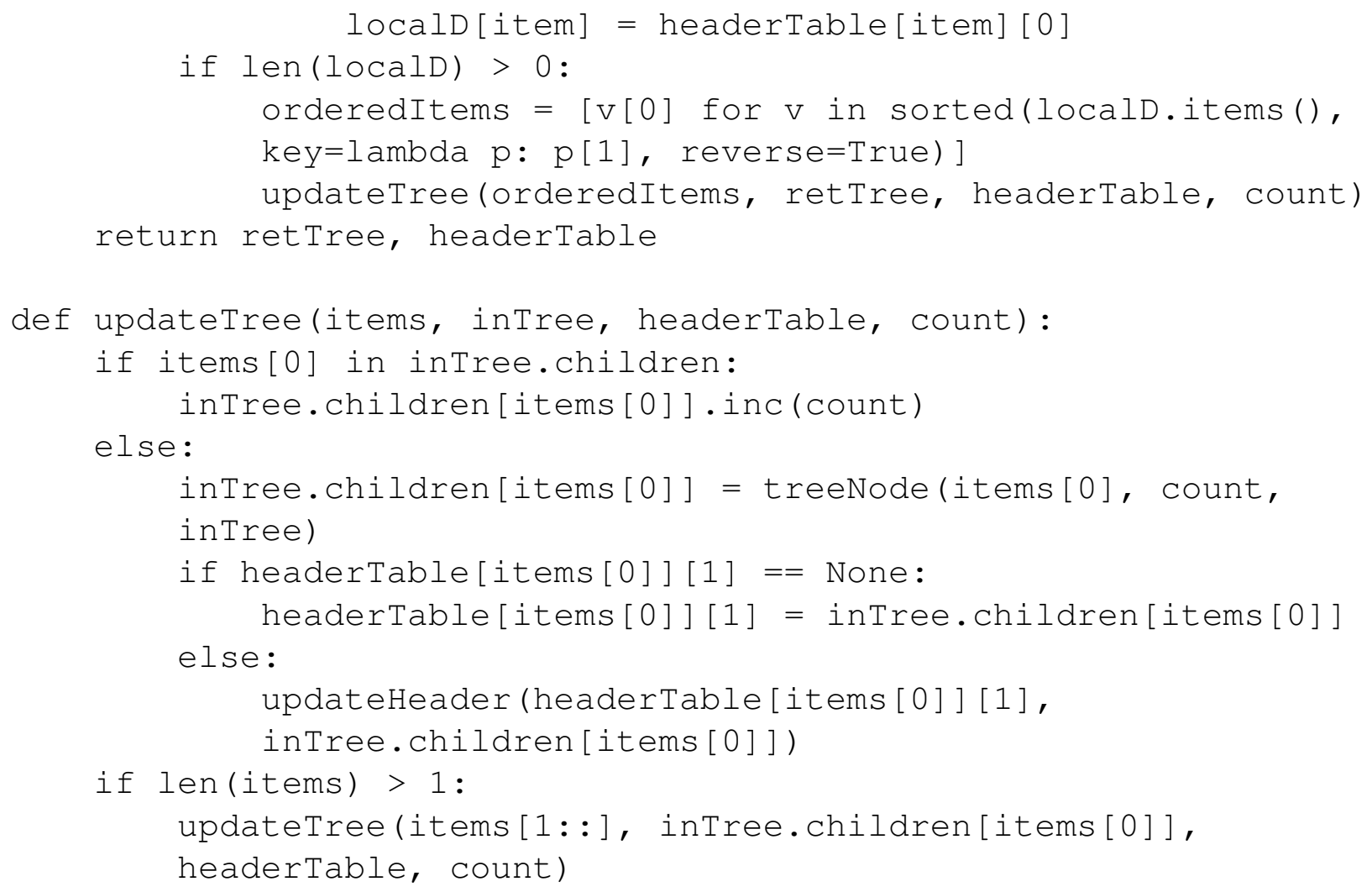

def updateHeader(nodeToTest, targetNode):

while (nodeToTest.nodeLink != None): nodeToTest $=$ nodeToTest.nodeLink nodeToTest. nodeLink = targetNode

def ascendTree(leafNode, prefixpath):

if leafNode.parent $!=$ None: prefixPath.append (leafNode.name) ascendTree (leafNode.parent, prefixPath)

def findPrefixPath(basePat, treeNode): condPats $=\{\}$

while treeNode $!=$ None:

prefixpath $=[]$

ascendTree (treeNode, prefixPath)

if len(prefixPath) > 1:

condPats [frozenset (prefixPath [1:]) ] = treeNode.count treeNode $=$ treeNode.nodeLink

return condPats

def mineTree (inTree, headerTable, minsup, prefix, freqItemList): bigL $=[\mathrm{v}[0]$ for $\mathrm{v}$ in sorted(headerTable.items(), key=lambda $p: p[1])]$

for basepat in bigL:

newFreqSet $=$ preFix.copy ()

newFreqSet.add (basePat)

freqItemList. append (newFreqSet) 
condPattBases = findPrefixPath (basePat,

headerTable [basePat] [1])

myCondTree, myHead = createTree (condPattBases, minsup)

if myHead $!=$ None:

mineTree (myCondTree, myHead, minSup, newFreqSet, freqItemList) 


\section{Apêndice C}

\section{As Características Selecionadas pelo FP-Growth e pela Regressão Logística}

\begin{tabular}{|c|c|c|c|c|}
\hline Variavel & Característica & Presença (\#) & $\begin{array}{l}\text { Razão de Chances } \\
\text { (estimativa) }\end{array}$ & $\begin{array}{c}\text { Critério Aderente } \\
\text { (Heurística) }\end{array}$ \\
\hline C_TAMANHO_EMAIL & "04-19 & 604 & 0,98 & 20 critério \\
\hline C_TEL_CEP_MATCH & IGUAL LOCAL TEL e CEP & 573 & 0,99 & 20 critério \\
\hline COMPR_CLASSE & CONSUMER & 527 & 1,01 & 10 critério \\
\hline C_TRX_VALOR_MEDIA & TRX VALOR MAIOR QUE MEDIA & 417 & 1,73 & 10 critério \\
\hline C_CLASSIF_EMAIL_COMPR & hotmail.com & 391 & 1,19 & 10 critério \\
\hline $\begin{array}{l}\text { C_TRX_VALOR_LIM_SUPERIOR } \\
\end{array}$ & TRX VALOR MAIOR QUE LIM SUPERIOR & 368 & 1,69 & 10 critério \\
\hline EC_TIPO & CONTA PROFISSIONAL & 362 & 1,21 & 10 critério \\
\hline C_TRX_IP_PAIS & BRASIL & 352 & 1,19 & 10 critério \\
\hline TRX_TIPO_PAGTO_DETALHE & VISA CRÉDITO & 350 & 1,05 & 10 critério \\
\hline C_TRX_NUM_PARCELAS & 1 & 348 & 0,93 & 20 critério \\
\hline C_CPF_COMPR_CARD_MATCH & 1 CPF INFORMADO $\gg$ NULL & 272 & 0,95 & 10 critério \\
\hline TRX_TIPO_PAGTO_DETALHE & MASTERCARD CRÉDITO & 260 & 1,04 & 10 critério \\
\hline EC_CNPJ_STATUS & ID COMPRADOR NAO VERIFICADO & 252 & 1,43 & 10 critério \\
\hline C_TRX_PERIODO & NOITE & 244 & 1,07 & 10 critério \\
\hline C_TRX_PERIODO & TARDE & 228 & 0,99 & 20 critério \\
\hline C_CPF_COMPR_CARD_MATCH & CPFs DIFERENTES & 173 & 1,63 & 10 critério \\
\hline $\begin{array}{l}\text { C_IDADE_COMPR_CARD_TRX } \\
\end{array}$ & $30-39$ & 158 & 0,97 & 20 critério \\
\hline C_CAT_VALOR_TRX & $200-499.99$ & 152 & 1,67 & 10 critério \\
\hline $\begin{array}{l}\text { C_IDADE_COMPR_CARD_TRX } \\
\text { - }\end{array}$ & $18-29$ & 140 & 1,30 & 10 critério \\
\hline C_GRUPO_BIN & B1 & 139 & 1,98 & 10 critério \\
\hline EC_TIPO_SERVICO & INTEGRAÇÃO HTML & 111 & 1,63 & 10 critério \\
\hline C_REGIAO_CEP & 0 & 104 & 1,12 & 10 critério \\
\hline C_REGIAO_CEP & 2 & 101 & 1,04 & 20 critério \\
\hline C_IDADE_COMPR_CARD_TRX & $40-49$ & 101 & 1,20 & 10 critério \\
\hline C_CAT_VALOR_TRX & $100-199.99$ & 100 & 0,99 & 20 critério \\
\hline C_COMPR_ESTADO & RIO DE JANEIRO & 97 & 1,05 & 10 critério \\
\hline TRX_TIPO_TERMINAL & 1-CHECKOUT & 97 & 0,91 & 20 critério \\
\hline C_TRX_VALOR_PERC95 & TRX VALOR MAIOR QUE PERC 95 & 57 & 3,17 & 10 critério \\
\hline C_TEL_CPF_MATCH & DIFERENTE LOCAL TEL e CPF & 57 & 2,57 & 10 critério \\
\hline C_TRX_DIA_SEMANA & QUINTA & 56 & 1,08 & 10 critério \\
\hline C_TRX_PERIODO & MADRUGADA & 52 & 1,94 & 10 critério \\
\hline C_CEP_CPF_MATCH & DIFERENTE LOCAL CEP e CPF & 51 & 2,45 & 10 critério \\
\hline C_REGIAO_CEP & 6 & 48 & 1,66 & 10 critério \\
\hline C_UF_CPF_COMPR_CARD & 7 & 46 & 0,99 & 20 critério \\
\hline C_REGIAO_CEP & 5 & 35 & 1,43 & 10 critério \\
\hline C_IDADE_COMPR_CARD_TRX & $50-59$ & 35 & 1,18 & 10 critério \\
\hline C_UF_CPF_COMPR_CARD & 4 & 35 & 1,34 & 10 critério \\
\hline C_SUBREGIAO_CEP & SUBREGIAO 8 & 30 & 1,15 & 10 critério \\
\hline C_SETOR_CEP & SETOR 1 & 30 & 1,16 & 10 critério \\
\hline C_CAT_VALOR_TRX & $50-99.99$ & 29 & 0,90 & 20 critério \\
\hline
\end{tabular}

Tabela C.1: Características presentes nas regras selecionadas pelo o algoritmo FP-Growth. Parte 01 de 02. 


\begin{tabular}{|c|c|c|c|c|}
\hline Varíavel & Característica & Presença (\#) & $\begin{array}{c}\text { Razão de Chances } \\
\text { (estimativa) }\end{array}$ & $\begin{array}{c}\text { Critério Aderente } \\
\text { (Heurística) }\end{array}$ \\
\hline "C_CLASSIF_EMAIL_COMPR & yahoo.com.br & 28 & 1,01 & 1o critério \\
\hline C_TRX_DIA_SEMANA & SABADO & 27 & 1,09 & 1o critério \\
\hline C_UF_CPF_COMPR_CARD & 5 & 26 & 1,44 & 1o critério \\
\hline C_COMPR_ESTADO & BAHIA & 25 & 1,66 & 1o critério \\
\hline C_SUBREGIAO_CEP & SUBREGIAO 0 & 24 & 0,98 & 2o critério \\
\hline C_REGIAO_CEP & 4 & 23 & 1,49 & 10 critério \\
\hline C_TRX_NUM_PARCELAS & 2 & 23 & 1,14 & 1o critério \\
\hline C_UF_CPF_COMPR_CARD & 6 & 23 & 1,05 & 1o critério \\
\hline C_TRX_DIA_SEMANA & TERCA & 22 & 0,98 & 2o critério \\
\hline C_REGIAO_CEP & 7 & 22 & 1,27 & 1o critério \\
\hline C_SUBREGIAO_CEP & SUBREGIAO 4 & 21 & 1,10 & 10 critério \\
\hline C_SUBREGIAO_CEP & SUBREGIAO 2 & 20 & 1,02 & 10 critério \\
\hline C_TEL_CEP_MATCH & DIFERENTE LOCAL TEL e CEP & 20 & 3,17 & 10 critério \\
\hline C_SUBREGIAO_CEP & SUBREGIAO 6 & 20 & 1,21 & 1o critério \\
\hline C_SUBREGIAO_CEP & SUBREGIAO 5 & 20 & 1,10 & 1o critério \\
\hline C_TRX_DIA_SEMANA & SEXTA & 20 & 0,99 & 2o critério \\
\hline C_TRX_DIA_SEMANA & QUARTA & 19 & 0,97 & 20 critério \\
\hline C_SUBREGIAO_CEP & SUBREGIAO 7 & 18 & 1,30 & 1o critério \\
\hline EC_CNPJ_STATUS & ID COMPRADOR VERIFICADO E INVALIDO & 18 & 1,70 & 1o critério \\
\hline C_TRX_DIA_SEMANA & SEGUNDA & 18 & 0,93 & 2o critério \\
\hline C_TELEFONE_COMPR_CARD_MATCP & -TEL COMPR E CARD DIFERENTES & 17 & 2,02 & 1o critério \\
\hline C_SETOR_CEP & SETOR 6 & 16 & 1,09 & 10 critério \\
\hline C_UF_CPF_COMPR_CARD & 1 & 16 & 1,23 & 10 critério \\
\hline C_SETOR_CEP & SETOR 8 & 16 & 1,14 & 10 critério \\
\hline C_UF_CPF_COMPR_CARD & 3 & 16 & 1,37 & 10 critério \\
\hline C_SETOR_CEP & SETOR 3 & 16 & 1,11 & 1o critério \\
\hline C_IDADE_COMPRADOR_TRX & $18-29$ & 16 & 1,30 & 1o critério \\
\hline C_CAT_VALOR_TRX & $500-999.99$ & 16 & 3,12 & 1o critério \\
\hline C_IDADE_COMPR_CARD_TRX & $60-69$ & 15 & 1,51 & 10 critério \\
\hline C_SETOR_CEP & SETOR 2 & 15 & 1,00 & 1o critério \\
\hline C_DIF_DTA_NASC_COMPR_CARD & MAIOR 7 MESES & 14 & 1,94 & 1o critério \\
\hline C_DTA_NASC_COMPR_CARD & DIFERENTE & 14 & 1,90 & 10 critério \\
\hline C_COMPR_ESTADO & CEARÁ & 13 & 1,52 & 10 critério \\
\hline C_SETOR_CEP & SETOR 9 & 13 & 1,16 & 10 critério \\
\hline C_TRX_NUM_PARCELAS & 10 & 12 & 1,47 & 10 critério \\
\hline C_COMPR_ESTADO & PERNAMBUCO & 11 & 1,27 & 10 critério \\
\hline C_CLASSIF_EMAIL_COMPR & bol.com.br & 11 & 1,80 & 10 critério \\
\hline C_SETOR_CEP & SETOR 5 & 11 & 1,01 & 1o critério \\
\hline C_EC_DATA_FILIACAO_TRX & $0-30$ & 10 & 1,80 & 10 critério \\
\hline C_CLASSIF_EMAIL_COMPR & live.com & 9 & 6,46 & 10 critério \\
\hline C_TRX_NUM_PARCELAS & 12 & 8 & 1,28 & 10 critério \\
\hline C_SUBREGIAO_CEP & SUBREGIAO 1 & 7 & 0,92 & 2o critério \\
\hline C_UF_CPF_COMPR_CARD & 2 & 7 & 1,43 & 1o critério \\
\hline C_EC_DATA_FILIACAO_TRX & $91-120$ & 7 & 1,59 & 10 critério \\
\hline C_SUBREGIAO_CEP & SUBREGIAO 3 & 7 & 0,94 & 20 critério \\
\hline C_EC_DATA_FILIACAO_TRX & $31-60$ & 6 & 2,09 & 1o critério \\
\hline C_CAT_VALOR_TRX & $1000+$ & 6 & 3,85 & 1o critério \\
\hline EC_TIPO_SERVICO & PAGAMENTO SIMPLES & 6 & 3,13 & 10 critério \\
\hline C_EC_DATA_FILIACAO_TRX & $61-90$ & 6 & 1,77 & 10 critério \\
\hline C_TAMANHO_EMAIL & MAIOR 19 & 6 & 2,05 & 1o critério \\
\hline C_TRX_NUM_PARCELAS & 6 & 5 & 1,29 & 10 critério \\
\hline C_COMPR_DATA_FILIACAO_TRX & $0-30$ & 5 & 1,80 & 10 critério \\
\hline C_EC_DATA_FILIACAO_TRX & $121-150$ & 5 & 1,20 & 1o critério \\
\hline EC_TIPO_SERVICO & COBRANÇA & 4 & 6,68 & 1o critério \\
\hline C_TRX_NUM_PARCELAS & 4 & 4 & 1,05 & 10 critério \\
\hline C_TRX_NUM_PARCELAS & 5 & 4 & 1,01 & 10 critério \\
\hline C_COMPR_ESTADO & GOIÁS & 2 & 1,79 & 10 critério \\
\hline C_UF_CPF_COMPRADOR & 4 & 2 & 1,49 & 10 critério \\
\hline C_EC_DATA_FILIACAO_TRX & $151-180$ & 1 & 1,00 & 1o critério \\
\hline C_UF_CPF_COMPRADŌR & 1 & 1 & 1,29 & 10 critério \\
\hline
\end{tabular}

Tabela C.2: Características presentes nas regras selecionadas pelo o algoritmo FP-Growth. Parte 02 de 02. 


\begin{tabular}{|c|c|c|c|c|}
\hline Variavel & Caracteristica & Presença (\#) & $\begin{array}{c}\text { Razão de Chances } \\
\text { (estimativa) }\end{array}$ & $\begin{array}{l}\text { Critério Aderente } \\
\text { (Heurística) }\end{array}$ \\
\hline COMPR CLASSE & CONSUMER & 113 & 1,01 & 10 critério \\
\hline C_TAMANHO_EMAIL & 04-19 & 103 & 0,98 & 20 critério \\
\hline $\begin{array}{l}\text { C_TRX_NUM_PARCELAS } \\
\end{array}$ & 1 & 89 & 0,93 & 20 critério \\
\hline C_TRX_VALOR_MEDIA & TRX VALOR MAIOR QUE MEDIA & 76 & 1,73 & 10 critério \\
\hline$\overline{\mathrm{EC}}$ TIPO & CONTA PROFISSIONAL & 73 & 1,21 & 10 critério \\
\hline TRX_TIPO_PAGTO_DETALHE & VISA CRÉDITO & 72 & 1,05 & 10 critério \\
\hline C_TEL_CEP_MATCH & IGUAL LOCAL TEL e CEP & 63 & 0,99 & 20 critério \\
\hline C_CLASSIF_EMAIL_COMPR & hotmail.com & 60 & 1,19 & 10 critério \\
\hline $\begin{array}{l}\text { C_CPF_COMPR_CARD_MATCH } \\
\end{array}$ & $1 \mathrm{CPF}$ INFORMADO $\diamond \mathrm{NULL}$ & 54 & 0,95 & 10 critério \\
\hline TRX_TIPO_PAGTO_DETALHE & MASTERCARD CRÉDITO & 52 & 1,04 & 10 critério \\
\hline EC_CNPJ_STATUS & ID COMPRADOR NAO VERIFICADO & 49 & 1,43 & 10 critério \\
\hline $\begin{array}{l}\text { C_TRX_VALOR_LIM_SUPERIOR } \\
\end{array}$ & TRX VALOR MAIOR QUE LIM SUPERIOR & 48 & 1,69 & 10 critério \\
\hline $\begin{array}{l}\text { C_GRUPO_BIN } \\
\end{array}$ & B1 & 40 & 1,98 & 10 critério \\
\hline C_TRX_PERIODO & NOITE & 38 & 1,07 & 10 critério \\
\hline C_CPF_COMPR_CARD_MATCH & CPFs DIFERENTES & 38 & 1,63 & 10 critério \\
\hline C_CAT_VALOR_TRX & $200-499.99$ & 35 & 1,67 & 10 critério \\
\hline C_TRX_PERIODO & TARDE & 34 & 0,99 & 20 critério \\
\hline C_IDADE_COMPR_CARD_TRX & $18-29$ & 32 & 1,30 & 10 critério \\
\hline C TRX IP PAIS & BRASIL & 32 & 1,19 & 10 critério \\
\hline C_CAT_VALOR_TRX & $100-199.99$ & 31 & 0,99 & 20 critério \\
\hline C REGIAO CEP & 0 & 27 & 1,12 & 10 critério \\
\hline $\begin{array}{l}\text { C_IDADE_COMPR_CARD_TRX } \\
\end{array}$ & $40-49$ & 25 & 1,20 & 10 critério \\
\hline C_IDADE_COMPR_CARD_TRX & $30-39$ & 22 & 0,97 & 20 critério \\
\hline C_TRX_PERIODO & MADRUGADA & 22 & 1,94 & 10 critério \\
\hline EC_TIPO_SERVICO & INTEGRAÇÃO HTML & 20 & 1,63 & 10 critério \\
\hline C_REGIAO_CEP & 6 & 19 & 1,66 & 10 critério \\
\hline C_TRX_VALOR_PERC95 & TRX VALOR MAIOR QUE PERC 95 & 19 & 3,17 & 10 critério \\
\hline C_CAT_VALOR_TRX & $50-99.99$ & 16 & 0,90 & 20 critério \\
\hline C_REGIAO_CEP & 2 & 15 & 1,04 & 20 critério \\
\hline C_COMPR_ESTADO & RIO DE JANEIRO & 13 & 1,05 & 10 critério \\
\hline C_TRX_DIA_SEMANA & QUINTA & 12 & 1,08 & 10 critério \\
\hline C_REGIAO_CEP & 5 & 11 & 1,43 & 10 critério \\
\hline C_CLASSIF_EMAIL_COMPR & yahoo.com.br & 11 & 1,01 & 10 critério \\
\hline C_IDADE_COMPR_CARD_TRX & $50-59$ & 11 & 1,18 & 10 critério \\
\hline C_TEL_CPF_MATCH & DIFERENTE LOCAL TEL e CPF & 11 & 2,57 & 10 critério \\
\hline C_CEP_CPF_MATCH & DIFERENTE LOCAL CEP e CPF & 10 & 2,45 & 10 critério \\
\hline TRX_TIPO_TERMINAL & 1-CHECKOUT & 9 & 0,91 & 20 critério \\
\hline C_REGIAO_CEP & 7 & 9 & 1,27 & 10 critério \\
\hline C_SETOR_CEP & SETOR 1 & 9 & 1,16 & 10 critério \\
\hline C_TEL_CEP_MATCH & DIFERENTE LOCAL TEL e CEP & 9 & 3,17 & 10 critério \\
\hline C_SUBREGIAO_CEP & SUBREGIAO 2 & 8 & 1,02 & 10 critério \\
\hline C_TRX NUM PARCELAS & 2 & 8 & 1,14 & 10 critério \\
\hline C_SUBREGIAO_CEP & SUBREGIAO 6 & 8 & 1,21 & 10 critério \\
\hline C_COMPR_ESTADO & BAHIA & 7 & 1,66 & 10 critério \\
\hline C_SUBREGIAO_CEP & SUBREGIAO 4 & 7 & 1,10 & 10 critério \\
\hline C_SUBREGIAO_CEP & SUBREGIAO 7 & 7 & 1,30 & 10 critério \\
\hline EC_CNPJ_STATUS & ID COMPRADOR VERIFICADO E INVALIDO & 7 & 1,70 & 10 critério \\
\hline C_SUBREGIAO_CEP & SUBREGIAO 0 & 6 & 0,98 & 20 critério \\
\hline C_SUBREGIAO_CEP & SUBREGIAO 8 & 6 & 1,15 & 10 critério \\
\hline C_EC_DATA_FILIACAO_TRX & $0-30$ & 6 & 1,80 & 10 critério \\
\hline C_IDADE_COMPR_CARD_TRX & $60-69$ & 6 & 1,51 & 10 critério \\
\hline C_CLASSIF_EMAIL_COMPR & live.com & 6 & 6,46 & 10 critério \\
\hline C_UF_CPF_COMPR_CARD & 6 & 5 & 1,05 & 10 critério \\
\hline C_SUBREGIAO_CEP & SUBREGIAO 5 & 5 & 1,10 & 10 critério \\
\hline C_EC_DATA_FILIACAO_TRX & $31-60$ & 5 & 2,09 & 10 critério \\
\hline C_CLASSIF_EMAIL_COMPR & bol.com.br & 5 & 1,80 & 10 critério \\
\hline C_TRX_DIA_SEMANA & SABADO & 5 & 1,09 & 10 critério \\
\hline C_TELEFONE_COMPR_CARD_MATCH & TEL COMPR E CARD DIFERENTES & 5 & 2,02 & 10 critério \\
\hline
\end{tabular}

Tabela C.3: Características presentes nas regras selecionadas pela regressão logística. Parte 01 de 02. 


\begin{tabular}{|c|c|c|c|c|}
\hline Variavel & Característica & Presença (\#) & $\begin{array}{c}\text { Razão de Chances } \\
\text { (estimativa) }\end{array}$ & $\begin{array}{c}\text { Critério Aderente } \\
\text { (Heuristica) }\end{array}$ \\
\hline 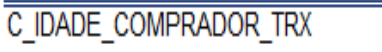 & $18-29$ & $\overline{5}$ & 1,30 & 10 critério \\
\hline$\overline{\text { C_CAT_VALOR_TRX }}$ & $500-999.99$ & 5 & 3,12 & 10 critério \\
\hline C_SETOR_CEP & SETOR 6 & 4 & 1,09 & 10 critério \\
\hline $\bar{C}$ C_UF_CPF_COMPR_CARD & 4 & 4 & 1,34 & 10 critério \\
\hline $\bar{C}$ C_DTA_NASC_COMPR_CARD & DIFERENTE & 4 & 1,90 & 10 critério \\
\hline C_TAMANHO_EMAIL & MAIOR 19 & 4 & 2,05 & 10 critério \\
\hline C_SETOR_CEP & SETOR 2 & 4 & 1,00 & 10 critério \\
\hline C_DIF_DTA_NASC_COMPR_CARD & MAIOR 7 MESES & 4 & 1,94 & 10 critério \\
\hline C_TRX_DIA_SEMANA & SEXTA & 4 & 0,99 & 20 critério \\
\hline EC_TIPO_SERVICO & PAGAMENTO SIMPLES & 4 & 3,13 & 10 critério \\
\hline C_EC_DATA_FILIACAO_TRX & $91-120$ & 4 & 1,59 & 10 critério \\
\hline C_SUBREGIAO_CEP & SUBREGIA0 1 & 3 & 0,92 & 20 critério \\
\hline C_TRX_DIA_SEMANA & TERCA & 3 & 0,98 & 20 critério \\
\hline C_TRX_DIA_SEMANA & QUARTA & 3 & 0,97 & 20 critério \\
\hline C_TRX_DIA_SEMANA & SEGUNDA & 3 & 0,93 & 20 critério \\
\hline C_COMPR_DATA_FLLIACAO_TRX & $0-30$ & 3 & 1,80 & 10 critério \\
\hline C_REGIAO_CEP & 4 & 3 & 1,49 & 10 critério \\
\hline C_SUBREGIAO_CEP & SUBREGIAO 3 & 3 & 0,94 & 20 critério \\
\hline C_SETOR_CEP & SETOR 3 & 3 & 1,11 & 10 critério \\
\hline C_COMPR_ESTADO & CEARÁ & 3 & 1,52 & 10 critério \\
\hline C_EC_DATA_FILIACAO_TRX & $61-90$ & 3 & 1,77 & 10 critério \\
\hline EC_TIPO_SERVICO & COBRANÇA & 3 & 6,68 & 10 critério \\
\hline C_TRX_NUM_PARCELAS & 10 & 3 & 1,47 & 10 critério \\
\hline C_UF_CPF_COMPR_CARD & 7 & 3 & 1,27 & 20 critério \\
\hline C_CAT_VALOR_TRX & $1000+$ & 3 & 3,85 & 10 critério \\
\hline C_EC_DATA_FILIACAO_TRX & 121-150 & 3 & 1,20 & 10 critério \\
\hline C_TRX_NUM_PARCELAS & 6 & 2 & 1,29 & 10 critério \\
\hline C_SETOR_CEP & SETOR 8 & 2 & 1,14 & 10 critério \\
\hline C_UF_CPF_COMPR_CARD & 1 & 2 & 1,23 & 10 critério \\
\hline C_UF_CPF_COMPR_CARD & 5 & 2 & 1,44 & 10 critério \\
\hline C_TRX_NUM_PARCELAS & 12 & 2 & 1,28 & 10 critério \\
\hline C_COMPR_ESTADO & PERNAMBUCO & 1 & 1,27 & 10 critério \\
\hline C_UF_CPF_COMPR_CARD & 2 & 1 & 1,43 & 10 critério \\
\hline C_COMPR_ESTADO & GOIÁS & 1 & 1,79 & 10 critério \\
\hline C_EC_DATA_FILIACAO_TRX & $151-180$ & 1 & 1,00 & 10 critério \\
\hline C_SETOR_CEP & SETOR 5 & 1 & 1,01 & 10 critério \\
\hline C_UF_CPF_COMPRADOR & 4 & 1 & 1,34 & 10 critério \\
\hline
\end{tabular}

Tabela C.4: Características presentes nas regras selecionadas pela regressão logística. Parte 02 de 02. 


\section{Referências Bibliográficas}

[ABE14] ABECS. Monitor abecs - números. http://www.abecs.org.br/ indicadores-de-mercado, 2014. último acesso em 10/06/2014. 8

[AIS93] Rakesh Agrawal, Tomasz Imieliński e Arun Swami. Mining association rules between sets of items in large databases. Em Proceedings of the 1993 ACM SIGMOD International Conference on Management of Data, SIGMOD '93, páginas 207-216, New York, NY, USA, 1993. ACM. 27

[AK12] Adnan M. Al-Khatib. Electronic payment fraud detection techniques. Em World of Computer Science and Information Technology Journal (WCSIT), páginas 137-141, 2012. x, 19, 22, 23

[All99] Paul Allison. Logistic Regression Using SAS: Theory and Application. SAS Publishing, first edição, 1999. 38

[AS94] Rakesh Agrawal e Ramakrishnan Srikant. Fast algorithms for mining association rules in large databases. Em Proceedings of the 20th International Conference on Very Large Data Bases, VLDB '94, páginas 487-499, San Francisco, CA, USA, 1994. Morgan Kaufmann Publishers Inc. 28

[BCdB10] et al. Banco Central do Brasil. Relatório sobre a indústria de cartões de pagamentos. Relatório técnico, BCB, SEAE/MF, SDE/MJ, 2010. 5

[Ber14] Fidel Beraldi. Atualização dinâmica de modelo de regressão logística binária para detecção de fraudes em transações eletrônicas com cartão de crédito. Dissertação de Mestrado, Instituto de Matemática e Estatística, Universidade de São Paulo, 2014. 19, 26, 48

[BL97] Avrim L. Blum e Pat Langley. Selection of relevant features and examples in machine learning. Artificial Inteligence, 97:245-271, 1997. 26

[BM10] Wilton O Bussab e Pedro A Morettin. Estatistica Básica. Saraiva, 6 edição, 2010. 35

[Cab12] E. L. S Cabette. Furto mediante fraude e estelionato no uso de cartões de crédito e/ou débito subtraídos ou clonados. http://migre.me/kjiYl, 2012. último acesso em 19/01/2014. 14

[Cen87] Jadzia Cendrowska. Prism: An algorithm for inducing modular rules. International Journal of Man-Machine Studies, páginas 349-370, 1987. 24

[CN89] Peter Clark e Tim Niblett. The cn2 induction algorithm. Mach. Learn., páginas 261-283, 1989. 24 
[Coh95] William W. Cohen. Fast effective rule induction. Em In Proceedings of the Twelfth International Conference on Machine Learning, páginas 115-123. Morgan Kaufmann, 1995. 24

[CS98] Philip K. Chan e Salvatore J. Stolfo. Toward scalable learning with non-uniform class and cost distributions: A case study in credit card fraud detection. Em In Proceedings of the Fourth International Conference on Knowledge Discovery and Data Mining, páginas 164-168. AAAI Press, 1998. 41, 54

[DAP09] L Delamaire, HAH Abdou e J Pointon. Credit card fraud and detection techniques: a review, 2009. 2

[Eb15] E-bit. Relatório webshoppers. http://img.ebit.com.br/webshoppers/pdf/31 webshoppers.pdf, 2015. último acesso em 15/06/2015. 10

[eCo14] eCommerce.Org. Meios de pagamento no e-commerce. http://www. e-commerce.org.br/meiosdepagamento-ecommerce.php, 2014. último acesso em 10/06/2014. 7

[Elk01] Charles Elkan. The foundations of cost-sensitive learning. Em In Proceedings of the Seventeenth International Joint Conference on Artificial Intelligence, páginas 973-978, 2001. 38, 55

[FF97] Jerome H. Friedman e Usama Fayyad. On bias, variance, 0/1-loss, and the curse-of-dimensionality. Data Mining and Knowledge Discovery, 1:55-77, 1997. 41

[Fla12] Peter Flach. Machine Learning: The art and science of algorithms that make sense of data. Cambridge University Press, 2012. 41

[Fre00] Alex Alves Freitas. Understanding the crucial differences between classification and discovery of association rules - a position paper. SIGKDD Explorations, 2(1):65-69, 2000. 32

[Gad08] Manoel Fernando Alonso Gadi. Uma comparação de métodos de classificação aplicados à detecção de fraude em cartões de crédito. Dissertação de Mestrado, Instituto de Matemática e Estatística, Universidade de São Paulo, 2008. 19, 22

[GdLM10] Manoel Fernando Alonso Gadi, Alair Pereira do Lago e Jörn Mehnen. Data mining with skewed data. Em New Advances in Machine Learning, 2010. 41, 54

[GWdL08a] Manoel Fernando Alonso Gadi, Xidi Wang e Alair Pereira do Lago. Comparison with parametric optimization in credit card fraud detection. Em Seventh International Conference on Machine Learning and Applications, páginas 279-285, 2008. 22,38

[GWdL08b] Manoel Fernando Alonso Gadi, Xidi Wang e Alair Pereira do Lago. Credit card fraud detection with artificial immune system. Em Peter J. Bentley, Doheon Lee e Sungwon Jung, editors, ICARIS, páginas 119-131, 2008. 18

[Har12] Peter Harrington. Machine Learning in Action. Manning Publications Co., 2012. 48,57 
[HL00] David W. Hosmer e Stanley Lemeshow. Applied logistic regression (Wiley Series in probability and statistics). Wiley-Interscience Publication, 2 edição, 2000. 34, $36,37,38,43,72$

[HPY00] Jiawei Han, Jian Pei e Yiwen Yin. Mining frequent patterns without candidate generation. Em Proceedings of the 2000 ACM SIGMOD International Conference on Management of Data, SIGMOD '00, páginas 1-12, New York, NY, USA, 2000. ACM. 29

[JMM96] Anil K. Jain, Jianchang Mao e K. Mohiuddin. Artificial neural networks: A tutorial. IEEE Computer, 29:31-44, 1996. 20

[Kar02] M. L. Karam. Competência no Processo Penal. Revista dos Tribunais, 2002. 15

[LHM98] Bing Liu, Wynne Hsu e Yiming Ma. Integrating classification and association rule mining. Em KDD-98 Proceedings, páginas 80-86, 1998. 33

[LMkW01] Bing Liu, Yiming Ma e Ching kian Wong. Classification using association rules: Weaknesses and enhancements, 2001. 33

[Mar09] Stephen Marsland. Machine Learning: An Algorithmic Perspective. Chapman \& Hall/CRC, 1st edição, 2009. 18

[MF11] J. F. Mirabete e R. N. Fabbrini. Manual de Direito Penal. Atlas, 2011. 15

[MF15] MySQL-Front. Mysql-front: a windows front end for the mysql database server. http://www.mysqlfront.de, 2015. último acesso em 18/07/2015. 48

[Mic69] R. Michalski. On the quasi-minimal solution of the general covering problem. Em Proceedings of the 5th International Symposium on Information Processing (FCIP-69), volume A3, páginas 125-128, 1969. 24

[Mit97] Tom M. Mitchell. Machine learning. McGraw-Hill, 1997. 19, 21

[ML02] Hiroshi Motoda e Huan Liu. Feature selection, extraction and construction, 2002. 26

[MM14] J. Zaki Mohammed e W. Meira. Data mining and analysis: Fundamental concepts and algorithms, 2014. viii, 29, 30, 31, 32

[MNPL09] Rafael Maranzato, Marden Neubert, Adriano M. Pereira e Alair Pereira do Lago. Feature extraction for fraud detection in electronic marketplaces. Em Proceedings of the 2009 Latin American Web Congress (La-web 2009), LA-WEB '09, páginas 185-192, Washington, DC, USA, 2009. IEEE Computer Society. 42

[Mor08] Dalila de Moraes. Modelagem de fraude em cartão de crédito. Dissertação de Mestrado, Departamento de Estatística, Universidade Federal de São Carlos, 2008. 36

[MTVM93] Sam Maes, Karl Tuyls, Bram Vanschoenwinkel e Bernard Manderick. Credit card fraud detection using bayesian and neural networks. Em In: Maciunas RJ, editor. Interactive image-guided neurosurgery. American Association Neurological Surgeons, páginas 261-270, 1993. 18 
[Mur12] Kevin P. Murphy. Machine Learning: A Probabilistic Perspective (Adaptive Computation and Machine Learning series). The MIT Press, Agosto 2012. 18

[PC15] PCI-Councli. Payment card industry (pci) - data security standard: Requirements and security assessment procedures. v3.1. https://www. pcisecuritystandards.org/documents/PCI_DSS_v3-1.pdf, 2015. último acesso em 17/07/2015. 16

[Pyt15] Python.org. Python.org. https://www.python.org, 2015. último acesso em 18/07/2015. 48

[Qui86] J. R. Quinlan. Induction of decision trees. Mach. Learn., páginas 81-106, 1986. 19,24

$\left[\mathrm{RMN}^{+}\right.$99] Saharon Rosset, Uzi Murad, Einat Neumann, Yizhak Idan e Gadi Pinkas. Discovery of fraud rules for telecommunications-challenges and solutions. Em Proceedings of the Fifth ACM SIGKDD International Conference on Knowledge Discovery and Data Mining, páginas 409-413. ACM Press, 1999. 2

[SFL $\left.{ }^{+} 97\right]$ Salvatore J. Stolfo, David W. Fan, Wenke Lee, Andreas L. Prodromidis e Philip K. Chan. Credit card fraud detection using meta-learning: Issues and initial results, 1997. 18

[TSK05] Pang-Ning Tan, Michael Steinbach e Vipin Kumar. Introduction to Data Mining, (First Edition). Addison-Wesley Longman Publishing Co., Inc., Boston, MA, USA, 2005. 24, 27, 40, 41

[Wir00] Rudiger Wirth. Crisp-dm: Towards a standard process model for data mining. Em Proceedings of the Fourth International Conference on the Practical Application of Knowledge Discovery and Data Mining, páginas 29-39, 2000. viii, 44, 45 